UNIVERSIDADE DE SÃO PAULO

ESCOLA DE ENGENHARIA DE SÃO CARLOS

DEPARTAMENTO ENGENHARIA DE TRANSPORTES

BRUNA KURAMOTO

EXPLORAÇÃO DE DADOS DE MAPAS COLABORATIVOS EM AVALIAÇÕES DE MORFOLOGIAS URBANAS BRASILEIRAS

São Carlos

2019 



\section{EXPLORAÇÃO DE DADOS DE MAPAS COLABORATIVOS EM AVALIAÇÕES DE MORFOLOGIAS URBANAS BRASILEIRAS}

Programa de Pós-graduação em Engenharia de Transportes da EESC-USP

Exemplar definitivo (corrigido). 0 exemplar original está disponível na CPG da EESC-USP

São Carlos, 02/07/2019

RESOLUÇÃo CoPGr N 6ㅣ, DE 13 DE OUTUBRO DE 2011, artigo $5^{\circ}$

Dissertação apresentada à Escola de Engenharia de São Carlos da Universidade de São Paulo, para a obtenção do título de Mestre em Ciências - Programa de PósGraduação em Engenharia de Transportes. Área de concentração: Planejamento e Operação de Sistemas de Transporte.

Orientador: Prof. Dr. André Luiz Barbosa Nunes da Cunha.

São Carlos 
AUTORIZO A REPRODUÇÃO TOTAL OU PARCIAL DESTE TRABALHO, POR QUALQUER MEIO CONVENCIONAL OU ELETRONNICO, PARA FINS DE ESTUDO E PESQUISA, DESDE QUE CITADA A FONTE.

Ficha catalográfica elaborada pela Biblioteca Prof. Dr. Sérgio Rodrigues Fontes da EESC/USP com os dados inseridos pelo(a) autor(a).

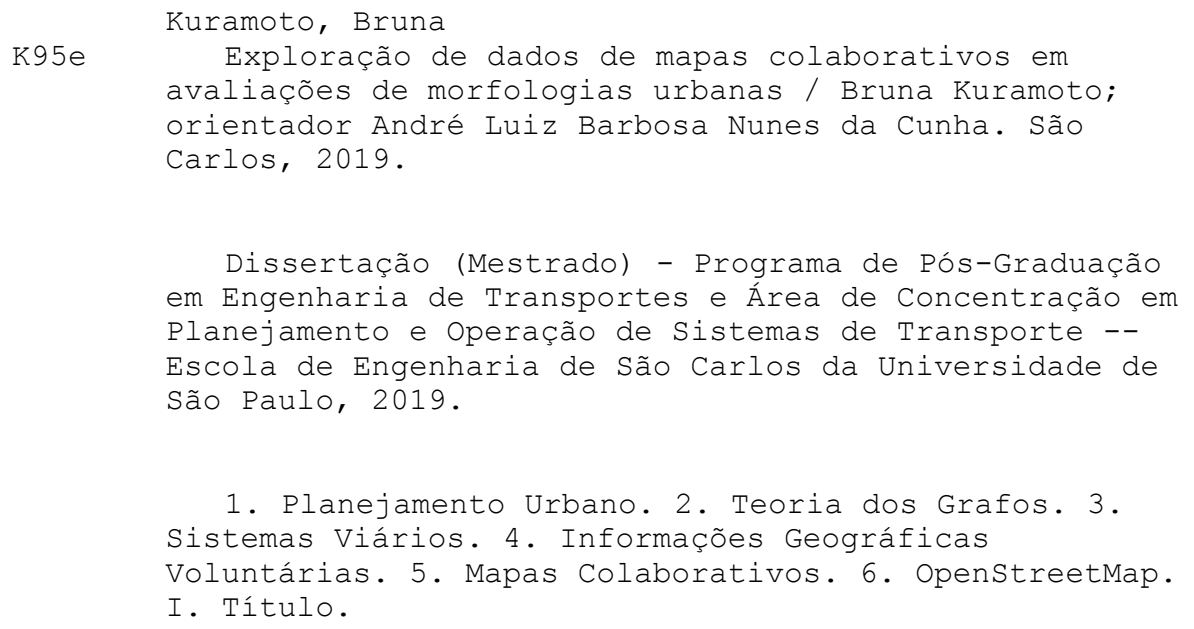

1. Planejamento Urbano. 2. Teoria dos Grafos. 3. Sistemas Viários. 4. Informações Geográficas

Voluntárias. 5. Mapas Colaborativos. 6. OpenStreetMap. I. Título.

Eduardo Graziosi Silva - CRB - 8/8907 


\section{Agradecimentos}

À minha família, em especial aos meus pais, Luci e Nilson, pelo suporte e pelos primeiros ensinamentos éticos e morais.

Ao Prof. André Luiz Cunha, pela orientação, paciência e pelo incentivo a sair da zona de conforto.

Ao meu enorme grupo de pesquisa, pelo companheirismo em todas situações: Alceu Júnior, André Morelli, Adriano Belletti, Elaine Ribeiro, Gabriel Oliveira, Helena Stein, Leandro Marcomini, Mariana Thebit e Natália Panice.

Aos amigos sempre presentes: Adrian Grasson, Ana Caroline Marques, Ana Laura Morais, Andressa Lima, Bianca Farias, Caroline Camilo, Cláudia Naizer, Denise Capasso, Júlia Cocozza, Lívia Magion, Mariana Aires e Paula Gerencer.

À Urze Companhia de Dança, pelo aprendizado que não se adquire em livros.

Aos colegas deste período de pós-graduação, pelo apoio e pelos momentos de descontração.

À Universidade de São Paulo e à Escola de Engenharia de São Carlos, pela estrutura disponibilizada.

Aos professores do Departamento de Engenharia de Transportes, pelos ensinamentos e aos técnicos e funcionários, pela atenção.

Ao Conselho Nacional de Desenvolvimento Científico, pela bolsa de estudos concedida para o desenvolvimento da pesquisa. 



\section{RESUMO}

\section{KURAMOTO, B. Exploração de dados de mapas colaborativos em avaliações de morfo-}

logias urbanas brasileiras. 135 p. Dissertação de Mestrado - Escola de Engenharia de São

Carlos, Universidade de São Paulo, São Carlos - SP, 2019

Esta dissertação está inserida na área de configuração urbana, com foco em sistemas viários segregados por cidades. O objetivo desta pesquisa foi a exploração de dados viários urbanos disponíveis na Web e a extração de parâmetros com aplicabilidade em análises de morfologias de cidades. A intenção do trabalho foi corroborar a hipótese: A qualidade adquirida por dados de mapas colaborativos permite sua utilização em análises da morfologia urbana a nível local. Mapas colaborativos são plataformas online que agregam informações geográficas fornecidas pelos próprios usuários, de acordo com a experiência local. O Projeto OpenStreetMap foi utilizado como fonte de dados para avaliar o potencial e as limitações dos mapas colaborativos na representação das malhas viárias de municípios brasileiros. Os sistemas viários foram expressos em forma de grafos, em que as arestas representaram as ruas e os nós, as interseções entre ruas. Do ponto de vista da Engenharia de Transportes, o foco do uso da Teoria de Grafos em pesquisas de morfologias viárias está em questões como mensuração da acessibilidade, eficiência e resiliência da rede a falhas. As principais ferramentas computacionais utilizadas foram as bibliotecas OSMnx e Networkx, escritas em linguagem Python, com funções de construção e análises de redes. Para avaliar a viabilidade de utilização das ferramentas e da plataforma de dados propostos, foi realizada uma comparação com o estudo de Lima, Silva e van der Waerden (2003). Esse trabalho avaliou a compacidade e a acessibilidade global das malhas viárias de 11 cidades, com intuito de comparar exemplos brasileiros com estrangeiros. A reprodução do estudo de referência foi possível, com construção de redes com aumento médio de $47 \%$ de elementos, o que indicou expansão e maior detalhamento dos sistemas viários. Além disso, foi detectada uma diferença na comparação das cidades brasileiras com o panorama internacional. Marília e São Carlos apresentaram malhas mais próximas do padrão americano, junto com Piracicaba que já estava nesse grupo. Por outro lado, a malha viária de Presidente Prudente passou ao grupo de cidades mais próximas do padrão europeu. Em seguida, os materiais propostos neste trabalho foram utilizados para montar um banco de dados com mais de 300 cidades brasileiras de diferentes portes. Os parâmetros avaliados caracterizaram os municípios de acordo com a conectividade, acessibilidade e regularidade da malha viária. A grande variação destes aspectos ressaltou a diferença nas 
configurações ocasionadas pelos fatores influentes na formação de malhas viárias: processo histórico-social de crescimento urbano, limites geográficos e diferentes políticas de expansão.

Palavras-chave: Planejamento urbano, Teoria dos grafos, Sistemas viários, Informações Geográficas Voluntárias, OpenStreetMap. 


\begin{abstract}
KURAMOTO, B. Data exploration of collaborative maps in evaluations of Brazilian ur-
\end{abstract} ban morphologies. 135 p. Master Thesis - São Carlos School of Engineering, University of São Paulo, São Carlos - SP, 2019

This dissertation is inserted in the area of urban configuration, focusing on road systems segregated by cities. The objective of this research was the exploration of urban road data available on the Web and the extraction of parameters with applicability in analyzes of city morphologies. The intention of the work was to corroborate the hypothesis: The quality acquired by collaborative maps data allows its use in analyzes of the urban morphology at the local level. Collaborative maps are online platforms that aggregate geographic information provided by the users themselves, according to local experience. The OpenStreetMap Project was used as a data source to evaluate the potential and limitations of collaborative maps in the representation of road networks in Brazilian municipalities. The road systems were expressed in graph form, in which the edges represented the streets and nodes, the intersections between streets. From the point of view of Transport Engineering, the focus of the use of Graph Theory in research on road morphologies is on issues such as accessibility, efficiency and network resilience to failure measurement. The main computational tools used were the OSMnx and Networkx libraries, written in Python language, with built-in functions and network analysis. To evaluate the feasibility of using the proposed tools and data platform, a comparison was made with the study by Lima, Silva and van der Waerden (2003). This work evaluated the compactness and global accessibility of the road networks of 11 cities, in order to compare Brazilian examples with foreigners. The reproduction of the reference study was possible, with construction of networks with an average increase of $47 \%$ of elements, which indicated expansion and greater detailing of the road systems. In addition, a difference was detected in the comparison of Brazilian cities with the international panorama. Marília and São Carlos presented meshes closer to the American standard, along with Piracicaba who was already in that group. On the other hand, the road network of Presidente Prudente passed to the group of cities closest to the European standard. Then, the materials proposed in this work were used to build a database with more than 300 Brazilian cities of different sizes. The evaluated parameters characterized the municipalities according to the connectivity, accessibility and regularity of the road network. The great varia- 
tion of these aspects highlighted the difference in the configurations caused by influencing factors in the formation of road networks: historical-social process of urban growth, geographical limits and different expansion policies.

Keywords: Urban planning, Graph Theory, Road System, Volunteered Geographical Information, OpenStreetMap. 


\section{LISTA DE FIGURAS}

Figura 1 - Disposição das pontes de Könisberg (a) e representação na forma de grafo (b)

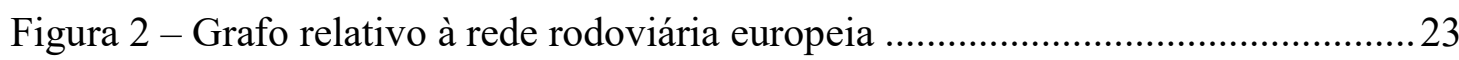

Figura 3 - Representações dos grafos correspondentes a malhas viárias de $1 \mathrm{~km}^{2} \ldots \ldots .24$

Figura 4 - Mapa axial referente a malha viária de Brasília - DF.................................26

Figura 5 - Comparação entre representações primais e duas de 6 cidades ...................27

Figura 8 - Cobertura do território brasileiro por escalas …........................................ 38

Figura 9 - Representação da infraestrutura rodoviária brasileira .................................39

Figura 10 - Página inicial do editor iD do OpenStreetMap ...................................... 40

Figura 11 - Página de edição de elemento do editor iD ............................................... 41

Figura 12 - Etapas de mapeamento do editor JOSM ................................................ 41

Figura 13 - Captura de tela da página da ferramenta Nominatim obtida em resposta à busca "São Carlos-Sp, Brazil".

Figura 14 - Sobreposição das redes viárias extraídas do OpenStreetMap (linhas brancas) e do PNL (linhas vermelhas)

Figura 7 - Exemplos de extração de redes viárias com o OSMnx

Figura 15 - Sobreposição de parte de um grafo em uma visualização de imagem de satélite disponível no software Google Earth.

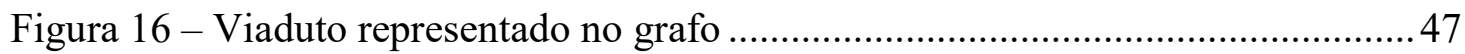

Figura 17 - Grafos da mesma região, não simplificado e simplificado ........................50

Figura 18 - Grafos extraídos com a função graph_from_point (sem escala) ...............51

Figura 19 - Grafo extraído a partir da função graph_from_bbox .................................54

Figura 20 - Grafos extraídos com a função graph_from_address (sem escala) ...........56

Figura 21 - Grafo extraído com a função graph_from_place .......................................59

Figura 22 - Comparação entre grafos fortemente e fracamente conectado ..................60

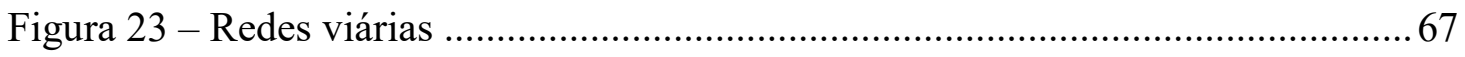

Figura 24 - Comparação de quantidade de nós e índice $E_{\text {real }}$ entre 2003 e 2019 ........... 72

Figura 25 - Comparação das variações percentuais dos índices $E_{\text {circ }}$ em relação aos $E_{\text {real, }}$ entre os dois períodos .76

Figura 26 - Valores normalizados de compacidade por Eindhoven e Madison ............77

Figura 27 - Valores normalizados de compacidade por Eindhoven e Columbus .......... 78

Figura 28 - Distribuição das cidades coletadas por Estado e Região ........................... 80 
Figura 29 - Distribuição das cidades do banco de dados, classificadas por porte demográfico.

Figura 30 - Proporções médias por Estado de elementos excluídos na extração do grafo direcionado fortemente conectado (DS)

Figura 31 - Proporção média por Estado de arestas excluídas na extração do grafo não direcionado fortemente conectado 82

Figura 32 - Histogramas de distribuição de frequência dos valores de graus dos nós 89 Figura 33 - Distribuições espaciais de valor de graus dos nós de Dourados e Petrópolis 90

Figura 34 - Histogramas de distribuição de frequência de centralidade de intermediação dos nós

Figura 35 - Distribuições espaciais dos valores de centralidade de intermediação de nós das cidades de Dourados e Petrópolis 95

Figura 36 - Representação de redes viárias e limites administrativos de Altamira e São Caetano do Sul 98

Figura 37 - Distribuição espacial dos índices de acessibilidade local de Barreiras e de São Caetano do Sul 99

Figura 38 - Índices de acessibilidade global em ordem crescente 101

Figura 39 - Acessibilidade média em quilômetros 101

Figura 40 - Distribuição espacial dos índices de acessibilidade local em Angra dos Reis$\mathrm{RJ}$ 102

Figura 41 - Representações das redes viárias e respectivos histogramas polares de Nilópolis e Salvador. 103

Figura 42 - Histograma de distribuição de frequência dos valores de entropia de orientação 104

Figura 43 - Histogramas polares de distribuição de frequência de orientação de ruas 105

Figura 44 - Distribuição das cidades por porte e grupo de entropia de orientação ... 107 Figura 45 - Diagramas de caixa de $\mathrm{I}_{\mathrm{C}}, \mathrm{I}_{\mathrm{O}}, \mathrm{C}$ e $\mathrm{K}$ dos grupos 1 e 2 108 


\section{LISTA DE TABELAS}

Tabela 1 - Tipos de valores da linguagem Python

Tabela 2 - Parâmetros de entrada da função graph_from_point .................................... 48

Tabela 3 - Opções de configuração do parâmetro network_type

Tabela 4 - Valores inserido nos parâmetros de entrada da função graph_from_point.50

Tabela 5 - Parâmetros de entrada da função graph_from_bbox 53

Tabela 6 - Parâmetros de entrada da função graph_from_address 55

Tabela 7 - Parâmetros de entrada da função graph_from_place .58

Tabela 8 - Funções para cálculos de parâmetros 61

Tabela 9 - Parâmetros de entrada da função basic_stats. 61

Tabela 10 - Critérios dos dados de saída da função basic_stats ...................................62 62

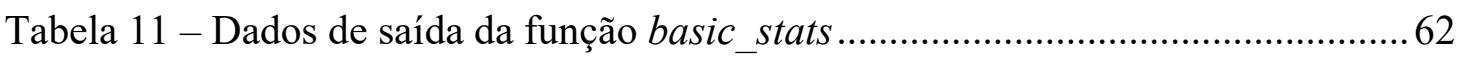

Tabela 12 - Funções e formatos de exportação de grafos.................................................63

Tabela 13 - Características dos grafos de malhas viárias urbanas ...............................67

Tabela 14 - Parâmetros de entrada da função all_pairs_dijkstra_path_length ............70

Tabela 15 - Parte da matriz de caminhos mínimos de São Carlos............................... 71

Tabela 16 - Resultados de acessibilidade global real ................................................ 72

Tabela 17 - Valores de $E_{\text {real }}$ e $E_{\text {ideal }}$ e variações percentuais em relação a E $E_{\text {real }}$ (resultados de 2003)

Tabela 18 - Valores de $\mathrm{E}_{\text {real }}$ e $\mathrm{E}_{\text {ideal }} \mathrm{e}$ variações percentuais em relação a $\mathrm{E}_{\text {real }}$ (resultados atuais) 75

Tabela 19 - Estatística descritiva das variáveis 87

Tabela 20 - Coeficientes de correlação de Pearson entre as variáveis..... 88

Tabela 21 - Testes não-paramétricos de homogeneidade entre as distribuições de valores de grau dos nós.....

Tabela 22 - Teste de Kolmogorov-Smirnov de homogeneidade de distribuições da variável centralidade de intermediação de nós....

Tabela 23 - Teste de Kolmogorov-Smirnov de homogeneidade das distribuições de valores de acessibilidade local.

Tabela 24 - Estatística descritiva das variáveis de cada grupo ................................. 108

Tabela 25 - Classificações do Teste de Mann - Whitney............................................ 109

Tabela 26 - Resultados do Teste de Mann - Whitney.................................................. 109

Tabela 27 - Banco de dados de métricas topológicas e topo-geométricas .................. 123 



\section{Sumário}

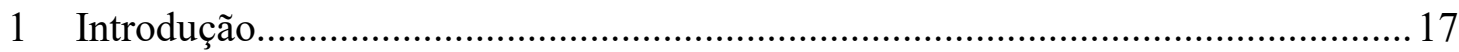

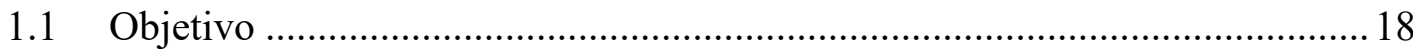

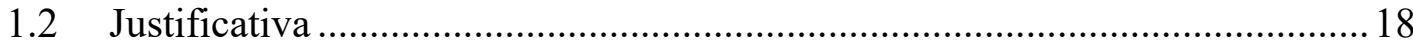

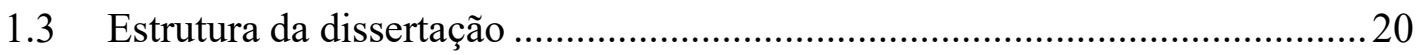

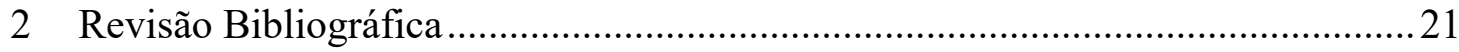

2.1 Teoria de Grafos na Engenharia de Transportes.......................................2

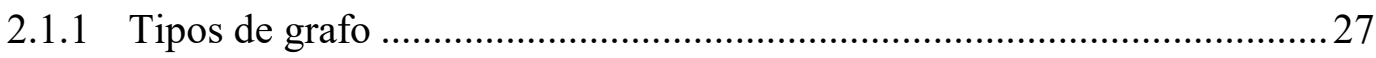

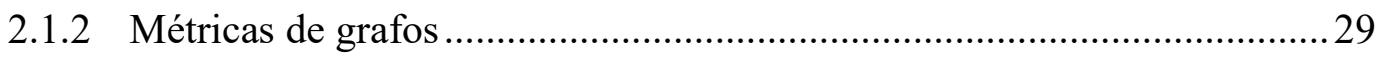

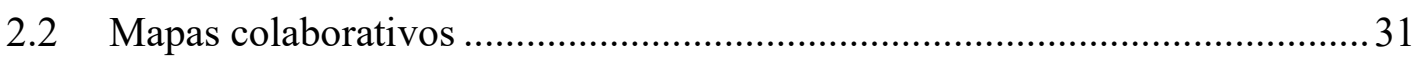

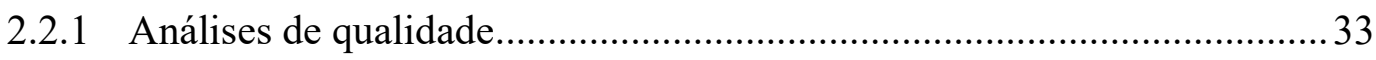

2.2.2 Utilização em trabalhos acadêmicos ...................................................... 34

3 Mapas disponíveis na Web e Ferramentas de análise de rede..............................37

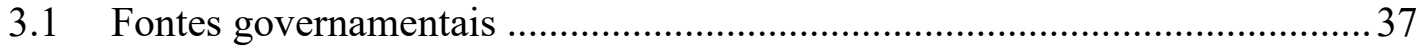

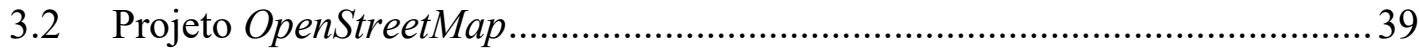

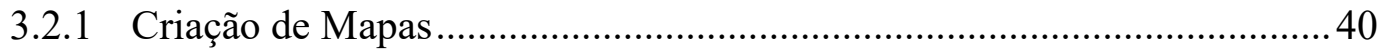

3.2.2 Acesso aos dados da plataforma ....................................................... 42

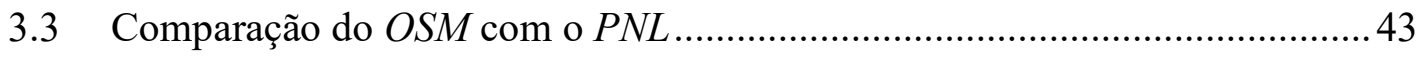

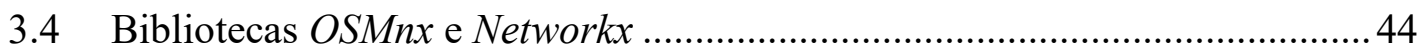

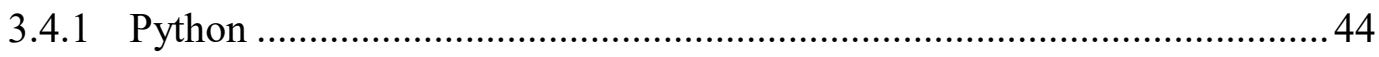

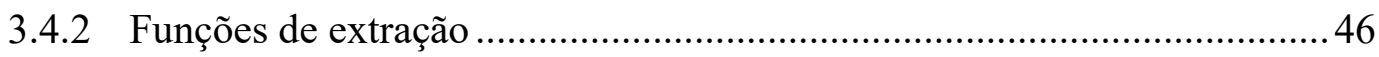

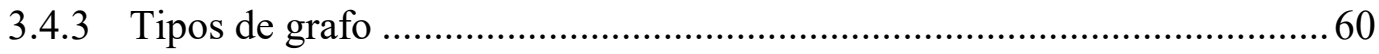

3.4.4 Funções de cálculo de métricas................................................................60

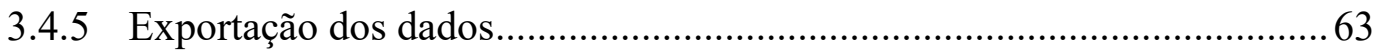

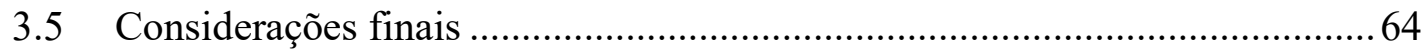

4 Verificação da qualidade dos dados de mapas colaborativos ................................65

4.1 Grafos de redes viárias e matrizes de menores caminhos..............................66 


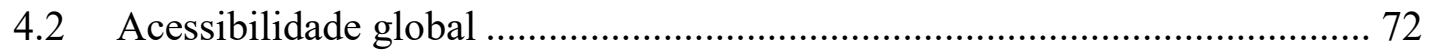

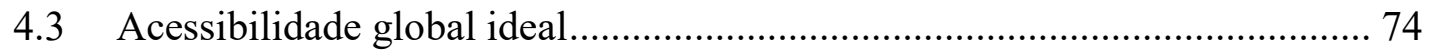

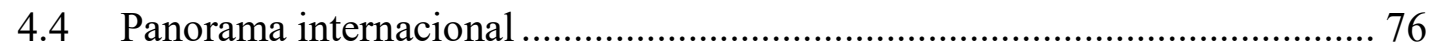

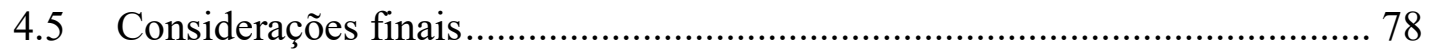

5 Banco de dados de métricas morfológicas......................................................... 79

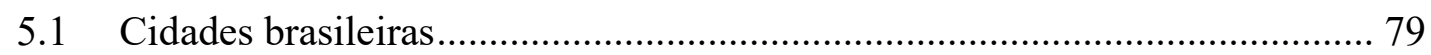

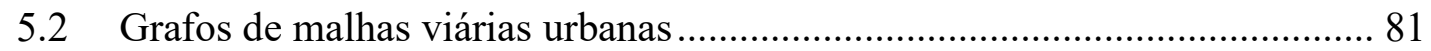

5.3 Banco de Dados e análises da morfologia das redes viárias urbanas brasileiras 83

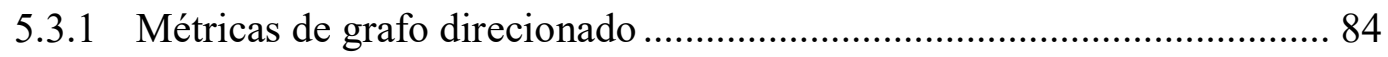

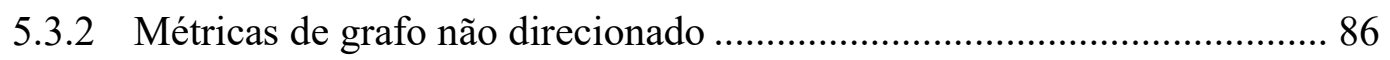

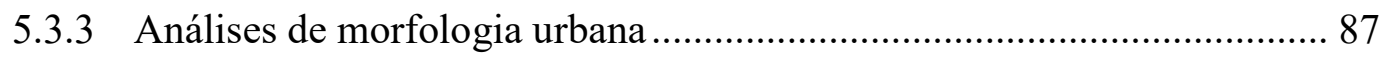

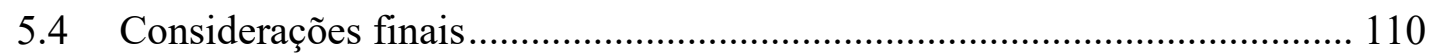

6 Conclusões e recomendações futuras .............................................................. 111

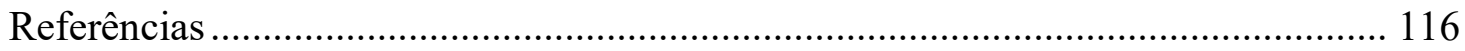

Apêndice A - Banco de dados de métricas topológicas e topo-geométricas ............. 122 


\section{INTRODUÇÃO}

Questões sobre eficiência operacional e sustentabilidade das cidades são importantes nas pautas de projetos de engenheiros, gestores e planejadores de cidades. O sistema de transportes é alvo dessas questões pois é quem promove os diversos tipos de movimentos em uma aglomeração. Uma forma de diagnosticar a situação envolve medidas que traduzem a configuração da rede, assunto inserido na morfologia viária urbana, que é o estudo da forma dos sistemas viários presentes nas cidades.

Um modo de avaliar o sistema de transportes é através da forma de grafos por meio de diversas formas de abstração. Grafos são formas de representação das relações entre diferentes elementos e possuem uma ampla teoria embasada na matemática. Os grafos podem ser de diferentes tipos, de acordo com as relações mais importantes para cada tipo de análise. Por exemplo, no contexto urbano, a versão não direcionada do grafo representa somente a estrutura física disponível para a malha viária, enquanto a versão direcionada representa as restrições de direções dos movimentos nas ruas e é utilizada em casos de avaliação do impacto dessas limitações na eficiência do uso da rede. Independentemente do tipo de construção, informações como geometria e limitações do movimento podem ser inseridas no grafo através de atributos. Da perspectiva da Engenharia de Transportes, o foco do uso da Teoria de Grafos em pesquisas de morfologias urbanas está em questões como mensuração da acessibilidade, eficiência e resiliência da rede a falhas. Ao conhecer a cidade a partir desses conceitos, o gestor pode direcionar os investimentos no sentido favorável ou contrário a cada um desses parâmetros.

A construção do grafo de redes viárias a nível municipal depende de dados georreferenciados detalhados e atualizados, por isso estudos anteriores eram limitados pela quantidade e qualidade das informações de malha viária disponíveis. No caso do Brasil, um país em desenvolvimento e de extensão continental, havia dificuldade nos trabalhos de reconhecimento do território diante da ausência de informações oficiais (LIMA et al., 2010). Além disso, quando essas informações existiam, eram disponibilizadas em formatos digitais inadequados para edição, manipulação ou desatualizados, com inconsistências. Outras vezes, nem o formato digital da malha era disponibilizado, acarretando em uso de mesas digitalizadoras ou scanners. Essas dificuldades comprometiam a conferência dos estudos e a replicabilidade dos métodos em outros locais. 
Com a popularização dos aparelhos de GPS e a evolução de plataformas de mapeamento colaborativo, essa demanda começou a ser atendida (GOODCHILD, 2007). As informações geográficas voluntárias, outro termo utilizado para denominar os mapas colaborativos, possuem grande potencial de aplicações em diversas áreas como base georreferenciada para desenvolvimento de outros estudos. Apesar de algumas desvantagens, principalmente em relação à qualidade dos dados, a escalabilidade e a inovação que as informações geográficas voluntárias podem fornecer às pesquisas devem ser exploradas.

Com o exposto, este trabalho buscou aliar as informações de mapas voluntários às análises de rede viárias urbanas expressas em forma de grafo. $\mathrm{O}$ intuito foi avaliar o potencial de utilização de dados de mapas colaborativos em análises de morfologia urbana. O método proposto pretende verificar a abrangência do território brasileiro por mapas voluntários e analisar os sistemas viários a partir das informações disponibilizadas na web.

\subsection{Objetivo}

O objetivo desta pesquisa é explorar dados viários urbanos disponíveis na web e extrair parâmetros topológicos e topo-geométricos da Teoria de Grafos aplicáveis em análises de morfologia de cidades. A hipótese deste trabalho é: A qualidade adquirida por dados de mapas colaborativos permite sua utilização em análises da morfologia urbana a nível local. Para atingir o objetivo são propostas as seguintes metas:

I. Avaliar a disponibilidade de dados viários urbanos de mapas colaborativos;

II. Obter a rede viária urbana e computar parâmetros topológicos e topo-geométri$\cos$

III. Verificar a qualidade dos dados de mapas colaborativos;

IV. Construir e um banco de dados de redes viárias urbanas brasileiras.

\subsection{Justificativa}

A justificativa desta pesquisa está baseada em três aspectos:

a) modelagem baseada em grafos

b) escassez de informações urbanas para planejamento

c) disponibilidade de mapas colaborativos online. 
A etapa de modelagem de redes na transposição das informações reais para a simplificação na forma de grafo é crítica e deve ser feita de forma transparente e embasada em uma teoria. As opções de modelagem envolvem escolhas sobre quais atributos da rede serão priorizados e quais aspectos serão avaliados, sendo que a primeira decisão abrange a fonte dos dados que construirão os grafos.

Em alguns estudos, as redes viárias foram desenhadas manualmente, uma abordagem considerada subjetiva e trabalhosa, que limita a reprodução e o alcance das pesquisas com esse objeto de estudo (MARSHALL et al., 2018). Essa dificuldade começou a ser diminuída com a evolução de aparelhos de GPS e de bases de dados cartográficos, juntamente com outros avanços da tecnologia de internet, como o compartilhamento de informações. Nesse contexto, o desenvolvimento de ferramentas computacionais auxilia na construção e análise de redes, por isso devem ser avaliadas do ponto de vista da aplicação em temas específicos, como a engenharia de transportes.

A outra questão deste trabalho é a falta de dados viários em questão de cobertura territorial e formato digital adequado para manipulação computacional. Esta atividade encontra obstáculos na atualização e na disponibilização de informações. No Brasil, a falta de investimentos na área de reconhecimento do território levou a uma realidade de mapeamento com cobertura escassa e mal distribuída (CAMBOIM; BRAVO; SLUTER, 2015). Além disso, as malhas viárias fornecidas por agentes governamentais como prefeituras e departamento de trânsitos, nem sempre estão no formato digital mais adequado (LIMA et al., 2010).

Por outro lado, a informação acerca dos espaços, principalmente os urbanos, tem se tornado mais acessível devido a disponibilização de mapas colaborativos online, construídos com o conhecimento do contribuidor sobre o local. Essa iniciativa de voluntários pode fazer parte da solução para as falhas de mapeamento oficiais (SZWOCH, 2019). O principal representante desse tema é o Projeto OpenStreetMap, iniciado em 2004 e que hoje reúne contribuições de pessoas comuns, órgãos oficiais, universidades e empresas privadas. Além disso, essa plataforma fornece livre acesso a seus dados que podem ser exportados em diversos formatos que permitem a manipulação computacional. As potencialidade e limitações dessa fonte de dados têm sido exploradas nos estudos acadêmicos da área nos últimos anos (ARSANJANI et al., 2015). 


\subsection{Estrutura da dissertação}

Esta dissertação é dividida em 6 capítulos e o primeiro traz a introdução dos assuntos abordados junto com o objetivo e a justificativa deste estudo. O segundo capítulo aborda os conceitos de Teoria dos Grafos e Informações Geográficas Voluntárias que embasaram este trabalho.

Os resultados obtidos estão reunidos a partir do capítulo 3, que aborda algumas fontes de dados viários urbanos disponíveis na web e reúne as funcionalidades das ferramentas de análise de rede utilizadas neste estudo. O capítulo 4 compara os resultados obtidos por informações geográficas voluntárias com os obtidos através de malhas digitalizadas em um estudo sobre acessibilidade por separação espacial. O capítulo 5 apresenta o banco de dados de métricas topológicas de rede construído e sua aplicação em análises morfologia urbana. O capítulo 6 finaliza a dissertação com as conclusões e sugestões para pesquisas futuras. 


\section{REVISÃO BIBLIOGRÁFICA}

Este capítulo discorre sobre as bases conceituais de Teoria dos Grafos e Mapas Colaborativos. O primeiro tema foca na utilização de grafos em estudos de Engenharia de Transportes e inclui os benefícios e as limitações dessa ferramenta. O segundo tópico aborda a importância dos Mapas Colaborativos no contexto do fornecimento de dados e sua aplicação em estudos acadêmicos.

\subsection{Teoria de Grafos na Engenharia de Transportes}

No campo da matemática, redes, representações de relacionamentos entre elementos, são denominadas grafos e possuem uma densa teoria com conceitos e propriedades aplicáveis a diferentes situações (ALBERT; BARABÁSI, 2002). Um grafo é uma estrutura que relaciona nós através de arestas, por isso Lipschutz e Lipson (2004) afirmam que um grafo $G(V, E)$ consiste em um par de conjuntos finitos:

a) um conjunto $V$ cujos elementos são chamados vértices, pontos ou nós;

b) um conjunto $E$ de pares não ordenados de nós distintos, chamados de arestas ou arcos.

O grau é uma propriedade dos elementos dos grafos que quantifica as relações com outros elementos, por exemplo, o grau de um nó é a quantidade de nós com os quais ele se conecta. Dentro da teoria dos grafos há a definição de cadeia como uma sequência alternada de nós e arestas, conectados entre si. Quando não há aresta repetida em uma cadeia, essa é chamada de trilha e quando não há nós repetidos, a denominação é caminho. O trabalho de 1736 do matemático Leonhard Euler é apontado como o início da Teoria de Grafos, nele foi abordado o problema das pontes de Könisberg, na antiga Prússia (HARRIS; HIRST; MOSSINGHOFF, 2008). Euler buscou responder a um desafio dos habitantes locais, percorrer as setes pontes que cortavam o rio Pregel, cuja disposição está representada na Figura 1, sem passar mais de uma vez sobre a mesma ponte. Ao avaliar a situação, o matemático constatou a irrelevância das distâncias envolvidas e focou na forma que as várias porções de terras estavam interligadas (SAMPAIO, 2002). 
Figura 1 - Disposição das pontes de Könisberg (a) e representação na forma de grafo (b)

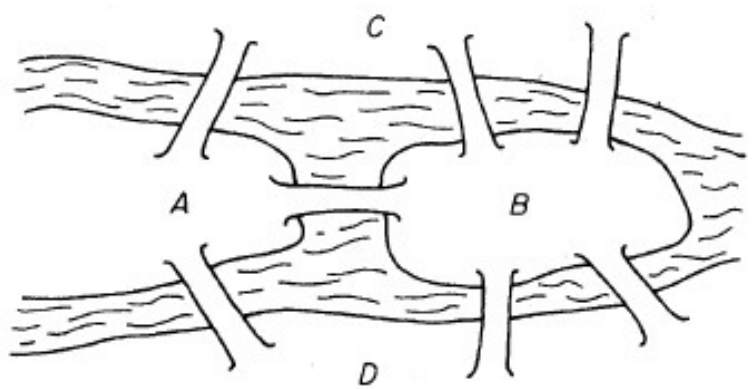

(a)

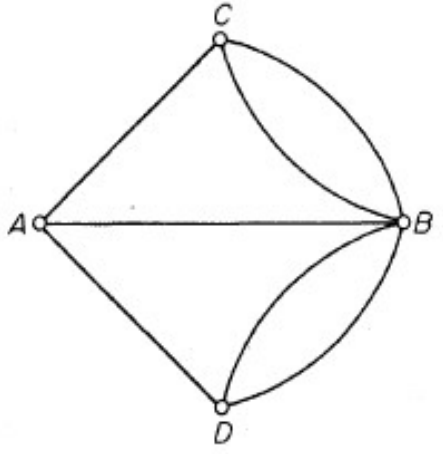

(b)

Fonte: Bondy e Murty (1976)

As ideias desenvolvidas por Euler então começaram a ser utilizadas em diferentes áreas do conhecimento para modelagem de diversos tipos de relações. Desde o surgimento da teoria, métodos e propriedades têm sido criados de forma a aumentar a sua abrangência. Um dos problemas clássicos da teoria dos grafos diz respeito a determinação do caminho mínimo. Nesse contexto, foi desenvolvido o algoritmo de Dijkstra, amplamente utilizado na determinação do caminho mais curto em grafos direcionados ou não, com arestas de peso não negativo (BONDY; MURTY, 1976).

Marshatll et al. (2018) destacam que no caso de redes viárias, por serem suporte de muitos processos urbanos, há uma grande dedicação de estudiosos de diferentes disciplinas como planejadores de transportes, arquitetos, geógrafos, psicólogos ambientais e físicos. Os autores afirmam, que na área de transportes, o estudo de redes vem sendo utilizado para a compreensão do movimento e dos custos associados. Essas análises acontecem em diferentes escalas, desde relacionamento entre países até abordagens em vizinhanças, e abrangem vários tipos de redes como sistema metroviário, rotas aéreas e malhas rodoviárias.

Um estudo em escala continental foi realizado por Dupuy e Stransky (1996) com o intuito de avaliar hierarquia das cidades europeias de acordo com a posição de cada uma em relação a rede viária que as conectava. Os autores construíram um grafo relativo à malha rodoviária que interligava cidades de 14 países (Figura 2). Os nós do grafo foram posicionados nas cidades e em locais de bifurcações e extremidades das rodovias, as arestas (ou links), que correspondiam às ligações rodoviárias, foram ponderadas com medidas como comprimento e velocidade média para representar a capacidade de transmissão de fluxo. Os autores utilizaram propriedades dos grafos como indicadores para comparar as cidades segundo diferentes parâmetros. 
Figura 2 - Grafo relativo à rede rodoviária europeia

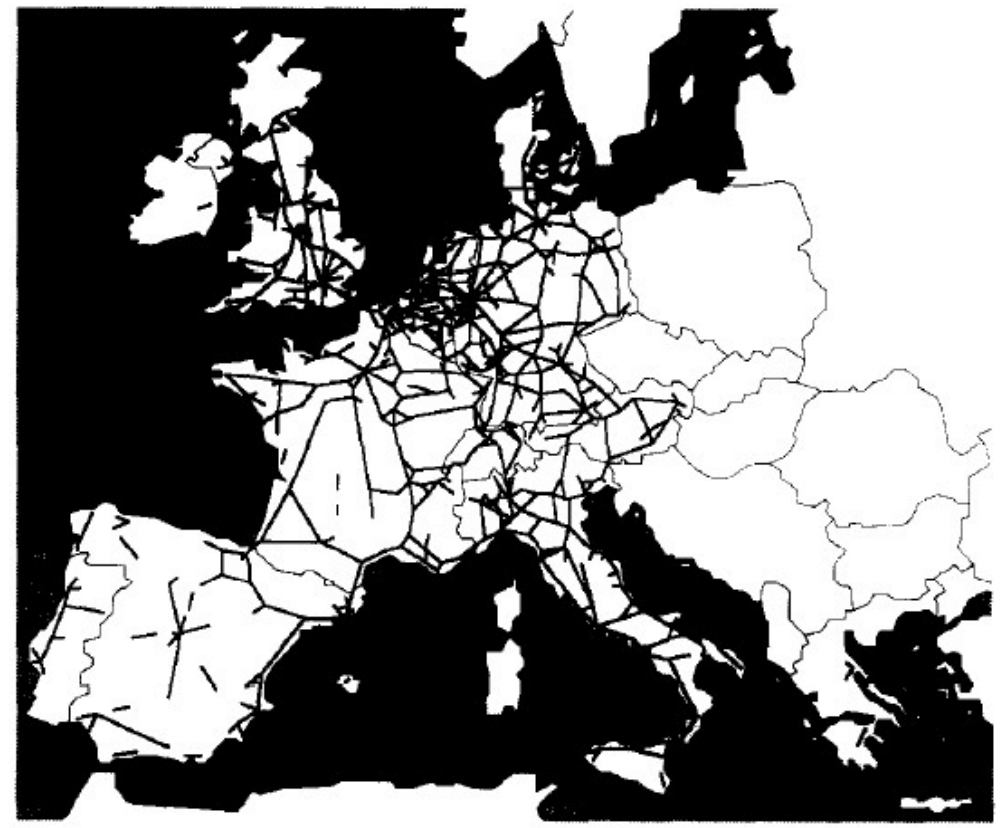

Fonte: Dupuy e Stransky (1996)

A acessibilidade foi determinada de duas formas, por separação temporal e espacial. A primeira quantificou a quantidade de nós que podiam ser alcançados a partir de um nó, dentro de um limite de tempo. A segunda, denominada acessibilidade nodal, representou a soma das distâncias dos menores caminhos entre um nó e todos os outros nós do grafo. A conectividade foi definida nesse trabalho como o número de arestas entre os nós do grafo, porém foi medida através de dois índices: o índice $\alpha$ (alfa) comparou a quantidade de circuitos independentes existentes em relação à quantidade máxima possível devido à planaridade do grafo (condição em que duas arestas só intersecionam em nós); o índice $\gamma$ (gama), com base na mesma condição de planaridade, calculou a relação entre a quantidade arestas do grafo e a quantidade máxima possível. Os parâmetros de velocidade, densidade de comprimento de via e de habitantes por área foram obtidos diretamente da formação da rede. Outra medida avaliada foi o grau de retidão de rotas (degree circuity) que verificou a divergência da das rodovias da disposição "ideal", a linha reta.

Em outra escala, a Teoria de Grafos forneceu o embasamento teórico para a comparação de 41 assentamentos não-planejados, localizados nos continentes europeu, africano e sul-americano, segundo termos de conectividade e eficiência (BUHL et al., 2006). Os grafos gerados de cada assentamento eram correspondentes a uma área de 1 quilômetro quadrado (exemplos na Figura 3), cuja malha viária foi obtida da base de dados de um laboratório universitário francês. 
Figura 3 - Representações dos grafos correspondentes a malhas viárias de $1 \mathrm{~km}^{2}$

a) Verona - Itália

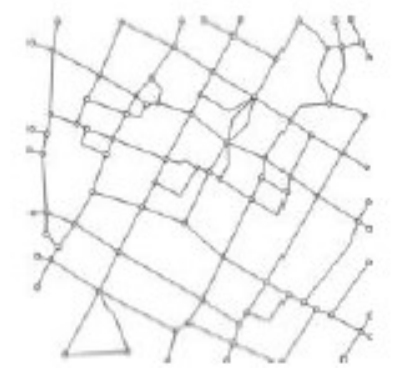

b) Martina Franca Itália

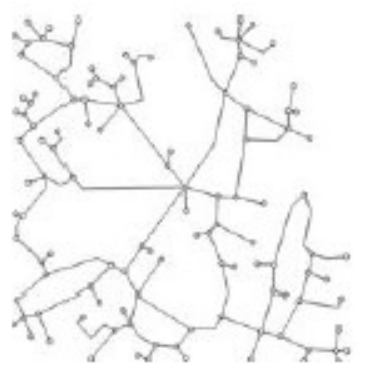

Fonte: Buhl et al. (2006) c) Benares - Índia

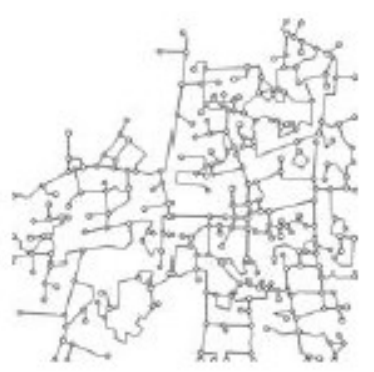

A conectividade foi calculada através do índice $\alpha$, conceito já mencionado no trabalho de Dupuy e Stransky (1996), e do coeficiente de assortatividade, que mede a correlação entre graus de nós adjacentes. Quando a assortatividade assume valores positivos é um indicativo de que os nós com um dado grau se conectam preferencialmente com nós de graus similares.

O conceito de eficiência, avaliação de como o tráfego poderia ser otimamente distribuído de forma a minimizar os congestionamentos, foi definida sob dois aspectos: a robustez e os caminhos mínimos computados pelas distâncias topológicas e geométricas. A distância topológica foi computada a partir da quantidade de nós do caminho mínimo, enquanto que a distância geométrica correspondeu à soma dos comprimentos das arestas do caminho mínimo.

Buhl et al. (2006) avaliaram a robustez do grafo através da análise da fragilidade da rede urbana contra falhas como interrupções causadas por deslizamentos de terras, alagamentos, desabamento de construções e outros eventos temporários. Essa característica verificou a diminuição do tamanho $S$ do maior componente conexo (parte do grafo em que todo os nós são conectados por alguma cadeia) à medida que foram excluídos nós, de forma aleatória e seletiva em ordem decrescente de grau. A eficiência em função das distâncias topológicas e geométricas dos caminhos mínimos também foi determinada para cada grafo G gerado para cada assentamento. Os autores calcularam a eficiência global $\left(E_{g l o b}\right)$ através da relação entre eficiência média de cada grafo $E(G)$ e a eficiência média $E\left(K_{n}\right)$ em um grafo completo de ordem $n$ com os mesmos vértices mas com todas as $n(n-1) / 2$ possíveis arestas.

$$
\begin{gathered}
E(G)=\frac{1}{n(n-1)} \sum_{v_{i} \neq v_{j}} \frac{1}{d_{i j}} \\
E_{\text {glob }}=E(G) / E\left(K_{n}\right)
\end{gathered}
$$

Sendo: 


\section{$n: \quad$ quantidade de nós \\ $d_{i j}: \quad$ distância do menor caminho entre os nós $i$ e $j$}

No Brasil também foram realizados estudos das malhas viárias urbanas, alguns sob a ótica da Sintaxe Espacial (SE) desenvolvida por Hillier e Hanson em 1984. Essa teoria estuda as implicações sociais do espaço arquitetônico, caracterizado pela "configuração urbana", e possui métricas que dialogam com as da Teoria de Grafos. Dentro desse contexto, Medeiros (2006) avaliou uma amostra de 164 assentamentos, sendo 44 cidades brasileiras através da exploração de quatro grupos de variáveis: forma e distribuição, densidade e compacidade, topologia e zoneamento e centralidades. Na tentativa de identificar um tipo de cidade brasileira, o autor destacou expressões como "colcha de retalhos" e "oásis no labirinto".

O autor explicou o termo "colcha de retalhos" como um fenômeno presente em grande parte das cidades do mundo, e nestas especialmente as brasileiras, em que, mesmo quando apresentam certo grau de planejamento e regulação, as malhas viárias são compostas de variadas grelhas sem uma articulação efetiva. Desta forma, as cidades crescem progressivamente e se tornam um conjunto de partes quase que independentes. Desta diversidade de configurações, surgem labirintos que aumentam a complexidade da rede.

Em outro trabalho para explorar o uso da teoria de Sintaxe Espacial e verificar a influência do espaço urbano nas atividades sociais, Pereira et al. (2011) fizeram análises de Regressão Linear entre uma variável de desempenho urbano e variáveis configuracionais. Os autores construíram representações dos sistemas viários, chamadas de mapa axial, do Distrito Federal e de cada uma da 19 Regiões Administrativas a partir de malhas cartográficas. A Figura 4 traz a representação o mapa axial construído para Brasília.

Para cada local foram determinadas medidas de conectividade, acessibilidade topológica e topo-geométrica e de tempo médio de deslocamento por modo (utilitário e táxi). A variável temporal foi adotada para a avaliação do desempenho do transporte urbano e obtida a partir da Pesquisa Origem-Destino realizada no DF no ano 2000. Dentre as conclusões desse trabalho, está a sugestão de que sistemas viários mais integrados e mais compactos tendem a ser economicamente eficientes e ambientalmente menos agressivos quanto às questões de consumo energético e emissão de poluentes. 
Figura 4 - Mapa axial referente a malha viária de Brasília - DF

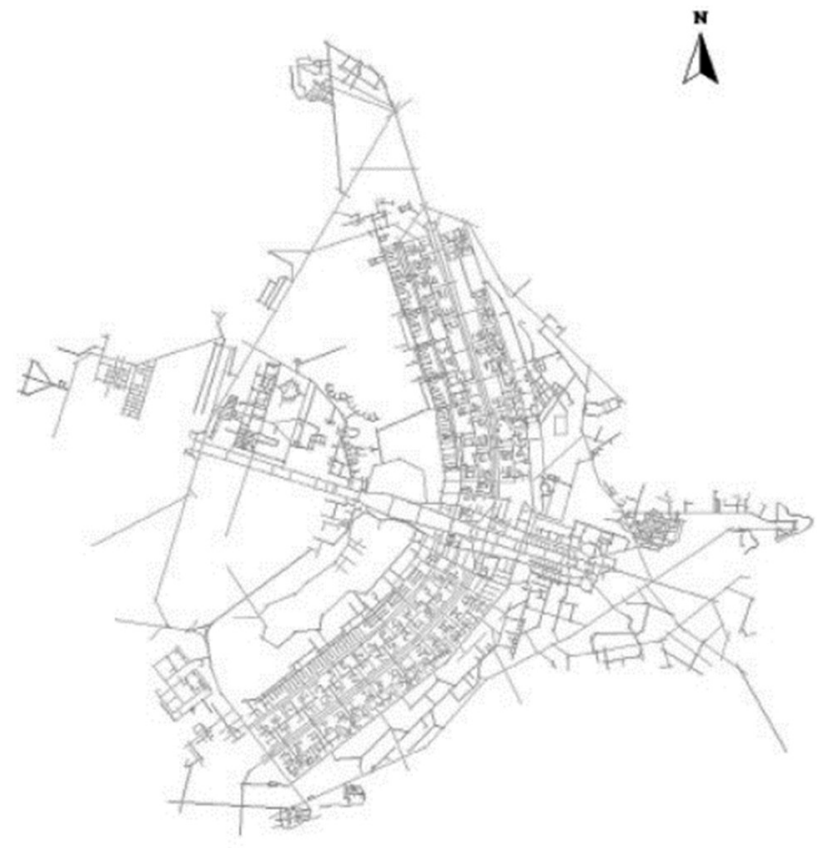

Fonte: Pereira et al. (2011)

Dentro do contexto da Sintaxe Espacial, Hajrasouliha e Yin (2015) avaliaram o poder explicativo de medidas de conectividade sobre o "movimento natural.". Esse termo, cunhado por Hillier et al.(1993) é referente à proporção de fluxo de movimentos de pedestres determinada somente pela configuração da malha, sem a consideração de elementos atratores ou destinos de viagens. Os autores elencaram diversas medidas de conectividade de ruas como densidade de interseções, comprimento médio de quarteirões, porcentagem de interseções de 4 vias e razão entre quantidade de arestas e nós. Um dos pressupostos adotados foi de que quarteirões menores e malhas viárias mais granulares promovem maiores taxas de caminhadas e aumentam o número de viagens utilitárias ou não-laborais. Os autores também destacaram que padrões de rua curvilíneos representam padrões típicos de subúrbios que muitas vezes têm alinhamentos curvos e geralmente ramificações de forma hierárquica, terminando em becos sem saída. Ao contrário das redes de rua curvilíneas, a geometria da grelha permite linhas de visão longa que podem ajudar os pedestres a entender melhor o ambiente e promover uma navegação melhor pela rede de ruas. Na conclusão foi destacado o alto impacto que a conectividade possui sobre a caminhabilidade e características como densidade de segmentos e interseções na rede e diversidade do uso do solo. 


\subsubsection{Tipos de grafo}

Em alguns estudos da Engenharia de Transporte e do Urbanismo, as redes representam sistemas viários, cujas estruturas são essenciais no cotidiano por influenciarem diretamente nos tempos de viagem e nos custos de transportes (COSTA et al., 2011). O tipo de grafo mais adequado para representar o relacionamento entre os elementos depende da informação em análise.

A representação primal do grafo é uma forma de abstração em que os eixos dos segmentos de ruas de uma cidade são associados às arestas e as interseções e as extremidades aos nós. Nesse caso, os nós são lugares importantes para tomada de decisão acerca do movimento dentro da rede (SOARES, 2007). Por outro lado, no grafo dual as ruas são representadas pelos nós e as interseções são as arestas. Essa configuração foi empregada em alguns trabalhos que focaram na questão de design urbano, segurança, acessibilidade, etc. (PORTA; CRUCITTI; LATORA, 2006a). Entretanto, a forma primal é a que tem sido adotada nos trabalhos que utilizam grafos para investigações de mobilidade urbana e engenharia de transportes (MARSHALL et al., 2018). A Figura 5 ilustra a diferença entre as formas de representações primal e dual para seis cidades.

Figura 5 - Comparação entre representações primais e duas de 6 cidades

a) Representações primais dos grafos referentes às malhas urbanas de $1 \mathrm{~km}^{2}: 1-$ Ahmedabad, 2 - Barcelona, 3- São Francisco, 4 - Veneza, 5 - Viena, 6 - Walnut Creek

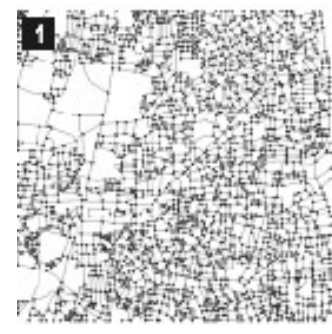

2

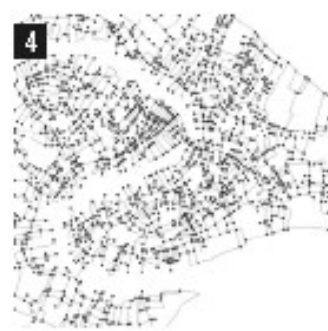

3

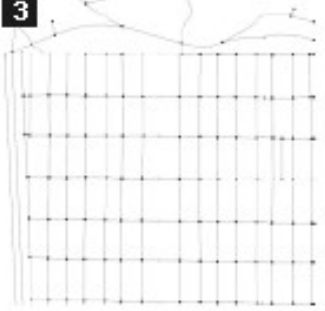

6

b) Representações duais dos grafos referentes às malhas urbanas de $1 \mathrm{~km}^{2}$, na mesma ordem 


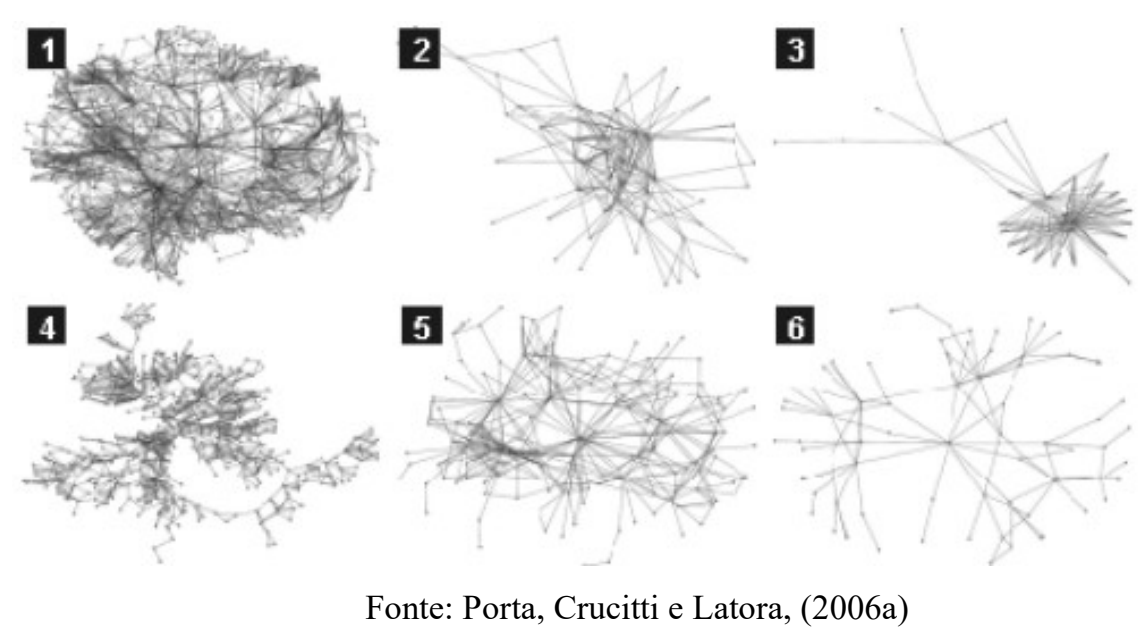

Uma forma de manter a fidelidade da geometria das malhas viárias na representação por meio de grafos é através da ponderação dos elementos. Esse processo pode ser realizado com qualquer tipo de informação, tanto nas arestas como nos nós. Nos elementos lineares, os pesos podem representar o comprimento e largura dos segmentos de ruas, a quantidade de faixas de rolamento, a inclinação, etc. Além das características reais, outros tipos de impedâncias podem ser impostos para estudos com simulações.

O grafo também pode ser do tipo direcionado (dígrafo) ou não direcionado, de acordo com a existência ou não de restrição na direção do movimento. A representação direcionada de uma malha viária considera as ruas de sentido único ou duplo, por isso descreve a rede do ponto de vista dos controles instituídos. Esse tipo mantém a semântica original da rede viária por representar como ela é utilizada pelos usuários. Por outro lado, a versão não direcionada ilustra a estrutura da rede viária, visto que representa a base física disponível sem restrições de movimento.

O direcionamento das arestas também influencia na distinção dos grafos quanto à conectividade. Os grafos direcionados são fortemente conectados se entre quaisquer pares de vértices $v$ e $u$ existe um caminho direto de $v$ para $u$ e vice-versa, sendo o caminho a sequência de arestas adjacentes. Quando esta reciprocidade não existe, os grafos direcionados são fracamente conectados, ou seja, existe caminho direto de $v$ para $u$ mas não existe o inverso. Para casos de grafos não direcionados, se existe um par de vértice não interligado por um caminho, o grafo é desconexo, caso contrário é conexo.

Outra variação dos tipos de grafo envolve a continuidade espacial da rede representada. Casos de redes de única camada podem ser associados aos grafos planares por formarem vértices sempre que há cruzamento entre duas arestas (CARDILLO et al., 2006). Por exemplo, um sistema viário exclusivamente com ruas no mesmo plano, sem considerar elementos em outros 
níveis, como túneis e pontes. A adequação ao grafo planar permite absorver parâmetros exclusivos para este tipo de rede e tem sido a principal forma utilizada na literatura, especialmente em análises de centros urbanos europeus antigos.

Porém, as cidades mais recentes vêm experimentando investimentos massivos em estruturas voltadas ao uso de automóveis, como túneis e viadutos, que geraram cidades com malha tipo grade cortadas por rodovias. Com base nessas diferenças, o estudo de Boeing (2018b) avaliou as áreas centrais urbanas da 50 maiores cidades mundiais. $\mathrm{O}$ autor concluiu que a consideração das redes viárias como grafos planares pode enviesar análises ao superestimar contagens de interseções, subestimar comprimentos de segmentos e deturpar indicadores de conectividade.

\subsubsection{Métricas de grafos}

As métricas de um grafo podem ser divididas em duas classes de acordo com o objeto estudado. As métricas locais são referentes aos elementos da rede, os nós (também chamados de vértices) e as arestas (laços, arcos) (GERVASONI et al., 2017). Por outro lado, as métricas globais identificam comportamentos do conjunto todo e permitem a comparação entre redes.

Uma categoria de métrica local é denominada centralidades, pois são medidas de hierarquização da importância de cada elemento de acordo com diferentes aspectos como participação em caminhos mínimos e distância média de outros elementos (CRUCITTI; LATORA; PORTA, 2006). Sharifi (2019) destacou a despolarização da centralidade de intermediação, ou seja, a busca pela uniformidade desses valores, como prática para diminuir o alcance das falhas da rede. Essa métrica quantifica a participação de cada elemento nos caminhos mínimos do grafo; seus valores elevados indicam pontos de vulnerabilidade visto que uma intervenção neles pode interromper mais de um caminho mínimo. O autor também afirmou que o desenvolvimento de um índice de resiliência de uma rede envolve minimizar a quantidade de segmentos isolados e evitar o posicionamento de serviços críticos próximo a eles. Tal comportamento pode ser avaliado com a determinação da centralidade de proximidade, que é uma medida de integração da rede e dimensiona a distância de cada nó até todos os outros nós da rede, através dos caminhos mínimos.

As médias das métricas locais geram métricas globais, que permitem a descrição de toda a rede por uma única medida. Com grafos primais, planares e não direcionados, Lima et al. (2000) calcularam o índice de acessibilidade global baseado em separação espacial idealizado 
por Allen, Liu e Singer (1993) de alguns municípios brasileiros buscando avaliar a proximidade deles com os padrões de cidades norte-americanas e europeias A escolha desses padrões foi justificada pela tradição de cidades europeias serem mais compactas e orientadas ao uso de transporte público, enquanto as norte-americanas são mais esparsas e priorizam o automóvel particular. Uma das críticas do índice de acessibilidade por separação espacial é baseada na sua natureza reflexiva (BHAT et al., 2000). O modo como é calculada tradicionalmente, não há diferenciação quanto ao uso do solo ou às restrições de movimento, a acessibilidade de um ponto A para B é a mesma da de B para A. A influência das restrições de movimento na acessibilidade pode ser avaliada através da consideração do sentido das ruas.

Em uma utilização prática dos conceitos topológicos em análises de planejamento urbano, o Plano de Mobilidade de Manaus aplicou conceitos da Sintaxe Espacial para diagnosticar o sistema viário urbano da capital amazonense. Em uma abordagem de macrocirculação, o Plano avaliou o grau de homogeneidade da rede referente à distribuição dos fluxos de tráfego urbanos nos segmentos. Baseado no estudo de Penn et al. (1998), que sugeriu alguns parâmetros de configuração viária urbana altamente correlacionados com fluxo de tráfego, o Plano adotou o pressuposto de que a homogeneidade é favorecida pela maior proporção de nós de cruzamento em detrimento dos nós de entroncamento, informações fornecidas pelo grau, nos conceitos topológicos. Nós de grau 1 são terminações, de grau 2 são junções e de graus maiores são interseções, sendo que nós de grau 3 geralmente são encontrados em limites ou interrupções de rede.

O indicador orgânico (ou razão orgânica), denominação que enfatiza o conceito de cidade como sistema vivo, quantifica interrupções na rede e é apropriado para o dimensionamento do "efeito barreira", que de acordo com Sousa e Braga (2011) é ocasionado por algum elemento decorrente de fenômenos naturais ou obras de engenharia. Esses obstáculos influenciam na mobilidade de indivíduos ao diminuir a acessibilidade de locais além de serem fortes candidatos a criarem gargalos no fluxo de movimentos.

Apesar de não existir um consenso sobre quais valores de cada métrica descrevem a melhor forma de planejamento urbano, há estudos para comparar o desempenho de diferentes sistemas viários e as vantagens e desvantagens que cada um deles traz para o funcionamento da cidade como um todo. Em um estudo preliminar em busca de padrões, Boeing (2019) analisou a direção, a linearização de rotas e o comprimento de ruas de 100 cidades de diferentes continentes, sendo a maioria da amostra composta de países asiáticos, europeus e norte-americanos, cujas malhas foram obtidas da plataforma do OpenStreetMap. Os grafos construídos eram primais, não direcionados e não planares. A desordem da malha foi contabilizada pelo grau de 
variação das orientações das arestas, que foi denominada entropia de orientação. O autor verificou que a orientação mais presente foi a norte-sul-leste-oeste. Cidades norte-americanas apresentaram maior número de malhas do tipo grade, característica relacionada a baixos valores de entropia da orientação das arestas. O autor comprovou a hipótese de cidades com malhas próximas do tipo grade tendem a ter mais ruas por nós, mais cruzamentos, ruas menos sinuosas e menos nós com grau 1, encontrados nas comumente chamadas "ruas sem saída".

Sharifi (2019) afirma que pode ser problemático a adoção de parâmetros ideais de projeto e de diretrizes específicas de planejamento sem a devida consideração do contexto. Ou seja, a análise mais eficiente para cada cidade deve ser com base em dados próprios. No caso do Brasil, a proporção continental do território e a falta de investimento dificultam a construção de bancos de dados estruturados, detalhados e abrangentes. Por isso, Camboim e Slutter (2015) declararam a importância da contribuição da comunidade científica para o subsídio da cartografia nacional. Mesmo que algumas cidades disponibilizem suas malhas viárias em formato digital, nem sempre elas estão atualizadas ou em formato de fácil manipulação, o que cria um outro obstáculo para o reconhecimento do território por parte de acadêmicos, gestores e habitantes.

As investigações das áreas de engenharia de transportes e de urbanismo ganharam impulso com o desenvolvimento dos Sistemas Inteligentes de Transportes (ITS Intelligent Transportation System) e de Big Data. Sobre as vantagens oferecidas pela "Revolução Telemática", Marchetti et al. (2015) afirmam que o Big Data pode ser um fornecedor mais rápido de variáveis auxiliares do que fontes oficiais de dados para modelos de pequenas áreas, mesmo com a indisponibilidade de informações individuais, devido às restrições de privacidade. Os autores ainda ressaltam o desafio de trabalhar com dados relacionados às novas Tecnologias de Comunicação e Informação (Information and Communication Technology - ICT). Esse desafio é justificado pela heterogeneidade, falta de estrutura e grande volume dos dados. Para que esta vantagem seja eficientemente aproveitada, as informações devem ser organizadas de forma rápida e precisa para serem interpretadas pelos engenheiros e urbanistas.

\subsection{Mapas colaborativos}

As pessoas absorvem informações a todo momento dos ambientes que frequentam como os nomes dos locais, as características topográficas, as redes de transportes, etc. Esse conheci- 
mento pode ser ampliado com o uso de dispositivos que coletam outras informações geográficas, de celulares e veículos equipados com GPS, de câmeras e outros sensores (GOODCHILD, 2007). Com o início do compartilhamento voluntário desses dados, através do que Turner (2006) chamou de Neogeografia, mapas começaram a ser criados e utilizados sem exigir conhecimentos especializados em cartografia. Diversos termos são utilizados como referência às bases de dados fornecidas de forma voluntária (NEIS; ZIELSTRA, 2014). Neste trabalho, as nomenclaturas adotadas foram mapas colaborativo e informações geográficas voluntárias (Volunteered Geographic Information - VGI).

Goodchild (2007) destacou as principais diferenças entre as plataformas VGI e as agências tradicionais de mapeamento. As agências seguem uma estrutura autoritária e hierárquica, em que especialistas da área produzem a informação consumida por amadores. O progresso é lento e custoso, além de exigir um consenso para definir as diretrizes do avanço. Por outro lado, de forma caótica e informal, as plataformas $V G I$ são ampliadas por um processo constante de criação e cruzamento de informações. Neste contexto, produtores e consumidores de dados não apresentam distinções e o avanço não segue direção definida.

Neis e Zielstra (2014) elencaram exemplos recentes de projetos de informações geográficas voluntárias. Os mais antigos são o OpenStreetMap ${ }^{1}$ (OSM), fundado em 2004, e seu similar WikiMapia ${ }^{2}$, em 2006. Posteriormente, com bases de dados parcialmente estruturadas por empresas, surgiram: MapMaker (Google) ${ }^{3}$, Here Map Creator (Nokia) ${ }^{4}$, Map Share (TomTom $)^{5}, W_{a z} e^{6}$, dentre outros. A principal diferença entre essas plataformas está na disponibilidade do uso dos dados, pois a maioria está sob propriedade de companhias privadas. A licença de conteúdo do WikiMapia permite a alteração e o compartilhamento dos dados, desde que os devidos créditos sejam atribuídos. O OSM é disponibilizado em dados abertos e é hospedado por diversas organizações, como a Universidade College London (UCL), a Universidade de Zagreb e a Universidade de Zaragoza.

\footnotetext{
${ }^{1} \mathrm{https}: / /$ www.openstreetmap.org/

2 https://wikimapia.org/

${ }^{3} \mathrm{O}$ MapMaker foi descontinuado em 2017 e alguns recursos foram integrados com o Google Maps

${ }^{4}$ https://mapcreator.here.com/

${ }^{5} \mathrm{https}: / /$ www.tomtom.com/mapshare/tools

${ }^{6} \mathrm{https}: / / \mathrm{www}$. waze.com/pt-BR
} 


\subsubsection{Análises de qualidade}

Diferentemente dos dados coletados em sistemas comerciais de Big Data, os fornecidos por plataformas VGI possuem origem na experiência local de cada usuário. Por isso, há uma preocupação acerca da qualidade das informações obtidas por essas fontes. No caso do $O S M$, membros da comunidade organizados em grupos de trabalhos voluntários são responsáveis pela correção dos dados, juntamente com algoritmos automáticos de manutenção (SZWOCH, 2019).

Em um estudo que avaliou informações do $O S M$ em relação ao banco de dados da agência nacional de mapeamento do Reino Unido, Haklay (2010) elencou os parâmetros de qualidade de informações espaciais sintetizados por Oort (2006):

a) Histórico: aspecto sobre a história do banco de dados, como foi coletado e como evoluiu.

b) Precisão posicional: avaliação da relação entre a posição do objeto no banco de dados e a posição real.

c) Precisão de atributos: avaliação de quão correto estão informações adicionais.

d) Consistência lógica: consistência interna do banco de dados em termos de correção topológica.

e) Integridade: medida da falta de dados.

f) Precisão semântica: avalia a interpretação do objeto no banco de dados em relação ao significado no mundo real.

g) Qualidade temporal: medida da validade das mudanças no banco de dados em relação às mudanças no mundo real.

h) Usabilidade e limitações: qualidade relacionada à adequação de finalidade, deve ajudar usuários em potencial a decidir como os dados podem ser usados.

Para as amostras britânicas, o autor detectou na época uma acurácia de 6 metros na posição de lugares na área urbana e uma sobreposição completa sobre a base oficial das rodovias cadastradas no OSM. Acerca da integridade, em 6 anos de funcionamento da plataforma $V G I$, quase $30 \%$ das rodovias inglesas já estavam adequadamente cobertas. Descontinuidades da cobertura foram detectadas com maior frequência em regiões mais pobres através da inspeção visual da integridade e precisão do atributo existência de ocupação. Por isso, o autor afirma que não existe uma distribuição aleatória dos erros entre as bases de dados tradicionais e as 
voluntárias. Segundo Arsanjani et al., 2015, em 2014, o Brasil foi um dos países emergentes em que mais foram criados elementos na plataforma OSM.

Camboim e Slutter (2015) investigaram o parâmetro de qualidade consistência lógica através da avaliação da compatibilidade das VGI fornecidas pelos sistemas do OpenStreetMap e do Wikimapia com o perfil de metadados oficial do Brasil. Com base nas regras determinadas pela Comissão Nacional de Cartografia (CONCAR), o perfil oficial é o adotado na estruturação da Infraestrutura Nacional de Dados Espaciais (INDE-BR). O OSM forneceu todos os elementos estruturantes obrigatórios do perfil e apresentou vantagens quanto a forma de distribuição ao permitir o download das informações de forma direta e em diversos formatos de arquivo (XML, SHP, PDF, SVG, WMS e OGC, padrão adotado pela INDE_BR)

No trabalho de Camboim e Slutter (2015), foram investigadas a qualidade temporal e a integridade dos dados do $O S M$ em áreas urbanas e rurais da Região Metropolitana de Curitiba. A tendência de maior disponibilização de dados voluntários em áreas urbanas densamente povoadas em áreas brasileiras corrobora as observadas em estudos internacionais. Outros parâmetros de qualidades não puderam ser medidos devido à ausência de bancos de dados confiáveis, porém a disponibilização desses dados é uma oportunidade sem precedentes para análises viárias contextualizadas e em larga escala (SHARIFI, 2019).

\subsubsection{Utilização em trabalhos acadêmicos}

Lima et al. (2010) afirmam que o mapeamento colaborativo apareceu como solução concreta para a falta de informações espaciais atualizadas e consistentes. Esse estudo teve o intuito de ilustrar a utilização dos mapas colaborativos na obtenção de mapas digitais para aplicações em transporte. Na ocasião, os autores desenvolveram o mapa do município mineiro de Itajubá através do Projeto Tracksource ${ }^{7}$, representante brasileiro na nova fase da cartografia.

No âmbito do gerenciamento de desastres naturais, Hirata et al. (2013) desenvolveram o esquema conceitual do sistema "Pontos de Alagamento", protótipo cujo objetivo foi mapear os pontos de alagamento da cidade de São Paulo através de informações voluntárias fornecidas pelos cidadãos em tempo real. Apesar das complexidades inerentes à dinamicidade do evento avaliado, os autores constataram a utilidade pública e o interesse da população pela aplicação.

\footnotetext{
${ }^{7}$ tracksource.org.br/
} 
No caso do projeto de mapa colaborativo OpenStreetMap, o uso das informações tem sido ampliado por métodos e ferramentas como os criados na proposta de Szwoch (2019) para combinar dados viários do OSM com bancos de dados mantidos por autoridades oficiais administrativas. Em outra iniciativa, Boeing (2016) desenvolveu uma biblioteca em linguagem de programação Python que extrai os dados disponíveis na plataforma OSM através de interfaces de programação de aplicação $(A P I)$ e constrói objetos do tipo grafo, incorporado espacialmente. O autor demonstrou aplicações da biblioteca OSMnx através de análises em múltiplas escalas de mais de 27.000 redes viárias urbanas (BOEING, 2018a).

Gervasoni et al. (2017) avaliaram o espalhamento urbano de Grenobla (França), Manhattan (EUA) e Mays Chapel (EUA) através de informações coletadas da plataforma OSM. Os autores utilizaram funções da $O S M n x$ e de outras ferramentas para avaliar a dispersão da ocupação, a acessibilidade a atividades e a proximidade entre diferentes tipos de uso de solo. A biblioteca também foi utilizada como ferramenta em simulações de emissão de $\mathrm{CO}_{2}$ por tráfego de carros para a cidade austríaca de Graz (HOFER; JÄGER; FÜLLSACK, 2018).

Em outra aplicação de dados abertos, Dingil et al. (2018) analisaram indicadores socioeconômicos de transportes e de performance de transporte em 151 áreas urbanas de diferentes portes populacionais, espalhadas por 51 países. Os dados socioeconômicos foram obtidos do site City Population ${ }^{8}$ e da base de dados da Organização para Cooperação Econômica e Desenvolvimento ${ }^{9}$. Um indicador denominado acessibilidade a infraestrutura foi calculado a partir de dados do OSM e quantificou a infraestrutura de transporte disponível por tipo (rodovia, ferrovia e ciclovia) em metros para cada 10 habitantes. A performance de transporte foi avaliada através dos níveis de congestionamento, em termos de tempo médio extra diário de viagem. Os dados foram obtidos da base de dados de tráfego da TomTom através das informações dos usuários dos produtos da empresa. Os autores avaliaram a correlação entre os indicadores e as características socioeconômicas e encontraram evidências significativas de que em cidades com altas densidade de população, um aumento na acessibilidade a infraestrutura ferroviárias é mais descongestionante do que um aumento na acessibilidade a infraestrutura rodoviária.

A utilização das informações geográficas voluntárias do projeto OSM, na forma de redes extraídas pela ferramenta OSMnx, tem potencial nos estudos acadêmicos de mobilidade e planejamento urbano. No Brasil, essa possibilidade diminui os efeitos da ausência de base de dados

\footnotetext{
${ }^{8}$ www.citypopulation.de

${ }^{9} \mathrm{https}$ ://stats.oecd.org
} 
detalhados. Trabalhos neste sentido devem ser desenvolvidos para investigar a capacidade de tornar mapas colaborativos um recurso de reconhecimento do território e subsídio para pesquisadores. 


\section{MAPAS DISPONÍVEIS NA WEB E FERRAMENTAS DE ANÁLISE DE REDE}

O objeto de estudo desta pesquisa é o sistema viário de ruas das cidades brasileiras. Tradicionalmente, as análises de morfologia urbana são realizadas a partir de informações da malha viárias disponibilizadas por órgãos governamentais, como prefeituras e departamentos de trânsito. No entanto, essas bases de dados geralmente eram fornecidas em formatos digitais inadequados para edição, manipulação ou desatualizados, com inconsistências (LIMA et al., 2010). Outras vezes, nem o formato digital da malha era disponibilizado, acarretando em uso de mesas digitalizadoras ou scanners.

O desenvolvimento de novas tecnologias contribuiu para a geração dos mapas digitais, incialmente com o advento das mesas digitalizadoras e em seguida com a popularização dos aparelhos equipados com GPS e da internet (GOODCHILD, 2007). Por isso, as informações de mapas estão cada vez mais disponíveis e acessíveis na web, o que culminou no objetivo deste trabalho de explorar esses dados disponíveis. Este capítulo buscou atender as metas de avaliar a disponibilidade de dados viários urbanos no projeto de mapas colaborativos, obter a rede viária urbana e computar parâmetros topológicos e topo-geométricos.

\subsection{Fontes governamentais}

Como o território é um elemento constitutivo do Estado, o conhecimento acerca dele é uma das prioridades do governo. No Brasil, diversas entidades, públicas e privadas, executam trabalhos topográficos e compõem o Sistema Cartográfico Nacional, como o Instituto Brasileiro de Geografia e Estatística (IBGE), a Diretoria de Serviço Geográfico (DSG), a Diretoria de Hidrografia e Navegação (DHN) e o Instituo de Cartografia Aeronáutica (ICA). O mapeamento topográfico do Brasil é representado de forma sistemática e contínua nas escalas padrão de 1:1.000.000, 1:500.000, 1:250.000, 1:100.000, 1:50.000 e 1:25.000 (BRASIL, 1967). A Figura 6 mostra a cobertura do mapeamento topográfico no Brasil por escalas em 2015. Na escala de 1:250.000, quase a integralidade do território está mapeada, porém, na escala 1:25.000 somente alguns locais foram elencados. 
Figura 6 - Cobertura do território brasileiro por escalas

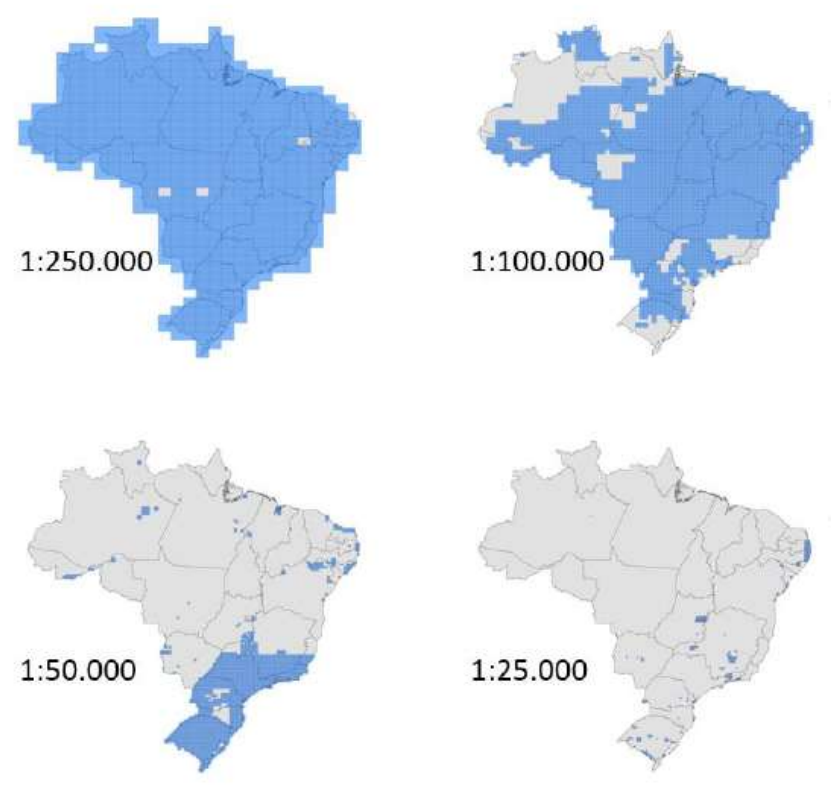

Fonte: Camboim, Bravo e Sluter (2015)

Outras iniciativas governamentais surgiram para mapeamentos de elementos específicos, como por exemplo a rede georreferenciada dos modos de transporte de carga. Essa rede é um dos produtos do Plano Nacional de Logística (PNL), resposta do governo brasileiro ao problema de dependência do país em relação ao transporte de cargas por rodovias (CHAPOLA, 2018). Um dos objetivos do PNL é representar a realidade da infraestrutura atual e as alternativas futuras, utilizando elementos geográficos dos diferentes sistemas de transporte do país. Apesar de levantar informações de infraestrutura de diferentes modos de transportes, o foco do PNL é na matriz de transporte de cargas, por isso não há detalhamento das redes viárias internas das cidades, mas somente da conexão entre elas. A Figura 7 traz a representação do cenário atual da rede rodoviária brasileira projetada no ambiente do software Google Earth e disponibilizada pelo PNL (EPL, 2018). 
Figura 7 - Representação da infraestrutura rodoviária brasileira

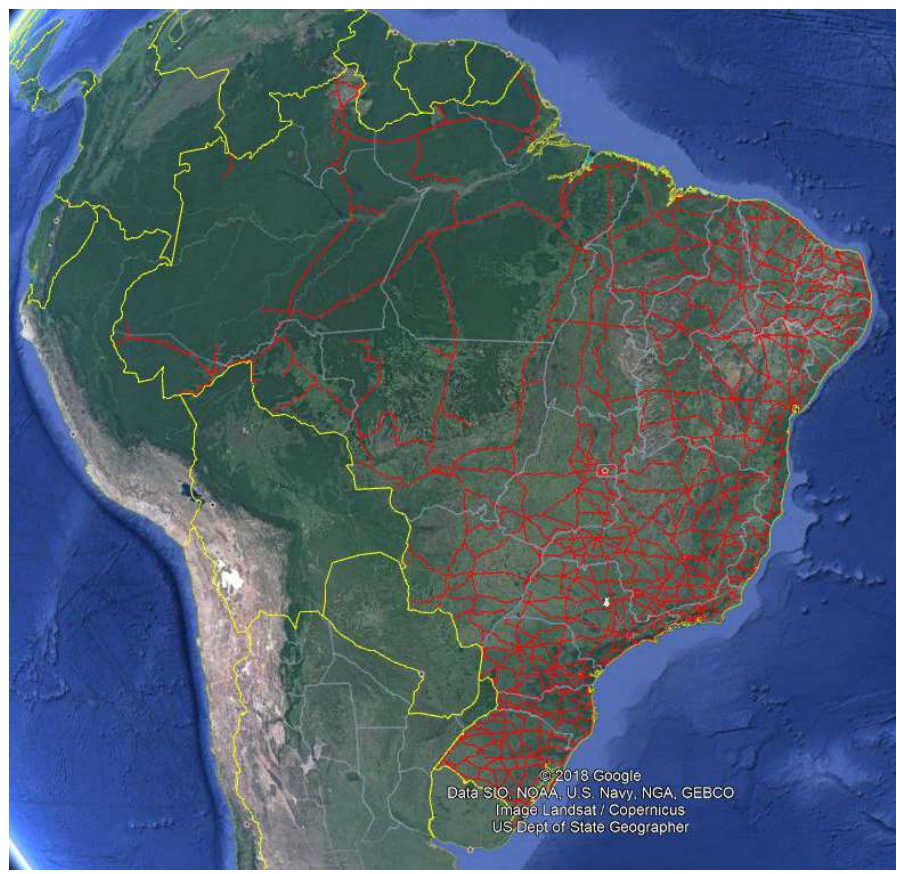

Fonte: Captura de tela do Google Earth

Entretanto, os dados fornecidos pelo PNL não são suficientes visto que o foco da pesquisa foi delimitado para estruturas viárias no nível das cidades. Logo, a busca por outras fontes de dados seguiu para iniciativas não governamentais e, para garantir a replicação deste trabalho, alternativas gratuitas e de acesso livre.

Dentre as opções de empresas privadas como Google Earth e TomTom, os termos de usos restritivos para pesquisas foram o principal critério de exclusão do rol de opções. Das fontes de dados, gratuitos e de livre acesso, os mapas colaborativos (também referenciados como informações geográficas voluntárias) surgiram como escolha adequada. O representante mais expoente desta categoria é o OpenStreetMap (OSM), que tem sido utilizado em estudos acadêmicos de diferentes áreas do conhecimento que necessitam de informações estruturais locais.

\subsection{Projeto OpenStreetMap}

O Projeto OpenStreetMap é uma iniciativa para criar e fornecer dados geográficos de forma gratuita para todos os interessados através da web (Fundação OpenStreetMap; 2018). A plataforma possui mais de 5 milhões de usuários cadastrados além de diversas entidades oficiais como fonte de dados. No Brasil o Departamento Nacional de Infraestrutura de Transportes (DNIT), O Instituto Brasileiro de Geografia e Estatística (IBGE), O Instituto Chico Mendes de 
Conservação da Biodiversidade (ICMBio) e o Banco de Dados Geográficos do Exército Brasileiro (BDGEx) provem dados ao projeto OSM (OpenStreetMap Wiki; 2018)

\subsubsection{Criação de Mapas}

Qualquer pessoa pode colaborar com o Projeto OSM, com inserções e alterações de informações. Para isso, os contribuidores criam um cadastro na plataforma e concordam com o compartilhamento das contribuições sob a licença do OSM. O mapeamento pode ser realizado de diferentes formas, as principais são realizadas por meio de programas editores. (OpenStreetMap Wiki, 2018a). O editor mais básico é o iD, utilizável diretamente do navegador, com interface mais simples e amigável para o iniciantes (OpenStreetMap Wiki, 2018b) A Figura 8 mostra a página inicial do editor iD do OSM. Além das boas vindas, um aviso sobre a vedação de cópia de dados de outras fontes é apresentado.

Figura 8 - Página inicial do editor iD do OpenStreetMap

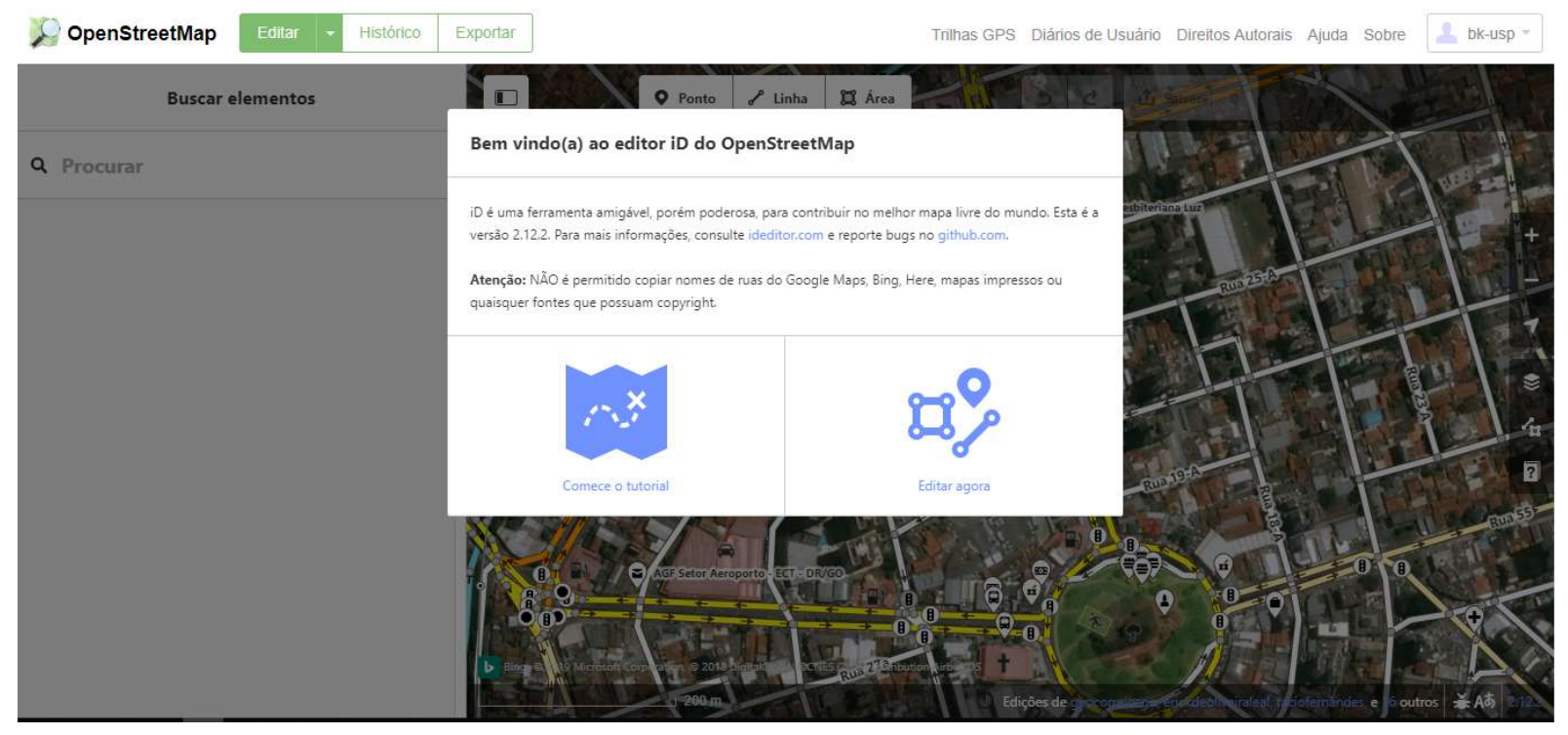

Fonte: OpenStreetMap Wiki (2018b)

A Figura 9 retrata a página de edição de um elemento do tipo caminho no editor iD. Neste exemplo de edição, é possível inserir ou alterar dados como nome da rua, tipo, sentido de deslocamento, limite de velocidade e total de faixas de rolamento. 
Figura 9 - Página de edição de elemento do editor iD

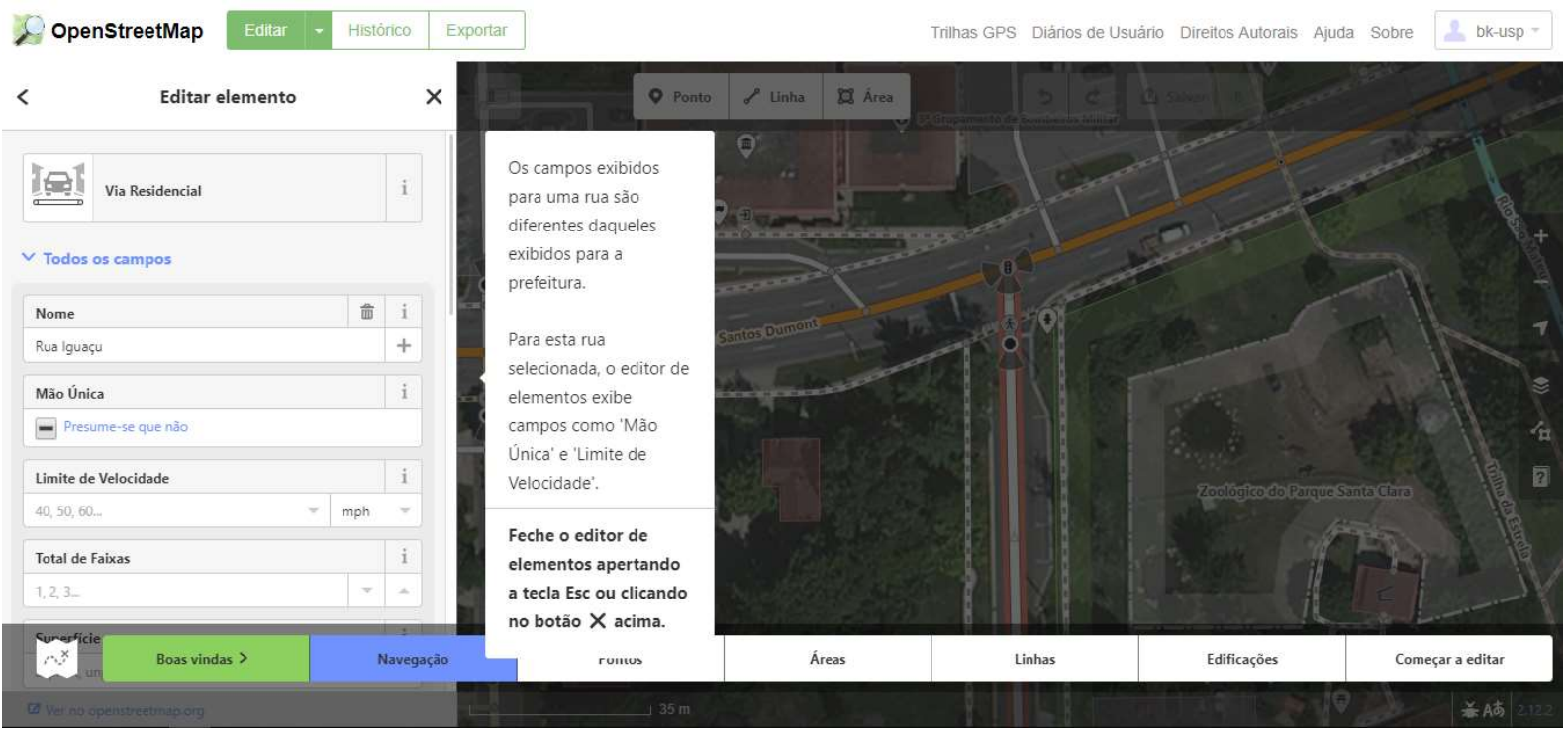

Fonte: OpenStreetMap Wiki (2018b)

Outro editor utilizado é o JOSM (Java OpenStreetMap) escrito em linguagem JAVA e disponível gratuitamente. A Figura 10 mostra o esquema de etapas de mapeamento através do editor JOSM.

Figura 10 - Etapas de mapeamento do editor JOSM

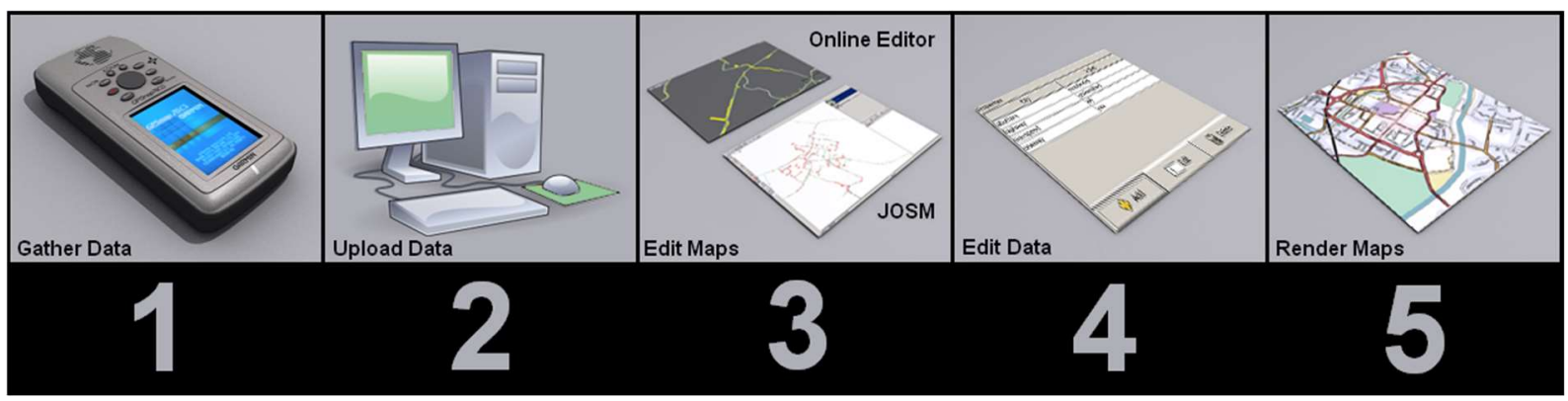

Fonte: OpenStreetMap Wiki (2018a)

A primeira etapa consiste na coleta de dados que pode ocorrer com uso de aparelhos equipados com GPS, traçado sobre imagens aéreas e conhecimento local. A segunda fase é a transferência dos dados coletados para a plataforma. Em seguida, dentro do ambiente do editor, o mapa é criado a partir dos elementos nós, caminhos, área e relações. Esses elementos podem ser descritos na etapa de edição de dados, com rotulações e detalhamentos. Por fim, o mapa é compilado e disponibilizado para os usuários. 


\subsubsection{Acesso aos dados da plataforma}

As informações disponíveis pelo Projeto $O S M$ podem ser acessadas através do site da plataforma. Para usuários que desejam utilizar os dados de forma diversa da simples visualização, o projeto disponibiliza uma interface de programação de aplicação (API) (OpenStreetMap Wiki, 2018a). Através desta interface, programadores desenvolveram ferramentas para facilitar a exploração das potencialidades da plataforma, como a biblioteca escrita em linguagem Python, OSMnx (BOEING, 2017). Outras opções para obtenção de dados são encontradas online como o arquivo Planet $O S M^{10}$, um retrato de toda a base de dados atualizado semanalmente, as extrações regionais fornecidas pela empresa GEOFABRIK e as ferramenta osmosis e osmium (BARRON; NEIS; ZIPF, 2014).

Outro instrumento importante para a exploração dos dados da plataforma do $O S M$ é o Nominatim $^{11}$, ferramenta de busca de informações através do nome de local ou endereço. $\mathrm{O}$ Nominatim também realiza a busca reversa, em que a partir das coordenadas geográficas são procurados os nomes e endereços dos locais. A Figura 11 traz parte da resposta que a ferramenta retorna quando o endereço "São Carlos-SP, Brazil” é requerido.

Figura 11 - Captura de tela da página da ferramenta Nominatim obtida em resposta à busca "São Carlos-Sp, Brazil"

Data last updated:
$201910311016: 55 \mathrm{GMT}$

\begin{tabular}{ll} 
Name & $\begin{array}{l}\text { Sanca (loc_name) } \\
\text { São Carlos (name) } \\
\text { São Carlos (name:pt) } \\
\text { São Carlos do Pinhal (old_name) }\end{array}$ \\
\hline boundary:administrative
\end{tabular}

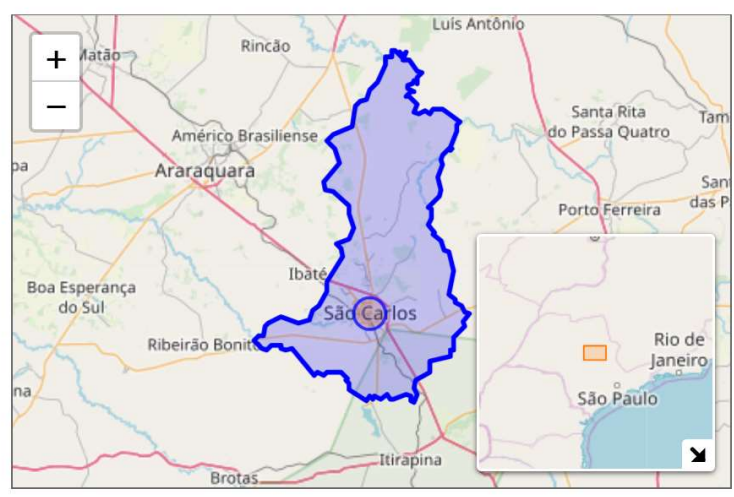

Fonte: Nominatim (2019)

\footnotetext{
${ }^{10} \mathrm{https}: / /$ planet.openstreetmap.org/

${ }^{11} \mathrm{https}$ ///nominatim.openstreetmap.org/
} 


\subsection{Comparação do $O S M$ com o $P N L$}

A Figura 12 traz a sobreposição das redes viárias extraídas do $O S M$ e do $P N L$ da cidade de São Carlos no estado de São Paulo. A imagem permite a diferenciação entre as abrangências de cada rede. Enquanto as informações do PNL são restritas às rodovias, as do OSM cobrem rodovias, ruas, avenidas e acessos.

Figura 12 - Sobreposição das redes viárias extraídas do OpenStreetMap (linhas brancas) e do PNL (linhas vermelhas)

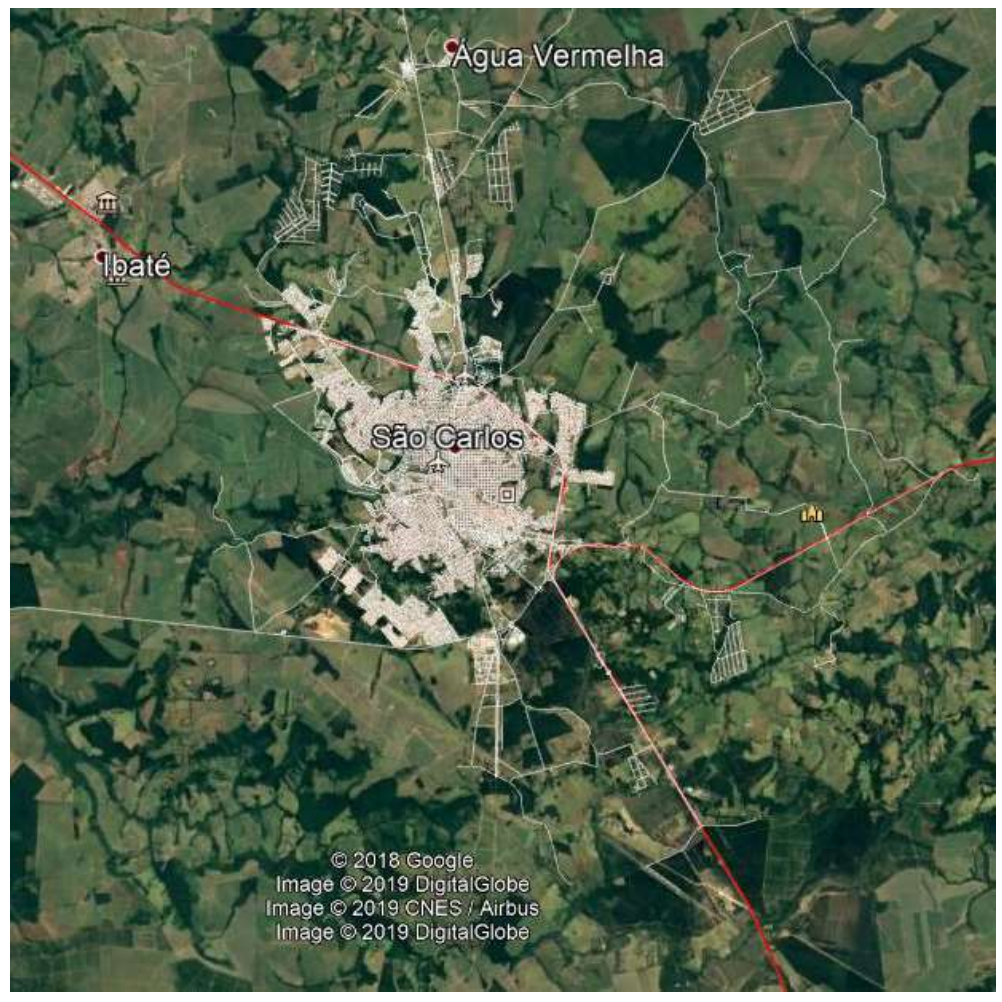

Fonte: Captura de tela do Google Earth

O Projeto OpenStreetMap (OSM) foi escolhido para o fornecimento das informações geográficas voluntárias utilizadas neste trabalho por ser uma fonte de dados viários urbanos de livre acesso. Além disso, ele é a principal iniciativa utilizada em trabalhos acadêmicos e referência para diversas ferramentas de criação e exploração de dados. As informações extraídas, referentes às configurações da infraestrutura viária, foram traduzidas em forma de grafos através do uso de funções da biblioteca OSMnx e da construção de rotinas computacionais em linguagem Python. Além da localização de pontos e conexões internos da malha viárias, também foram obtidas informações como comprimento do segmento de rua e direção de movimento permitidas. Estes dados são cadastrados, alterados e corrigidos na plataforma quando os contribuidores criam elementos e ficam disponibilizados para consulta e manipulação através de API. 


\subsection{Bibliotecas OSMnx e Networkx}

As redes viárias urbanas são representadas por corredores de circulação conectados e possuem diversas camadas. A camada referente às ruas e suas interseções foi selecionada como objeto de estudo e esta seção tem como objetivo exemplificar modos de construí-la em forma de grafo, exportar os resultados para vários formatos de arquivo e analisar segundo diferentes parâmetros. Para atender ao objetivo de reconhecimento das bibliotecas de análise de rede, foram consultadas as documentações das bibliotecas OSMnx, versão 0.8.2 e Networkx, versão 2.1. As rotinas computacionais foram escritas em linguagem de programação Python.

\subsubsection{Python}

Python é uma linguagem de programação poderosa, com estruturas de dados de alto nível e um abordagem simples e eficaz para programação orientada a objetos (Python Software Foundation). Os comandos da linguagem são mais próximos da linguagem humana do que a de máquina e são flexíveis para diversos usos. O campo de aplicações envolve desenvolvimento web, computação científica, desenvolvimento de softwares, aplicações de negócios, etc. A sintaxe do Python envolve a associação de valores a variáveis que podem ser de diferentes tipos, conforme exemplificado na Tabela 1.

Tabela 1 - Tipos de valores da linguagem Python

\begin{tabular}{cl}
\hline Tipo de valor & \multicolumn{1}{c}{ Descrição } \\
\hline string & sequência de letras \\
\hline int & números inteiros \\
\hline float & números decimais \\
\hline bool & binário \\
\hline \multicolumn{2}{l}{ Fonte: Adaptado de Severance (2009) }
\end{tabular}

As variáveis podem ser manipuladas através de operadores como adição $(+)$, subtração $(-)$, multiplicação $(*)$, divisão (/), exponenciação $(* *)$, entre outros. Outra forma de manipulação ocorre através de expressões condicionais e iterativas, estruturas frequentemente utilizadas na confecção de programas (scripts). Os dados ainda podem ser organizados em diferentes tipos de estruturas como listas, tuplas (pares de valores), dicionários (valores referenciados por chaves), matrizes, etc.

O interpretador do Python e a biblioteca padrão de pacotes de softwares são distribuídos de forma gratuita através do site oficial que também traz a documentação das diferentes versões 
da linguagem. Outros pacotes também são encontrados no repositório oficial PyPi (Python Software Foundation). Alguns pacotes são componentes da instalação padrão do Python e fornecem diversas funcionalidades. O NumPy e o $S c i P y$ são bibliotecas para aplicações científicas com diversas funções matemáticas (OLIPHANT, 2007) e o Matplotlib reúne ferramentas de construção de diferentes tipos de gráficos e figuras (HUNTER, 2007). O pacote Pandas é uma biblioteca de estrutura de dados e ferramentas estatísticas desenvolvida para diversas áreas, desde manipulação de dados financeiros até de tempo (MCKINNEY, 2010)

\subsubsection{Biblioteca Networkx}

Em 2002, existia a necessidade de uma ferramenta capaz de analisar dados e estratégias de intervenção na disseminação de doenças epidêmicas e de estudar estruturas e dinâmica de redes sociais, biológicas e de infraestrutura (HAGBERG; SCHULT; SWART, 2008). Neste contexto, foi desenvolvido o Networkx, um pacote de ferramentas para exploração e análise de redes e algoritmos de redes. O pacote foi liberado como software de código aberto em 2005, possui núcleo escrito completamente em linguagem Python e foi desenvolvido no Laboratório Nacional de Los Alamos. A instalação é fácil e a biblioteca interage com outros pacotes como NumPy, SciPy e Matplotlib.

\subsubsection{Biblioteca OSMnx}

O pacote OSMnx é uma extensão das funções da biblioteca Networkx, pois coleta fronteiras administrativas e redes viárias a partir da base de dados do OpenStreetMap. A extração dos dados é feita quando o usuário determina uma área de interesse. A região de interesse pode ser definida de diferentes formas: a partir do nome da cidade e do país; definição de coordenadas dos extremos de um retângulo ou as coordenadas de um ponto central. A Figura 13 ilustra os resultados de duas áreas extraídas da cidade de Goiânia, em Goiás, por diferentes formas de determinação da região de interesse. 
Figura 13 - Exemplos de extração de redes viárias com o OSMnx

a) Extração por nome de cidade

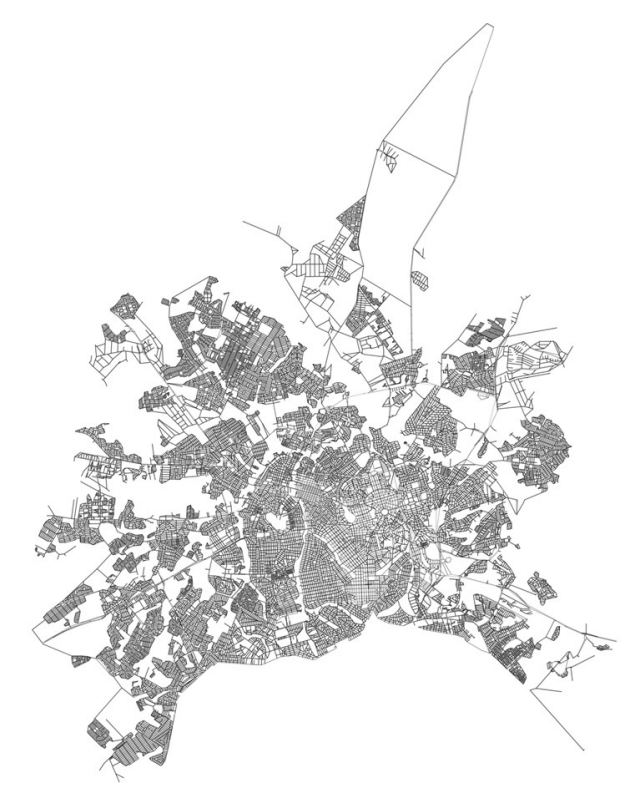

b) Extração por retângulo delimitante

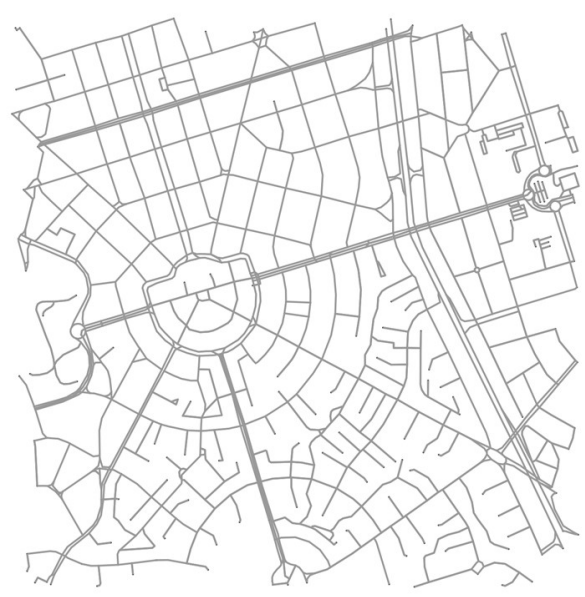

Fonte: A autora

Além disso, é possível especificar o tipo de rede, como exclusivamente dirigível, ou que as podem ser utilizadas por pedestres e/ou ciclistas, entre outras. Este pacote também é gratuito, possui código aberto e realiza análises de redes pois é construído com base em bibliotecas do Python como o próprio Networkx, Matplotlib e Geopandas (BOEING, 2017).

\subsubsection{Funções de extração}

A biblioteca $O S M n x$ possui funções pré-construídas para a extração do grafo de acordo com a preferência do usuário quanto aos critérios de entrada (BOEING, 2017). As funções possuem muitas configurações em comum e são diferenciadas basicamente pelo tipo de informação que embasa o requerimento. Todas as funções geram multidígrafos não planares. Os multidígrafos são dígrafos que permitem a ocorrência de arestas paralelas, aquelas que possuem nós iniciais e finais iguais. A característica de não planaridade ocorre nos grafos em que as arestas se cruzam sem formar nós. O exemplo da Figura 14 apresenta a sobreposição de parte de um grafo em uma visualização de imagem de satélite disponível no software Google Earth. As arestas do grafo são as linhas brancas e nos pontos de interseções com outras arestas estão os nós, representados por círculos com pontos pretos internos. Cruzamentos de arestas sem interseção não criam nó, como no caso retratado na Figura 15 em que ocorre a passagem de um viaduto sobre uma via. 
Figura 14 - Sobreposição de parte de um grafo em uma visualização de imagem de satélite disponível no software Google Earth.

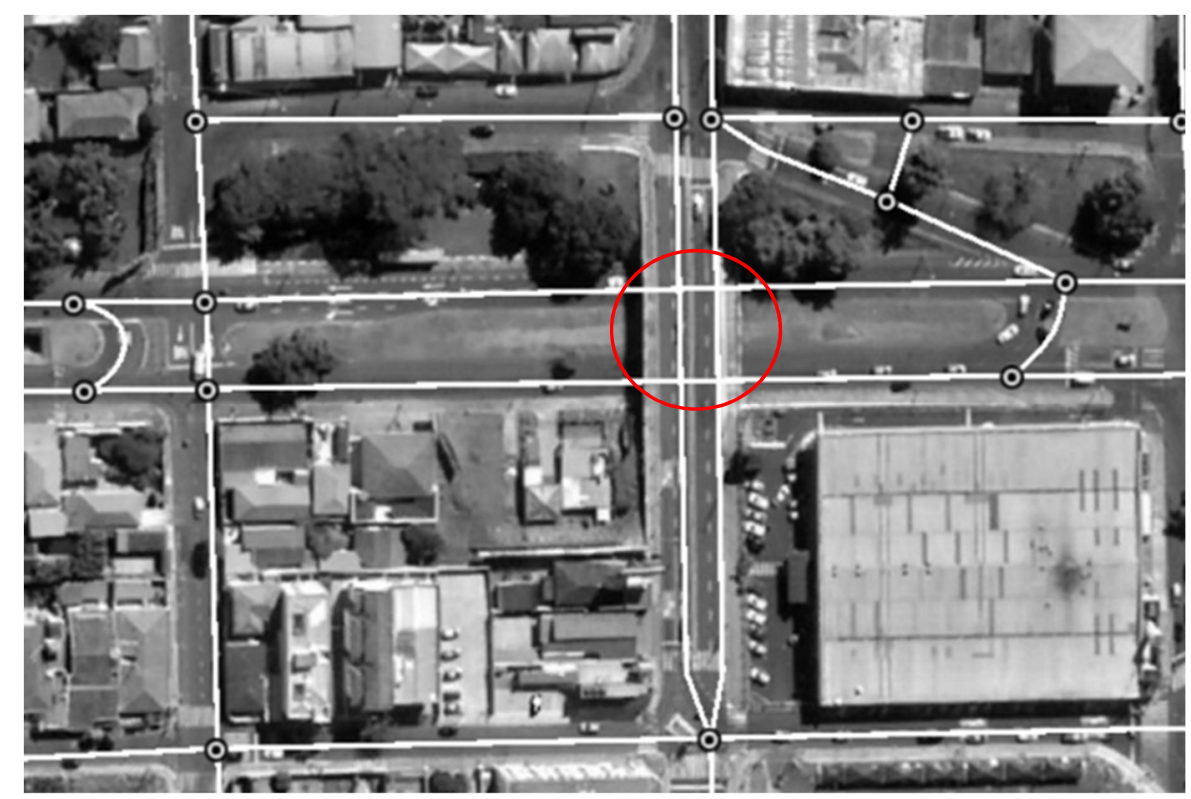

Fonte: Captura de tela do Google Earth

Figura 15 - Viaduto representado no grafo

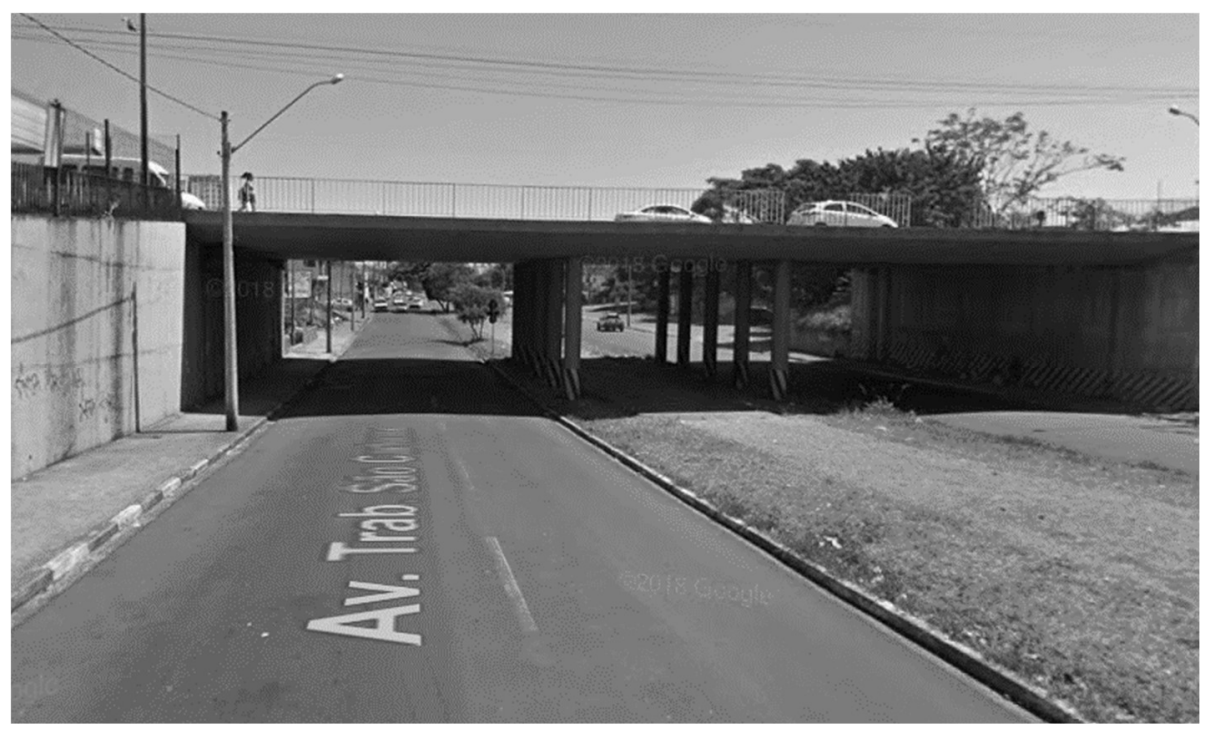

Fonte: Captura de tela do Google Street View

\subsubsection{Ponto e raio}

A função graph_from_point extrai o grafo a partir do fornecimento de coordenadas de um ponto e de uma distância referente ao raio da área abrangida em torno do ponto. A sintaxe da função e os parâmetros de entrada os valores padrões são os seguintes: 


\section{Sintaxe:}

osmnx.core.graph_from_point (center_point, distance=1000, distance_type='bbox' , network_type='all_private', simplify=True, retain_all=False, truncate_by_edge=False, name $=$ ' unnamed' , timeout $=180$, memory $=$ None, max_query_area_size $=2500000000$, clean_periphery=True, infrastructure='way ["highway"] ', custom_filter=None)) .

A Tabela 2 traz a descrição de cada parâmetro de entrada e o tipo de dado que cada parâmetro aceita como valor.

Tabela 2 - Parâmetros de entrada da função graph_from_point

\begin{tabular}{|c|c|c|}
\hline Parâmetro & Tipo de dado & Descrição \\
\hline center point & tupla & $\begin{array}{l}\text { As coordenadas do ponto central em torno do qual cons- } \\
\text { truir o grafo }\end{array}$ \\
\hline distance & inteiro & $\begin{array}{l}\text { Distância em metros a partir do center_point que deli- } \\
\text { mita a àrea abrangida pelo grafo }\end{array}$ \\
\hline distance_type & string & $\begin{array}{l}\text { Critério para criação da área do grafo. Se assume valor } \\
\text { "bbox", a rede é limitada por um retângulo cujo centro é } \\
\text { o center point e os lados são o dobro do valor estabele- } \\
\text { cido no parâmetro distance. Se assume valor "network", } \\
\text { são retidos na rede os nós dentro da distância estabele- } \\
\text { cida no parâmetro distance. }\end{array}$ \\
\hline network_type & string & Tipo de rede viária que comporá o grafo (ver Tabela 3) \\
\hline simplify & booleano & Se assume valor True, simplifica a topologia do grafo \\
\hline retain_all & booleano & $\begin{array}{l}\text { Se assume valor True retorna todo grafo interno à área, } \\
\text { mesmo que desconexo. }\end{array}$ \\
\hline truncate_by_edge & booleano & $\begin{array}{l}\text { Se assume valor True, nós que estão fora da área delimi- } \\
\text { tada, mas possuem vizinhos que estão dentro são retidos } \\
\text { no grafo }\end{array}$ \\
\hline name & string & Nome do grafo \\
\hline timeout & inteiro & Intervalo de tempo limite para obter resposta da $A P I$ \\
\hline memory & inteiro & $\begin{array}{l}\text { Tamanho em bytes da alocação de memória do servidor } \\
\text { Se nenhum valor é determinado, o servidor utilizará o } \\
\text { tamanho padrão }\end{array}$ \\
\hline max_query_area_size & decimal & $\begin{array}{l}\text { Tamanho máximo da área delimitado em metros quadra- } \\
\text { dos. Se o grafo possuir área maior que este limite, será } \\
\text { dividido em várias consultas para a } A P I\end{array}$ \\
\hline clean_periphery & booleano & $\begin{array}{l}\text { Se assume valor True e o parâmetro simplify também } \\
\text { está ativado, utiliza uma margem de } 0,5 \mathrm{~km} \text { para extrair } \\
\text { um grafo maior que o requerido, que em seguida é sim- } \\
\text { plificado e truncado para o tamanho delimitado }\end{array}$ \\
\hline infrastructure & string & Tipo de infra-estrutura. O padrão é rua (highway) \\
\hline
\end{tabular}




\begin{tabular}{ccc}
\hline Parâmetro & Tipo de dado & Descrição \\
\hline custom-filter & string & $\begin{array}{l}\text { Filtro de rede personalizado a ser usado em vez das pre- } \\
\text { definições do tipo determinado em network_type. }\end{array}$ \\
\hline & & conclusão \\
\hline
\end{tabular}

Fonte: Adaptado de Boeing (2018)

Tabela 3 - Opções de configuração do parâmetro network_type

\begin{tabular}{lc}
\hline Tipo de rede & \multicolumn{1}{c}{ Descrição } \\
\hline drive & Ruas públicas dirigíveis, exceto estradas de serviço \\
\hline drive_service & Ruas públicas dirigíveis, incluindo estradas de serviço \\
\hline walk & Todas as ruas e caminhos que podem ser utilizadas por pedestres \\
\hline bike & Todas as ruas e caminhos que podem ser utilizados por ciclistas \\
\hline all & Todas as ruas e caminhos não privativos \\
\hline all_private & Todas as ruas e caminhos, incluindo as de acesso privativo \\
\hline
\end{tabular}

O parâmetro simplify, influencia no modo de extração do grafo (completo ou simplificado). O processo de simplificação corrige a topologia da rede ao retirar nós que não representam conexões entre arestas e foram criados somente para adequação geométrica, conforme pode ser comparado na Figura 16. Os nós que permanecem são interseções entre arestas ou nós finais (dead-ends). A geometria espacial dos elementos descartados é mantida, assim como atributos relevantes como o comprimento das arestas. Os grafos exemplificados neste capítulo utilizaram o modo simplificado. 
Figura 16 - Grafos da mesma região, não simplificado e simplificado

a) Não simplificado

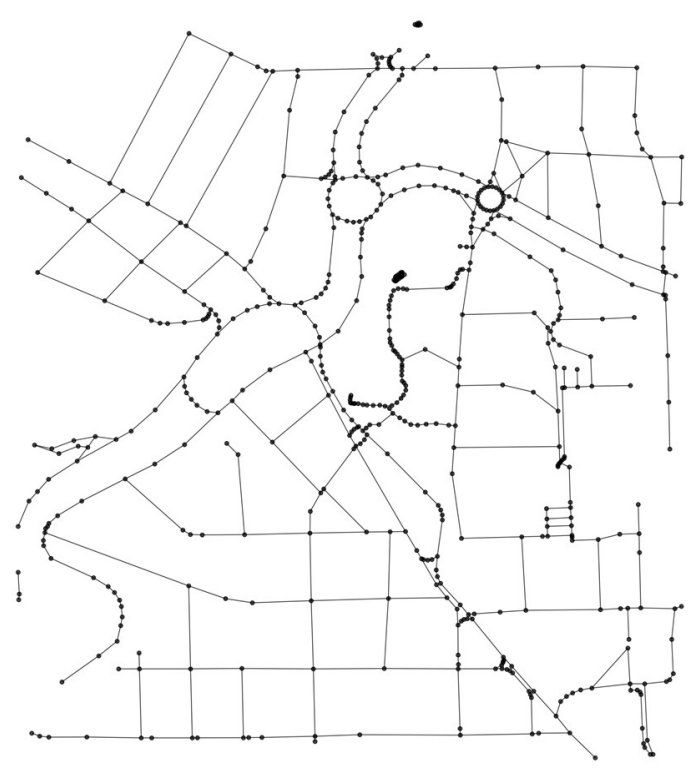

b) Simplificado

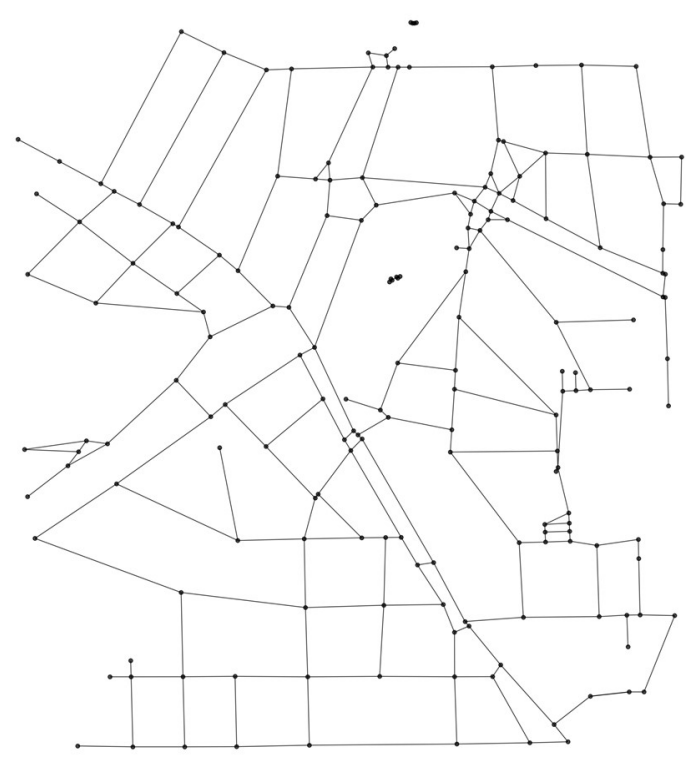

Fonte: A autora

Para exemplificar o uso desta função, foram extraídos grafos referentes a diferentes tamanhos de área, cujo ponto central escolhido foi o Departamento de Engenharia de Transporte da EESC-USP, em São Carlos, São Paulo. A Tabela 4 traz os valores dos parâmetros de entrada que foram inseridos na sintaxe da função. Os outros parâmetros foram mantidos de acordo com os valores padrões.

Tabela 4 - Valores inserido nos parâmetros de entrada da função graph_from_point

\begin{tabular}{cl}
\hline Parâmetro & Valor \\
\hline center_point & $-22,0048,-47,8991$ \\
\hline distance & Variação de 1000 a 5000, com incremento de 1000 \\
\hline network_type & all \\
\hline & Fonte: A autora
\end{tabular}

A Figura 17 traz as representações dos grafos extraídos para cada valor de distância atribuído ao parâmetro distance. O ponto em vermelho é o referente ao ponto central definido no parâmetro center_point. 
Figura 17 - Grafos extraídos com a função graph_from_point (sem escala)

a) Distância $=1000 \mathrm{~m}$

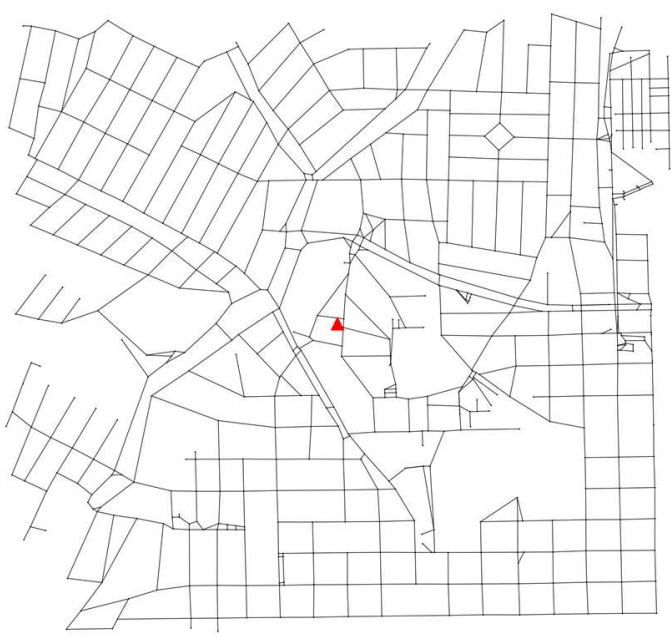

c) Distância $=3000 \mathrm{~m}$

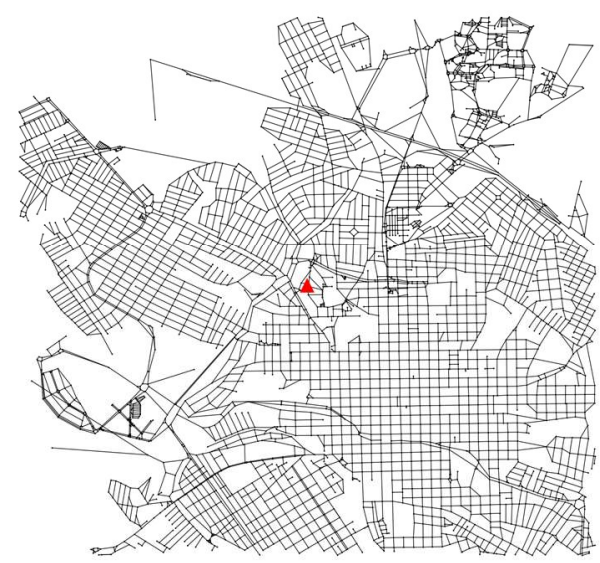

b) Distância $=2000 \mathrm{~m}$

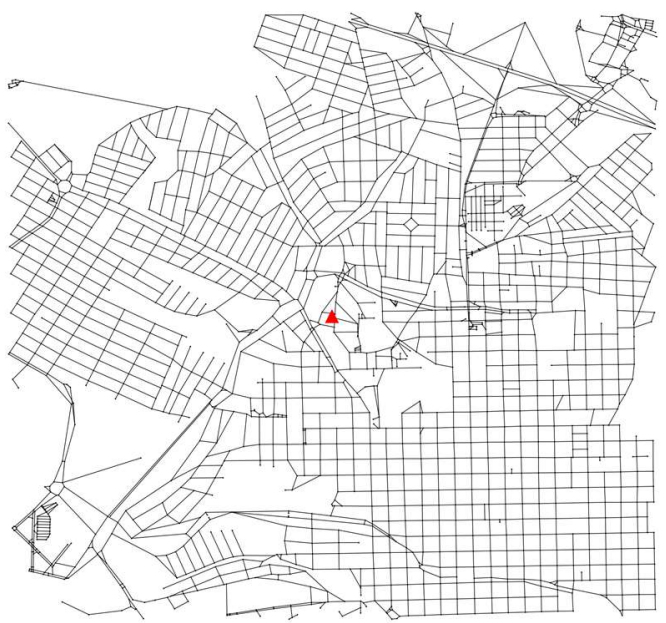

d) Distância $=4000 \mathrm{~m}$

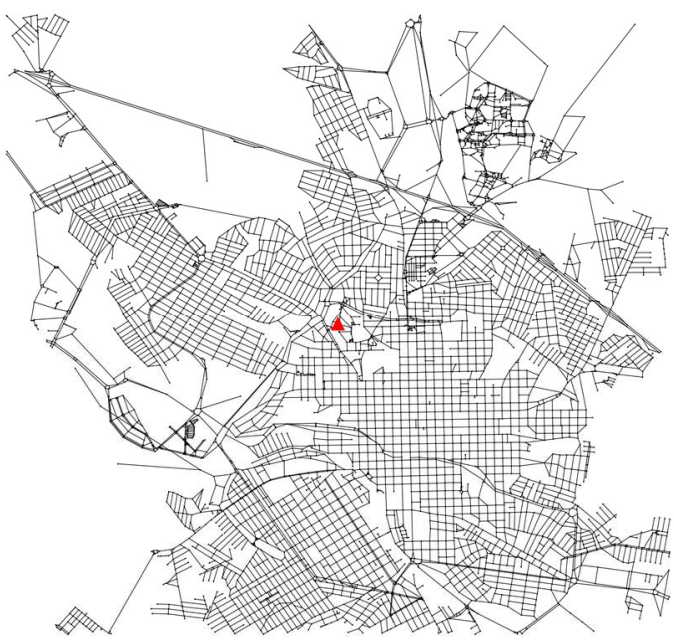


e) Distância $=5000 \mathrm{~m}$

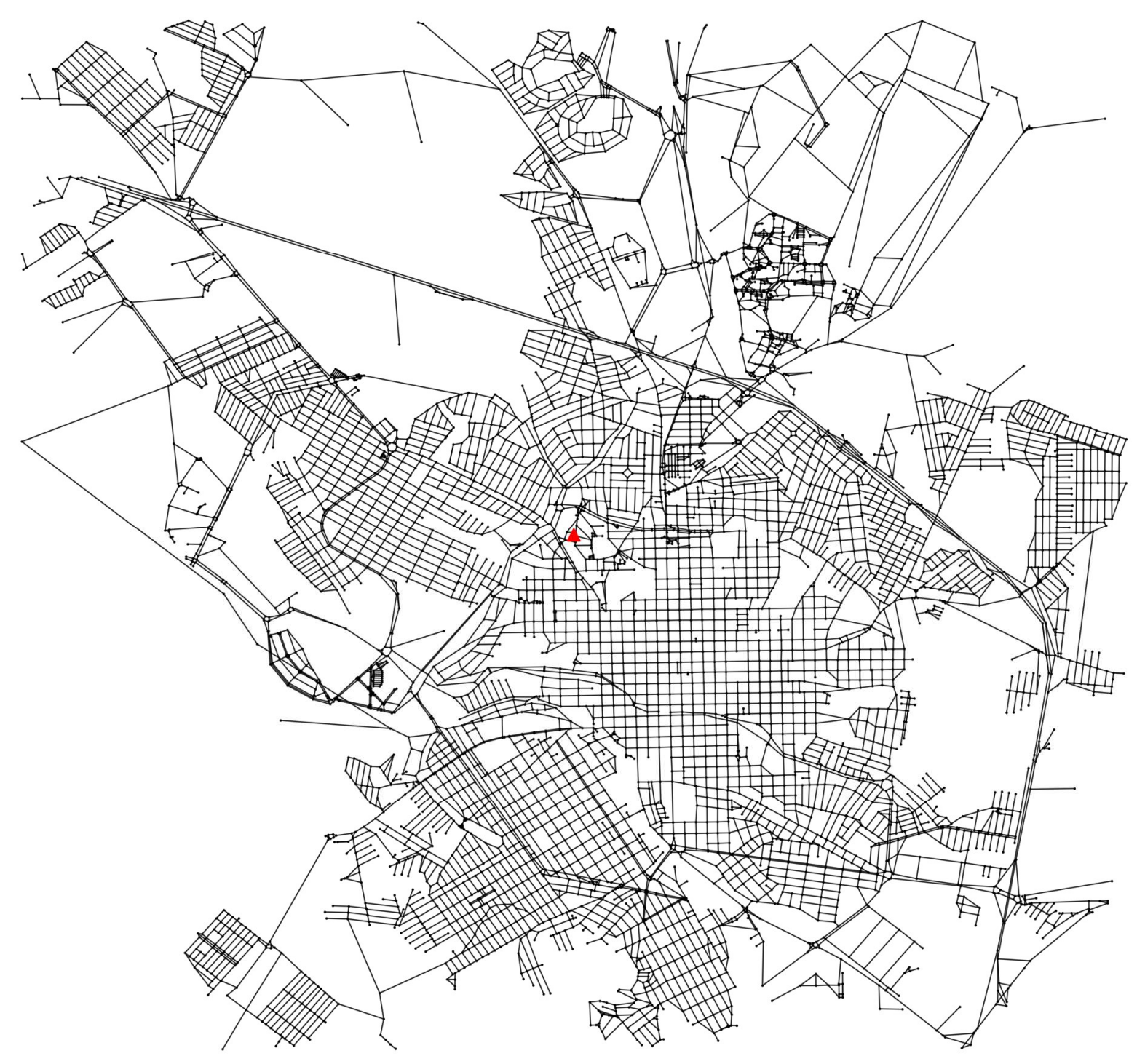

Fonte: A autora

\subsubsection{Limite retangular}

A função graph_from_bbox possui como parâmetros de entrada as coordenadas de um retângulo que abrange a área desejada.

Sintaxe:

osmnx.core.graph_from_bbox(north, south, east, west, network_type='all_private', simplify=True, retain_all=False, truncate_by_edge=False, name='unnamed' , timeout=180, memory=None, max_query_area_size=2500000000, clean_periphery=True, infrastructure='way ["highway"] ', custom_filter=None) 
A Tabela 5 traz a descrição de cada parâmetro de entrada e o tipo de dado que cada parâmetro aceita como valor.

Tabela 5 - Parâmetros de entrada da função graph_from_bbox

\begin{tabular}{|c|c|c|}
\hline Parâmetro & Tipo de dado & Descrição \\
\hline north & decimal & Latitude do ponto extremo ao norte do retângulo \\
\hline south & decimal & Latitude do ponto extremo ao sul do retângulo \\
\hline east & decimal & Longitude do ponto extremo ao leste do retângulo \\
\hline west & decimal & Longitude do ponto extremo a oeste do retângulo \\
\hline network_type & string & Tipo de rede viária que comporá o grafo (ver Tabela 3) \\
\hline simplify & booleano & Se assume valor True, simplifica a topologia do grafo \\
\hline retain_all & booleano & $\begin{array}{l}\text { Se assume valor True retorna todo grafo interno à área, } \\
\text { mesmo que desconexo. }\end{array}$ \\
\hline truncate_by_edge & booleano & $\begin{array}{l}\text { Se assume valor True, nós que estão fora da área delimi- } \\
\text { tada, mas possuem vizinhos que estão dentro são retidos } \\
\text { no grafo }\end{array}$ \\
\hline name & string & Nome do grafo \\
\hline timeout & inteiro & Intervalo de tempo limite para obter resposta da $A P I$ \\
\hline memory & inteiro & $\begin{array}{l}\text { Tamanho em bytes da alocação de memória do servidor } \\
\text { Se nenhum valor é determinado, o servidor utilizará o } \\
\text { tamanho padrão }\end{array}$ \\
\hline max_query_area_size & decimal & $\begin{array}{l}\text { Tamanho máximo da área delimitado em metros quadra- } \\
\text { dos. Se o grafo possuir área maior que este limite, será } \\
\text { dividido em várias consultas para a } A P I\end{array}$ \\
\hline clean_periphery & booleano & $\begin{array}{l}\text { Se assume valor True e o parâmetro simplify também } \\
\text { está ativado, utiliza uma margem de } 0,5 \mathrm{~km} \text { para extrair } \\
\text { um grafo maior que o requerido, que em seguida é sim- } \\
\text { plificado e truncado para o tamanho delimitado }\end{array}$ \\
\hline infrastructure & string & Tipo de infra-estrutura. O padrão é rua (highway) \\
\hline custom-filter & string & $\begin{array}{l}\text { Filtro de rede personalizado a ser usado em vez das pre- } \\
\text { definições do tipo determinado em network type. }\end{array}$ \\
\hline
\end{tabular}

Fonte: Adaptado de Boeing (2018)

São necessários dois valores de latitudes, referentes aos extremos norte e sul da área, e dois de longitude, referente aos extremos leste e oeste. A Figura 18 mostra o grafo obtido a partir das coordenadas de dois hospitais de São Carlos-SP, A Santa Casa (latitude $=-22.0142^{\circ}$ e longitude $=-47.8997^{\circ}$ ) e o Hospital Escola (latitude $=-22.0029^{\circ}$ e longitude $=-47.8891^{\circ}$ ). 
Figura 18 - Grafo extraído a partir da função graph_from_bbox

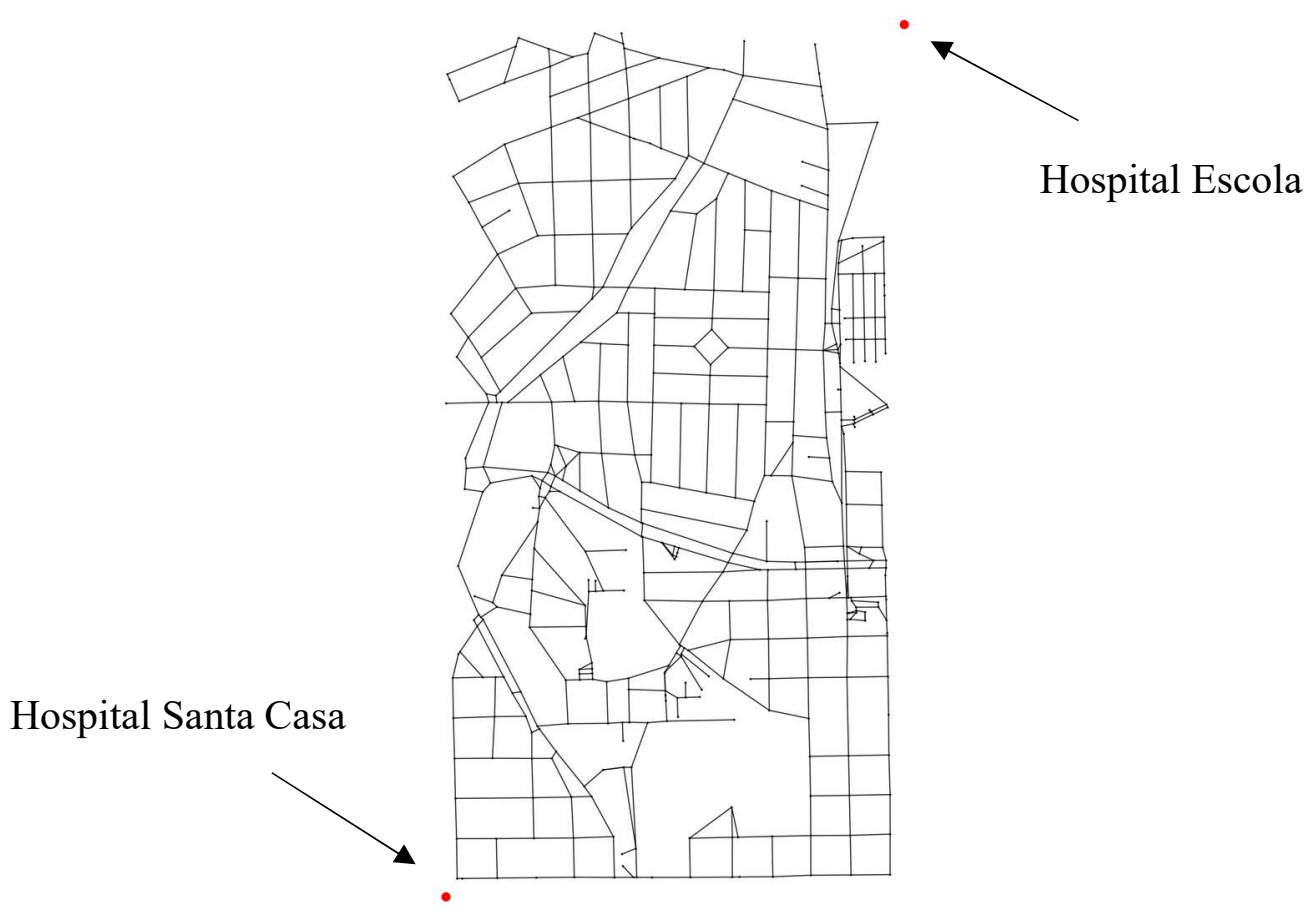

Fonte: A autora

\subsubsection{Endereço}

A função graph_from_address extrai o grafo a partir do fornecimento de um endereço, que é relacionado a um ponto automaticamente atribuído pela plataforma do OSM. Este ponto é um dos retornos da função, juntamente com o grafo. $O$ endereço é codificado com o uso da interface de programação de aplicativos $(A P I)$ Nominatim do $O S M$.

Sintaxe:

osmnx.core.graph_from_address(address, distance=1000, distance_type='bbox', network_type='all_private', simplify=True, retain_all=False, truncate_by_edge=False, return_coords=False, name='unnamed', timeout=180, memory=None, max_query_area_size=2500000000, clean_periphery=True, infrastructure='way["highway"] ', custom_filter=None)

A Tabela 6 traz a descrição de cada parâmetro de entrada e o tipo de dado que cada parâmetro aceita como valor. 
Tabela 6 - Parâmetros de entrada da função graph_from_address

\begin{tabular}{|c|c|c|}
\hline Parâmetro & Tipo de dado & Descrição \\
\hline address & string & O endereço para codificação \\
\hline distance & inteiro & $\begin{array}{l}\text { Distância em metros a partir do center point que deli- } \\
\text { mita a área abrangida pelo grafo }\end{array}$ \\
\hline distance_type & string & $\begin{array}{l}\text { Critério para criação da área do grafo. Se assume valor } \\
\text { "bbox", a rede é limitada por um retângulo cujo centro é } \\
\text { o center_point e os lados são o dobro do valor estabele- } \\
\text { cido no parâmetro distance. Se assume valor "network", } \\
\text { são retidos na rede os nós dentro da distância estabele- } \\
\text { cida no parâmetro distance. }\end{array}$ \\
\hline network_type & string & Tipo de rede viária que comporá o grafo (ver Tabela 3) \\
\hline simplify & booleano & Se assume valor True, simplifica a topologia do grafo \\
\hline retain_all & booleano & $\begin{array}{l}\text { Se assume valor True retorna todo grafo interno à área, } \\
\text { mesmo que desconexo. }\end{array}$ \\
\hline truncate_by_edge & booleano & $\begin{array}{l}\text { Se assume valor True, nós que estão fora da área delimi- } \\
\text { tada, mas possuem vizinhos que estão dentro são retidos } \\
\text { no grafo }\end{array}$ \\
\hline return_coords & booleano & $\begin{array}{l}\text { Se assume valor True, retorna com resultado da função } \\
\text { as coordenadas geocodificadas do endereço }\end{array}$ \\
\hline name & string & Nome do grafo \\
\hline timeout & inteiro & Intervalo de tempo limite para obter resposta da $A P I$ \\
\hline memory & inteiro & $\begin{array}{l}\text { Tamanho em bytes da alocação de memória do servidor. } \\
\text { Se nenhum valor é determinado, o servidor utilizará o } \\
\text { tamanho padrão }\end{array}$ \\
\hline max_query_area_size & decimal & $\begin{array}{l}\text { Tamanho máximo da área delimitado em metros quadra- } \\
\text { dos. Se o grafo possuir área maior que este limite, será } \\
\text { dividido em várias consultas para a } A P I\end{array}$ \\
\hline clean_periphery & booleano & $\begin{array}{l}\text { Se assume valor True e o parâmetro simplify também } \\
\text { está ativado, utiliza uma margem de } 0,5 \mathrm{~km} \text { para extrair } \\
\text { um grafo maior que o requerido, que em seguida é sim- } \\
\text { plificado e truncado para o tamanho delimitado }\end{array}$ \\
\hline infrastructure & string & Tipo de infra-estrutura. O padrão é rua (highway) \\
\hline custom-filter & string & $\begin{array}{l}\text { Filtro de rede personalizado a ser usado em vez das pre- } \\
\text { definições do tipo determinado em network type. }\end{array}$ \\
\hline
\end{tabular}

Fonte: Adaptado de Boeing (2018)

A Figura 19 traz os exemplos dos grafos extraídos com o parâmetro de endereço com valor "Sao Carlos-SP, Brazil" e o de distância variando de 1 a $5 \mathrm{~km}$. O ponto obtido como resposta deste requerimento foi referente à localização da Catedral de São Carlos (latitude = $22,0183^{\circ}$ e longitude $\left.=-47,8909^{\circ}\right)$. 
Figura 19 - Grafos extraídos com a função graph_from_address (sem escala)

a) Distância $=1000 \mathrm{~m}$

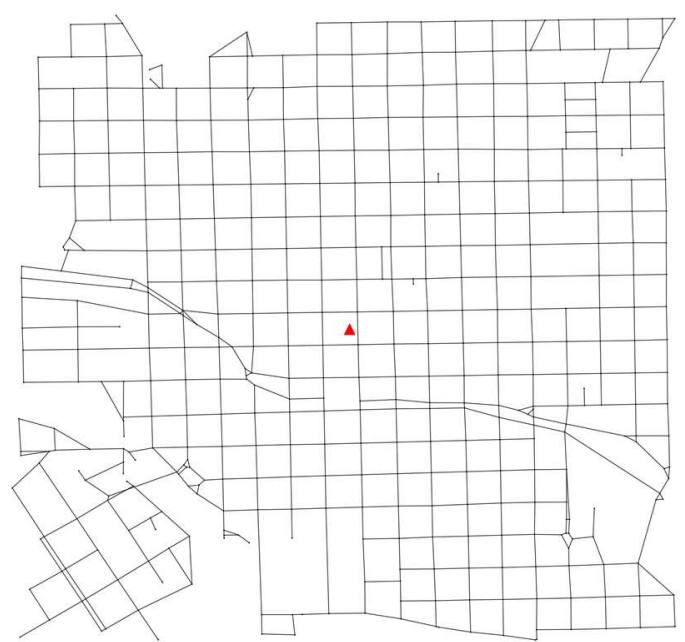

c) Distância $=3000 \mathrm{~m}$

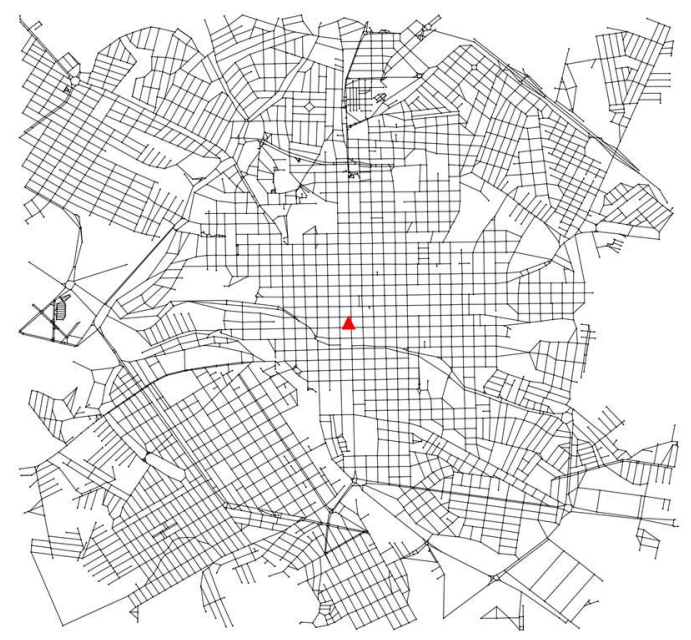

b) Distância $=2000 \mathrm{~m}$

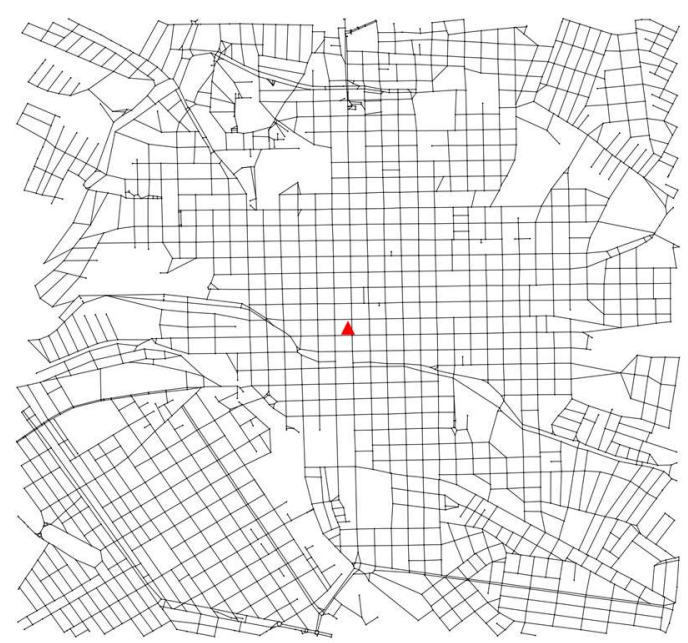

d) Distância $=4000 \mathrm{~m}$

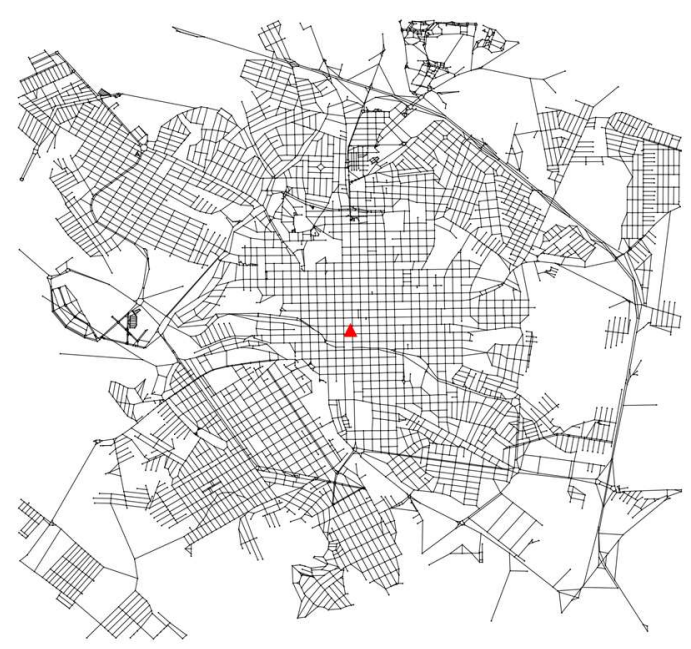


e) Distância $=5000 \mathrm{~m}$

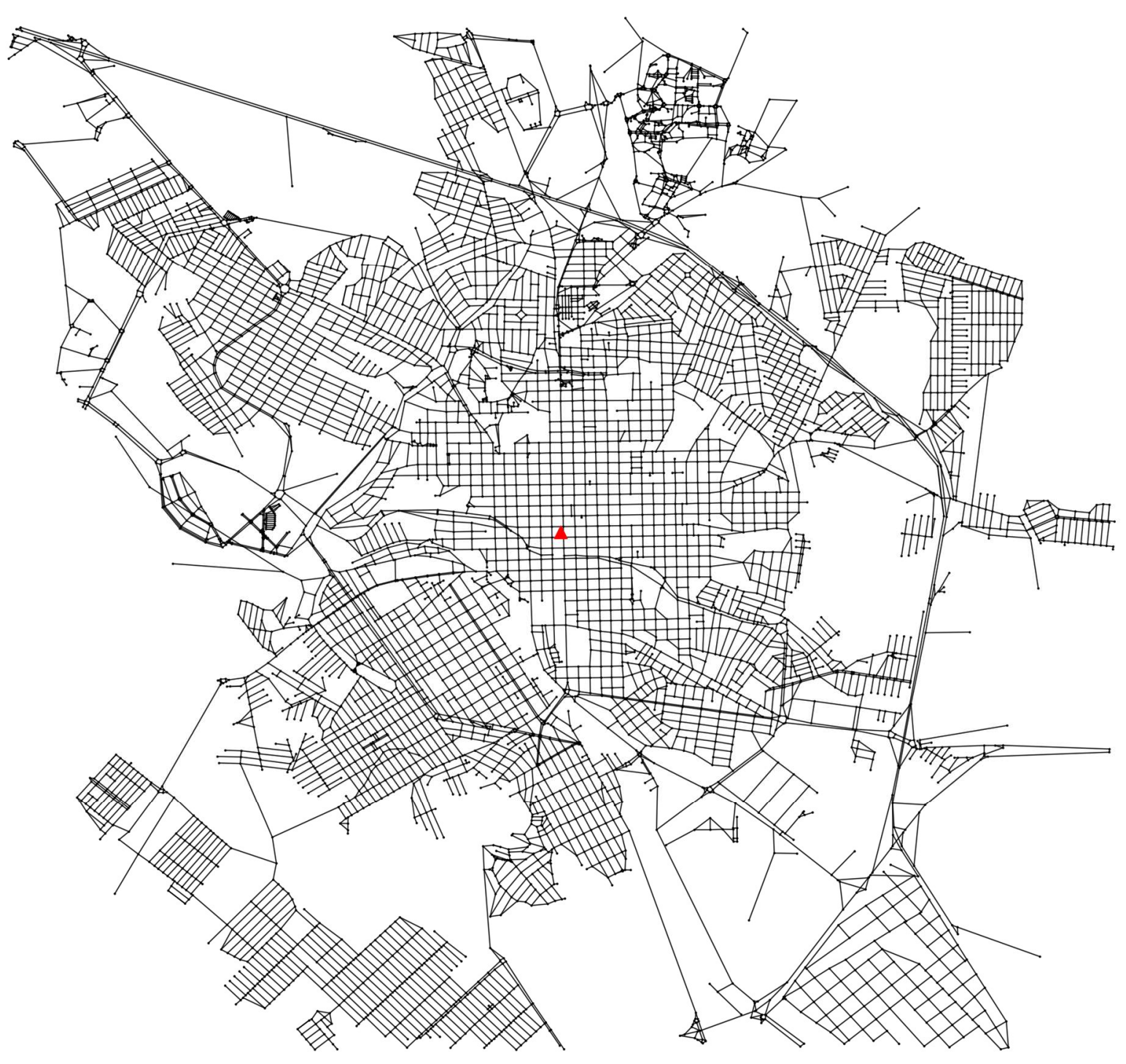

Fonte: A autora

\subsubsection{Nome de lugar}

A função graph_from_place recebe o nome de um local como parâmetro de entrada que é codificado pela API Nominatim. O local pode receber nomes de lugares oficiais como países, estados, distritos, regiões, províncias e municípios ou de assentamentos povoados como bairros, subúrbios, vizinhanças, etc., desde que disponível no OSM (BOEING, 2017). O grafo obtido como resposta é relativo a toda estrutura interna aos limites administrativos do local requerido cadastrados no OSM. 
Sintaxe:

osmnx.core.graph_from_place(query, network_type='all_private', simplify=True, retain_all=False, truncate_by_edge=False, name=' unnamed', which_result=1, buffer_dist=None, timeout=180, memory=None, max_query_area_size=2500000000, clean_periphery=True, infrastructure='way["highway"]', custom_filter=None)

A Tabela 7 traz a descrição de cada parâmetro de entrada e o tipo de dado que cada parâmetro aceita como valor.

Tabela 7 - Parâmetros de entrada da função graph_from_place

\begin{tabular}{|c|c|c|}
\hline Parâmetro & Tipo de dado & Descrição \\
\hline query & string & O lugar para codificação \\
\hline network_type & string & Tipo de rede viária que comporá o grafo (ver Tabela 3) \\
\hline simplify & booleano & Se assume valor True, simplifica a topologia do grafo \\
\hline retain_all & booleano & $\begin{array}{l}\text { Se assume valor True retorna todo grafo interno à área, } \\
\text { mesmo que desconexo. }\end{array}$ \\
\hline truncate_by_edge & booleano & $\begin{array}{l}\text { Se assume valor True, nós que estão fora da área delimi- } \\
\text { tada, mas possuem vizinhos que estão dentro são retidos } \\
\text { no grafo }\end{array}$ \\
\hline name & string & Nome do grafo \\
\hline which_result & inteiro & $\begin{array}{l}\text { número máximo de resultados a serem retornados e } \\
\text { quais processar após o recebimento dos dados }\end{array}$ \\
\hline buffer_dist & decimal & $\begin{array}{l}\text { distância em metros para aumentar a área abrangida em } \\
\text { torno da geometria requisitada }\end{array}$ \\
\hline timeout & inteiro & Intervalo de tempo limite para obter resposta da $A P I$ \\
\hline memory & inteiro & $\begin{array}{l}\text { Tamanho em bytes da alocação de memória do servidor. } \\
\text { Se nenhum valor é determinado, o servidor utilizará o } \\
\text { tamanho padrão }\end{array}$ \\
\hline max_query_area_size & decimal & $\begin{array}{l}\text { Tamanho máximo da área delimitado em metros quadra- } \\
\text { dos. Se o grafo possuir área maior que este limite, será } \\
\text { dividido em várias consultas para a } A P I\end{array}$ \\
\hline clean_periphery & booleano & $\begin{array}{l}\text { Se assume valor True e o parâmetro simplify também } \\
\text { está ativado, utiliza uma margem de } 0,5 \mathrm{~km} \text { para extrair } \\
\text { um grafo maior que o requerido, que em seguida é sim- } \\
\text { plificado e truncado para o tamanho delimitado }\end{array}$ \\
\hline infrastructure & string & Tipo de infra-estrutura. O padrão é rua (highway) \\
\hline custom-filter & string & $\begin{array}{l}\text { Filtro de rede personalizado a ser usado em vez das pre- } \\
\text { definições do tipo determinado em network_type. }\end{array}$ \\
\hline
\end{tabular}

Fonte: Adaptado de Boeing (2018)

A Figura 20 mostra o grafo obtido com o parâmetro de entrada "Sao Carlos-SP, Brazil". 
Figura 20 - Grafo extraído com a função graph_from_place

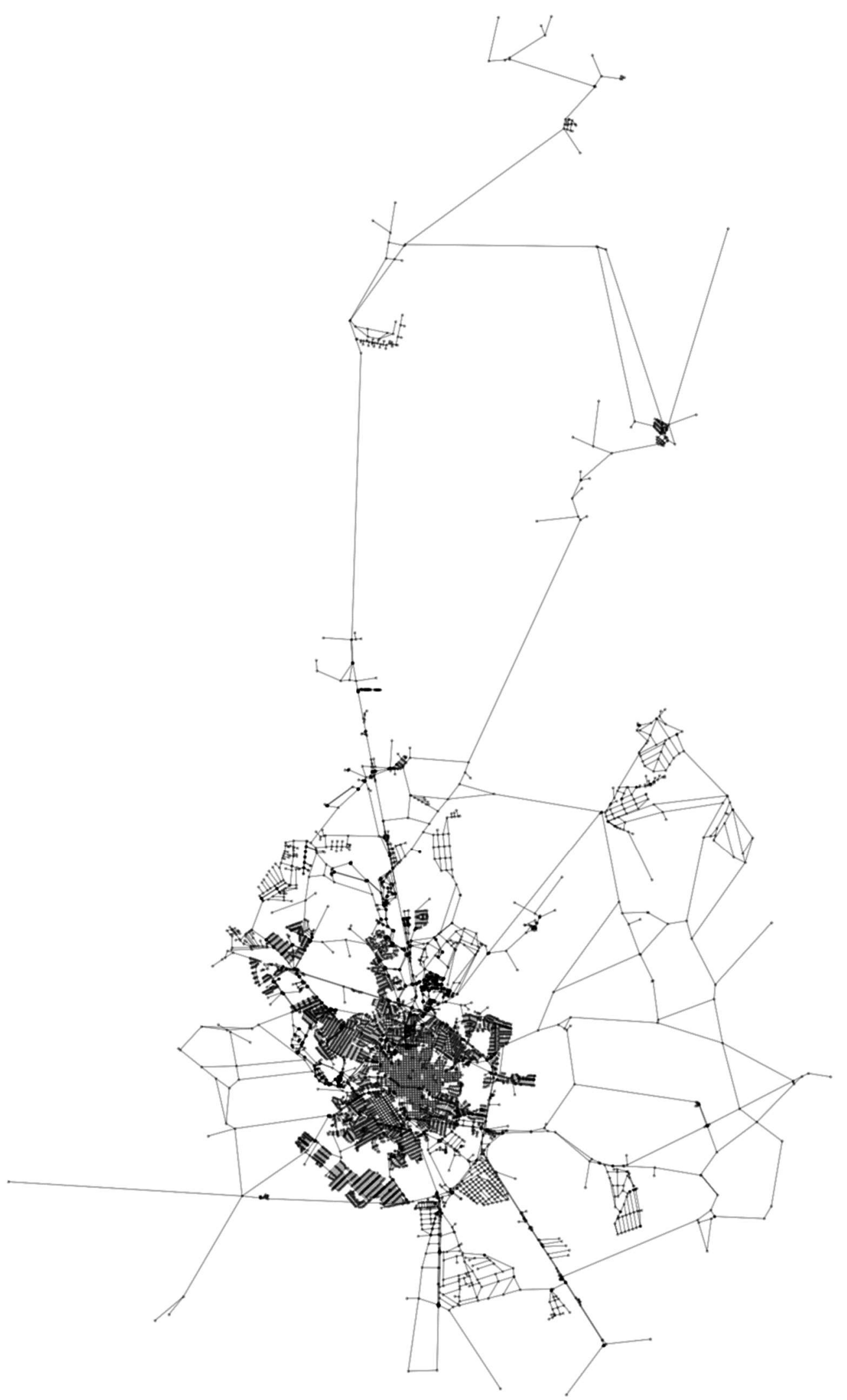

Fonte: A autora 


\subsubsection{Tipos de grafo}

Os grafos obtidos pelas funções descritas anteriormente fazem parte da classe MultiDigraphs, grafos direcionados em que arestas paralelas não são excluídas. A reprodução das vias de sentido duplo é feita com duas arestas idênticas, porém com direções contrárias. Outros tipos de grafo podem ser obtidos a partir do MultiDigraph com o uso de funções da biblioteca OSMnx e Networkx que realizam essas transformações. A versão não direcionada do grafo pode ser obtida através da função to_undirected da Networkx que gera um grafo com os mesmos nós e substitui as arestas que representam vias de duplo sentido por uma única, sem direção.

Uma função que pode ser aplicada aos objetos da classe MultiDigraph da biblioteca OSMnx é a get_largest_component, que seleciona a maior porção do grafo conectada por pelo menos uma aresta. Esta função permite acionar o critério strongly, que se for falso define que o subgrafo gerado será fracamente conectado, e será analisada a sua forma não direcionada. Caso o critério strongly assuma valor verdadeiro, o subgrafo será fortemente conectado, o que ocorre quando cada um dos nós pode ser alcançado por todos os outros por meio de um caminho. A Figura 21 exemplifica a diferença obtida com esta função através da representação dos dois tipos de grafo, em que os elementos destacados em vermelho na Figura 21a foram excluídos pois são partes da malha separadas por rodovias e vias de acesso.

Figura 21 - Comparação entre grafos fortemente e fracamente conectado
a) Grafo fracamente conectado
b) Grafo fortemente conectado
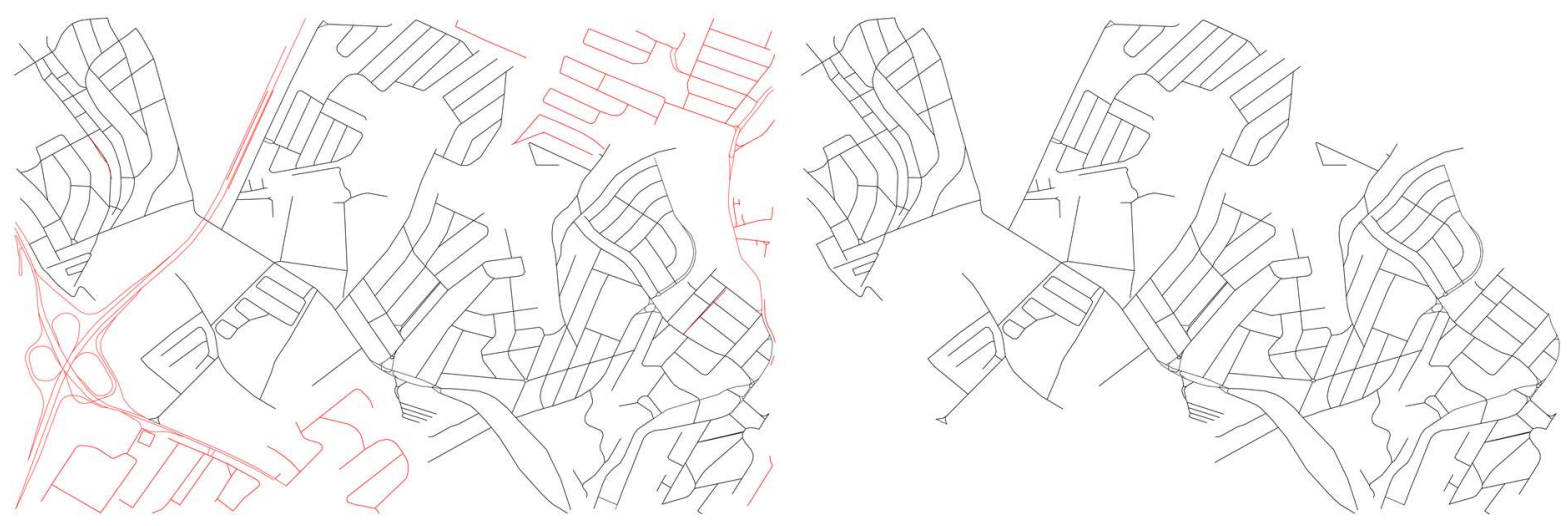

Fonte: A autora

\subsubsection{Funções de cálculo de métricas}

Além da obtenção dos grafos, as bibliotecas possuem funções para o cálculo de diversas medidas de desempenho. A Tabela 8 resume a sintaxe de cada função de acordo com a métrica 
desejada, sendo as que pertencem à biblioteca Networkx as que iniciam com $n x$ e as da OSMnx, as que iniciam com $o x$.

Tabela 8 - Funções para cálculos de parâmetros

\begin{tabular}{|c|c|c|}
\hline Parâmetro & $\begin{array}{l}\text { Tipo de } \\
\text { grafo }\end{array}$ & Sintaxe \\
\hline Quantidade de nós & Todos & $n x . n u m b e r \_o f \_n o d e s(G)$ \\
\hline Quantidade de arestas & Todos & nx.number_of_edges $(G)$ \\
\hline Grau do nó & Todos & nx.degree $(G)$ \\
\hline $\begin{array}{l}\text { Centralidade de intermediação de } \\
\text { nós }\end{array}$ & Todos & nx.betweenness_centrality $(G)$ \\
\hline $\begin{array}{l}\text { Comprimentos de todos caminhos } \\
\text { mínimos }\end{array}$ & Ponderado & $n x . a l l \_p a i r s \_d i j k s t r a \_p a t h \_l e n g t h(G, w e i g h t=$ 'length') \\
\hline $\begin{array}{l}\text { Comprimento médio dos menores } \\
\text { caminhos }\end{array}$ & Conexo & $n x . a v e r a g e$ shortest_path_length $(G)$ \\
\hline Orientação das arestas & Direcionado & ox.add_edge_bearings $(G)$ \\
\hline
\end{tabular}

Fonte: A autora

A orientação das arestas é adicionada como atributo do elemento através da função mostrada na tabela. Após a inclusão deste dado é possível a contabilização da frequência. Outra função útil é a que reúne estatísticas básicas métricas e topológicas de um grafo. A sintaxe da função está descrita a seguir, os parâmetros de entrada estão na Tabela 9.

Sintaxe:

osmnx.stats.basic_stats(G, area=None, clean_intersects=False, tolerance $=15$, circuity_dist='gc' )

Tabela 9 - Parâmetros de entrada da função basic_stats

\begin{tabular}{ccl}
\hline Parâmetro & Tipo de dado & \multicolumn{1}{c}{ Descrição } \\
\hline$G$ & $\begin{array}{c}\text { Multidígrafo } \\
\text { do Networkx }\end{array}$ & Objeto da análise \\
\hline area & inteiro & $\begin{array}{l}\text { Área em } \mathrm{km}^{2} \text { coberta pela rede viária; se não for } \\
\text { determinado nenhum valor, a função não calculará } \\
\text { métricas baseadas em densidade }\end{array}$ \\
\hline clean_intersects & booleano & $\begin{array}{l}\text { Se assume valor True, considera nós que estão dentro de } \\
\text { uma distância de tolerância como somente um nó no } \\
\text { centroide }\end{array}$ \\
\hline tolerance & inteiro & $\begin{array}{l}\text { Distância de tolerância para considerar nós próximos } \\
\text { como um nó }\end{array}$
\end{tabular}

continua 


\begin{tabular}{ccc}
\hline Parâmetro & Tipo de dado & \multicolumn{1}{c}{ Descrição } \\
\hline circuity_dist & string & $\begin{array}{l}\text { Forma de calcular distâncias em linha reta para medida } \\
\text { de grau de rotas indiretas. Se assume valor gc, utiliza o } \\
\end{array}$ \\
& $\begin{array}{l}\text { grafo não projetado, se assume valor euclidean, utiliza o } \\
\text { grafo projetado de acordo com a zona UTM. }\end{array}$ \\
&
\end{tabular}

conclusão

Fonte: Adaptado de Boeing (2018a)

Os dados de saída foram denominados de forma diferente de acordo com alguns critérios, as padronizações adotadas estão na Tabela 10 .

Tabela 10 - Critérios dos dados de saída da função basic_stats

\begin{tabular}{cl}
\hline Parâmetro de saída & Descrição \\
\hline nó & ponto de junção entre duas arestas \\
\hline interseção & nó com grau maior que 1 \\
aresta & aresta em grafo direcionado \\
\hline rua & aresta em grafo não direcionado \\
\hline & Fonte: Adaptado de Boeing (2018a)
\end{tabular}

Os resultados da função basic_stats são fornecidos no formato de dicionário, em que os valores são referenciados pelos nomes dos parâmetros, conforme a Tabela 11.

Tabela 11 - Dados de saída da função basic_stats

\begin{tabular}{ccl}
\hline Parâmetro de saída & Tipo de dado & \multicolumn{1}{c}{ Descrição } \\
\hline$n$ & inteiro & número de nós do grafo \\
\hline$m$ & inteiro & número de arestas do grafo \\
\hline$k$ avg & decimal & média dos graus dos nós do grafo \\
\hline intersection_count & inteiro & número de interseções \\
\hline streets_per_node_avg & string & média de ruas adjacentes por nó \\
\hline streets_per_node_counts & dicionário & número de ruas adjacentes de cada nó \\
\hline streets_per_node_proportion & dicionário & $\begin{array}{l}\text { igual ao anterior, porém em termos de proporção } \\
\text { do total }\end{array}$ \\
\hline edge_length_total & decimal & $\begin{array}{l}\text { soma de todos comprimentos das arestas em } \\
\text { metros }\end{array}$ \\
\hline edge_length_avg & decimal & média de comprimento das arestas \\
\hline street_length_total & decimal & soma de todos comprimentos das ruas \\
\hline street_length_avg & decimal & média de comprimentos das ruas \\
\hline street_segments_count & inteiro & número de ruas \\
\hline node_density_km & decimal & número de nós dividido pela área \\
\hline & & \\
\hline
\end{tabular}




\begin{tabular}{ccl}
\hline Parâmetro de saída & Tipo de dado & \multicolumn{1}{c}{ Descrição } \\
\hline intersection_density_km & decimal & numéro de interseções dividido pela área \\
\hline edge_density_km & decimal & comprimento total das arestas dividido pela área \\
\hline street_density_km & decimal & comprimento total das ruas dividido pela área \\
\hline circuity_avg & decimal & $\begin{array}{l}\text { comprimento total das arestas dividido pela soma } \\
\text { das distâncias em linha reta entre nós adjacentes }\end{array}$ \\
\hline self_loop_proportion & decimal & $\begin{array}{l}\text { proporção de arestas que possuem um único } \\
\text { ponto como extremos }\end{array}$ \\
\hline clean_intersection_count & inteiro & $\begin{array}{l}\text { número de interseções na rede após a junção de } \\
\text { nós próximos em um nó simples }\end{array}$ \\
\hline clean_intersection_density_km & decimal & valor anterior dividido pela área \\
\hline
\end{tabular}

conclusão

Fonte: Adaptado de Boeing (2018a)

\subsubsection{Exportação dos dados}

Os grafos extraídos carregam, informações sobre as relações topológicas dos elementos e atributos cadastrados na plataforma $O S M$ (nome da rua, limite de velocidade, comprimento e classificação viária dos segmentos de via, coordenadas dos nós, tipo de sinalização na interseção). Através de uma estrutura de dicionário, as informações de cada elemento são detalhadas com a ativação do parâmetro data nos comandos MultiDigraph.edges(data=True) para arestas e MultiDigraph.nodes(data=True) para nós. Este tipo de mapeamento permite ser manipulado para tabelas que podem ser exportadas para arquivos de formato texto (txt) ou separados por vírgulas (csv). Outros formatos para armazenar os dados dos grafos são apresentados na Tabela 12, juntamente com as funções para exportação de cada biblioteca.

Tabela 12 - Funções e formatos de exportação de grafos

\begin{tabular}{|c|c|}
\hline Formato & Sintaxe \\
\hline GeoDataFrame & $\begin{array}{l}\text { ox.save_load.graph_to_gdfs(G, nodes=True, edges=True, node_geome- } \\
\text { try=True, fill_edge_geometry=True) }\end{array}$ \\
\hline GraphML & $\begin{array}{l}\text { ox.save_load.save_graphml(G, filename='graph.graphml', folder=None, } \\
\text { gephi=False) }\end{array}$ \\
\hline ESRI shapefile & $\begin{array}{l}\text { ox.save_load.save_graph_shapefile(G, filename='graph', folder=None, } \\
\text { encoding='utf-8') }\end{array}$ \\
\hline Lista de adjacência & $\begin{array}{l}\text { nx.write_adjlist(G, path, comments='\#', delimiter=' ', encoding='utf- } \\
\left.8^{\prime}\right)\end{array}$ \\
\hline Lista de arestas & $\begin{array}{l}\text { nx.write_weighted_edgelist(G, path, comments='\#', delimiter=' ', en- } \\
\text { coding='utf-8') }\end{array}$ \\
\hline $\begin{array}{l}\text { GEXF (Graph Ex- } \\
\text { change XML For- } \\
\text { mat) }\end{array}$ & $\begin{array}{l}\text { nx.write_gexf(G, path, encoding='utf- } 8 \text { ', prettyprint=True, ver- } \\
\text { sion='1.2draft') }\end{array}$ \\
\hline
\end{tabular}




\begin{tabular}{|c|c|}
\hline Formato & Sintaxe \\
\hline $\begin{array}{l}\text { GML, the Graph } \\
\text { Modelling Lan- } \\
\text { guage }\end{array}$ & nx. write_gml(G, path, stringizer=None) \\
\hline Pickle & nx.write_gpickle(G, path, protocol=2) \\
\hline GraphML & $\begin{array}{l}\text { nx.write_graphml(G, path, encoding='utf-8', prettyprint=True, in- } \\
\text { fer_numeric_types=False) }\end{array}$ \\
\hline JSON & $\begin{array}{l}\text { nx.adjacency_graph(data, directed=False, multigraph=True, at- } \\
\text { trs }=\{\text { 'id': 'id', 'key': 'key' }\} \text { ) }\end{array}$ \\
\hline LEDA & $\begin{array}{l}\text { nx.adjacency_graph(data, directed=False, multigraph=True, at- } \\
\text { trs }=\{\text { 'id': 'id', 'key': 'key' }\} \text { ) }\end{array}$ \\
\hline YAML & nx.write_yaml(G_to_be_yaml, path_for_yaml_output, **kwds) \\
\hline SparseGraph6 & nx.write_graph6(G, path, nodes=None, header=True) \\
\hline Pajek & nx.write_pajek(G, path, encoding='UTF-8') \\
\hline GIS Shapefile & nx.write_shp(G, outdir) \\
\hline
\end{tabular}

conclusão

\section{Fonte: A autora}

Os atributos e métricas de cada elementos foram organizados em tabelas e exportados no formato csv para arquivamento e manipulação em planilhas. Os grafos gerados foram arquivados em formato GPICKLE, que armazenam todos os atributos dos elementos, inclusive as informações de direções das arestas.

\subsection{Considerações finais}

Este capítulo apresentou os materiais utilizados para a exploração dos dados de mapas colaborativos e a extração das malhas viárias em diferentes tipos de grafos. Inicialmente a abrangência e o detalhamento dos dados obtidos de fontes governamentais e do Projeto OpenStreetMap foram comparados para justificar a escolha da plataforma de mapas colaborativos como origem das informações. Em seguida foi realizado o reconhecimento de algumas funções das bibliotecas de análises de rede OSMNx e Networkx. 


\section{VERIFICAÇÃO DA QUALIDADE DOS DADOS DE MAPAS COLA- BORATIVOS}

Este capítulo buscou atender a meta de verificação da qualidade dos dados de mapas colaborativos através da avaliação do parâmetro "usabilidade e limitações". Por demonstrar possíveis aplicações de métricas topo-geométricas em análises de morfologia viárias, foi realizada a repetição do estudo de Lima, Silva e Van der Waerden realizado em 2003, que teve como objeto malhas viárias urbanas analisadas em ambientes de sistemas de informações geográficas. O estudo de referência teve como objetivo analisar características das redes viárias de cidades brasileiras e estrangeiras e identificar a aproximação em relação a dois padrões: cidades espalhadas e dependentes do automóvel e cidades compactas e adaptadas aos sistemas de transporte público. As cidades foram representadas através das respectivas malhas viárias, com informações de comprimento das ruas e pontos de interseção.

O estudo comparou os índices de acessibilidade real $\left(E_{\text {real }}\right)$ de cada rede com sua variante adotada como ideal, calculada para redes circulares com a mesma quantidade de interseções $\left(E_{\text {circ }}\right)$. A acessibilidade de rede viária urbana real foi determinada através do Índice de Allen, em que o custo do deslocamento entre dois pontos foi adotado como a separação espacial entre eles, segundo a equação (1).

$$
E_{\text {real }}=\frac{1}{v} \sum_{i} \frac{1}{v-1} \sum_{j} c_{i j}
$$

Sendo:

$c_{i j}$ : custo do deslocamento entre os nós $i$ e $j$.

Para a determinação de $\mathrm{E}_{\text {circ, }}$ os autores adotaram que no padrão ideal de cidade circular, com quadras de 100 por 100 metros, o número de interseções da rede equivale ao número de habitantes dividido pela densidade populacional (hab/ha) (LIMA et al., 2000). Desta forma, o valor de $\mathrm{E}_{\text {circ }}$ ficou definido como abaixo:

$$
E_{\text {circ }}=0,0651 * I^{0.4995}
$$

Sendo:

Ecirc: $\quad$ índice de acessibilidade global de uma cidade circular;

I: $\quad$ quantidade de interseções. 
A consideração dos autores foi que o padrão ideal em termos de compacidade é o circular, portanto, quanto mais próximo o valor real do $E_{\text {circ }}$, melhor a configuração da cidade. Com base nisso, eles avaliaram as diferenças entre os valores reais e os ideais para cada cidade. Ao final, foi verificada a proximidade dos índices brasileiros com os das cidades estrangeiras.

As cidades brasileiras avaliadas foram Araraquara, Presidente Prudente, São Carlos, Marília, Limeira, Maringá, Bauru e Piracicaba. Os autores verificaram que as cidades brasileiras apresentaram níveis de compacidade intermediários entre os extremos encontrados nas cidades estrangeiras. As representantes americanas foram as cidades de Columbus e Madison, que, segundo os autores, apresentaram padrões urbanos de menores índices de compacidade. Por outro lado, a representante europeia, Eindhoven, apresentou o maior nível de compacidade.

A repetição do estudo visou verificar a acessibilidade e a compacidade das mesmas cidades, porém com o uso de dados da plataforma OpenStreetMap e de ferramentas computacionais de análises de rede (OSMnx e Networkx). Além de avaliar a viabilidade de obtenção das malhas viárias atualizadas e em formatos digitais, este capítulo analisou as diferenças entre os resultados obtidos e suas razões.

\subsection{Grafos de redes viárias e matrizes de menores caminhos}

O primeiro passo envolveu a extração das redes viárias das cidades, a partir da informação disponível na plataforma do Projeto $O S M$, através de uma rotina computacional desenvolvida com a funções apresentadas no Capítulo 3.4. A função graph_from_place foi utilizada para extrair os grafos das malhas viárias das cidades. Os únicos parâmetros de entrada função alterados foram query e network_type que recebeu o valor drive.

Após a extração dos dados, os grafos gerados pela função foram convertidos para as versões não-direcionadas através da função to_undirected da biblioteca Networkx. A Tabela 13 traz características das cidades do grupo de estudo, obtidas através dos grafos das redes viárias. As malhas viárias resultantes deste processo foram extraídas entre os meses de agosto e outubro de 2018 e estão representadas na Figura 22. As quantidades de arestas e de nós são relativas ao grafo conexo e não direcionado e estão detalhadas na tabela, junto com o comprimento médio das arestas em metros $(C)$ e a média dos graus dos nós $(K)$. 
Tabela 13 - Características dos grafos de malhas viárias urbanas

\begin{tabular}{lrrrr}
\hline \multicolumn{1}{c}{ Local } & Arestas & Nós & $\boldsymbol{K}$ & $\boldsymbol{C}[\mathbf{m}]$ \\
\hline Araraquara-SP & 13063 & 8118 & 3,23 & 127,47 \\
\hline Bauru-SP & 17585 & 10683 & 3,32 & 105,38 \\
\hline Columbus-GA & 12699 & 9206 & 2,75 & 195,36 \\
\hline Eindhoven-NB & 10284 & 7109 & 2,91 & 99,33 \\
\hline Limeira-SP & 12235 & 8018 & 3,11 & 123,60 \\
\hline Madison-WI & 11700 & 7940 & 3,11 & 131,63 \\
\hline Marília-SP & 12067 & 7744 & 3,13 & 140,36 \\
\hline Maringá-PR & 16249 & 9930 & 3,29 & 127,53 \\
\hline Piracicaba-SP & 17035 & 11580 & 2,96 & 131,63 \\
\hline Presidente Prudente-SP & 13899 & 8706 & 3,21 & 107,91 \\
\hline São Carlos-SP & 11260 & 7191 & 3,14 & 133,57 \\
\hline
\end{tabular}

Fonte: A autora

Figura 22 - Redes viárias

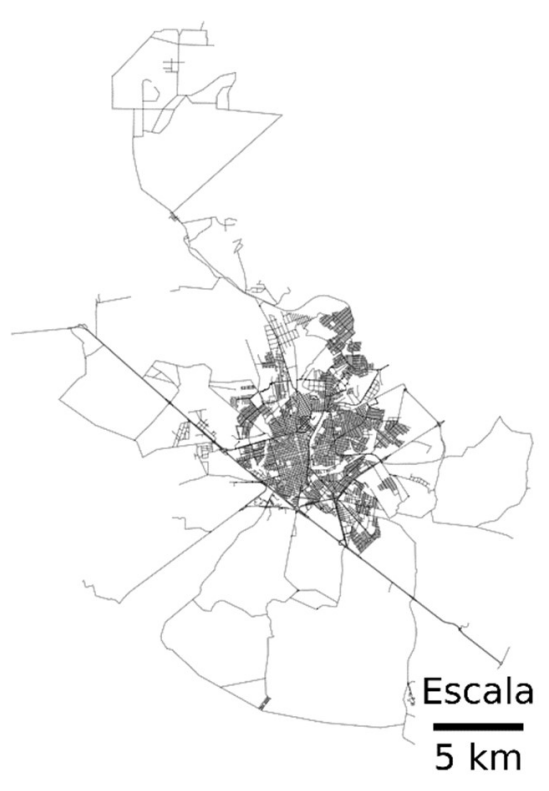

Araraquara - SP

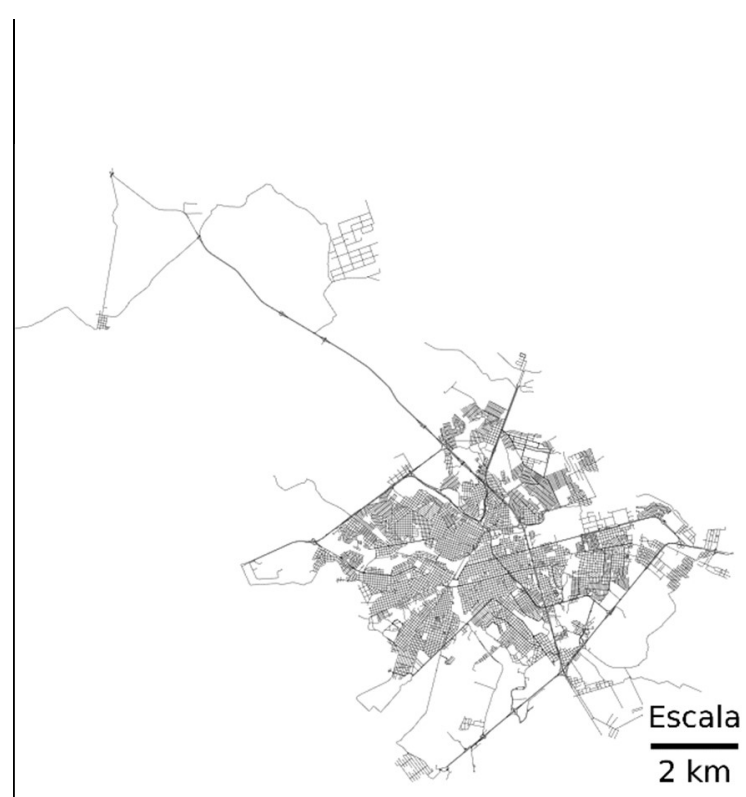

Bauru - SP 


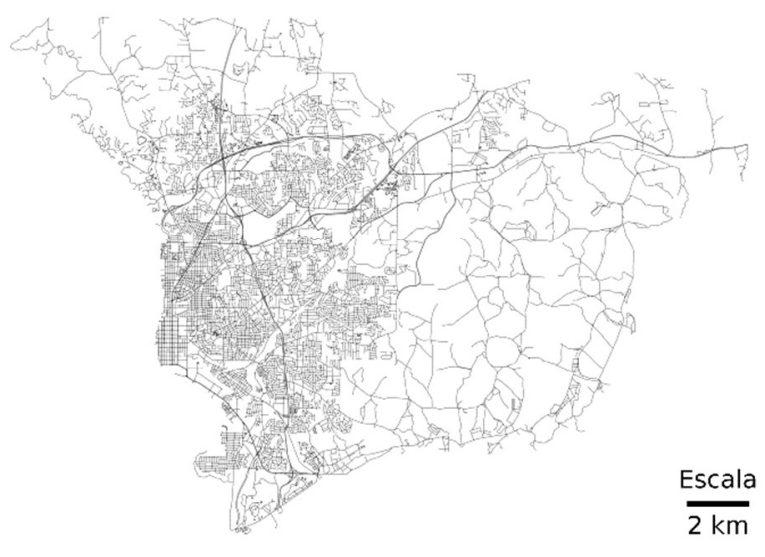

Columbus - GA
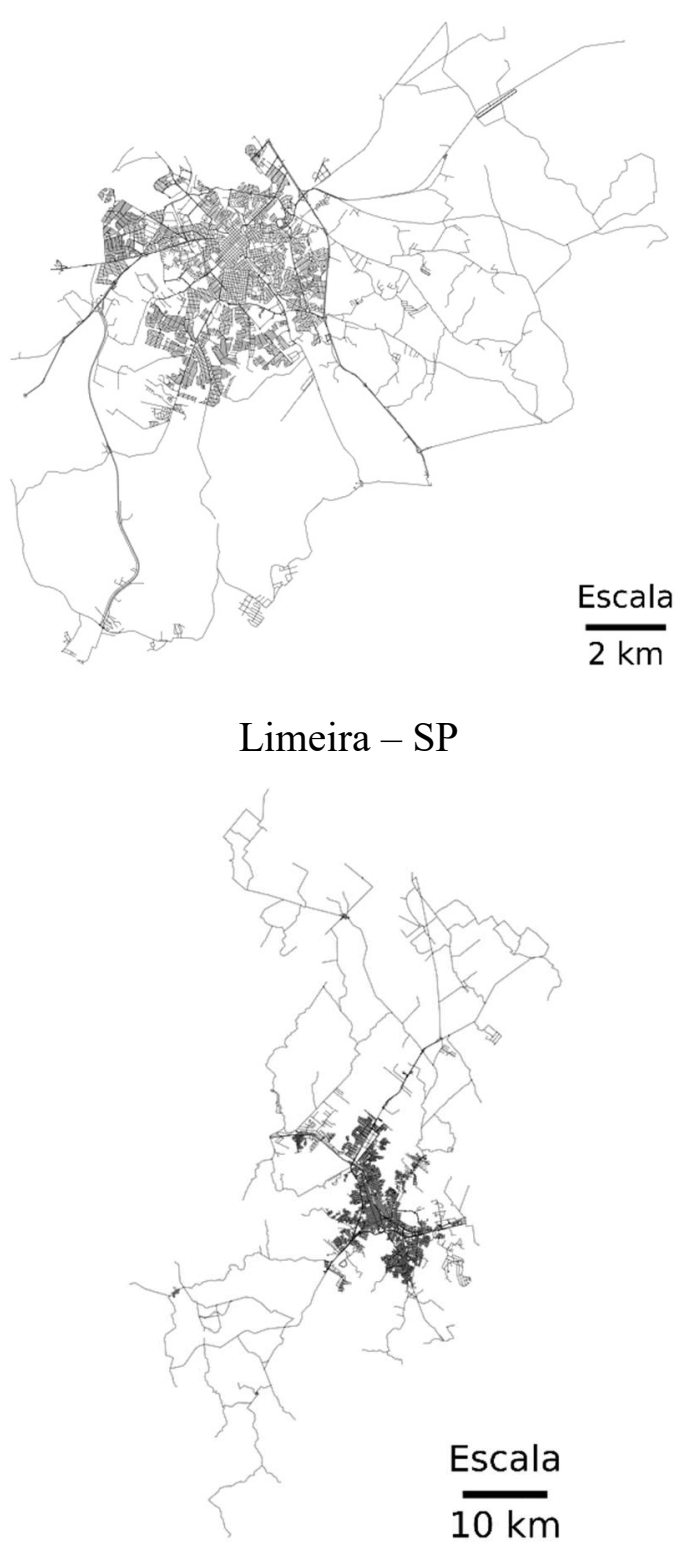

Marília - SP

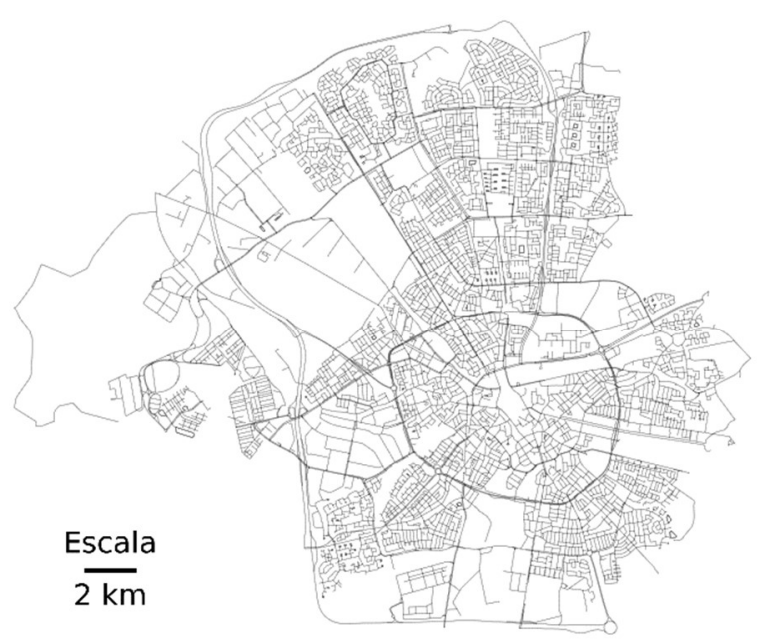

Eindhoven - NB
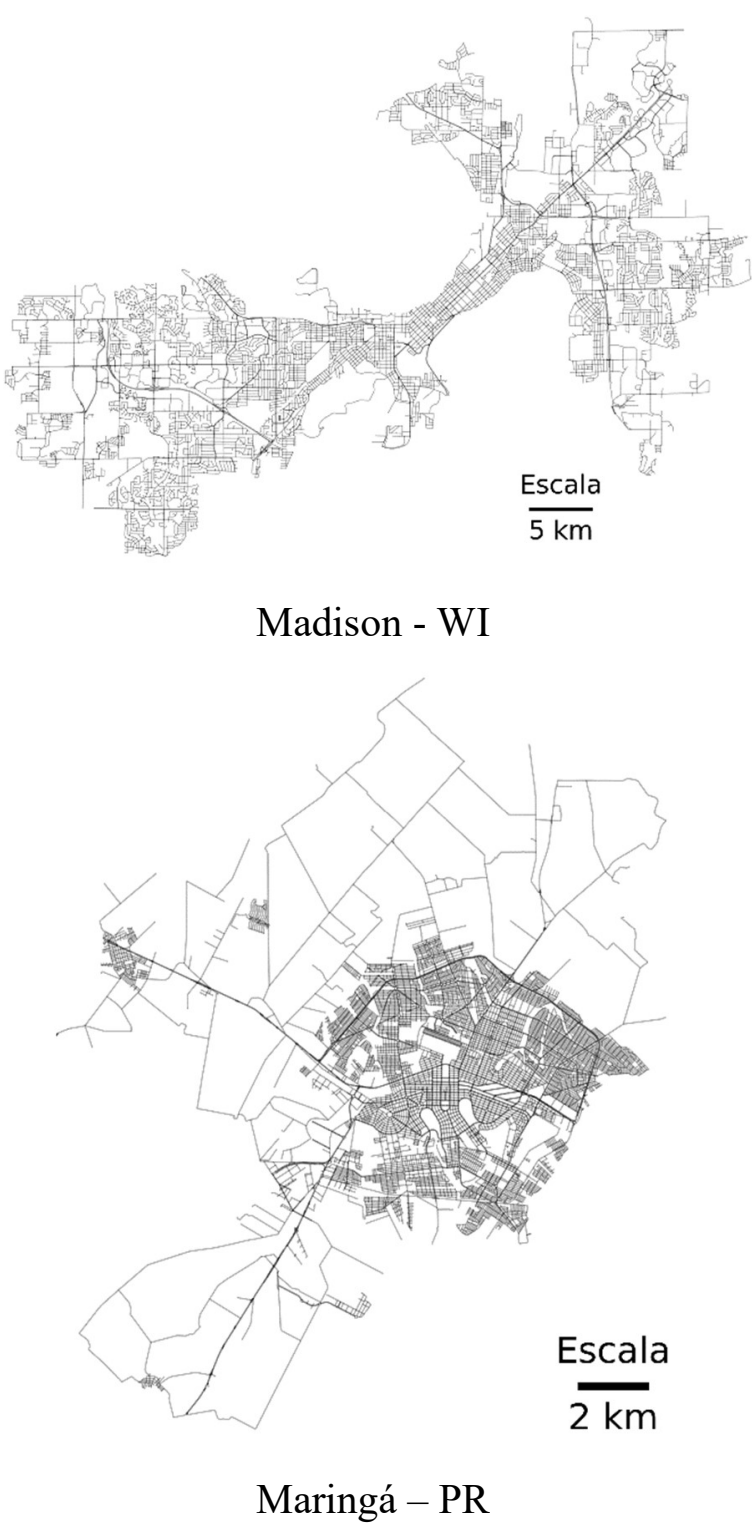


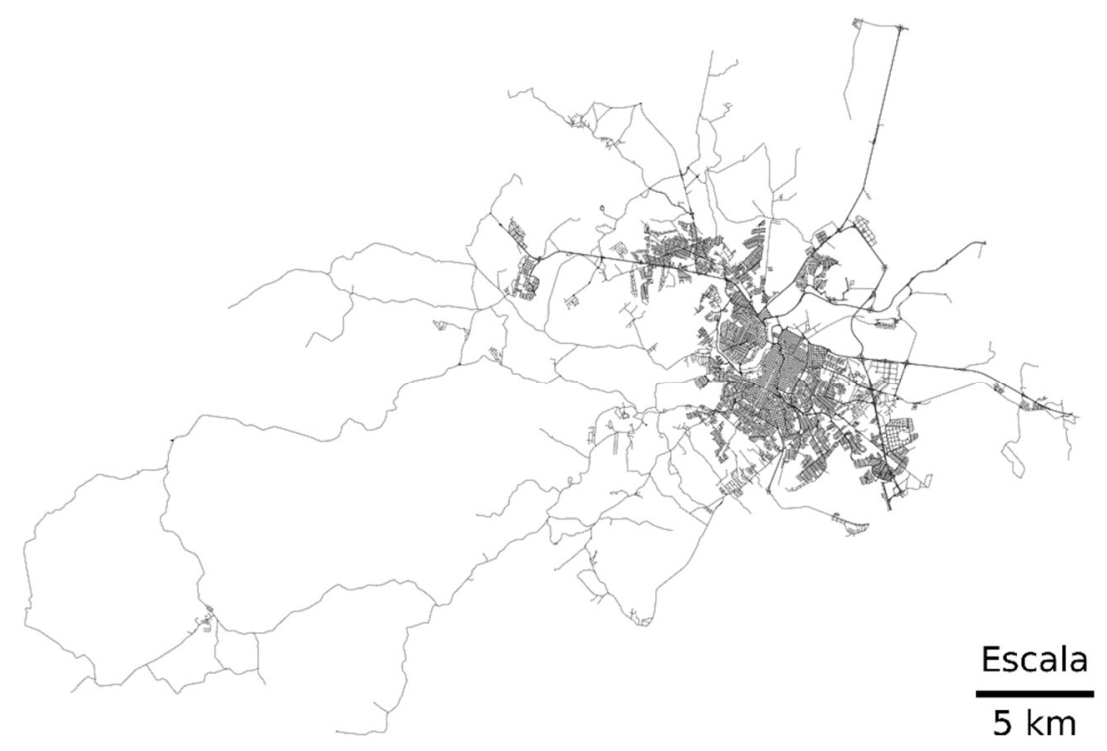

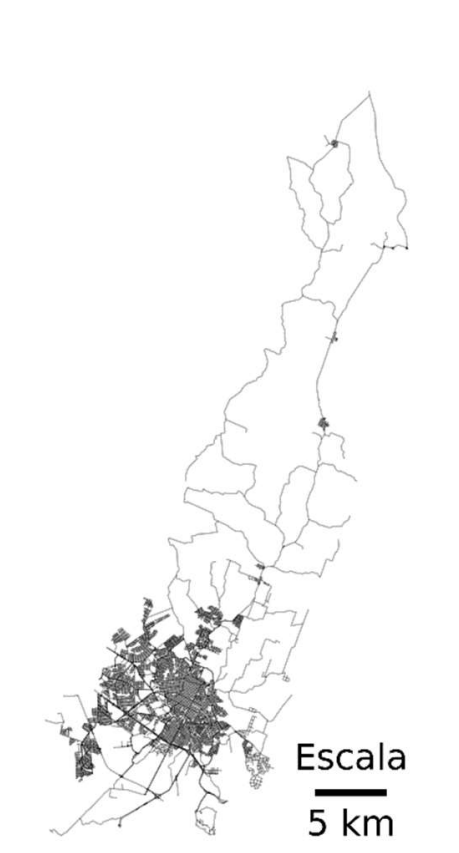

Presidente Prudente - SP
Piracicaba - SP

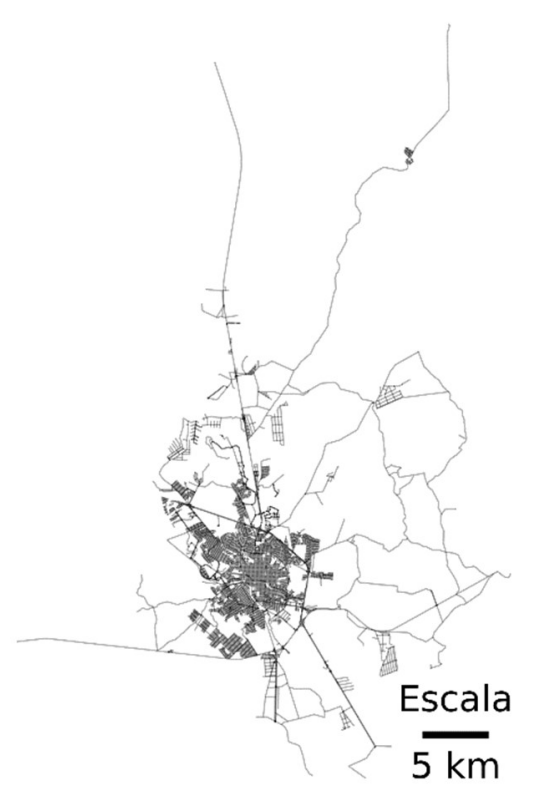

São Carlos - SP

\section{Fonte: A autora}

Em seguida, outra rotina foi desenvolvida para a determinação de uma matriz com os comprimentos dos caminhos mínimos entre todos os nós da rede, com o uso do algoritmo de Dijkstra. A biblioteca Networkx possui a função all_pairs_dijkstra_path_length que aplica o algoritmo de modo iterativo para todos os pares de nós. A sintaxe da função está descrita a seguir e os parâmetros de entrada estão na Tabela 14. 
Sintaxe:

nx.algorithms.shortest_paths.weighted.all_pairs_dijkstra_path_length(G,

cutoff=None, weight=' weight)

Tabela 14 - Parâmetros de entrada da função all_pairs_dijkstra_path_length

\begin{tabular}{ccl}
\hline Parâmetro & $\begin{array}{c}\text { Tipo de } \\
\text { dado }\end{array}$ & Descrição \\
\hline$G$ & $\begin{array}{c}\text { Grafo do } \\
\text { Networkx }\end{array}$ & Objeto de análise \\
\hline cutoff & $\begin{array}{c}\text { inteiro ou } \\
\text { decima }\end{array}$ & Limite máximo de caminho mínimo a ser computado \\
\hline weight & string & $\begin{array}{l}\text { Nome do atributo que será considerado como peso nas arestas. Se as- } \\
\text { sume valor length, computa os caminhos mínimos com o valores dos } \\
\text { comprimentos das arestas }\end{array}$ \\
\hline
\end{tabular}

Fonte: Adaptado de Boeing (2018a)

Os resultados da função all_pairs_dijkstra_path_length foram modelados em forma de matriz em que a primeira coluna e a primeira linha receberam os nós do grafo. Os valores dos caminhos mínimos entre cada par de nó preencheram a matriz. A Tabela 15 traz uma parte da matriz de caminhos mínimos gerada para a cidade de São Carlos.

Em seguida, para cada nó foi calculada média dos comprimentos dos caminhos mínimos originados nele. Este cálculo foi realizado para todas as colunas, com a soma dos valores e a divisão pela quantidade de nós, menos uma unidade, referente à distância do nó a ele mesmo. Desta forma foi obtida uma medida de acessibilidade local para cada nó. A obtenção da acessibilidade global foi realizada com a determinação da média da acessibilidade local de todos os nós do grafo. 
Tabela 15 - Parte da matriz de caminhos mínimos de São Carlos

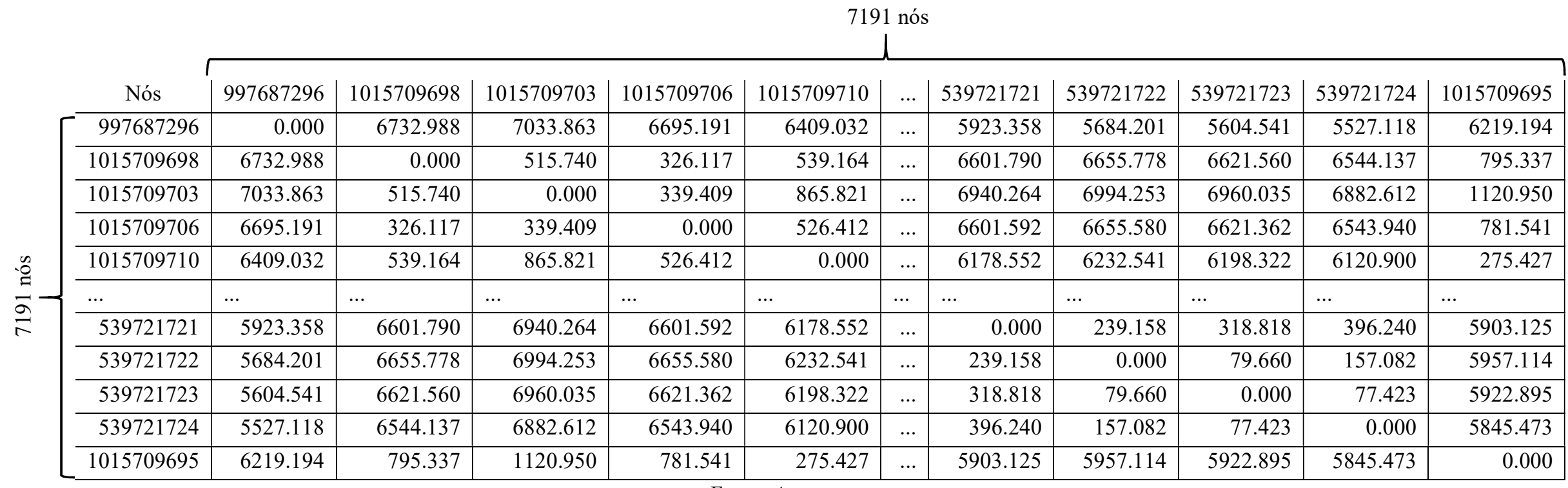




\subsection{Acessibilidade global}

Nesta seção são comparados os resultados de índice de acessibilidade global real obtidos paras as cidades do grupo de estudo. A quantidade de nós, assim como os índices de acessibilidade global real calculados para a cidade estão apresentados na Tabela 16 juntamente com o resumo dos resultados do estudo anterior. Os resultados também estão demonstrados no gráfíco Figura 23.

Tabela 16 - Resultados de acessibilidade global real

\begin{tabular}{lrr|rr}
\hline \multirow{2}{*}{ Cidades } & \multicolumn{2}{c|}{$\mathbf{2 0 0 3}$} & \multicolumn{2}{c}{$\mathbf{2 0 1 9}$} \\
\cline { 2 - 5 } & \multicolumn{1}{c}{ Nós } & $\mathbf{E}_{\text {real }}$ & \multicolumn{1}{|c}{ Nós } & E $_{\text {real }}$ \\
\hline Araraquara - SP & 4893 & 5,66 & 8118 & 6,91 \\
\hline Bauru - SP & 10518 & 7,49 & 10683 & 6,72 \\
\hline Columbus-GA & 8498 & 9,69 & 9206 & 11,68 \\
\hline Eindhoven-NB & 5814 & 4,98 & 7109 & 5,29 \\
\hline Limeira - SP & 4872 & 4,97 & 8018 & 6,91 \\
\hline Madison-WI & 7228 & 10,37 & 7940 & 11,92 \\
\hline Marília - SP & 5301 & 6,32 & 7744 & 8,57 \\
\hline Maringá - PR & 7268 & 6,70 & 9930 & 7,73 \\
\hline Piracicaba - SP & 6372 & 7,11 & 11580 & 9,67 \\
\hline Presidente Prudente - SP & 5323 & 6,01 & 8706 & 7,37 \\
\hline São Carlos - SP & 4957 & 5,23 & 7191 & 7,93 \\
\hline
\end{tabular}

Fonte: A autora

Figura 23 - Comparação de quantidade de nós e índice $E_{\text {real }}$ entre 2003 e 2019

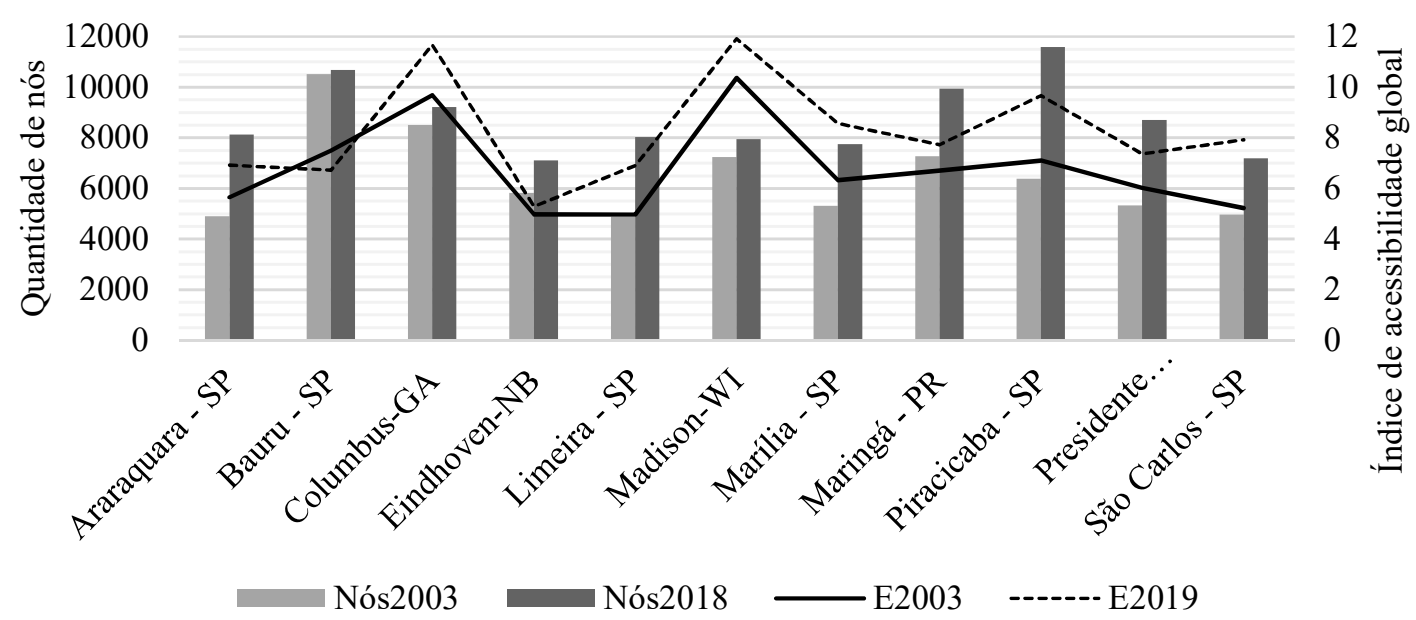

Fonte: A autora 
O índice $E_{\text {real }}$ é uma medida de distância média entre as interseções de uma rede expresso em quilômetros, quanto maior a separação entre os nós, maior o seu valor. Em 9 das 11 cidades analisadas houve um aumento médio de $47 \%$ da quantidade de nós no período analisado, associado a um acréscimo médio de $29 \%$ do índice $E_{\text {real }}$, provavelmente devido à expansão das cidades. A quantidade de vértices em Piracicaba apresentou o maior aumento de $82 \%$, com um índice $E_{\text {real }}$ passando de 7,11 km para 9,67 km. Este comportamento não foi verificado nas cidades de Bauru e Eindhoven.

A cidade de Bauru apresentou uma diferença de somente $2 \%$ na quantidade de nós entre os períodos analisado, e na contramão da tendência do grupo, o índice $E$ diminuiu $10 \%$ no cálculo atual em relação ao valor encontrado em 2003. Uma possível explicação para esse fato pode ser a criação de ligações entre as interseções, ou seja, a abertura de novas ruas, que podem ter alterado a topologia da rede e diminuído o comprimento dos caminhos mínimos entre esses nós. De fato, os dados da Figura 23 mostram que a rede viária de Bauru foi a que apresentou maior valor de média de grau dos nós e o segundo menor comprimento médio de aresta, que indicam uma malha conectada e compacta.

Apesar de ter sido detectado um aumento de $22 \%$ no tamanho da malha para a cidade de Eindhoven, o índice $E_{\text {real }}$ aumentou somente $6 \%$. Isto pode indicar que os nós acrescidos na rede a expandiram, porém de forma mais compacta do que o detectado nas outras cidades. Esta constatação também pode ser feita através da Tabela 13 em que a cidade de Eindhoven apresenta o menor comprimento médio de aresta, de 99,33 metros. Esta situação pode ter ocorrido devido a uma maior densidade urbana na cidade europeia, em relação aos outros casos avaliados.

Esta seção mostrou a possibilidade de modelar grafos a partir de informações geográficas voluntárias extraídas do OpenStreetMap com o uso das funções da biblioteca OSMnx. Esta etapa foi realizada para as cidades brasileiras e estrangeiras e obteve um retrato de aumento da quantidade nós em todas as redes extraídas. Esse fato, aliado às representações gráficas geradas indicam que as malhas viárias estão mais detalhadas do que as utilizadas por Lima; Silva e van der Waerden (2003) e que ocorreram processos de expansão urbana com espalhamento das cidades por áreas antes não ocupadas.

As computações de índices de acessibilidade global foram realizadas da mesma forma que o estudo de referência, porém com a função da biblioteca Networkx. A diferença entre os 
valores do índice $E$ paras as mesmas cidades pode ser atribuída ao processo natural de expansão das aglomerações urbanas.

\subsection{Acessibilidade global ideal}

Além do diagnóstico da acessibilidade global das cidades, o estudo de 2003 buscou identificar o quão distante as cidades analisadas estavam de um padrão idealizados pelos autores, o da rede circular. Foram comparados os resultados das variações dos índices ideais em relação aos índices reais, valores indicadores do grau de compacidade. Em seguida os autores compararam todas as cidades em um panorama internacional. As Tabela 17 e Tabela 18 mostram os resultados do estudo de 2003 e deste trabalho, respectivamente, em ordem crescente de grau de compacidade. Como o objetivo desta seção é comparar os resultados obtidos pelos métodos de construção da rede do estudo de 2003 com os atuais, foram analisadas somente as variações dos índices $\mathrm{E}_{\text {circ, }}$ que utilizam a quantidade de nós como parâmetro de cálculo. Os outros índices ideais ( $E_{\text {dens50 }}$ e $E_{\text {dens100}}$ ) foram calculados com dados de população, que não são dependentes dos grafos extraídos.

Tabela 17 - Valores de $E_{\text {real }}$ e $E_{\text {ideal }}$ e variações percentuais em relação a $E_{\text {real }}$ (resultados de 2003)

\begin{tabular}{lrrrr}
\hline \multicolumn{1}{c}{ Cidade } & Nós & $\mathbf{E}_{\text {real }}$ & $\mathbf{E}_{\text {circ }}$ & Variação de $\mathbf{E}_{\text {circ } \%}$ \\
\hline Eindhoven & 5.814 & 4,98 & 4,94 & $0,8 \%$ \\
\hline Limeira & 4.872 & 4,97 & 4,52 & $9,1 \%$ \\
\hline Bauru & 10.518 & 7,49 & 6,65 & $11,2 \%$ \\
\hline São Carlos & 4.957 & 5,23 & 4,56 & $12,8 \%$ \\
\hline Maringá & 7.268 & 6,7 & 5,53 & $17,5 \%$ \\
\hline Araraquara & 4.893 & 5,66 & 4,53 & $20,0 \%$ \\
\hline Presidente Prudente & 5.323 & 6,01 & 4,73 & $21,3 \%$ \\
\hline Marília & 5.301 & 6,32 & 4,72 & $25,3 \%$ \\
\hline Piracicaba & 6.372 & 7,11 & 5,17 & $27,3 \%$ \\
\hline Columbus & 8.498 & 9,69 & 5,97 & $38,4 \%$ \\
\hline Madison & 7.228 & 10,37 & 5,51 & $46,9 \%$ \\
\hline
\end{tabular}

Fonte: Lima; Silva e van der Waerden (2003) 
Tabela 18 - Valores de $E_{\text {real }}$ e $E_{\text {ideal }}$ e variações percentuais em relação a $E_{\text {real }}$ (resultados atuais)

\begin{tabular}{lrrrr}
\hline \multicolumn{1}{c}{ Cidade } & \multicolumn{1}{c}{ Nós } & $\mathbf{E}_{\text {real }}$ & $\mathbf{E}_{\text {circ }}$ & Variação de $\mathbf{E}_{\text {circ }} \mathbf{\%}$ \\
\hline Eindhoven & 7109 & 5,29 & 5,46 & $-3,3 \%$ \\
\hline Bauru & 10683 & 6,72 & 6,70 & $0,3 \%$ \\
\hline Araraquara & 8118 & 6,91 & 5,84 & $15,6 \%$ \\
\hline Limeira & 8018 & 6,91 & 5,80 & $16,0 \%$ \\
\hline Maringá & 9930 & 7,73 & 6,46 & $16,5 \%$ \\
\hline Presidente Prudente & 8706 & 7,37 & 6,05 & $17,9 \%$ \\
\hline Piracicaba & 11580 & 9,67 & 6,97 & $27,9 \%$ \\
\hline São Carlos & 7191 & 7,93 & 5,50 & $30,7 \%$ \\
\hline Marília & 7744 & 8,57 & 5,70 & $33,5 \%$ \\
\hline Columbus & 9206 & 11,68 & 6,22 & $46,8 \%$ \\
\hline Madison & 7940 & 11,92 & 5,77 & $51,5 \%$ \\
\hline
\end{tabular}

Fonte: A autora

O valor negativo do grau de compacidade calculado para a rede atual de Eindhoven mostra a necessidade de revisão do padrão ideal (malha circular com quadras de 100 x 100 metros) proposto por Lima; Silva e van der Waerden (2003). Mesmo com esta demanda, o resultado encontrado foi coerente com a premissa adotada pelos autores de que a cidade europeia é a mais compactada. A Figura 24 mostra os valores de variação percentual de $\mathrm{E}_{\text {circ }}$ em relação ao $E_{\text {real }}$ em cada cidade, para os dois períodos comparados. A primeira percepção está na proximidade dos pontos nas cidades de Maringá e Piracicaba, que mostra que houve pouca mudança na compacidade das redes em relação ao considerado ideal. 
Figura 24 - Comparação das variações percentuais dos índices $E_{\text {circ }}$ em relação aos $E_{\text {real, }}$ entre os dois períodos

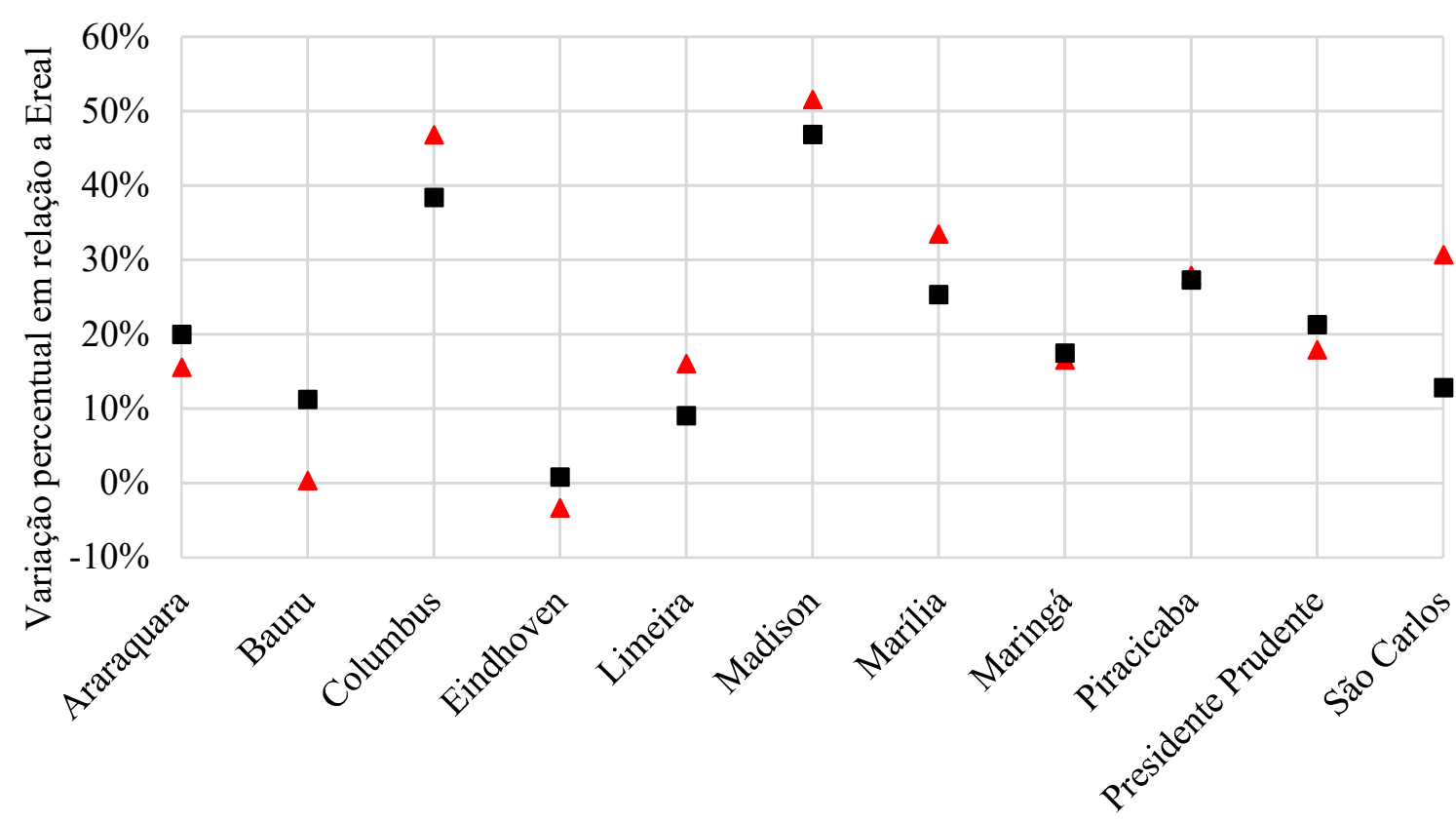

$\Delta$ Variação de Ecirc Variação de Ecirc (2003)

Fonte: A autora

As cidades de Araraquara, Bauru, Eindhoven, e Presidente Prudente apresentaram diminuição da variação percentual de $\mathrm{E}_{\text {circ, }}$ o que indica que as novas conexões aproximaram as redes do modelo circular. As maiores variações positiva de $\mathrm{E}_{\text {circ }}$ ocorreram nas cidades de Columbus, Limeira, Madison, Marília e São Carlos, o que sugere que estas redes foram desenvolvidas de encontro ao modelo adotado como ideal. A posição de cidade mais próxima do ideal, continuou ocupada por Eindhoven, seguida por Bauru. As cidades mais distantes do modelo circular continuam sendo as americanas, caracterizadas pelos autores como espalhadas e altamente dependente de automóveis.

\subsection{Panorama internacional}

O objetivo do trabalho de Lima, Silva e; van der Waerden (2003) foi identificar de qual padrão viário as cidades brasileiras mais se aproximavam, em termo de compacidade $\left(\mathrm{E}_{\text {real }}\right.$ $\left.E_{\text {circ }}\right) / E_{\text {real. }}$ Os valores de variação percentual de $E_{\text {circ }}$ das cidades americanas foram utilizados como extremos superiores e os da cidade holandesa como extremo inferior. A classificação das cidades brasileiras verificou se os valores de compacidade estavam acima de 0,5 , o que indicou uma proximidade do padrão americano, ou abaixo, o que mostrou inclinação ao padrão holan- 
dês/europeu. A Figura 25 mostra a classificação com Eindhoven e Madison como padrões europeu e americano, respectivamente. A cidade de São Carlos, que antes aparecia no grupo do padrão europeu, apresentou valor de compacidade que a aproxima mais do padrão americano. As outras cidades continuaram com a mesma classificação.

Figura 25 - Valores normalizados de compacidade por Eindhoven e Madison

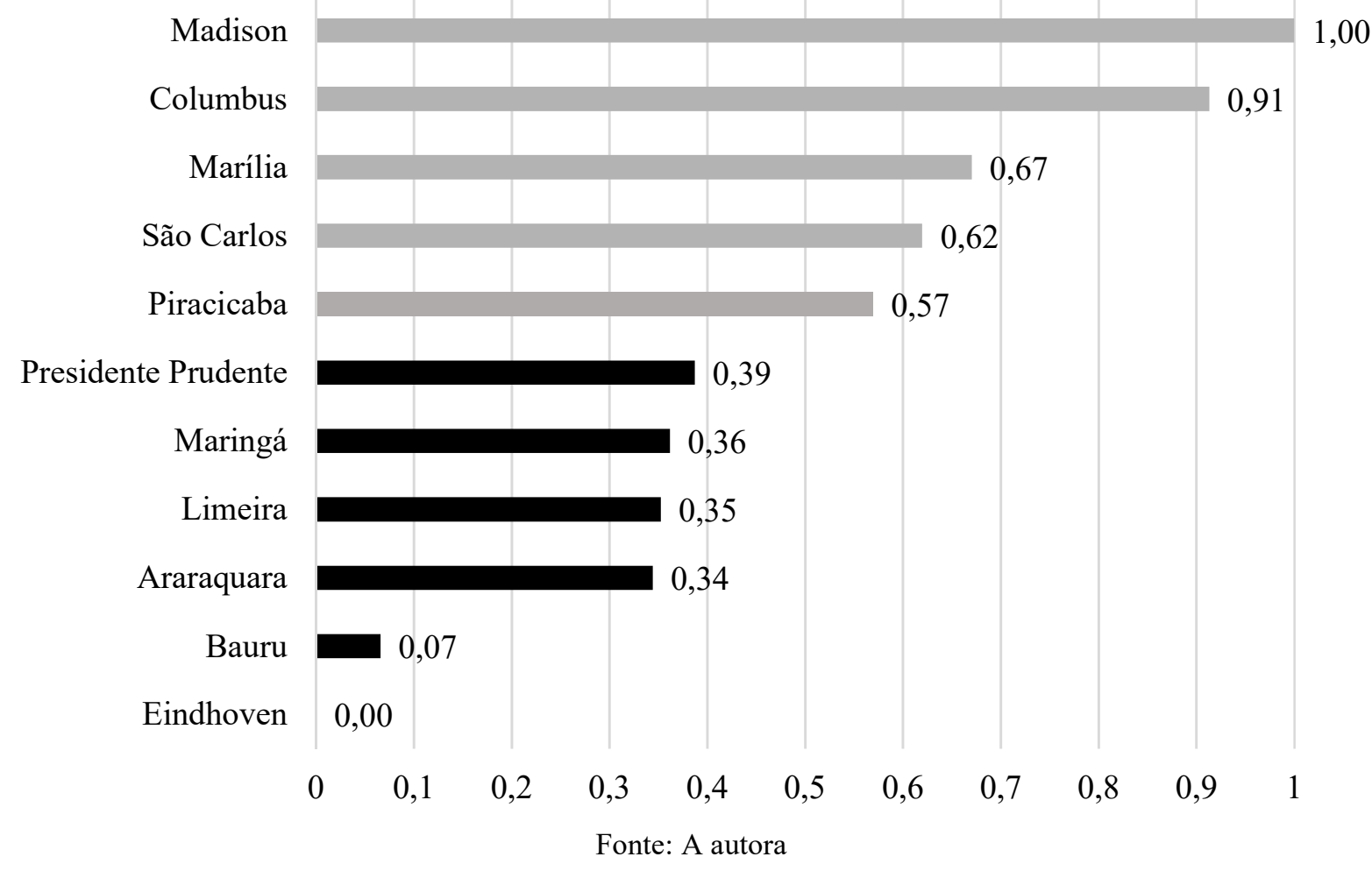

A Figura 26 mostra a classificação com Eindhoven e Columbus como extremos. A opção por esta segunda análise envolveu o fato de Madison ser uma cidade com presença de grandes lagos em sua forma física, o que influencia na escolha dela como bom parâmetro de padrão americano. Esta segunda classificação mostrou uma dinâmica diferente da constatada no estudo de 2003. Neste trabalho, Presidente Prudente e Araraquara mudaram de grupo e apresentaram valores de compacidade mais próximos do de Eindhoven, enquanto que São Carlos passou a se aproximar mais do comportamento de Columbus. 
Figura 26 - Valores normalizados de compacidade por Eindhoven e Columbus

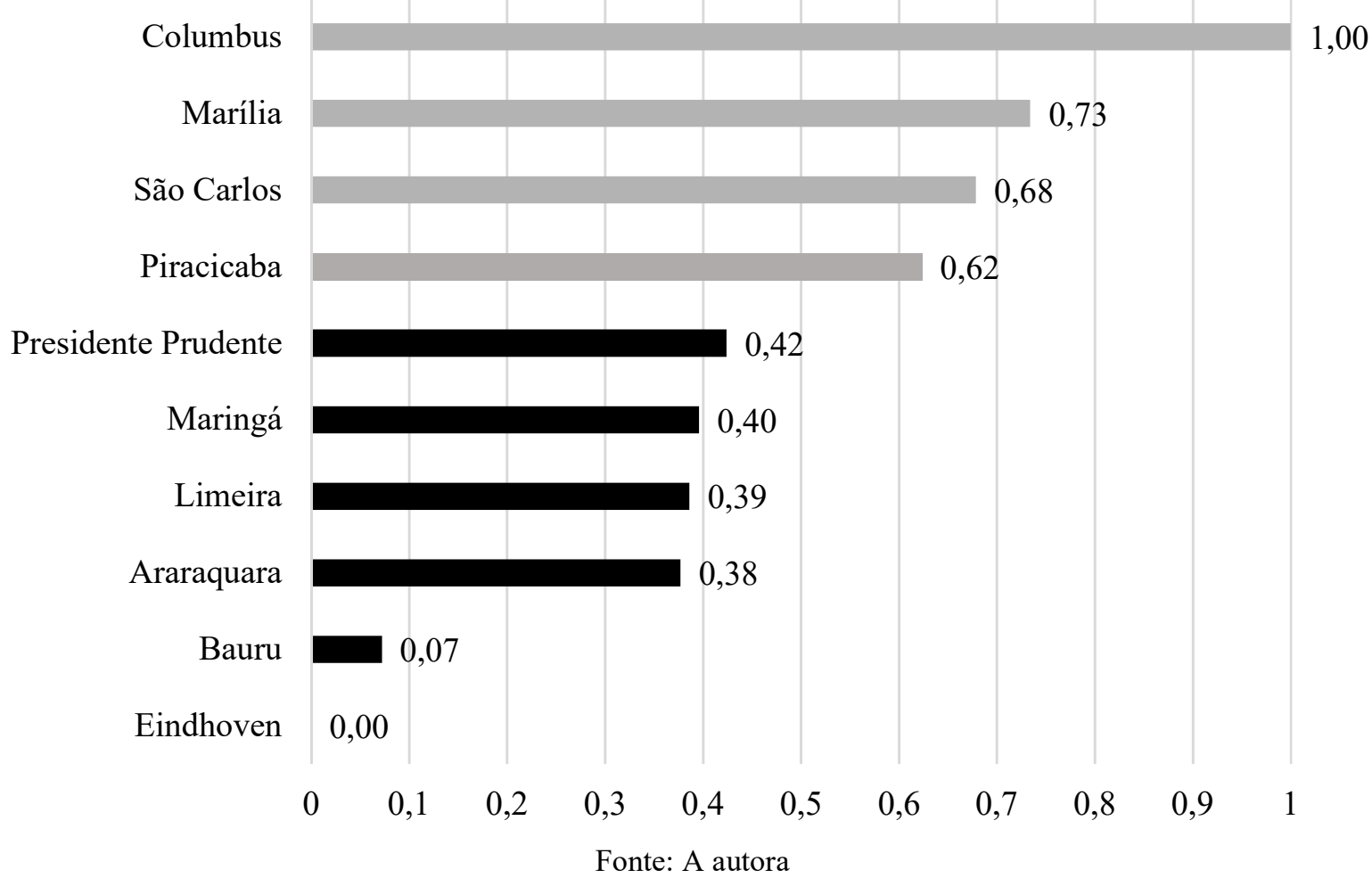

As divergências entre os panoramas visualizados em cada estudo não indicam erro no método adotado neste trabalho, mas somente uma atualização da situação de cada cidade. Com as ferramentas apresentadas, outras cidades podem ser incluídas no panorama de forma a obter mais exemplos que formem o padrão de cada região.

\subsection{Considerações finais}

A repetição do estudo de Lima; Silva e van der Waerden (2003) verificou a acessibilidade e a compacidade das mesmas cidades com o uso de dados da plataforma OpenStreetMap e de ferramentas computacionais de análises de rede (OSMnx e Networkx). As malhas viárias foram obtidas de maneira rápida em forma de grafos computacionalmente manipuláveis. O capítulo também analisou as diferenças entre os resultados obtidos no estudo de referência e no atual e suas razões. Apesar das diferenças entre as ferramentas utilizadas, as maiores diferenças nos indicadores calculados ocorreram devido às atualizações das malhas viárias que foram alteradas no intervalo de 15 anos entre os trabalhos.

Este capítulo permitiu a avaliação da qualidade dos dados de mapas colaborativos ao demonstrar a usabilidade e as limitações deles em avaliações de acessibilidade de diferentes cidades. 


\section{BANCO DE DADOS DE MÉTRICAS MORFOLÓGICAS}

Este capítulo atende a meta de construir um banco de dados de redes viárias urbanas de cidades brasileiras. A partir da ferramenta $O S M N x$ apresentada no capítulo 3, as malhas viárias cadastradas no OSM foram extraídas em forma de grafo. As características foram selecionadas de acordo com os significados que assumem na morfologia urbana e calculadas por rotinas computacionais escritas em linguagem Python. As métricas foram determinadas para diferentes tipos de grafos de acordo com a natureza das informações no contexto aplicado. O capítulo está dividido em três partes: a primeira descreve a seleção das cidades, a segunda os grafos gerados, e a terceira o banco de dados construído e as análises das variáveis obtidas.

As análises das variáveis do banco de dados utilizaram estatística descritiva, análises de correlações e testes não-paramétricos, obtidos a partir do software estatístico SPSS. Os testes não-paramétricos avaliaram a igualdade de distribuições de variáveis (Kolmogorov -Smirnov e Qui-Quadrado) e a igualdade de medianas em amostras independentes (Mann - Whitney). Além de avaliar os diferentes tipos de ordenamento viário, foi verificado se para as cidades brasileiras é corroborada a hipótese de Boeing (2019) de que cidades com malhas mais regulares tendem a apresentar maior conectividade em termos de grau dos nós e índice de cruzamentos e menor perda de eficiência em rotas indiretas.

\subsection{Cidades brasileiras}

A estimativa populacional para 2017 feita pelo IBGE (2017b) apontou que cerca de 56\% dos residentes brasileiros estavam reunidos em 310 municípios com mais de 100 mil habitantes. Portanto, optou-se por selecionar essas cidades como a amostra inicial da pesquisa, visto que abrange a maioria da população nacional. A extração das redes viárias da base de dados do projeto $O S M$ ocorreu nos meses de agosto a outubro de 2018. Nesse período, não foram detectados elementos viários cadastrados nos municípios de Campo Largo-PR, Ourinhos-SP e Tailândia-PA, por isso eles foram excluídos da amostra.

Por outro lado, Brasília-DF também foi excluída devido ao tamanho da rede nos limites administrativos cadastrados no projeto OSM. Brasília é a capital federal e é dividida em 31 regiões administrativas, abrangendo uma área de mais de 5 mil km² e uma população de mais de 2 milhões de pessoas. Apesar de possuir elementos viários cadastrados, a quantidade total não foi extraída por extrapolar o limite de resposta da solicitação feita à plataforma OSM. 
Desta forma, a amostra final ficou composta de 306 municípios dos 5.570 que formam o Brasil (IBGE, 2017a). Apesar de representar uma pequena parcela $(5,5 \%)$ da totalidade de cidades brasileiras, as populações que habitam essas cidades somam 55\% do total nacional, segundo estimativas do IBGE em 2017. Embora não exista consenso sobre os números limitantes, as cidades podem ser classificadas segundo critérios demográficos da seguinte forma: cidades médias (população entre 100 mil e 300 mil habitantes), cidades médias-grandes (população entre 300 mil e 500 mil habitantes), cidades grandes (população entre 500 mil e 1 milhão de habitantes) e metrópoles (população maior que 1 milhão de habitantes). A distribuição das cidades coletadas segundo as respectivas unidades federativas e regiões estão descritas na Figura 27 e Figura 28. A amostra escolhida contempla cidades em todas as unidades da federação, com no mínimo uma cidade por Estado, como é o caso do Acre e Roraima. A região Sudeste tem a maior amostra de cidades, sendo o Estado de São Paulo com 77 cidades, seguido pelo Estado de Minas Gerais com 32, o Rio de Janeiro com 27 e Espírito Santo com 9.

Figura 27 - Cidades com mais de 100 mil habitantes coletadas por Estado e Região

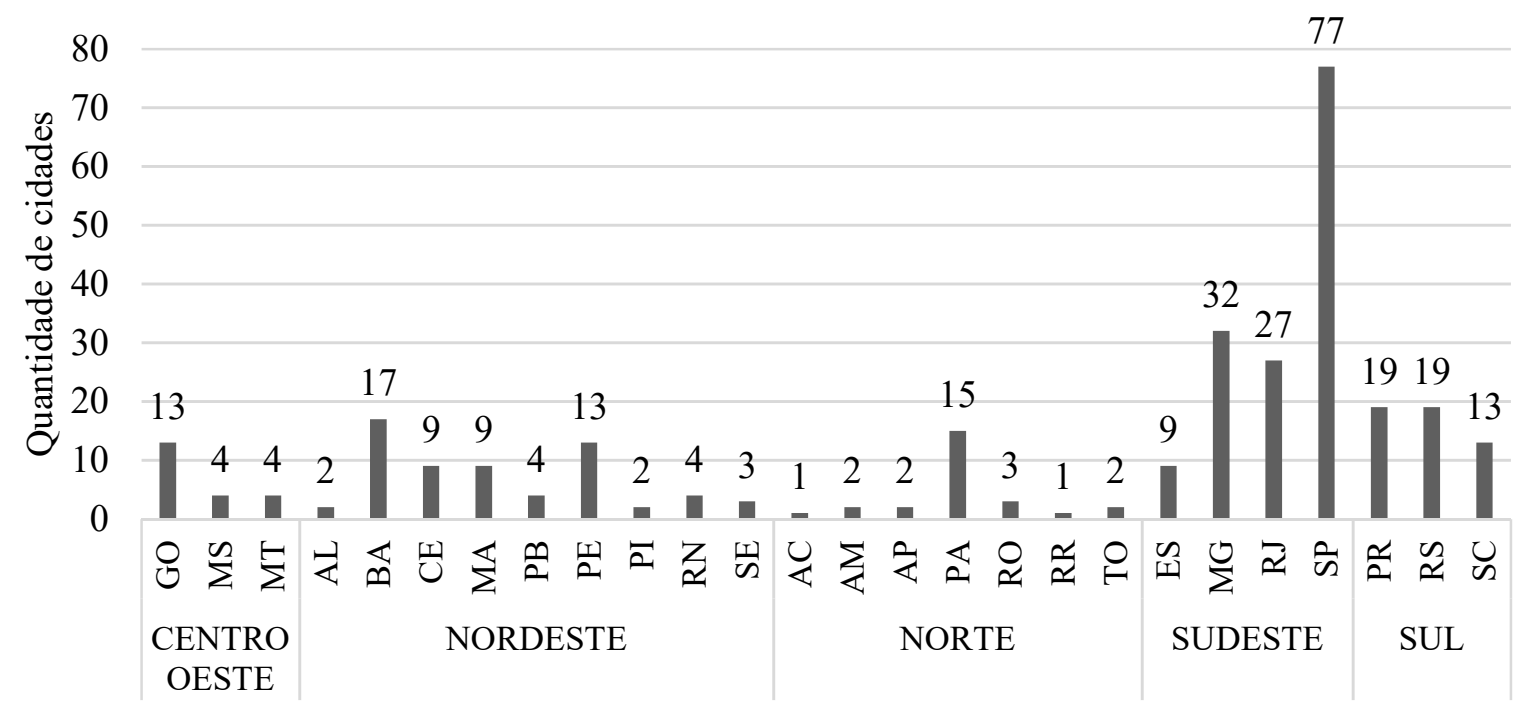

Fonte: A autora 
Figura 28 - Distribuição das cidades do banco de dados, classificadas por porte demográfico.

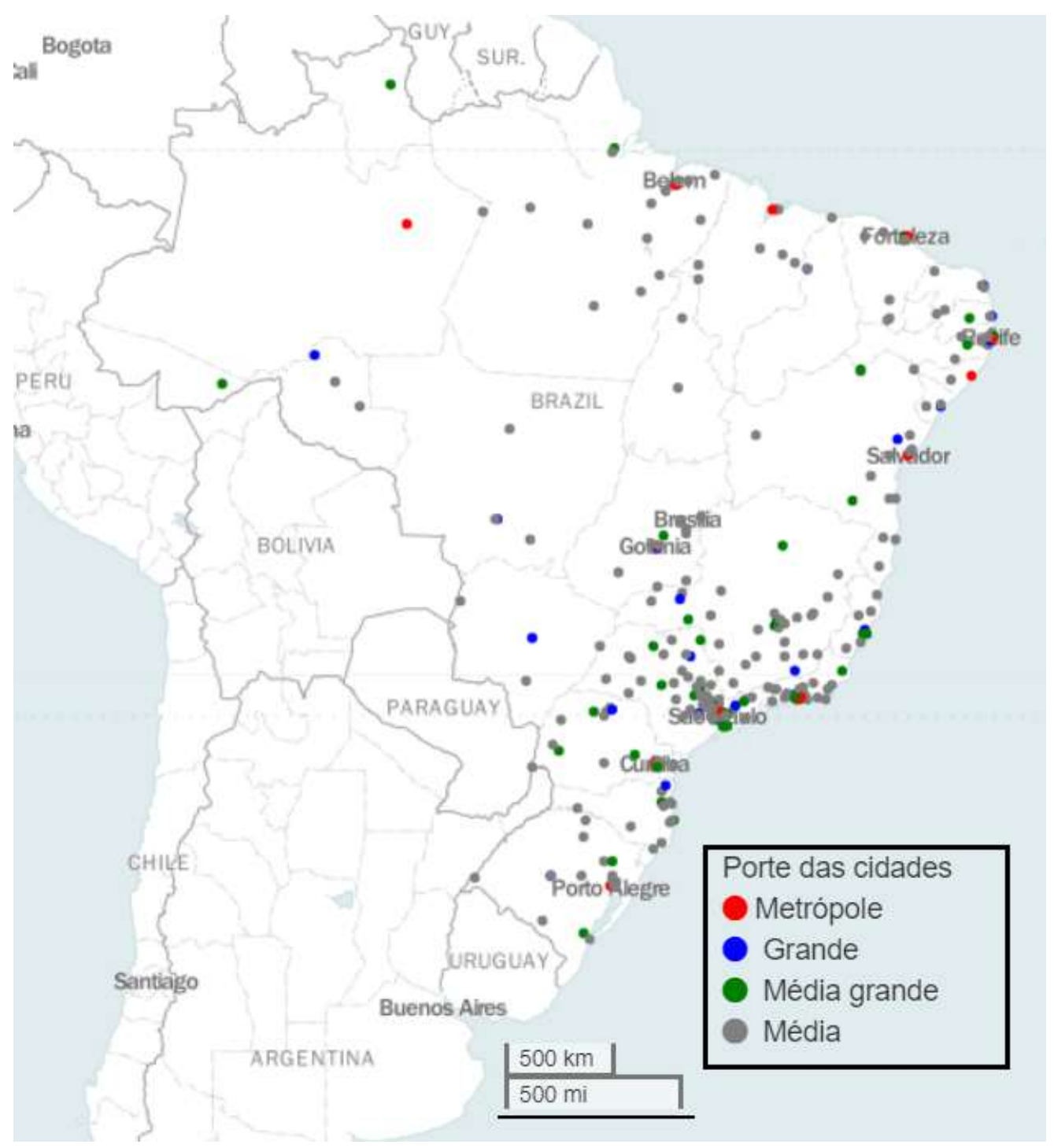

Fonte: A autora

5.2 Grafos de malhas viárias urbanas

Para cada município, foram extraídos três grafos simplificados: grafo direcionado fracamente conectado (DW - directed weakly connected), grafo direcionado fortemente conectado (DS - directed strongly connected) e o grafo não direcionado fortemente conectado (US - undirected strongly connected). Entre esses grafos foram detectadas diferenças nas quantidades de elementos, visto que o DS é um subgrafo do DW e o US é a versão não direcionada do DS. A Figura 29 mostra a proporção média de elementos excluído na extração do grafo DS em relação à quantidade de elementos do grafo DW. 
Figura 29 - Proporções médias por Estado de elementos excluídos na extração do grafo direcionado fortemente conectado (DS)

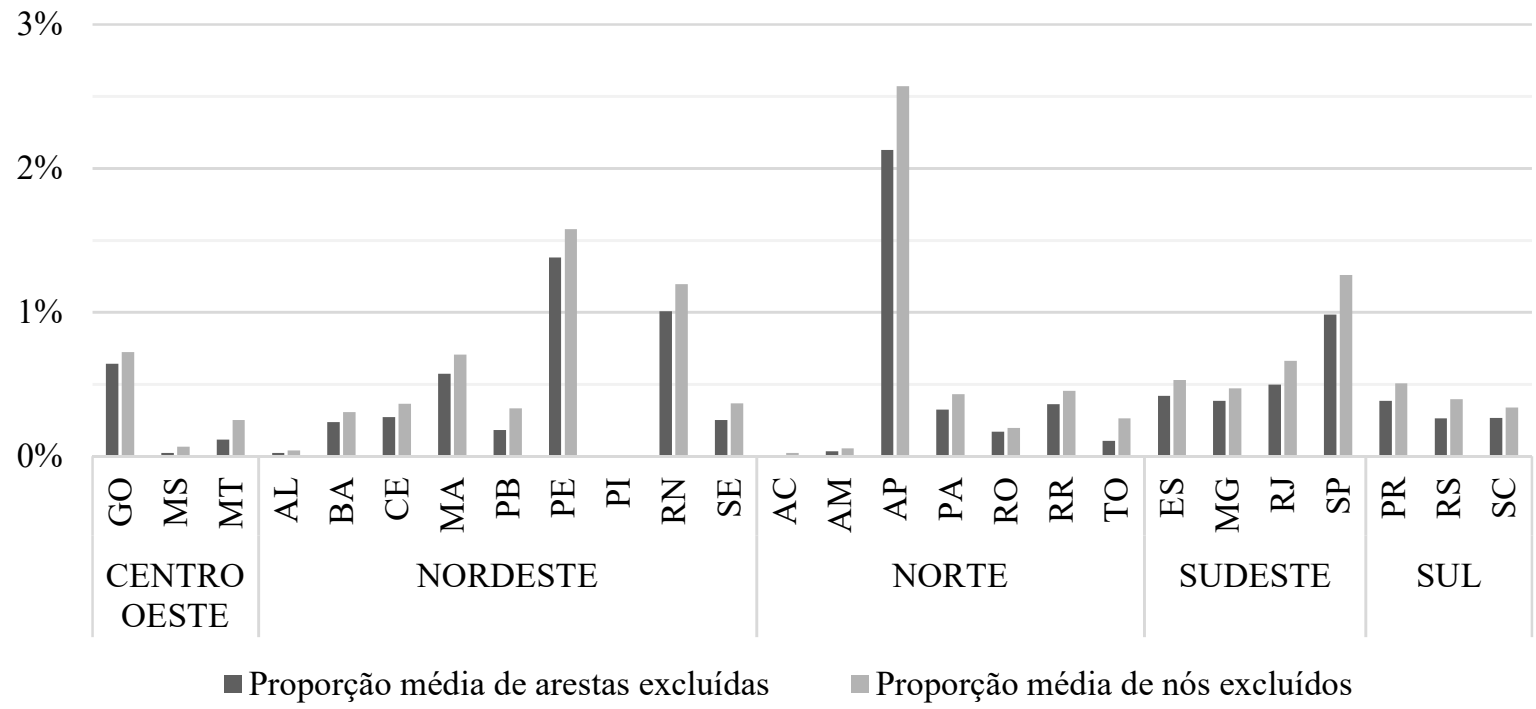

Fonte: A autora

Em média, houve redução de $1 \%$ na quantidade de arestas e de nós no processo de retirada das porções fracamente conectadas. As maiores perdas foram detectadas no Estado do Amapá, com apenas duas cidades na amostra - Macapá e Santana. Os grafos de Macapá acompanharam a proporção de redução do número de elementos, já os de Santana excluíram 3\% das arestas e 4\% dos nós, que correspondem respectivamente aos valores de 114 e 51 elementos, no processo de extração do grafo fortemente conectado. A diferença entre as proporções indica que a malha viária extraída da cidade de Santana apresenta uma porção desconectada da malha mais ampla, o que pode indicar: (1) ineficiência da rede real; (2) ausência de dados, (3) ou deficiência na consistência lógica na plataforma do $O S M$. A Figura 30 mostra a proporção média de arestas excluída na extração dos grafos não direcionados fortemente conectados.

Figura 30 - Proporção média por Estado de arestas excluídas na extração do grafo não direcionado fortemente conectado

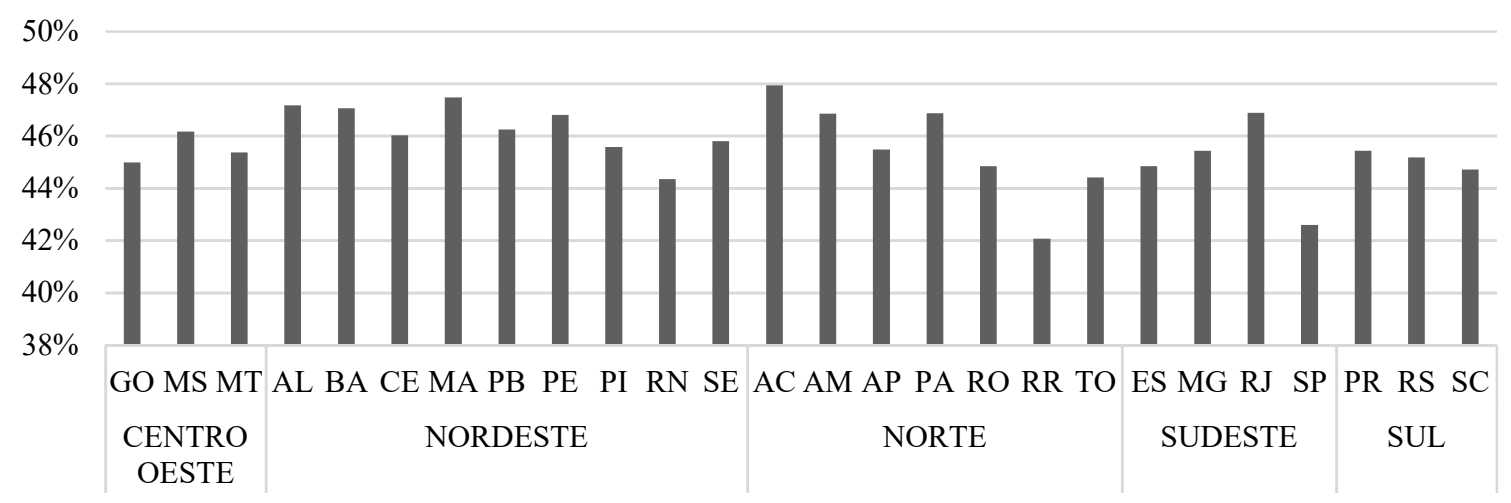

Fonte: A autora 
As informações sobre as quantidades dos elementos nos diferentes tipos de grafo mostram que as maiores variações ocorreram na conversão do grafo conexo direcionado para o não direcionado. Nesse processo, as arestas que estavam em duplicidade, por representarem segmentos de ruas com duplo sentido, foram excluídas, o que resultou em uma redução média de $45 \%$ da quantidade total de arestas. Nenhum nó foi excluído nesse processo, como esperado.

\subsection{Banco de Dados e análises da morfologia das redes viárias urbanas brasileiras}

Após a extração dos grafos das malhas viárias das cidades brasileiras selecionadas para o banco de dados, foram calculadas métricas topológicas e topo-geométricas globais e locais. Além destas métricas, o banco de dados incorporou informações sobre a área e a população de cada cidade e a quantidade de nós e arestas. As métricas foram selecionadas de acordo com os significados que assumem na caracterização da morfologia das redes e calculadas por meio de rotinas computacionais elaboradas na linguagem Python. As métricas foram determinadas para diferentes tipos de grafos de acordo com a natureza das informações no contexto aplicado. Em seguida foram realizadas análises da morfologia das redes viárias urbanas brasileiras extraídas. Dentre as análises, foi testada a hipótese de Boeing (2019) de que cidades com malhas mais regulares tendem a apresentar maior conectividade em termos de grau dos nós e índice de cruzamentos e menor perda de eficiência em rotas indiretas.

As avaliações do banco de dados foram realizadas com base em estatísticas descritivas, análises de correlações e testes não-paramétricos, obtidos a partir do software estatístico SPSS. Os testes não-paramétricos avaliaram a homogeneidade de distribuições de variáveis e a igualdade de medianas em amostras independentes.

A extração da rede viária com as funções da biblioteca OSMnx resultou em um grafo direcionado fracamente conectado. Porém, para diminuir as inconsistências devido à falta de elementos cadastrados na plataforma OSM, foi extraída o maior subgrafo fortemente conectado. A partir deste subgrafo, foram utilizadas as versões direcionada e não direcionada para a determinação das métricas deste trabalho. Grafos direcionados foram a base de métricas que traduzem a rede de acordo com a percepção do usuário. Grafos não direcionados foram utilizados para cálculo de métricas que refletem a estrutura disponível da malha viária. 


\subsubsection{Métricas de grafo direcionado}

A partir do grafo direcionado fracamente conectado, foi extraído um subgrafo $G_{d f}$ referente aos elementos fortemente conectados da rede. Com este processo, grupos menores de elementos que estivessem totalmente separados dos maiores, ou seja, sem nenhuma ligação entre eles, foram excluídos. Em seguida, alguns parâmetros foram calculados.

a) Centralidade de intermediação

A centralidade de intermediação $B_{i}$ (betweenness centrality) hierarquiza os elementos diante da importância deles na rede pois, um nó ou aresta $\operatorname{com} B_{i}$ alto implica que a maioria dos caminhos existentes de alguma forma passam por ele. Newman (2003) afirmou que a centralidade de intermediação também pode ser interpretada como uma medida de resiliência da rede, pois indica o efeito que a remoção de um nó tem sobre os comprimentos dos caminhos. Essa métrica foi calculada da seguinte forma para cada elemento $i$

$$
B_{i}=\sum_{s, t \in V} \frac{\sigma(s, t \mid i)}{\sigma(s, t)}
$$

Sendo:

$V: \quad$ o conjunto de nós

$\sigma(s, t): \quad$ quantidade de caminhos mínimos entre os nós s e $\mathrm{t}$

$\sigma(s, t \mid i)$ : quantidade de caminhos mínimos entre os nós $s$ e $t$ que passam pelo elemento $i$.

Esta variável indica a proporção de caminhos mínimos da rede que cada nó participa e pela justaposição deles é possível identificar essas rotas. Esta identificação permite o direcionamento de ações para evitar falhas em locais que concentram as principais conexões da rede.

b) Entropia de orientação

Ainda com base no grafo conexo, informações sobre a forma física da rede também foram descritas através da entropia de Shannon (SHANNON, 1948) da distribuição das orientações das arestas. Para representar a heterogeneidade da orientação da rede, foram considerados 36 setores de $10^{\circ}$. As arestas foram distribuídas entre os setores de acordo com o ângulo que cada uma formava com a horizontal. Em seguida, a frequência $P\left(s_{i}\right)$ em cada setor $i$ foi calculada para a determinação da entropia de orientação $H_{O}$ da seguinte forma: 


$$
H_{O}=-\sum_{i=1}^{n} P\left(s_{i}\right) \log _{e} P\left(s_{i}\right)
$$

Matematicamente os valores de entropia de orientação podem variar de 0 , situação de vias paralelas em uma direção, a 3,584, caso de distribuição uniforme de vias em todas as direções. Porém, o mais plausível é que a menor entropia de orientação seja 1,386 , referente a uma rede tipo grade, com arestas perpendiculares entre si (BOEING, 2018d).

c) Centralidade de proximidade

A centralidade de proximidade mede o quão próximo um nó está de todos os outros nós de um grafo que deve ser conectado (PORTA; CRUCITTI; LATORA, 2006b). O inverso do valor de centralidade de proximidade corresponde à distância média de um nó para todos os outros nós da rede. Segundo Sharifi (2019), essa métrica de centralidade deve ser considerada no aumento da resiliência da forma urbana em termos de acessibilidade. De fato, a forma de cálculo deste índice é semelhante ao índice de acessibilidade global de Allen, utilizado no trabalho de Lima, Silva e Van Der Waerden (2003), a diferença está no tipo de grafo utilizado, que nesse trabalho foi não direcionado. Apesar desta divergência, através da analogia, a distância média do nó a todos os outros nós foi denominada acessibilidade local. Desta forma, a expressão da centralidade de proximidade e sua relação com a acessibilidade local é dada pela equação 8.

$$
C(u)=a^{-1}=\frac{N-1}{\sum_{j \in G ; j \neq i} d_{i j}}
$$

Sendo:

$C(u): \quad$ centralidade de proximidade do nó u

$N$ : quantidade de nós

$j, i: \quad$ nós do grafo

$d_{j i}$ : comprimento em metros do menor caminho entre os nós j e i.

$a$ : $\quad$ acessibilidade local do nó, equivalente à distância média do nó i para todos os outros nós

Para a totalidade da rede foi calculada a média dos valores de centralidade de proximidade dos nós. Por analogia, esta média foi denominada acessibilidade global no banco de dados deste trabalho. 


\subsubsection{Métricas de grafo não direcionado}

Para o cálculo de algumas métricas que envolvem a quantidade de nós e arestas, foi utilizado a versão não direcionada do grafo $G_{d f}$, o grafo $G$. Dessa forma, a representação topológica do sistema viário se aproximou mais da estrutura física disponível, pois todas as vias passaram a ser representadas por uma única aresta.

a) Índice de cruzamentos (Ic)

O índice de cruzamentos é a proporção de interseções onde as vias se atravessam e é representada pelos nós de grau maior ou igual a 4. Os nós de cruzamento proporcionam uma distribuição mais homogênea dos caminhos mínimos pela rede e, no caso de sistemas de transportes, fornecem mais opções para o fluxo nas ruas. O cálculo do índice de cruzamentos foi realizado da seguinte forma:

$$
I c=\frac{N_{k \geq 4}}{\sum N_{k}}
$$

Sendo:

$N_{k}$ : a quantidade de nós com grau $k$.

b) Indicador orgânico (Io)

O indicador orgânico é uma relação que representa a proporção de nós de entroncamentos ou terminais que pode ser influenciada pela presença de barreiras físicas como grandes vazios, cursos d'água, encostas ou depressões no relevo, etc. Estes obstáculos interrompem a rede e forçam o desvio do fluxo para outras ruas. Segundo Courtat, Gloaguen e Douady (2011), este parâmetro discrimina rapidamente se uma cidade foi planejada, com valores para Io próximos de 0 , ou não, Io próximos de 1 A forma de obtenção do indicador orgânico é:

$$
I o=\frac{N_{k=1}+N_{k=3}}{\sum_{k \neq 2} N_{k}}
$$

Sendo:

$N_{k}: \quad$ quantidade de nós com grau $k$.

c) Grau de rotas indiretas

O grau de rotas indiretas (circuity average) computa o quanto o caminho entre dois pontos imposto pela configuração do grafo é diferente do caminho mais curto (linha reta). 
Sharifi (2019) aponta estudos que afirmam que rotas com menos desvios facilitam uma interação mais eficiente entre os nós.

$$
C=\frac{\sum L}{\sum L_{\text {euclidiana }}}
$$

Sendo:

$\sum L: \quad$ Soma dos comprimentos de todas as arestas

$\sum L_{\text {euclidiana }}: \quad$ Soma das distâncias em linha reta entre todos os nós

\subsubsection{Análises de morfologia urbana}

O banco de dados gerado está apresentado em detalhes no Apêndice A, as medidas de posição e de dispersão de cada variável estão expostas na Tabela 19 e os coeficientes de correlação de Pearson entre as variáveis com as respectivas probabilidades de significância estão na Tabela 20. Com o intuito de explorar os dados extraídos da web e organizados no banco de dados, esta seção ilustra as possibilidades de análises de morfologia urbana. As análises focam no comportamento dos parâmetros de forma individual e inserida no conjunto.

Tabela 19 - Estatística descritiva das variáveis

\begin{tabular}{ccccccccccc}
\hline & $\mathbf{I}_{\mathbf{O}}$ & $\mathbf{I}_{\mathbf{C}}$ & $\mathbf{L}[\mathbf{m}]$ & $\mathbf{B}_{\mathbf{i}}$ & $\mathbf{K}$ & $\mathbf{H}_{\mathbf{O}}$ & $\mathbf{A}[\mathbf{k m}]$ & $\mathbf{N} / \mathbf{k m}^{\mathbf{2}}$ & $\mathbf{m} / \mathbf{k m}^{\mathbf{2}}$ & $\mathbf{C}$ \\
\hline Média & 0,754 & 0,246 & 147,053 & 0,010 & 2,971 & 3,440 & 9,180 & 19,653 & 3313,376 & 1,066 \\
\hline Mediana & 0,763 & 0,237 & 135,032 & 0,009 & 2,975 & 3,510 & 7,932 & 9,631 & 1958,251 & 1,060 \\
\hline Desvio padrão & 0,096 & 0,096 & 49,961 & 0,005 & 0,200 & 0,194 & 5,799 & 24,542 & 3526,984 & 0,037 \\
\hline Mínimo & 0,497 & 0,039 & 76,183 & 0,001 & 2,310 & 2,357 & 2,522 & 0,013 & 4,390 & 1,013 \\
\hline Máximo & 0,961 & 0,503 & 493,909 & 0,031 & 3,383 & 3,581 & 67,878 & 121,975 & 17189,161 & 1,270
\end{tabular}


Tabela 20 - Coeficientes de correlação de Pearson entre as variáveis

\begin{tabular}{ccccccccccc}
\hline & $\mathbf{I}$ & $\mathbf{I} \mathbf{C}$ & $\mathbf{L}$ & $\mathbf{B}_{\mathbf{i}}$ & $\mathbf{K}$ & $\mathbf{H o}$ & $\mathbf{A}$ & $\mathbf{C}$ & $\mathbf{N} / \mathbf{k m}^{\mathbf{2}}$ & $\mathbf{\mathbf { m }} / \mathbf{k m}^{\mathbf{2}}$ \\
\hline $\mathbf{I} \mathbf{o}$ & 1,000 & $-1,000$ & $-0,102$ & 0,221 & $-0,729$ & 0,405 & 0,062 & 0,462 & 0,276 & 0,289 \\
valor-p & 0,000 & 0,000 & 0,075 & 0,000 & 0,000 & 0,000 & 0,284 & 0,000 & 0,000 & 0,000 \\
\hline $\mathbf{I} \mathbf{C}$ & $-1,000$ & 1,000 & 0,102 & $-0,221$ & 0,729 & $-0,405$ & $-0,062$ & $-0,462$ & $-0,276$ & $-0,289$ \\
valor-p & 0,000 & 0,000 & 0,075 & 0,000 & 0,000 & 0,000 & 0,284 & 0,000 & 0,000 & 0,000 \\
\hline $\mathbf{L}$ & $-0,102$ & 0,102 & 1,000 & 0,149 & $-0,049$ & $-0,122$ & 0,537 & 0,542 & $-0,506$ & $-0,495$ \\
valor-p & 0,075 & 0,075 & 0,000 & 0,009 & 0,398 & 0,033 & 0,000 & 0,000 & 0,000 & 0,000 \\
\hline $\mathbf{B}_{\mathbf{i}}$ & 0,221 & $-0,221$ & 0,149 & 1,000 & $-0,317$ & $-0,117$ & $-0,195$ & 0,251 & $-0,056$ & $-0,061$ \\
valor-p & 0,000 & 0,000 & 0,009 & 0,000 & 0,000 & 0,041 & 0,001 & 0,000 & 0,327 & 0,284 \\
\hline $\mathbf{K}$ & $-0,729$ & 0,729 & $-0,049$ & $-0,317$ & 1,000 & $-0,184$ & $-0,003$ & $-0,480$ & $-0,053$ & $-0,064$ \\
valor-p & 0,000 & 0,000 & 0,398 & 0,000 & 0,000 & 0,001 & 0,962 & 0,000 & 0,356 & 0,266 \\
\hline $\mathbf{H o}$ & 0,405 & $-0,405$ & $-0,122$ & $-0,117$ & $-0,184$ & 1,000 & 0,071 & 0,240 & 0,130 & 0,156 \\
valor-p & 0,000 & 0,000 & 0,033 & 0,041 & 0,001 & 0,000 & 0,215 & 0,000 & 0,023 & 0,006 \\
\hline $\mathbf{A}$ & 0,062 & $-0,062$ & 0,537 & $-0,195$ & $-0,003$ & 0,071 & 1,000 & 0,292 & $-0,204$ & $-0,205$ \\
valor-p & 0,284 & 0,284 & 0,000 & 0,001 & 0,962 & 0,215 & 0,000 & 0,000 & 0,000 & 0,000 \\
\hline $\mathbf{C}$ & 0,462 & $-0,462$ & 0,542 & 0,251 & $-0,480$ & 0,240 & 0,292 & 1,000 & $-0,295$ & $-0,282$ \\
valor-p & 0,000 & 0,000 & 0,000 & 0,000 & 0,000 & 0,000 & 0,000 & 0,000 & 0,000 & 0,000 \\
\hline N/km ${ }^{2}$ & 0,276 & $-0,276$ & $-0,506$ & $-0,056$ & $-0,053$ & 0,130 & $-0,204$ & $-0,295$ & 1,000 & 0,989 \\
valor-p & 0,000 & 0,000 & 0,000 & 0,327 & 0,356 & 0,023 & 0,000 & 0,000 & 0,000 & 0,000 \\
\hline m/km² & 0,289 & $-0,289$ & $-0,495$ & $-0,061$ & $-0,064$ & 0,156 & $-0,205$ & $-0,282$ & 0,989 & 1,000 \\
valor-p & 0,000 & 0,000 & 0,000 & 0,284 & 0,266 & 0,006 & 0,000 & 0,000 & 0,000 & 0,000 \\
\hline
\end{tabular}

Fonte: A autora

\subsubsection{Métricas topológicas}

As métricas estritamente topológicas das redes apresentadas no banco de dados são o índice orgânico, o indicador de cruzamento, o grau dos nós e a centralidade de intermediação. Os índices orgânico e de cruzamento são complementares e inversamente proporcionais, e são obtidos a partir dos valores de grau de cada nó da rede. O valor de coeficiente de correlação desses índices com o grau médio dos nós $\left(\left|r\left(I_{0}\right)\right|=\left|r\left(I_{c}\right)\right|=0.729, p=0.000\right)$ foi significativo e era esperado devido à interdependência entre os parâmetros. A Figura 31 mostra os histogramas de distribuição de frequência dos valores de graus para duas cidades com comportamentos diferentes em relação aos índices. 
Figura 31 - Histogramas de distribuição de frequência dos valores de graus dos nós

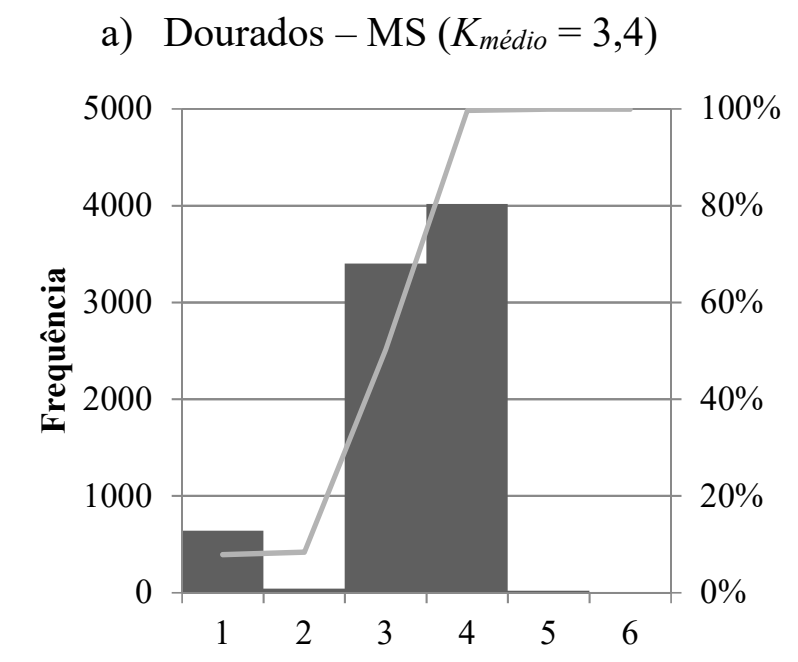

b) Petrópolis $-\mathrm{RJ}\left(K_{\text {médio }}=2,31\right)$

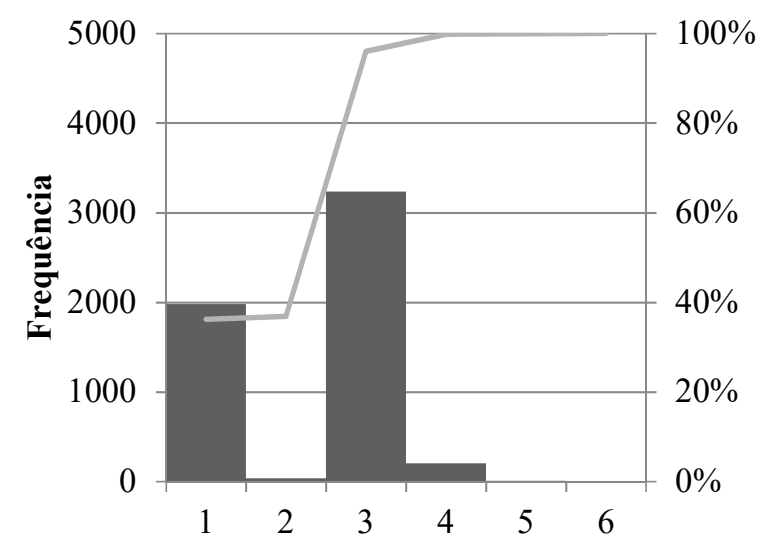

Fonte: A autora

A rede viária de Dourados apresentou uma maior proporção de nós de grau maior igual a 4 que foi praticamente igualada com a quantidade de nós graus 1 e 3, ocasionando equilíbrio entre os índices de cruzamento e orgânico. Já a rede viária de Petrópolis exibiu uma proporção de $96 \%$ nós de grau 1 e 3 contra somente 3\% de nós com grau maior igual a 4 da rede de Dourados. Além disso, os testes não-paramétricos de Qui-Quadrado $\left(\chi^{2}\right)$ e de KolmogorovSmirnov foram utilizados para testar a hipótese nula de que as amostras apresentavam distribuições iguais. Os testes apresentaram estatísticas superiores aos valore críticos, com o valor $p$ igual a zero, ou seja, menor que o nível de significância de 5\%, o que rejeitou a hipótese nula. Os resultados estão dispostos na Tabela 21.

Tabela 21 - Testes não-paramétricos de homogeneidade entre as distribuições de valores de grau dos nós

\begin{tabular}{lrlr}
\hline Kolmogorov Smirnov & 0,458 & $\chi^{2}$ & 16911,25 \\
\hline Kolmogorov Smirnov crítico & 0,02 & $\chi^{2}$ crítico & 36,42 \\
\hline valor-p & 0,00 & valor-p & 0,00 \\
\hline \multicolumn{4}{c}{ Fonte: A autora }
\end{tabular}

As distribuições espaciais dos valores de grau de cada nó destas redes estão representadas na Figura 32 
Figura 32 - Distribuições espaciais de valor de graus dos nós de Dourados e Petrópolis

a) Dourados - MS $\left(K_{\text {médio }}=3,4\right.$, Io $=0,50$ e Ic $\left.=0,50\right)$

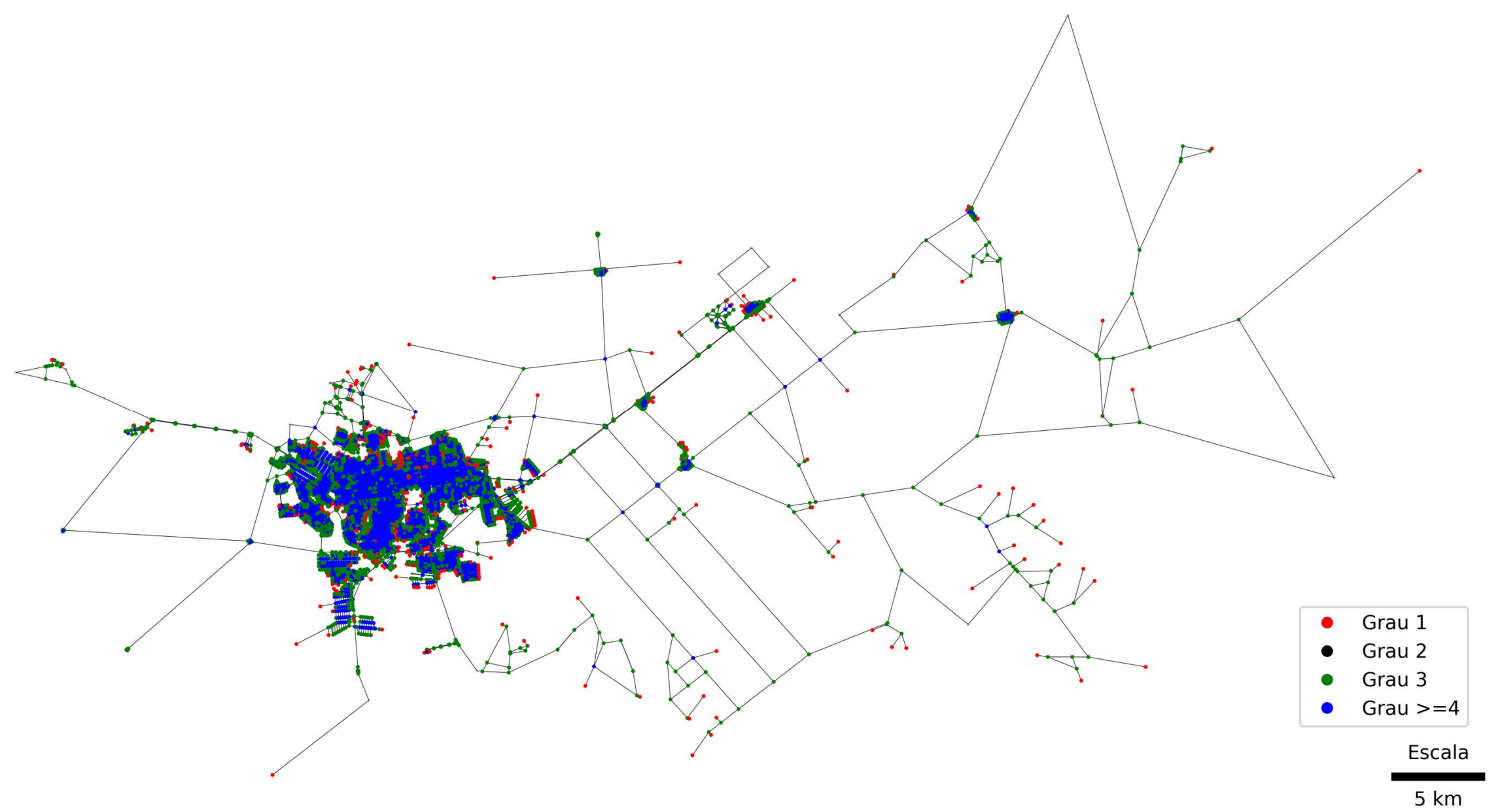


b) Petrópolis $-\mathrm{RJ}\left(K_{\text {médio }}=2,31\right.$, Io $=0,961$ e Ic $\left.=0,039\right)$

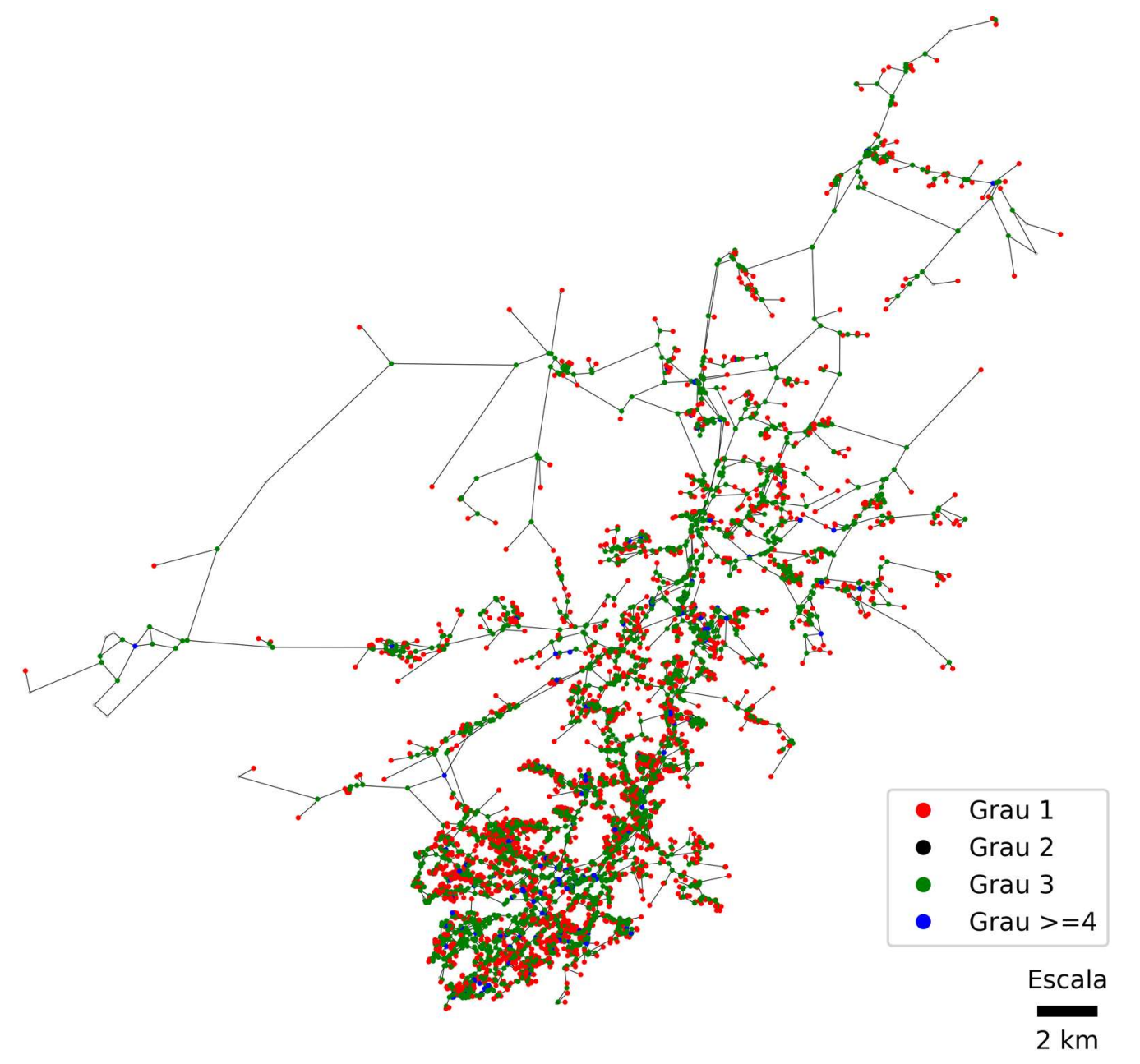

Fonte: A autora 
Vale ressaltar que a rede viária de Dourados (Figura 32a) mostrou uma grande concentração dos nós de cruzamento cercados por nós limites, que formaram uma malha tipo grade. Na rede de Petrópolis, a predominância de nós limites não permitiu a identificação de uma malha cíclica, mas somente de ramos que partem de um eixo principal. Uma avaliação contextualizada da localização dos nós pode indicar a existência de obstáculos nos nós com grau 1 e 3. Córregos, desníveis, rodovias e linhas férreas são exemplos de estruturas que interrompem a malha viária urbana e favorecem a criação de gargalos nos fluxos de deslocamento. Nos casos em questão, as cidades possuem geografias físicas diferentes, enquanto Petrópolis tem o relevo extremamente acidentado, o que pode dificultar a continuidade das vias, Dourados está em um local com topografia plana, mais suscetível à expansão urbana

Malhas do tipo grade tendem a ter mais caminhos redundantes, característica que pode ser medida pelos valores de centralidade de intermediação dos nós da rede. Essa métrica relaciona para cada vértice a quantidade de caminhos mínimos que ele participa e a quantidade total de caminhos mínimos do grafo. Valores altos indicam nós mais importantes, pois mais caminhos mínimos dependem dele. Para Dourados, o valor médio da rede para esta variável foi de 0,005 e para Petrópolis foi de 0,011. Pela análise de correlação entre os valores de $\mathrm{I}_{\mathrm{O}} \mathrm{I}_{\mathrm{C}}$ e Bi, não foi possível perceber uma relação imediata entre as variáveis, pois o módulo do coeficiente de Pearson foi 0,221. Mas é válido ressaltar que os valores de Bi foram obtidos da média de todos os valores de centralidade de intermediação de cada nó da rede, o que não permite conclusões específicas sobre a hierarquia dos nós e ressalta a importância da variável a nível local.

Os histogramas de distribuição de frequência da centralidade de intermediação dos nós de Dourados e de Petrópolis, representados na Figura 33, explicam as diferenças entre os valores de $\mathrm{Bi}$. 
Figura 33 - Histogramas de distribuição de frequência de centralidade de intermediação dos nós

a) Dourados $-\mathrm{MS}(\mathrm{Bi}=0.005)$

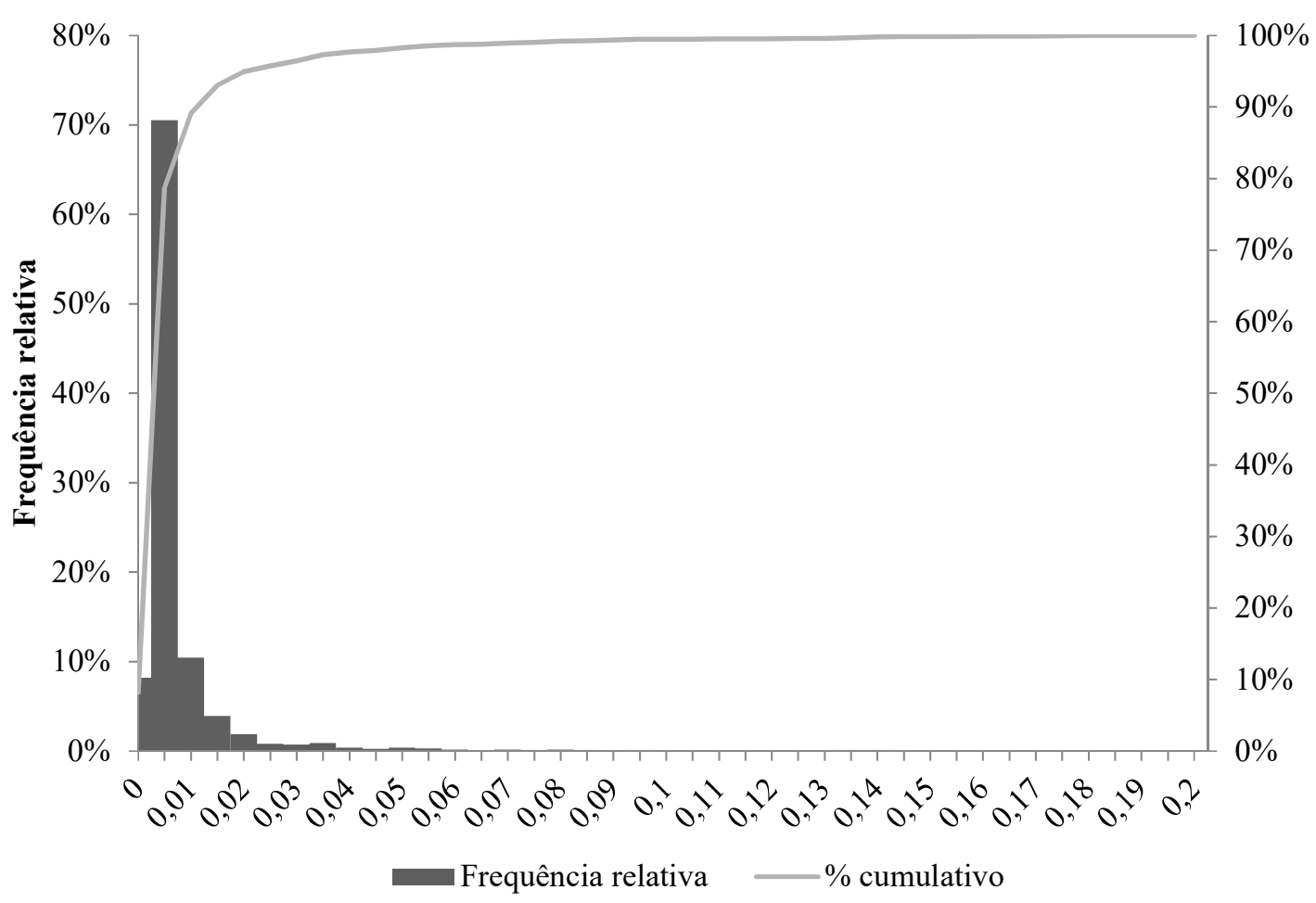

b) Petrópolis - $\mathrm{RJ}(\mathrm{Bi}=0,011)$

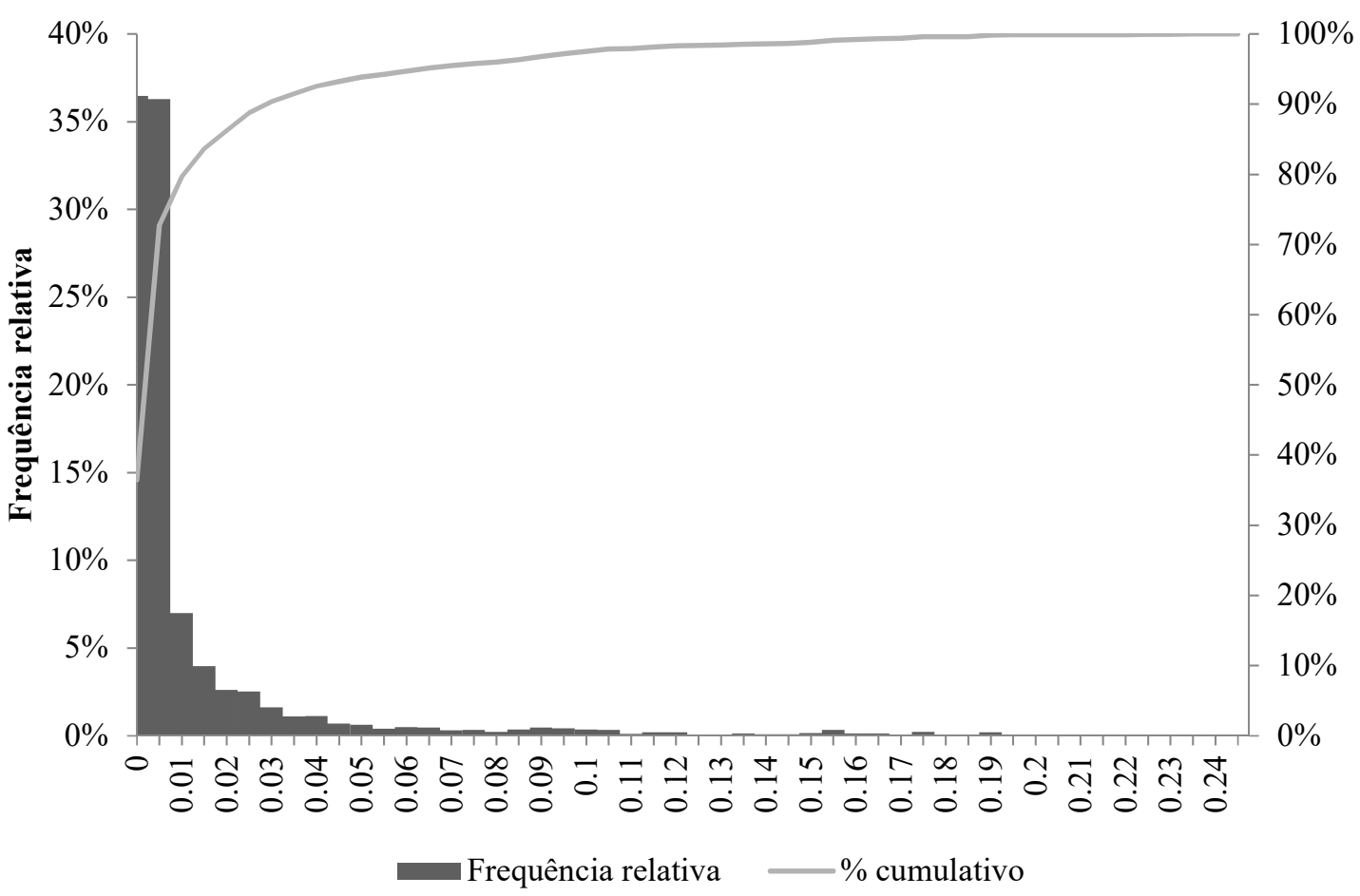

Fonte: A autora 
Pelo histograma da Figura 33-a, cerca de 70\% dos nós de Dourados apresentam centralidade de intermediação entre a faixa de valores de 0,005 e 0,01, enquanto que para Petrópolis esta faixa possui aproximadamente $36 \%$ dos nós. As curvas de frequência acumulada também apontam para uma maior homogeneidade de valores para a cidade de Dourados do que a de Petrópolis. A hipótese nula de que não há diferença entre as distribuições dos valores de centralidade de intermediação entre as duas cidades foi testada pelo teste não-paramétrico Kolmogorov-Smirnov, cujo resultado está na Tabela 22.

Tabela 22 - Teste de Kolmogorov-Smirnov de homogeneidade de distribuições da variável centralidade de intermediação de nós

\begin{tabular}{lr}
\hline Kolmogorov Smirnov & 0,283 \\
\hline Kolmogorov Smirnov crítico & 0,02 \\
\hline valor-p & 0,00 \\
\hline \multicolumn{2}{c}{ Fonte: A autora }
\end{tabular}

A obtenção do valor da estatística superior ao valor crítico rejeita a hipótese. A partir dessas informações foi possível inferir que os nós de Dourados, por serem distribuídos de forma mais concentrada em torno de um valor $(0,01)$ participam de forma mais igual dos caminhos mínimos do sistema viários do que os de Petrópolis, nas respectivas redes. Os nós de Petrópolis foram divididos em basicamente duas categorias de valores de centralidade de intermediação, o que mostrou que existem nós com maior participação em caminhos mínimos do que outros. Uma opção para aprofundar esta análise é avaliar os valores locais em cada nó da centralidade de intermediação através da distribuição espacial destes valores, conforme demonstrado nas imagens da Figura 34. Para representar os nós em uma escala gradativa de cores, os valores de centralidade de intermediação de cada nó foram normalizados. 
Figura 34 - Distribuições espaciais dos valores de centralidade de intermediação de nós das cidades de Dourados e Petrópolis

a) Dourados - MS

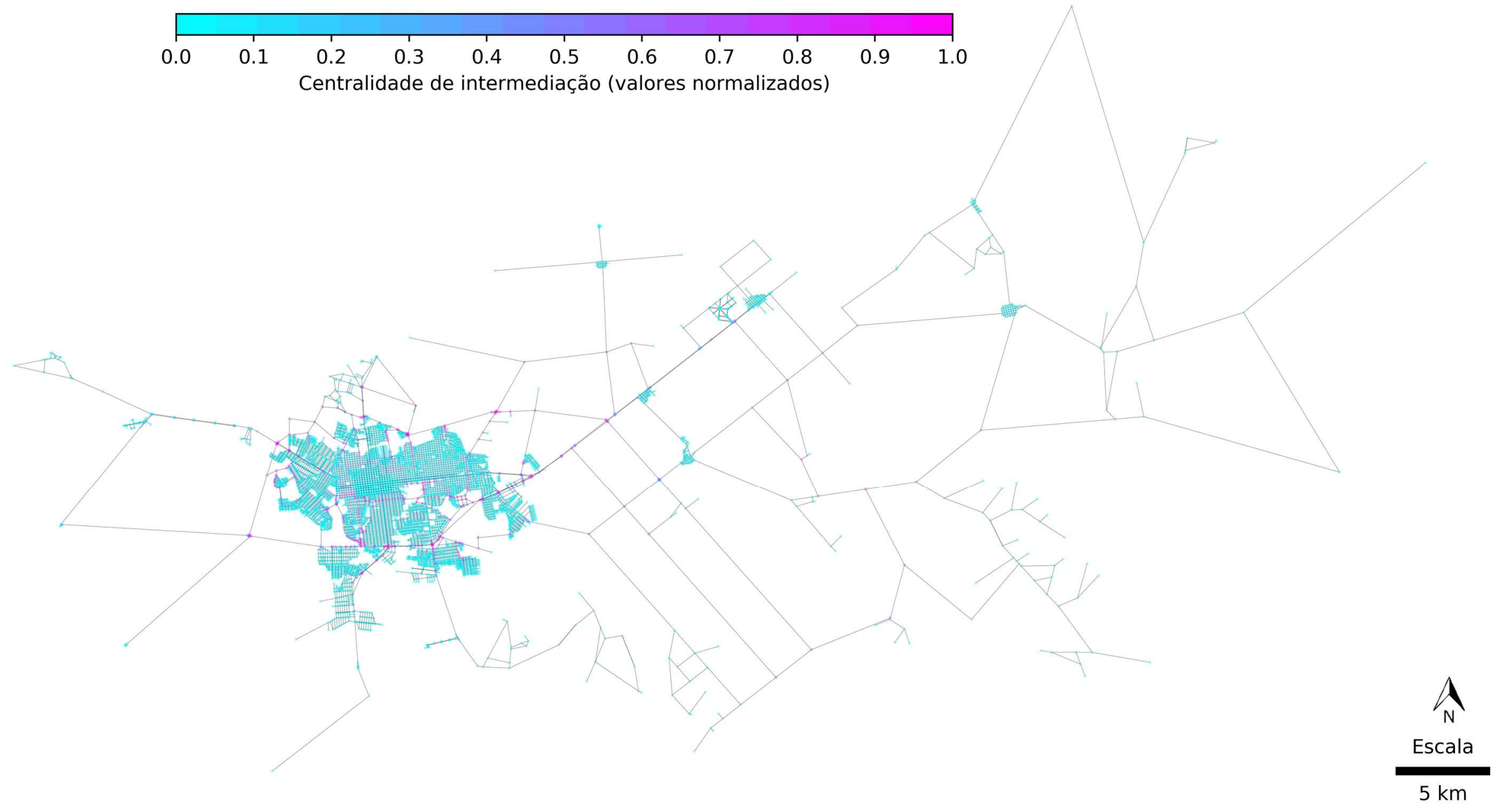

a) Petrópolis - RJ 


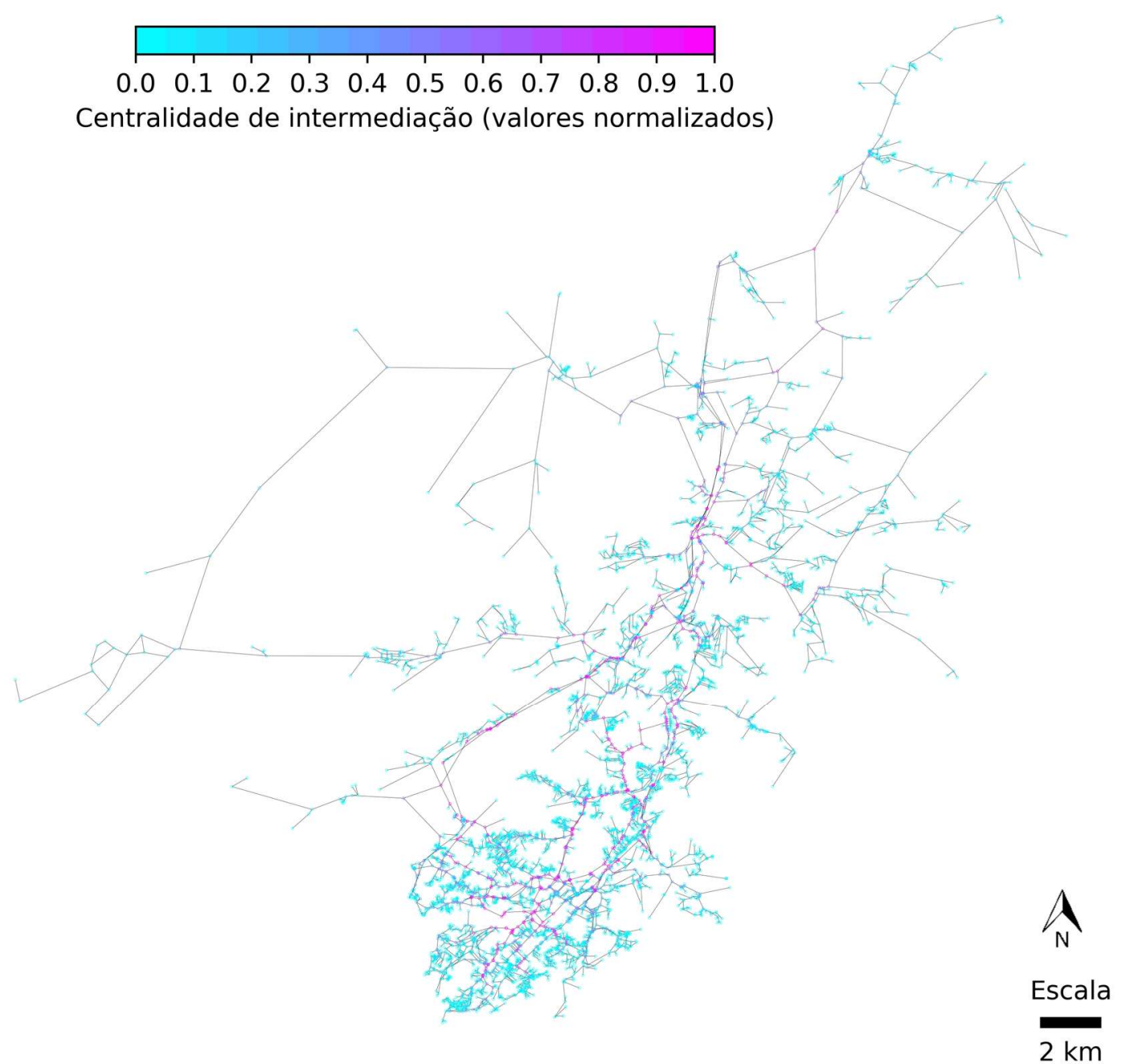

Fonte: A autora 
Na representação de Dourados (Figura 34a) os nós com maiores Bi (tons de rosa) formaram pelo menos 2 eixos paralelos dentro da malha que concentrou nós com grau maior ou igual a 4. Na representação de Petrópolis, os nós com maiores Bi destacaram o eixo com concentração de nós de grau 3. As observações destes casos, mostraram que a topologia com a maior presença de nós de cruzamento favoreceu a homogeneidade da rede em relação à distribuição de caminhos mínimos. Por outro lado, o sistema viário com predominância de nós terminais de entroncamento promoveu a concentração das possibilidades de escoamento do fluxo de movimento em poucas vias.

As sequências formadas pela justaposição de nós com maiores valores de centralidade de intermediação geralmente identificam corredores troncais estruturados em avenidas ou marginais. Estas vias costumam ser as mais conhecidas dos usuários e atraem grande parte do volume de tráfego, por isso é necessário evitar que elas falhem, ou seja, deixem de funcionar dentro do sistema, seja por congestionamento, enchentes, etc. Outra prática que pode aumentar a resiliência viária é a construção de mais corredores, de forma a diminuir os valores de centralidade de intermediação dos já existentes e criar mais opções de rotas.

\subsubsection{Métricas topo-geométricas}

As métricas topo-geométricas captam características definidas pelas relações entre os nós em um contexto espacial. Desta forma, as arestas representam mais que conexões pois recebem informações de extensão e direção. Exemplos deste tipo de métrica são as densidades de elementos por área. Os dados de área foram obtidos do IBGE (2017a) por município e são referentes às regiões internas aos limites administrativos, por isso, os valores mínimos de densidade encontrados no banco de dados foram baixos.

A menor densidade de comprimento de segmentos de rua por área foi encontrada na cidade de Altamira, localizada no Estado do Pará, que em 2010 possuía mais de 70\% da área ocupada por vegetação natural florestal (IBGE, 2013). Já a maior densidade de nós por área foi referente à malha viária da cidade de São Caetano do Sul, na Região Metropolitana de São Paulo. As redes viárias extraídas pela biblioteca OSMnx e os limites administrativos obtidos da base de dados do IBGE estão expressos na Figura 35 juntamente com os dados de área de densidades de elementos por município. 
Figura 35 - Representação de redes viárias e limites administrativos de Altamira e São Caetano do Sul

a) Altamira - PA

Área $=159.153,3 \mathrm{~km}^{2}$

Densidade de nós $=0,023$ nós $/ \mathrm{km}^{2}$

Densidade de arestas $=4,39 \mathrm{~m} / \mathrm{km}^{2}$

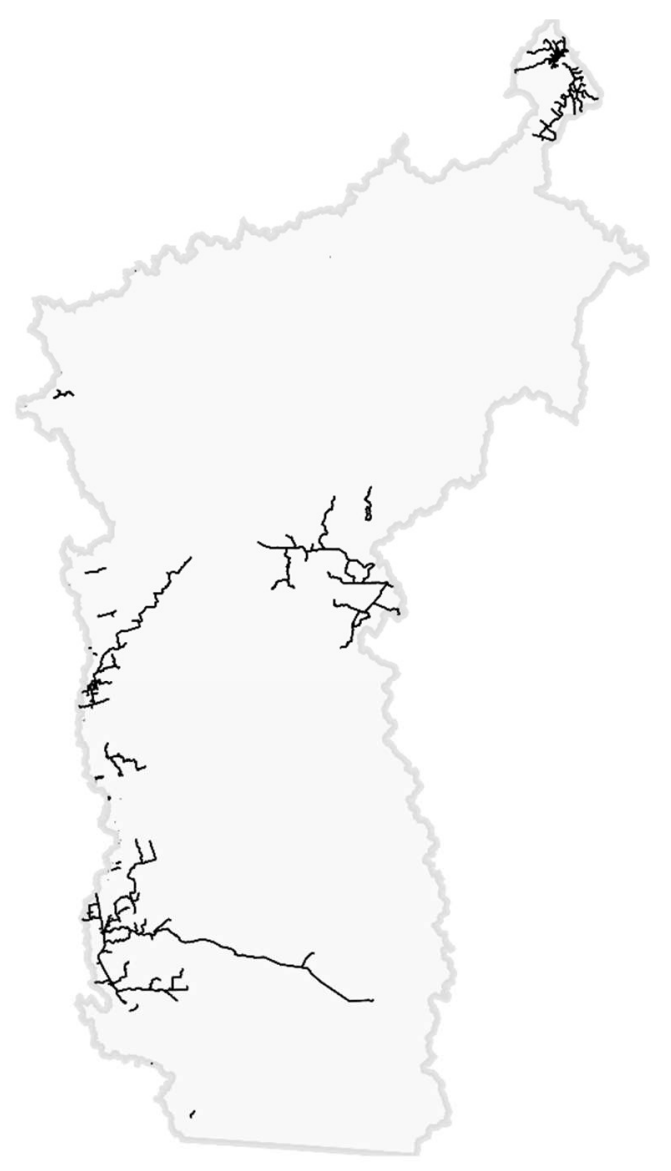

\section{Escala}

150 km b) São Caetano do Sul - SP Área $=15,3 \mathrm{~km}^{2}$

Densidade de nós $=121,975$ nós $/ \mathrm{km}^{2}$

Densidade de arestas $=16782,59 \mathrm{~m} / \mathrm{km}^{2}$

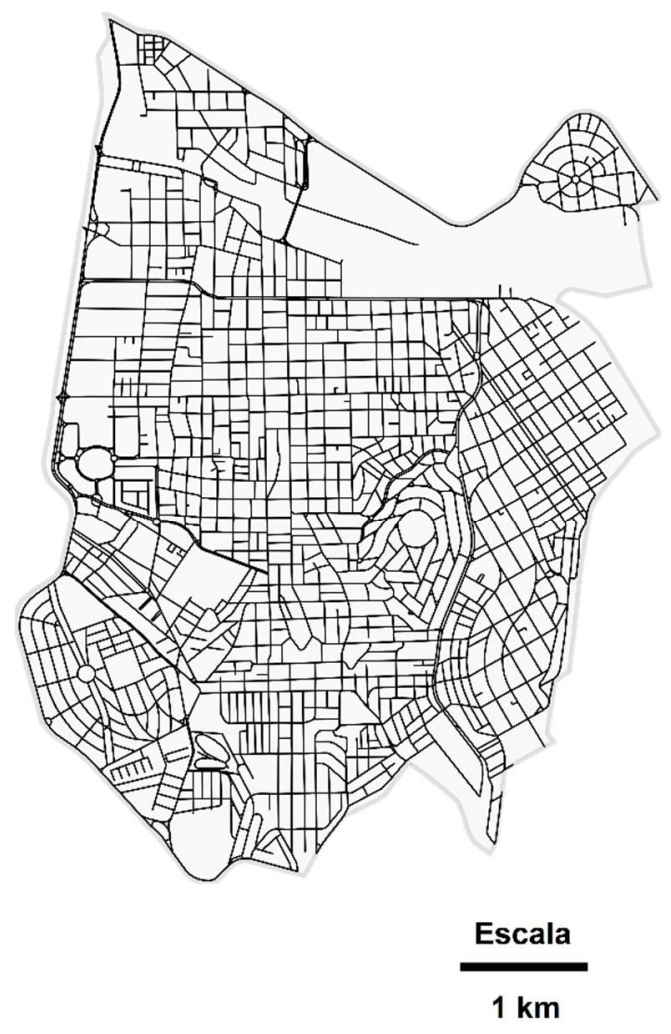

Fonte: A autora

São Caetano do Sul também foi a cidade cuja malha viária apresentou a menor média de acessibilidade global, medida topo-geométrica formada pela média dos valores de acessibilidade local de uma rede. A acessibilidade local foi determinada para cada nó e expressa a distância média entre todos os nós da rede e o nó de referência. O extremo superior do índice foi encontrado no sistema viário de Barreiras, Bahia.

Para investigar as diferenças dessas cidades em termos de acessibilidade, a Figura 36 ilustra as distribuições espaciais dos índices de acessibilidade local de cada cidade. 
Figura 36 - Distribuição espacial dos índices de acessibilidade local de Barreiras e de São Caetano do Sul

a) Barreiras - BA $(\mathrm{A}=67,878 \mathrm{~km})$

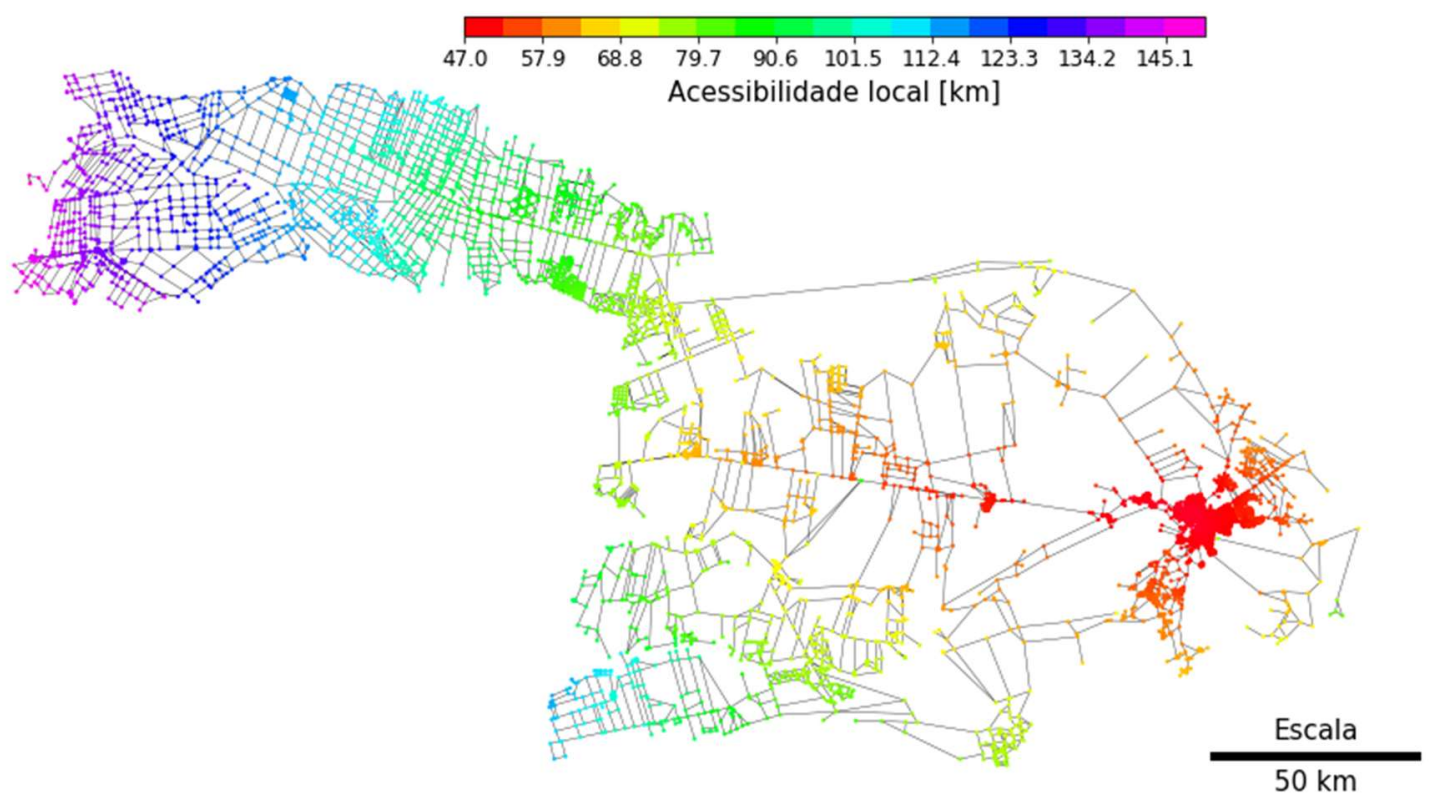

b) São Caetano do Sul - SP $(\mathrm{A}=2,522 \mathrm{~km})$

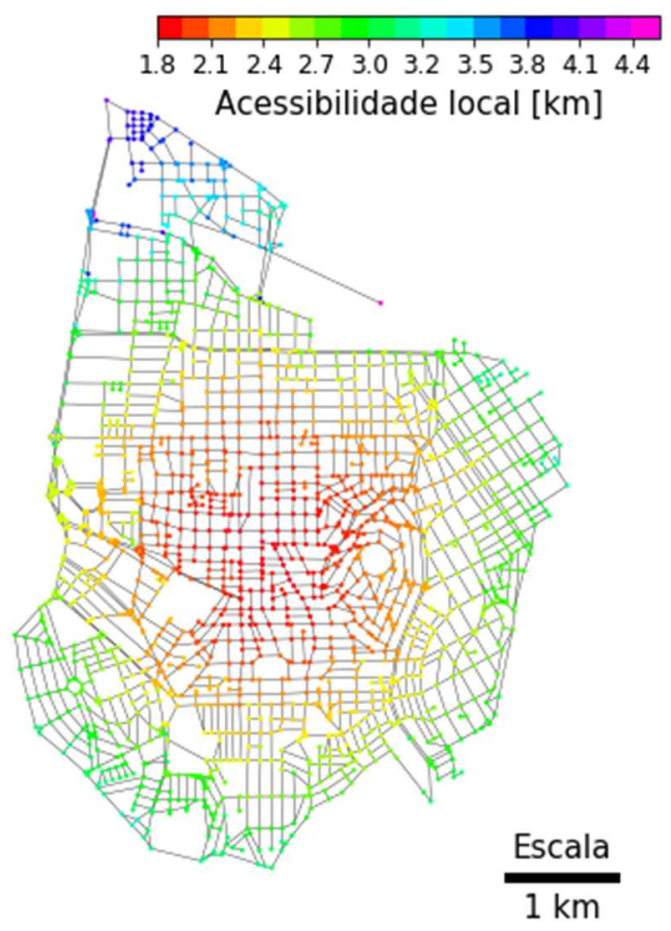

Fonte: A autora

As informações da Figura 36 mostram dois padrões de redes discrepantes. A acessibilidade local de São Caetano do Sul variou entre faixas de valores com menos de $5 \mathrm{~km}$ e aumentou 
da área central para os limites de forma radial. Já a acessibilidade local de Barreiras variou de $46 \mathrm{~km}$ no extremo leste da cidade até $150 \mathrm{~km}$ no extremo oeste. A hipótese nula de igualdade entre as distribuições desta métrica para as cidades de São Caetano do Sul e Barreiras foi rejeitada a partir dos resultados do teste de Kolmogorov - Smirnov (Tabela 23).

Tabela 23 - Teste de Kolmogorov-Smirnov de homogeneidade das distribuições de valores de acessibilidade local

\begin{tabular}{ll}
\hline Kolmogorov Smirnov & 1,00 \\
\hline Kolmogorov Smirnov crítico & 0,03 \\
\hline valor-p & 0,00 \\
\hline \multicolumn{2}{c}{ Fonte: A autora }
\end{tabular}

A avaliação espacial da acessibilidade local permite identificar a localização e a forma das regiões mais afastadas do grafo. A acessibilidade local em São Caetano do Sul evoluiu de forma radial a partir da região central e mostrou um equilíbrio na distribuição da malha viária que permite inferir que a ocupação também ocorre de forma mais homogênea. Esta configuração, mais compacta, favorece o uso de modos de transportes não-motorizados aptos a vencer distâncias menores. Em uma situação extremamente oposta, na rede de Barreiras, a região mais acessível, representada por nós com valores de acessibilidade local entre 47,0 e 57,9 km, foi detectada perto do extremo leste. A expansão da rede praticamente ocorreu no sentido oeste até a divisa com o Estado do Tocantins, mas não de forma densa a ponto de deslocar a região central. O município de Barreiras é um dos 20 maiores produtores agrícolas (IBGE, 2016), o que justifica parte do seu território possuir menor densidade viária.

Como a média de acessibilidade global do banco de dados foi de 9,180 km com desvio padrão de 5,799, é possível afirmar que a cidade de Barreiras é um exemplo atípico de acessibilidade no contexto brasileiro. A Figura 37 mostra os valores do índice em ordem crescente e a Figura 38 mostra o mapa com a distribuição espacial da acessibilidade média por faixa de valores. Além de Barreira, somente Porto Seguro na Bahia e Porto Velho em Rondônia apresentaram índices superiores a $30 \mathrm{~km}$. 
Figura 37 - Índices de acessibilidade global em ordem crescente

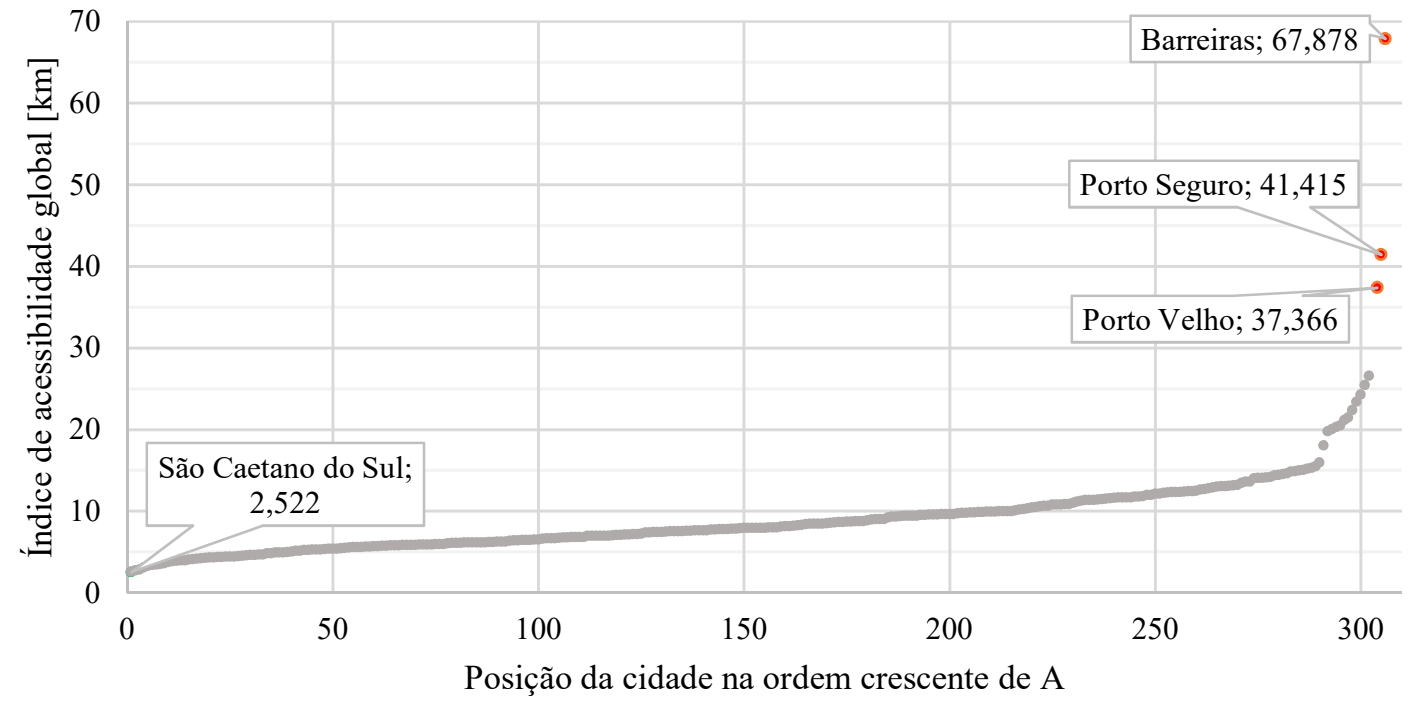

Fonte: A autora

Figura 38 - Acessibilidade média em quilômetros

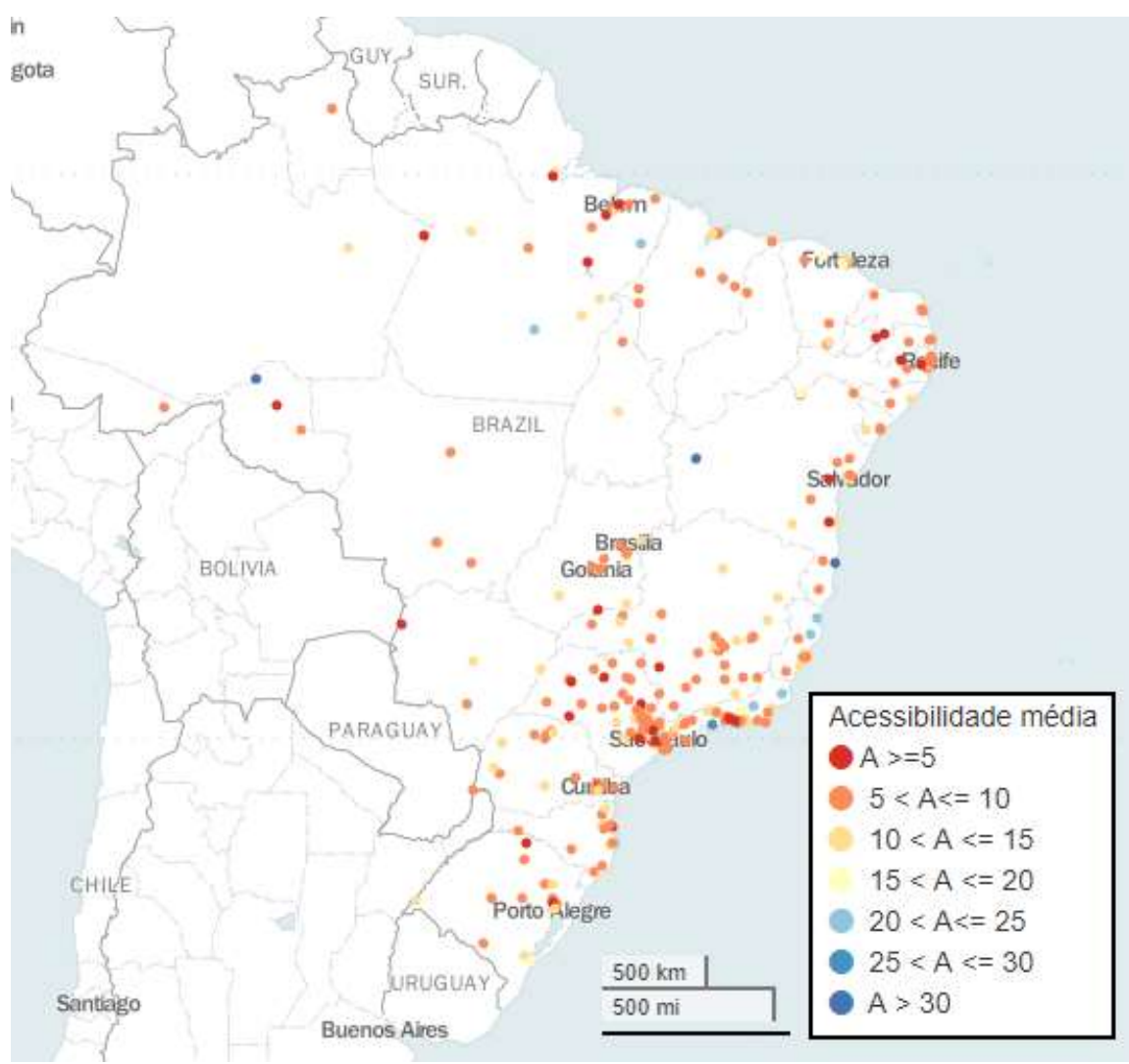

Fonte: A autora

Figura 37 mostra que cerca de $65 \%$ das cidades apresentaram índices de acessibilidade média limitados a $10 \mathrm{~km}$, enquanto em somente $2 \%$ estes valores foram superiores a $25 \mathrm{~km}$. 
Pelo mapa da Figura 38 foi possível detectar as cidades com maiores valores médio de acessibilidade nas regiões Norte e Nordeste e no litoral da região Sudeste, como Angra dos Reis, cuja distribuição dos valores de acessibilidade local está representada na Figura 39.

Figura 39 - Distribuição espacial dos índices de acessibilidade local em Angra dos Reis-RJ

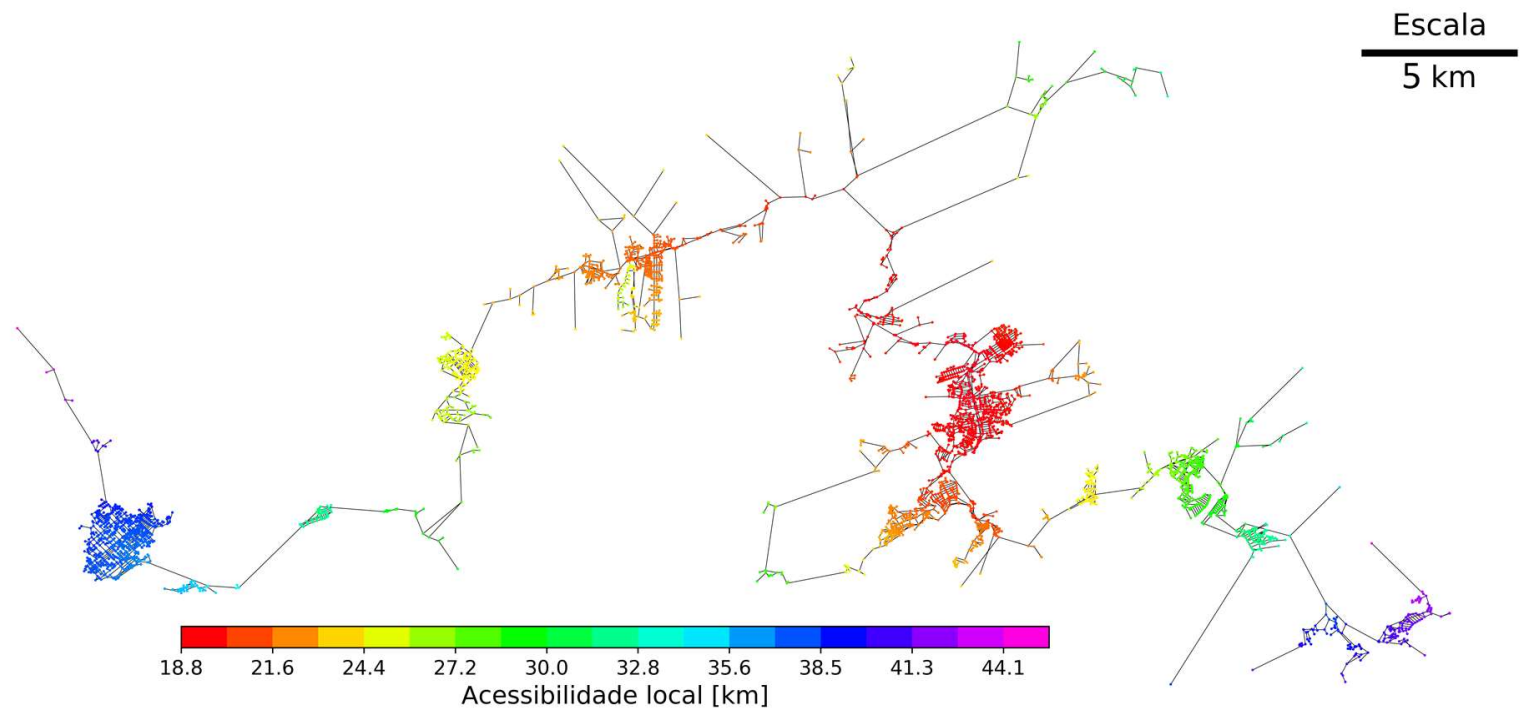

Os altos valores médios de acessibilidade em cidades como Angra dos Reis podem ser justificados pelas limitações geográficas impostas, pelo mar de um lado e pela serra no outro. Além disso, a rede viária foi desenvolvida ao longo do litoral, o que torna os caminhos mais sinuosos e aumentam as distâncias a serem percorridas. Uma opção para diminuição dos índices de acessibilidade local, nestes casos, está na construção de pontes e túneis que aumentem as alternativas de conexão da malha e tornem as rotas mais diretas.

O grau de rotas indiretas avalia a perda de eficiência da malha viária devido aos desvios impostos pela estrutura disponível ou limitantes espaciais como grandes áreas verdes ou de construções. Ou seja, a forma e o tamanho das quadras influenciam o grau de rotas indiretas e isto foi verificado com o alto coeficiente de correlação positivo com o comprimento médio das $\operatorname{arestas}(r=0,542, p=0,000)$ e negativo com o grau dos nós $(r=-0,480, p=0,000)$. O comprimento médio das arestas geralmente representa o tamanho das quadras e o grau dos nós revela a segmentação da malha. Em casos que as malhas são quadriculares, como as curvas são formadas por trechos retilíneos unidos nos nós, a menor quantidade de trechos contribui para que as rotas sejam mais diretas. A regularidade da malha viária também foi quantificada pela métrica entropia de orientação que avalia a variação das direções das arestas. 
A entropia de orientação é uma medida da desordem do grafo obtida a partir da direção de cada aresta. Para esta pesquisa foram consideradas 36 categorias possíveis, ou seja, 36 setores de $10^{\circ}$. Os valores de entropia de orientação dos grafos assumiram valores entre os limites mínimos de 2,357 na rede de Nilópolis e de 3,581 na de Salvador. As representações das redes viárias de Nilópolis e de Salvador e os histogramas polares da distribuição das direções das arestas estão reunidos na Figura 40.

Figura 40 - Representações das redes viárias e respectivos histogramas polares de Nilópolis e Salvador

a) Nilópolis $-\mathrm{RJ}(\mathrm{Ho}=2,357, \mathrm{C}=1,013)$
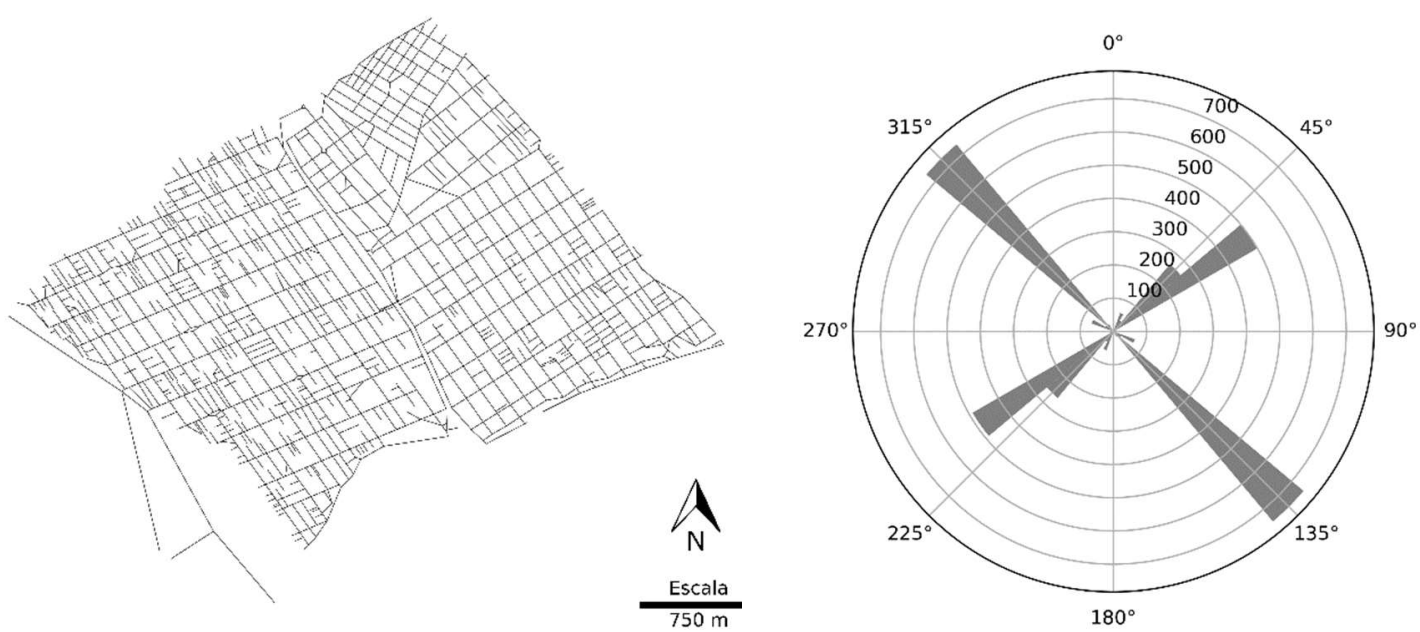

b) Salvador $-\mathrm{BA}(\mathrm{Ho}=3,581, \mathrm{C}=1,092)$
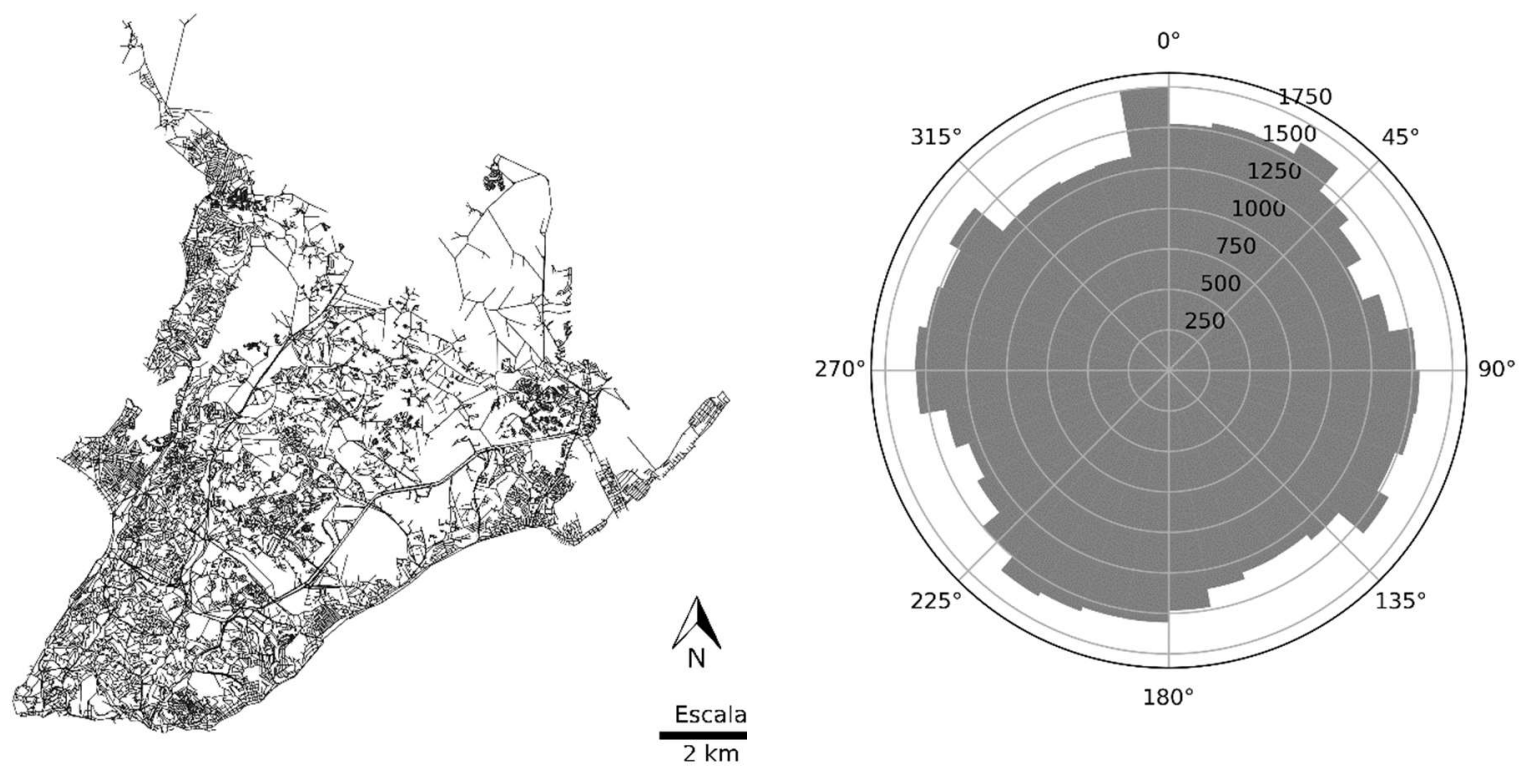

Fonte: A autora 
Pelas imagens é possível perceber a presença de um ordenamento das ruas de Nilópolis nas direções nordeste e noroeste. Já as ruas de Salvador estão dispostas quase que uniformemente em todas as direções, por isso o valor de entropia de orientação próximo do máximo. Este caso pode ser um exemplo de ocorrência alta do fenômeno "colcha de retalhos" (MEDEIROS, 2006), em que diferentes padrões de malha viárias são articulados de forma independente.

Estas cidades também apresentaram graus de rotas indiretas divergentes, enquanto Nilópolis apresentou uma proporção de distâncias mais sinuosas de1,3\% maior do que as em linha reta, Salvador apresentou o valor de 9,2\%. Estes resultados indicaram a menor perda de eficiência na malha mais regular, porém não foi detectado uma correlação forte entre as variáveis entropia de orientação e grau de rotas indiretas no banco de dados.

Estes extremos mostram a existência de diferentes padrões de ordenamentos das malhas viárias coletadas neste estudo. Os ordenamentos foram influenciados por fatores geográficos como relevo, e socioeconômicos como uso do solo e existência de planejamento contínuo da urbanização. A Figura 41 mostra o histograma da distribuição de frequência dos valores de entropia de orientação das 306 cidades coletadas.

Figura 41 - Histograma de distribuição de frequência dos valores de entropia de orientação

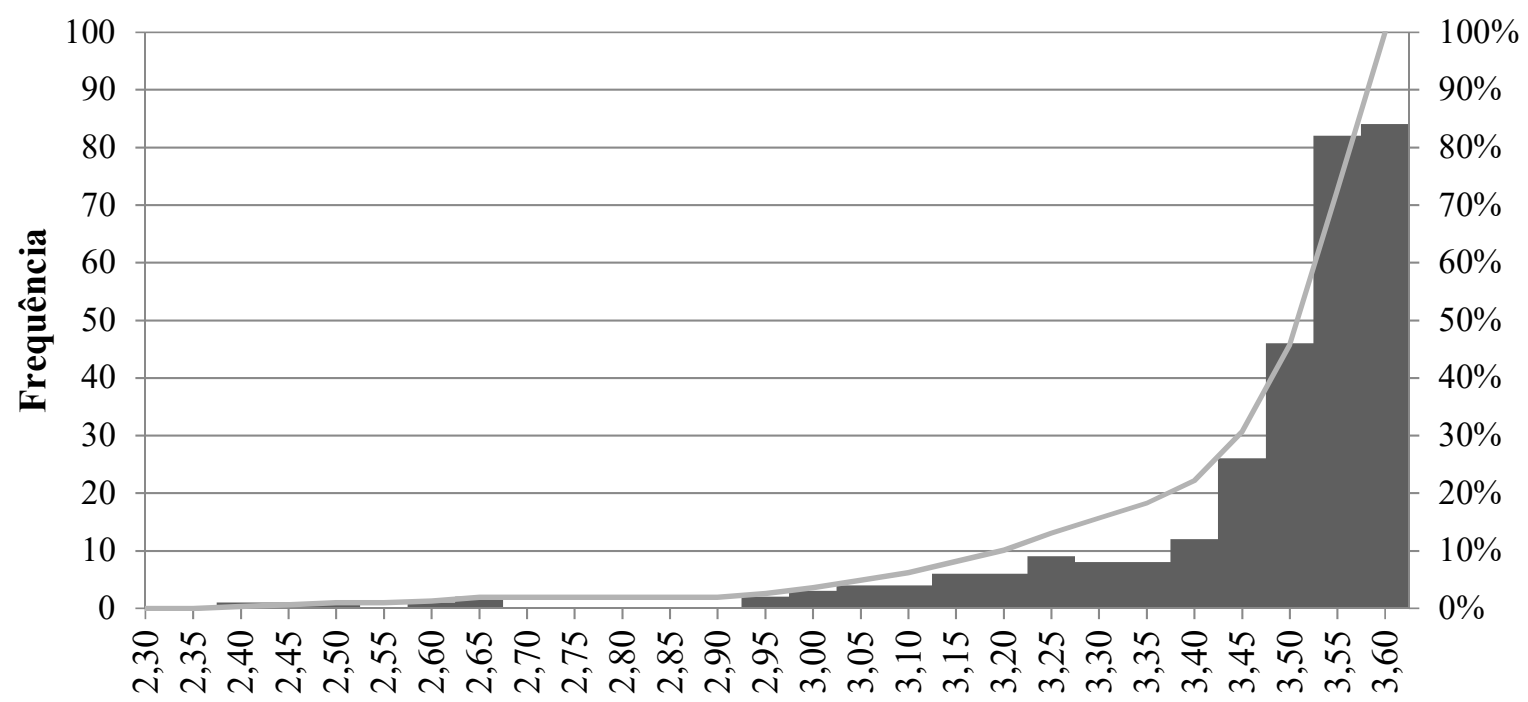

Entropia de orientação

Freqüência — \% cumulativo

Fonte: A autora

A curva de frequência acumulada do histograma da Figura 41 mostra que $45,42 \%$ das cidades coletadas apresentam valores de entropia de orientação inferiores a 3,50, enquanto que 
a outra parcela está concentrada na faixa de valores de $\mathrm{H}_{\mathrm{O}}$ que vai de 3,50 até 3,581. Um exemplo de evolução dos valores de $\mathrm{H}_{\mathrm{O}}$ associados aos respectivos histogramas polares de distribuição da orientação das arestas está exposto na Figura 42.

Figura 42 - Histogramas polares de distribuição de frequência de orientação de ruas

a) Nilópolis - RJ

$(\mathrm{E}=2,357)$

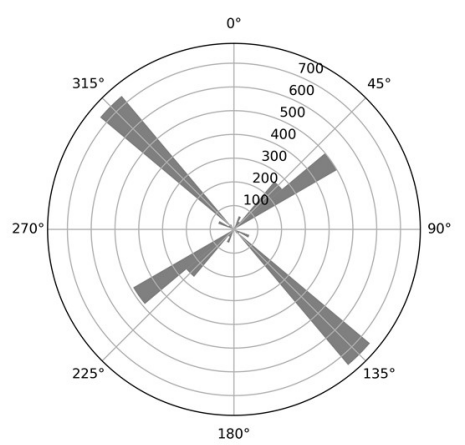

d) Timon - MA

$(\mathrm{E}=3,098)$

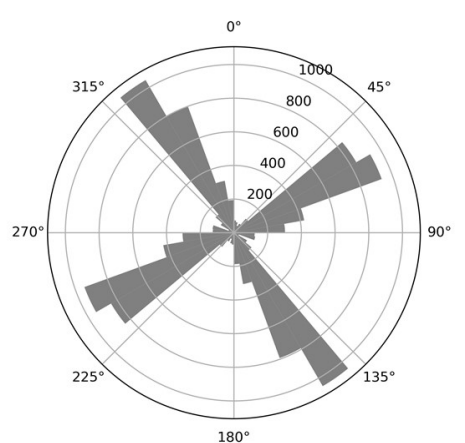

g) Fortaleza - CE $(\mathrm{E}=3,401)$

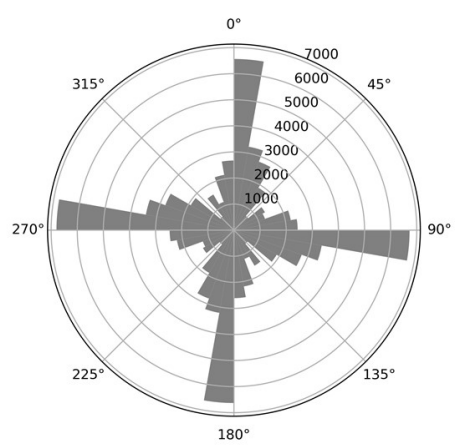
j) Cuiabá - MT $(\mathrm{E}=3,520)$

b) Parintins - AM $(\mathrm{E}=2,906)$

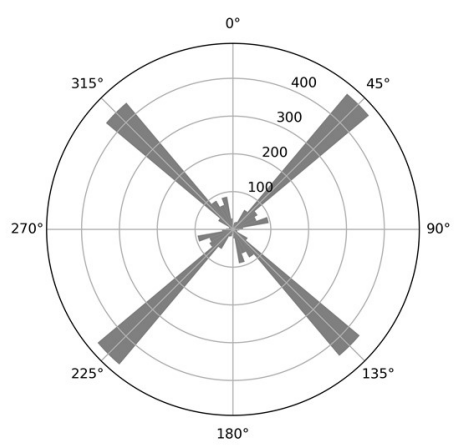

e) Palmas - TO

$(E=3,204)$

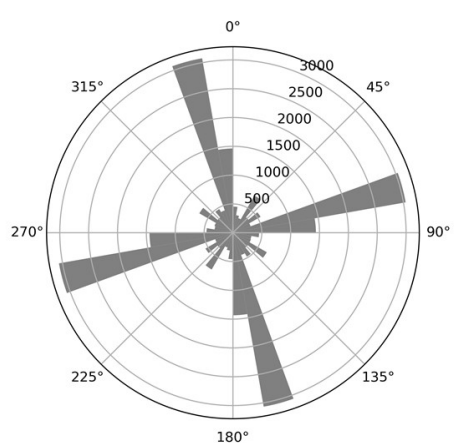

h) Várzea Grande - MT $(E=3,500)$

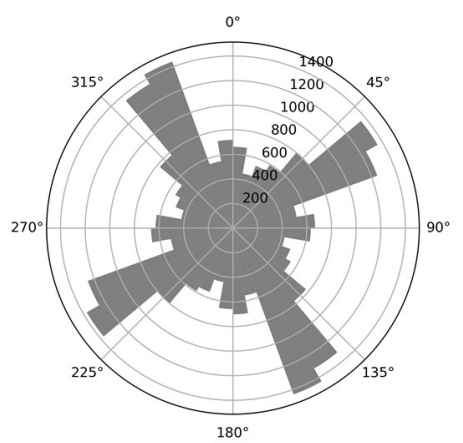

k) Paulo Afonso - BA $(E=3,530)$ c) Paço do Lumiar MA $(E=3,008)$

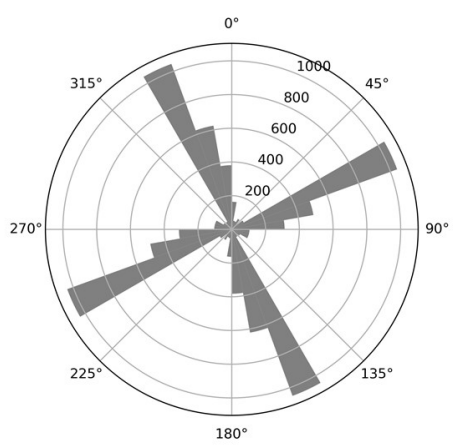

f) Santarém - PA $(E=3,300)$

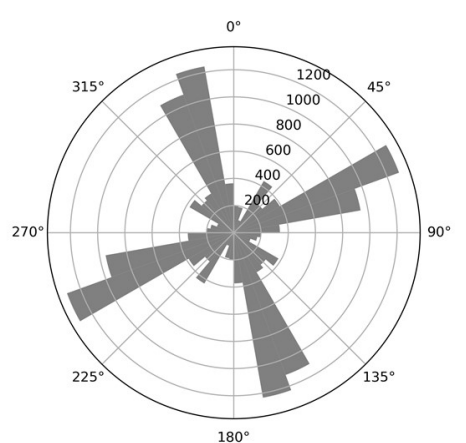

i) Porto Alegre - RS $(E=3,509)$

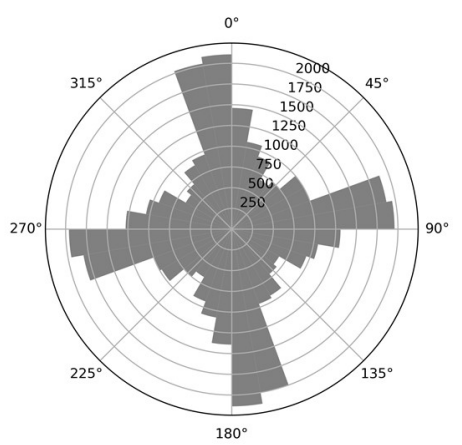

1) Paulista - PE $(E=3,540)$ 


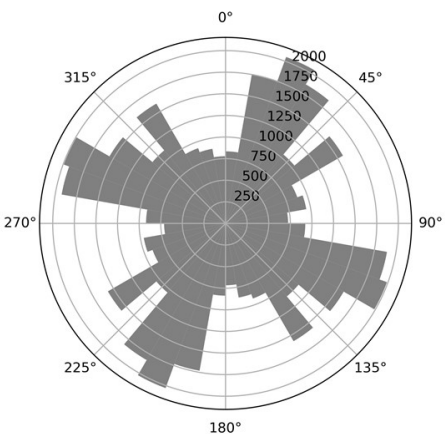

m) Rio Branco - AC $(\mathrm{E}=3,550)$

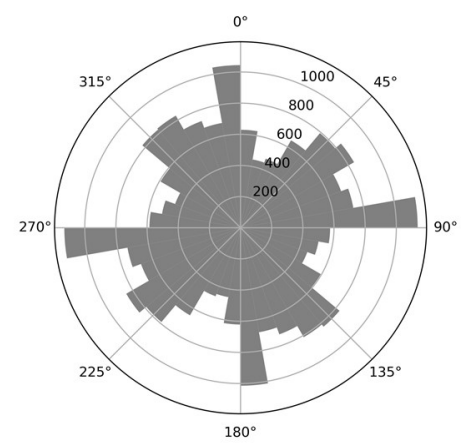

p) São Paulo - SP $(\mathrm{E}=3,579)$

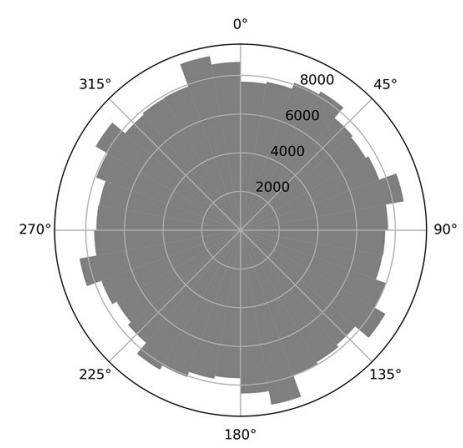

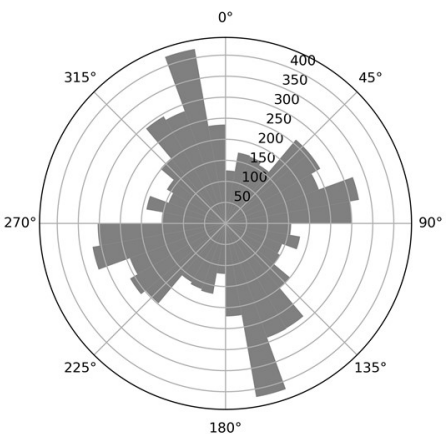

n) Rio de Janeiro -RJ $(\mathrm{E}=3,561)$

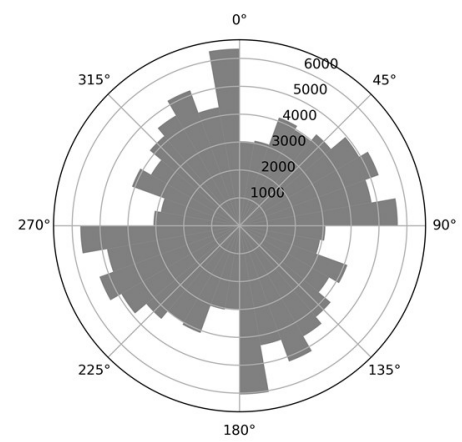

q) Salvador - BA $(3,581)$

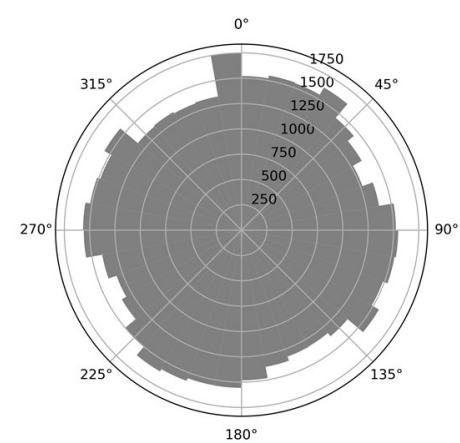

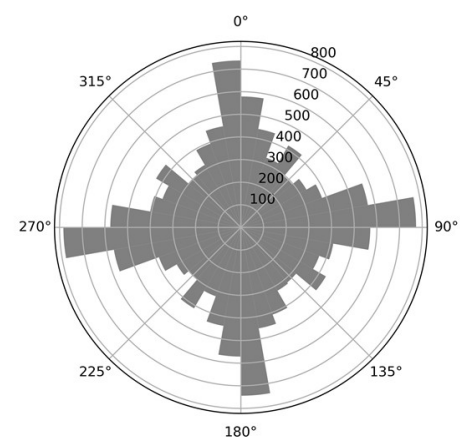

o) Atibaia - SP $(E=3,570)$

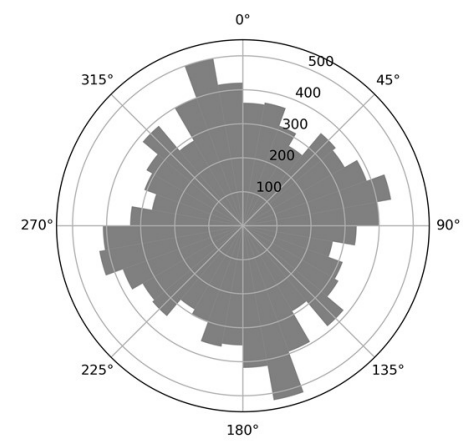

Fonte: A autora

Os histogramas representados na Figura 42 mostram que o banco de dados pode ser separado em dois grandes grupos de acordo com o ordenamento das arestas. O grupo 1, agrega cidades cujas malhas viárias apresentam tendência a ortogonalidade, pode ser identificado por valores de $\mathrm{H}_{\mathrm{O}}$ que variam de 2,357 até 3,499. O grupo 2, de cidades com valores de $\mathrm{H}_{\mathrm{O}}$ no intervalo entre 3,500 e 3,581, apresenta malhas viárias com ruas sem orientação contínua definida.

A predominância de cidades no grupo 2 indica a preponderância de malhas viárias não regulares que podem ser produtos de falta ou descontinuidade de planejamento urbano. Apesar 
de cada caso merecer um estudo detalhado, historicamente as cidades brasileiras foram expandidas de forma desordenada que comprometeram a eficiência do sistema. O gráfico da Figura 43 mostra que a diferença na composição dos grupos está nas cidades de portes maiores, enquanto as cidades médias estão igualmente divididas entre malhas ortogonais e desorientadas.

Figura 43 - Distribuição das cidades por porte e grupo de entropia de orientação

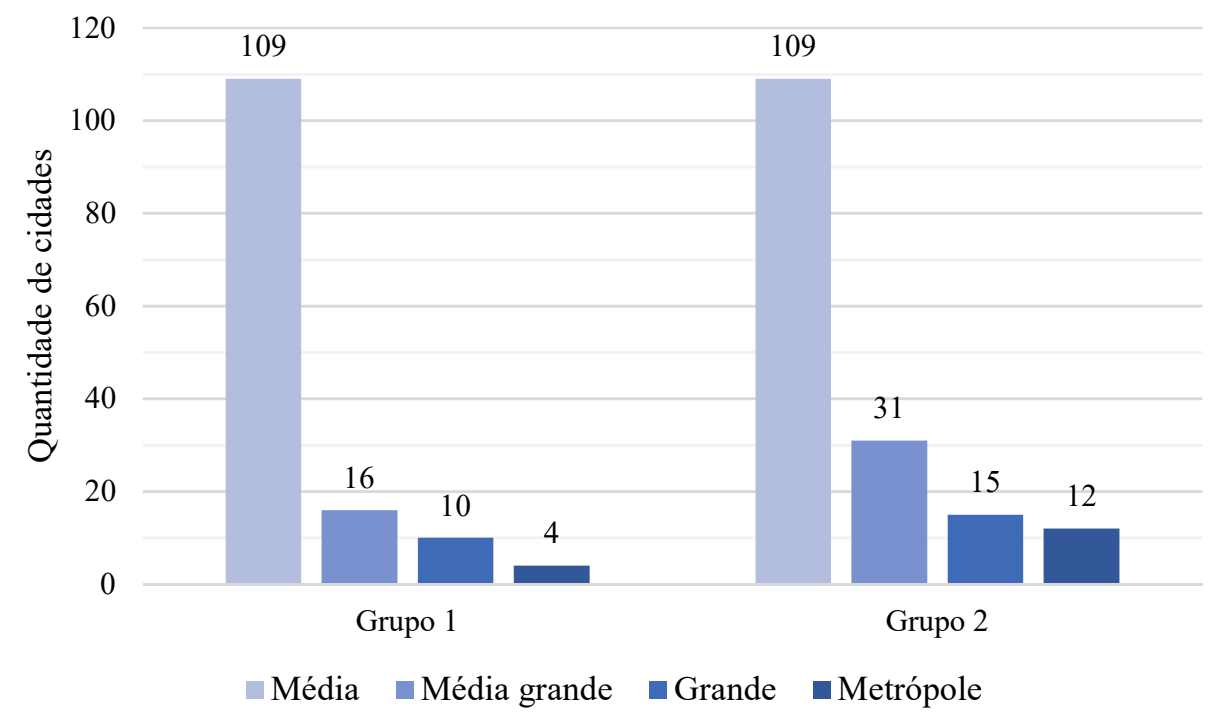

Fonte: A autora

Neste contexto, o desenvolvimento de planos diretores e planos de mobilidade são importantes para viabilizar a expansão dos municípios brasileiros no sentido de tornar as malhas viárias mais eficientes. A observação das políticas de expansão e de estrutura viária adotadas nas cidades do Grupo 1, especialmente as de maiores portes, pode direcionar para que crescimento de cidades menores ocorra de forma ordenada. Esta prática também pode ser adotada para as regiões limítrofes ou não ocupadas das cidades do Grupo 2, de forma a evitar que os níveis de entropia aumentem.

\subsubsection{Relação entre métricas topológicas e topo-geométricas}

Boeing (2019) propôs a hipótese de que cidades com malhas mais regulares tendem a apresentar maior conectividade em termos de grau dos nós e índice de cruzamentos e menor perda de eficiência em rotas indiretas. As estatísticas descritivas destas variáveis foram calculadas de forma separada para cada grupo e estão descritas na Tabela 24. A Figura 44 mostra, através de diagramas de caixa, as distribuições das métricas: índice de cruzamento, indicador orgânico, grau de rotas indiretas e média dos graus dos nós dos dois grupos. 
Tabela 24 - Estatística descritiva das variáveis de cada grupo

\begin{tabular}{lrrrrr}
\hline Grupo 1 & $\mathbf{I}_{\mathbf{O}}$ & $\mathbf{I}_{\mathbf{C}}$ & \multicolumn{1}{c}{ K } & $\mathbf{H}_{\mathbf{O}}$ & \multicolumn{1}{c}{$\mathbf{C}$} \\
\hline Média & 0,706 & 0,294 & 3,040 & 3,311 & 1,055 \\
\hline Mediana & 0,709 & 0,291 & 3,049 & 3,403 & 1,047 \\
\hline Desvio padrão & 0,086 & 0,086 & 0,186 & 0,227 & 0,027 \\
\hline Contagem & 139 & 139 & 139 & 139 & 139 \\
\hline Grupo 2 & $\mathbf{I}_{\mathbf{O}}$ & $\mathbf{I}_{\mathbf{C}}$ & $\mathbf{K}$ & $\mathbf{H}_{\mathbf{O}}$ & $\mathbf{C}$ \\
\hline Média & 0,794 & 0,206 & 2,928 & 3,547 & 1,076 \\
\hline Mediana & 0,805 & 0,195 & 2,906 & 3,550 & 1,069 \\
\hline Desvio padrão & 0,086 & 0,086 & 0,261 & 0,023 & 0,041 \\
\hline Contagem & 167 & 167 & 167 & 167 & 167 \\
\hline \multicolumn{5}{c}{ Fonte: A autora } \\
\end{tabular}

Figura 44 - Diagramas de caixa de $\mathrm{I}_{\mathrm{C}}, \mathrm{I}_{\mathrm{O}}, \mathrm{C}$ e $\mathrm{K}$ dos grupos 1 e 2

a) Índice de cruzamentos

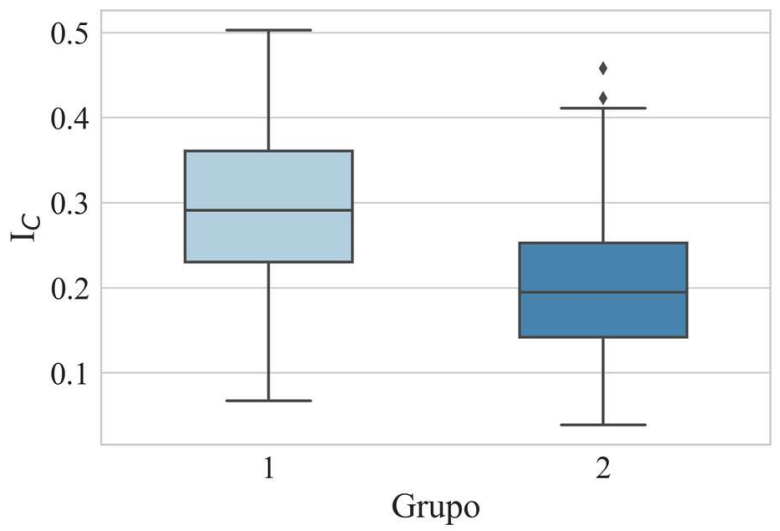

c) Grau de rotas indiretas

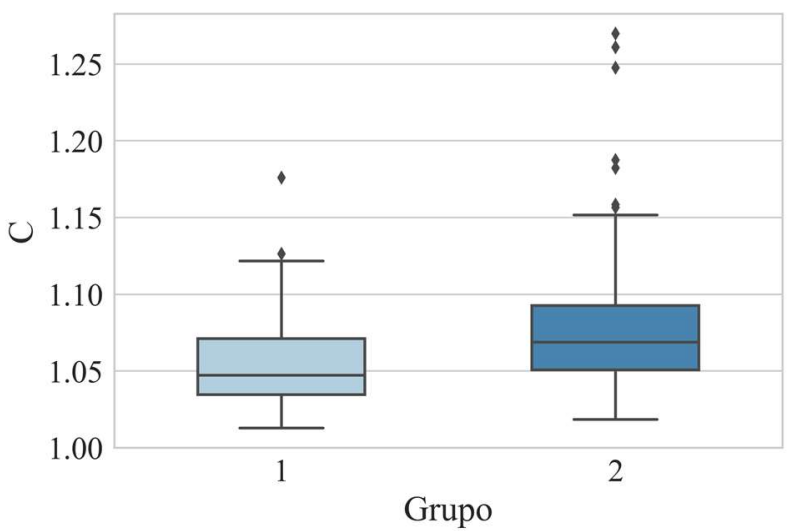

b) Indicador orgânico

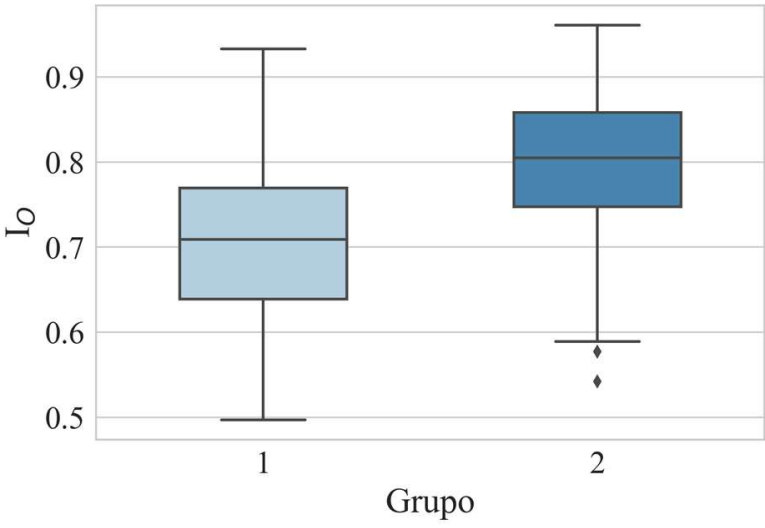

d) Média dos graus

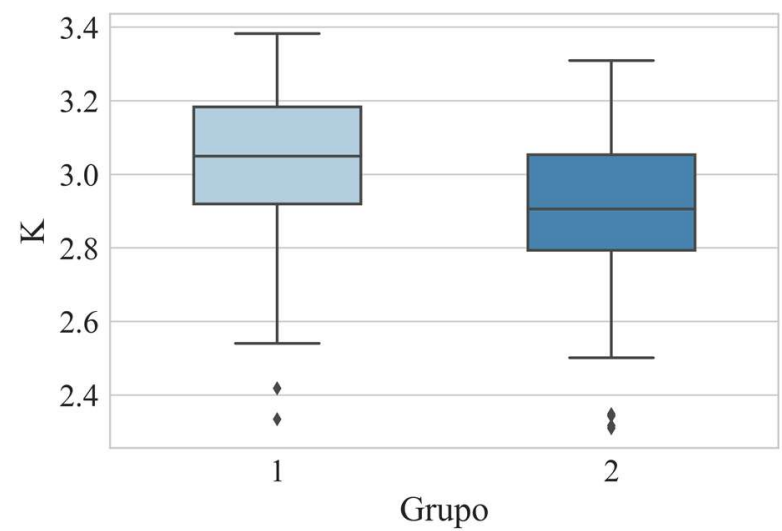

Fonte: A autora

Os diagramas de caixa da Figura 44 mostram que o grupo 1, formado por cidades com $H_{\mathrm{O}}$ menores que 3,50, possui maiores valores de média de grau dos nós, maior proporção de nós de cruzamento, menor de nós de entroncamento e menos desvios das rotas em linha reta do 
que o grupo 2. Buscando corroborar a hipótese de Boeing (2019) para o caso de cidades brasileiras, foram realizados testes não-paramétricos de Mann - Whitney para as variáveis de cada grupo. O teste de Mann - Whitney verifica a hipótese de igualdade entre medianas das variáveis de amostras independentes com base no ranking das variáveis tomando as amostras em conjunto. A Tabela 25 traz os resultados obtidos a partir dos rankings das variáveis testadas na hipótese.

Tabela 25 - Classificações do Teste de Mann - Whitney

\section{Classificações}

\begin{tabular}{|c|c|c|c|c|}
\hline \multicolumn{2}{|c|}{ Grupo } & \multirow{2}{*}{$\begin{array}{l}\mathbf{N} \\
139\end{array}$} & \multirow{2}{*}{$\begin{array}{r}\text { Postos de média } \\
108,44\end{array}$} & \multirow{2}{*}{$\begin{array}{r}\text { Soma de Classificações } \\
15073,00\end{array}$} \\
\hline & 1 & & & \\
\hline $\mathbf{I}_{\mathbf{O}}$ & 2 & 167 & 191,01 & 31898,00 \\
\hline \multirow{2}{*}{$\mathbf{I}_{\mathbf{C}}$} & 1 & 139 & 198,56 & 27600,00 \\
\hline & 2 & 167 & 115,99 & 19371,00 \\
\hline \multirow{2}{*}{$\mathbf{H}_{\mathbf{O}}$} & 1 & 139 & 70,00 & 9730,00 \\
\hline & 2 & 167 & 223,00 & 37241,00 \\
\hline \multirow{2}{*}{$\mathrm{C}$} & 1 & 139 & 123,73 & 17198,00 \\
\hline & 2 & 167 & 178,28 & 29773,00 \\
\hline \multirow{2}{*}{$\mathbf{K}$} & 1 & 139 & 184,32 & 25620,00 \\
\hline & 2 & 167 & 127,85 & 21351,00 \\
\hline
\end{tabular}

A tabela de classificações permitiu comparar para cada variável, qual grupo apresentou os maiores valores, a partir da verificação da coluna de "Soma de Classificações". Desta forma, a hipótese foi corroborada pois as variáveis índice de cruzamento e grau médio dos nós foram maiores no grupo 1, que reuniu as cidades com malha mais ordenada. Por outro lado, as variáveis índice de cruzamento e grau de rotas indiretas foram menores neste grupo. Os resultados estatísticos do Teste de Mann-Whitney estão na Tabela 26.

Tabela 26 - Resultados do Teste de Mann - Whitney

\begin{tabular}{llrrr}
\hline & IO & \multicolumn{1}{l}{ IC } & \multicolumn{1}{l}{ C } & \multicolumn{1}{l}{ K } \\
\hline U de Mann-Whitney & 5,343 & 5,343 & 7,468 & 7,323 \\
\hline $\mathbf{Z}$ & $-8,128$ & $-8,128$ & $-5,370$ & $-5,558$ \\
\hline p-valor &, 000 &, 000 &, 000 &, 000 \\
\hline \multicolumn{4}{l}{ Fonte: A autora } &
\end{tabular}

Para um nível de significância de 5\%, foi rejeitada a hipótese nula de igualdade entre as medianas para todas as variáveis. 


\subsection{Considerações finais}

O banco de dados criado buscou retratar a variação do comportamento das cidades brasileiras em termos de configuração do sistema viário. Foram selecionadas cidades com população superior a 100 mil habitantes o que totalizou 310 cidades. Porém três cidades não possuíam dados cadastrados na plataforma OSM e por isso não foram incluídas no banco. Brasília também foi excluída devido ao tamanho da rede envolvida nos limites administrativos cadastrados na plataforma.

Para as 306 cidades restantes foram construídos diferentes tipos de grafos para o cálculo das métricas propostas para caracterizar as configurações das malhas viárias urbanas brasileiras. Com isso, as variáveis não ficaram restritas à representação da estrutura física do sistema viário, através do grafo não direcionado, mas envolveram também aspectos comportamentais definidos por limitações do movimento na rede, através do grafo direcionado.

As análises deste trabalho trataram cada parâmetro de forma isolada e conjunta com intuito de avaliar a conectividade, acessibilidade, eficiência e resiliência das redes viárias. Por fim, a hipótese de Boeing (2019) de que cidades com malhas mais regulares tendem a apresentar maior conectividade em termos de grau dos nós e índice de cruzamentos e menor perda de eficiência em rotas indiretas foi corroborada para os casos brasileiros. 


\section{CONCLUSÕES E RECOMENDAÇÕES FUTURAS}

Esta dissertação está inserida na área de configuração urbana, com foco em sistemas viários segregados por cidades, abordada do ponto de vista de Engenharia e Planejamento de Transportes. O objetivo desta pesquisa foi explorar dados viários urbanos disponíveis na web e extrair parâmetros aplicáveis em análise de morfologia de cidades. A intenção do trabalho foi corroborar a hipótese: A qualidade adquirida por dados de mapas colaborativos permite sua utilização em análises da morfologia urbana a nível local. A finalidade do estudo foi alcançada para mais de 300 cidades brasileiras de diferentes portes com o uso das informações geográficas voluntárias disponíveis no mapa colaborativo do Projeto OpenStreetMap. As metas propostas foram cumpridas à medida que foram realizadas as etapas do método.

A revisão bibliográfica buscou a contextualização teórica envolvida na hipótese do trabalho e a atualização do cenário atual das ferramentas utilizadas. Base desta pesquisa, a Teoria dos Grafos tem amplo suporte conceitual na matemática e é aplicada no contexto de sistemas de transportes em diversos exemplos na literatura. A ampla gama de disciplinas que analisam a forma urbana com modelos de grafos criou uma dificuldade no entendimento do tema. Questões acerca de como modelar os grafos, quais dados utilizar, quais métricas calcular e seus significados apresentaram diversas respostas que precisaram ser filtradas. Conforme explicam Marshall et al. (2018), cada abordagem tem seu objetivo e suas limitações, compreendê-los é necessário para verificar o quanto são respondidas perguntas diferentes ou, por outro lado, criadas confusões. Marshall et al. (2018) encorajam a consolidação teórica do campo para clarear a relação entre os diferentes tipos de modelos adotados para representar as redes viárias.

Para comunicar com outras áreas, foi realizada uma pesquisa dos conceitos da Teoria de Grafos aplicados a cada situação. Os trabalhos de Lima, Silva e Van der Waerden (2003) e Boeing (2019) direcionaram este estudo. Por isso, este trabalho abordou a malha viária modelada como um grafo do tipo primal, não planar e simplificado. As métricas oriundas da teoria foram interpretadas segundo propriedades da morfologia urbana como orientação das ruas, resiliência da rede a falhas, acessibilidade e eficiência

Uma questão do trabalho envolveu a avaliação da disponibilidade de dados de sistemas viários urbanos disponíveis da web. Estudos anteriores com a mesma abordagem ficavam restritos à disponibilização desses dados em formato de malhas digitais por prefeituras, departamentos de trânsito, com casos de confecção manual dos mapas. Essas situações limitavam a 
reprodução e a ampliação dos estudos que também encontravam obstáculos quanto a atualização das informações frente às alterações na rede real. Uma solução surgiu com os mapas colaborativos de dados abertos, como o Projeto OpenStreetMap. Assim, a proposta deste trabalho para ultrapassar o obstáculo de ausência de dados foi utilizar informações geográficas voluntárias de malhas viárias urbanas, de forma estruturada e em larga escala.

Para o cumprimento desta meta, foram investigadas soluções computacionais consolidadas. A utilização das informações geográficas voluntárias inspirou o desenvolvimento de diversas ferramentas, entre elas, a utilizada neste trabalho, a biblioteca OSMnx. Este pacote de ferramentas criado por Boeing (2016) permite a aquisição, análise e visualização dos dados do Projeto $O S M$ em forma de grafos, de forma rápida, automática e consistente. Além disso, a OSMnx foi escrita em linguagem Python e disponibilizada de forma gratuita com código aberto. Outro aspecto está no suporte oferecido pela comunidade que é ampliado devido à integração da biblioteca OSMnx com outras criadas há mais tempo. Como o objeto de estudo deste trabalho foi redes viárias urbanas, as funções da biblioteca descritas neste trabalho focaram na extração destas informações. Outra vantagem desta ferramenta foi a facilitação da manipulação dos grafos, como por exemplo a geração das versões direcionadas, não direcionadas e conexas.

Os dados obtidos por informações geográficas voluntárias foram comparados com os do estudo de Lima, Silva e Van der Waerden realizado em 2003, antes do surgimento do OpenStreetMap. A comparação foi realizada sobre os cálculos de uma métrica de acessibilidade global por separação espacial para 8 cidades brasileiras e 3 estrangeiras, com o intuito de verificar a proximidade dos exemplos nacionais em relação aos modelos norte-americanos e europeu. Além da fonte de dados, outra distinção estava nas ferramentas de análise de rede utilizadas. Enquanto este trabalho utilizou as bibliotecas OSMnx e Networkx, aquele utilizou um software de Sistemas de Informações Geográficas.

As malhas viárias extraídas do OSM foram modeladas em forma de grafos primais, não direcionados, não planares e simplificados. Em todos os casos, os grafos gerados continham mais nós dos que as malhas do estudo de referência (47\%), o que indicou um maior detalhamento do sistema e/ou uma consequência do crescimento das redes. Parte deste aumento na quantidade de elementos também ocorreu devido à delimitação da área utilizada no trabalho de 2003, que foi limitado à mancha urbana. Em 9 das 11 cidades foi detectado um aumento médio de $29 \%$ do índice de acessibilidade global (E), uma sugestão de que ocorreu o fenômeno de “espalhamento" nestes casos. Uma das exceções foi a cidade de Bauru que, apesar de manter a quantidade de nós quase constante em relação ao estudo de 2003, apresentou uma diminuição 
no índice E que pode ter sido efeito da expansão das ligações internas da rede. A representante europeia Eindhoven foi a outra cidade com comportamento destoante, apresentou um crescimento de $22 \%$ na quantidade de nós em face de um aumento de somente $6 \%$ do índice E. Uma explicação para esta situação estaria no aumento da compacidade da rede em detrimento da expansão que pode ter ocorrido devido a uma maior densidade populacional na cidade europeia, em relação aos outros casos avaliados

Lima, Silva e Van der Waerden (2003) compararam os índices de acessibilidade global das redes reais com os calculados para redes fictícias circulares, adotadas como modelos ideais de compacidade. Os resultados desta parte mostraram que as cidades brasileiras avaliadas continuam em um patamar intermediário de compacidade entre os "padrões" europeu e norte-americanos. Desta forma, foi possível utilizar os dados do OSM para avaliar os mesmos parâmetros do trabalho de 2003. Após esta etapa, a pesquisa foi direcionada para a exploração da base de dados para cidades brasileiras, o que resultou em um banco de dados com 306 elementos.

O banco de dados gerado neste trabalho buscou retratar a variação do comportamento das cidades brasileiras em termos de configuração do sistema viário. Apesar de representar somente $5,5 \%$ dos municípios do país, os componentes do banco de dados concentram $56 \%$ da população nacional. Dificuldades de obtenção de dados foram detectadas em três cidades com porte médio (Campo Largo-PR, Ourinhos-SP e Tailândia-PA) e uma metrópole (Brasília - DF). As configurações das malhas viárias urbanas brasileiras foram caracterizadas por métricas topológicas e topo-geométricas. Com isso, as variáveis não ficaram restritas à representação da estrutura física do sistema viário, mas envolveram também aspectos comportamentais definidos por limitações do movimento na rede.

As análises deste trabalho trataram cada parâmetro de forma isolada e conjunta. As primeiras métricas avaliadas foram o indicador orgânico, o índice de cruzamento e o grau dos nós que medem a conectividade topológica da rede. Para exemplificar as informações que estes valores podem fornecer, foram analisados os casos pontuais que apresentaram o maior equilíbrio e a maior discrepância entre Io e IC. Como complementação desta avaliação, os valores médios de centralidade de intermediação (Bi) foram avaliados para as mesmas cidades. Apesar do baixo valor dos coeficientes de correlação de Pearson entre $\mathrm{I}_{\mathrm{O}}$ e $\mathrm{I}_{\mathrm{C}}$ com $\mathrm{Bi}$, as distribuições de frequência e espacial da métrica a nível local mostroaram diferença entre as configurações viárias das duas cidades (Dourados e Petrópolis) em termos de conectividade e resiliência da rede. A rede com maior proporção de nós com grau 1 e 3, característicos de entroncamentos e ruas sem saída, apresentou maior heterogeneidade de distribuição dos caminhos mínimos na 
malha formada por estes vértices. Esta característica foi utilizada no Plano de Mobilidade de Manaus para identificar desvios de rotas que sobrecarregavam trechos de eixos viários com fluxos desnecessários (MANAUS, 2015).

As análises das métricas topo-geométricas iniciaram com as medidas de densidade de elementos dos grafos dentro da área delimitada pelo IBGE para cada município. Nesta ocasião foram demonstradas as razões das discrepâncias entre Altamira e São Caetano do Sul, representantes de regiões distintas do país. Altamira, no estado do Pará, uma das maiores cidades brasileiras, apresentou a menor densidade de segmentos de rua por quilômetro quadrado devido a existência de grandes reservas ambientais em seu território. Já na região metropolitana de São Paulo, está São Caetano do Sul, com a maior densidade de interseções por área, resultado da intensa urbanização a qual a cidade foi sujeita.

São Caetano do Sul também foi a cidade com menor índice de acessibilidade global, média da acessibilidade local, que é a distância de um nó para todos os outros nós da rede. $\mathrm{O}$ coeficiente de correlação entre as densidades dos elementos e o índice de acessibilidade global também foi baixo $(-0,205)$, o que levou à análise da distribuição espacial da acessibilidade local dos nós. Como comparação, também foi avaliada a cidade com maior índice de acessibilidade global, Barreiras na Bahia. Esta posição foi justificada pela existência de rede conectando os extremos do limite deste município que abarca uma área de mais de 7 mil km². Na verificação do comportamento do índice de acessibilidade global, foi possível perceber que Barreiras, junto com Porto Seguro e Porto Velho foram elementos atípicos dentro do banco de dados, pois cerca de $98 \%$ das cidades avaliadas apresentaram índice de acessibilidade global abaixo de $20 \mathrm{~km}$.

A maior correlação da acessibilidade global ocorreu em relação ao comprimento médio das arestas, parâmetro indicativo do tamanho dos quarteirões. Esta medida variou de 76,18 até 493,91 metros. Segundo Hajrasouliha e Yin (2015) arestas com valores baixos de comprimento médio e organizadas em forma de grade estimulam o aumento de caminhadas e de viagens por motivos não laborais. A forma da malha também foi avaliada quanto à eficiência de integração entre os nós com os parâmetros de grau de rotas indiretas e entropia de orientação.

A orientação das ruas foi avaliada pela entropia de orientação associada ao histograma polar e permitiu a divisão das cidades em dois grupos com padrões distintos. O grupo 1 reuniu cidades com $\mathrm{H}_{\mathrm{O}}$ menor que 3,5, que demonstraram predominância de ruas ortogonais entre si o que caracterizou uma forma de grade. O grupo 2, representado por cerca de $55 \%$ do banco de dados, apresentou valores de Ho maiores que 3,5 e malhas compostas por diferentes tipos de 
ordenamento, o que podem ser indicativos de falta ou descontinuidade de um planejamento da expansão urbana. Como afirmou Medeiros, (2006), as malhas viárias das cidades brasileiras, mesmo quando apresentam certo grau de planejamento e regulação, são compostas de variadas grelhas sem uma articulação efetiva. Com a separação das cidades nos dois grupos, foi possível corroborar a hipótese de Boeing (2019) de que cidades com malhas mais regulares apresentam maior conectividade em termos de grau dos nós e índice de cruzamentos e menos perda de eficiência em rotas indiretas .

As sugestões para os trabalhos futuros podem ser divididas de acordo com os resultados apresentados nos capítulos 4 e 5 . A continuidade da verificação da qualidade dos dados de mapas colaborativos pode avaliar a adoção de outras formas de malha viária como padrão ideal de compacidade. No trabalho de Lima, Silva e Van der Waerden (2003), foi adotado o padrão circular com quadras de $100 \times 100$ metros. Com as técnicas atuais, é possível testar outros tamanhos de quadra para o mesmo padrão ou verificar outros padrões, como o radial por exemplo. Outra recomendação no contexto desse trabalho é computar a acessibilidade e a compacidade das porções urbanas e rurais das malhas viárias, de forma separada. Essa análise pode fornecer informações sobre a velocidade e a dimensão do espalhamento da mancha urbana. Além disso, devido ao alcance da plataforma de mapa colaborativo e à praticidade das ferramentas utilizadas no método deste trabalho, é possível reproduzir o estudo de forma a produzir uma série histórica de dados.

Em relação ao banco de dados de municípios brasileiros, a primeira sugestão para trabalhos futuros é a exploração do potencial dos dados em uma identificação de padrões viários. Esta identificação pode guiar os planejadores para adotarem ações urbanísticas que foram aplicadas em sistemas viários semelhantes. Outra recomendação é a composição de métricas, como a entropia de orientação, de forma ponderada por quantidade de arestas. Esse estudo pode ser feito com o intuito de comparar as cidades com outras do mesmo tamanho. O tamanho do banco de dados também pode ser ampliado tanto na quantidade de cidades quanto na de variáveis, com o uso das ferramentas apresentadas. Uma outra sugestão, decorrente da teoria do movimento natural da sintaxe espacial é utilizar o banco de dados para fomentar pesquisas como foco em redes urbanas e análises espaço-temporal, adicionando informações como volume de tráfego. 


\section{REFERÊNCIAS}

ALBERT, R.; BARABÁSI, A.-L. Statistical mechanics of complex networks. Reviews of Modern Physics, v. 74, n. 1, p. 47-97, 30 jan. 2002.

ALLEN, W. B.; LIU, D.; SINGER, S. Accesibility measures of U.S. metropolitan areas. Transportation Research Part B: Methodological, v. 27, n. 6, p. 439-449, dez. 1993.

ARSANJANI, J. J. et al. OpenStreetMap in GIScience. Cham: Springer International Publishing, 2015. (Lecture Notes in Geoinformation and Cartography).

BARRON, C.; NEIS, P.; ZIPF, A. A Comprehensive Framework for Intrinsic OpenStreetMap Quality Analysis. Transactions in GIS, v. 18, n. 6, p. 877-895, dez. 2014.

BHAT, C. et al. Development of Urban Accessibility Index: Literature Review. Centro de Pesquisa em Transportes, Universidade do Texas, 2000.

BOEING, G. A multi-scale analysis of 27,000 urban street networks: Every US city, town, urbanized area, and Zillow neighborhood. Environment and Planning B: Urban Analytics and City Science, 8 ago. 2018a.

Documentação da biblioteca OSMnx. Disponível em: $<$ https://osmnx.readthedocs.io/en/stable/>, 2016.

. OSMnx: New methods for acquiring, constructing, analyzing, and visualizing complex street networks. Computers, Environment and Urban Systems, v. 65, p. 126-139, set. 2017.

. Planarity and street network representation in urban form analysis.

Environment and Planning B: Urban Analytics and City Science, n. Novembro, 2018b. Disponível em: <http://journals.sagepub.com/doi/10.1177/2399808318802941>.

. Urban Spatial Order: Street Network Orientation, Configuration, and Entropy. SSRN Electronic Journal, p. 1-20, fev. 2019.

BOndy, J. A.; MURTY, U. S. R. Graph Theory with Applications. Londres: Macmillan, 1976. v. 290.

BRASIL. Decreto-lei no 243, de 28 de fevereiro de 1967. Fixa as Diretrizes e Bases da Cartografi Brasileira e dá outras providências. Disponível em: $<$ http://www.planalto.gov.br/ccivil_03/Decreto-Lei/1965-1988/Del0243.htm>. 
BRAVO, J. V. M. et al. A Compatibilidade dos metadados disponíveis em sistemas VGI com perfil de metadados empregado na Infraestruturua Nacional de Dados Espacial do Brasil (INDE-BR). Boletim de Ciências Geodésicas, v. 21, n. 3, p. 465-483, set. 2015.

BUHL, J. et al. Topological patterns in street networks of self-organized urban settlements. European Physical Journal B, v. 49, n. 4, p. 513-522, 2006.

CAMBOIM, S.; BRAVO, J.; SLUTER, C. An Investigation into the Completeness of, and the Updates to, OpenStreetMap Data in a Heterogeneous Area in Brazil. ISPRS International Journal of Geo-Information, v. 4, n. 3, p. 1366-1388, 2015.

CARDILLO, A. et al. Structural properties of planar graphs of urban street patterns. Physical Review E, v. 73, n. 6, p. 066107, jun. 2006.

CHAPOLA, R. O que é o plano nacional de logística. E do que precisa para funcionar. Nexo Jornal, jul. 2018. Disponível em: $<$ https://www.nexojornal.com.br/expresso/2018/07/07/O-que-é-o-plano-nacional-delogística.-E-do-que-precisa-para-funcionar>.

COSTA, L. da F. et al. Analyzing and modeling real-world phenomena with complex networks: a survey of applications. Advances in Physics, v. 60, n. 3, p. 329-412, jun. 2011. Disponível em: <http://www.tandfonline.com/doi/abs/10.1080/00018732.2011.572452>.

COURTAT, T.; GLOAGUEN, C.; DOUADY, S. Mathematics and morphogenesis of cities: A geometrical approach. Physical Review E, v. 83, n. 3, 11 mar. 2011.

CRUCITTI, P.; LATORA, V.; PORTA, S. Centrality in networks of urban streets. Chaos: An Interdisciplinary Journal of Nonlinear Science, v. 16, n. 1, mar. 2006.

DINGIL, A. E. et al. Transport indicator analysis and comparison of 151 urban areas, based on open source data. European Transport Research Review, v. 10, n. 2, p. 58, jun. 2018 .

DUPUY, G.; STRANSKY, V. Cities and highway networks in Europe. Journal of Transport Geography, v. 4, n. 2, p. 107-121, jun. 1996.

EPL, Empresa de Planejamento e Logística S.A. Rede Georreferenciada. Disponível em: <https://www.epl.gov.br/rede-georeferenciada $>$.

FOUNDATION, O. OpenStreetMap Foundation. Disponível em: $<$ https://wiki.osmfoundation.org/wiki/Main_Page $>$. 
FOUNDATION, P. S. Python Package Index - PyPi. Disponível em: $<$ https://pypi.org/>.

The Python Tutorial. Disponível em: <https://docs.python.org/3/tutorial/>.

GERVASONI, L. et al. Calculating spatial urban sprawl indices using open data. 2017, Adelaide, Austrália, 2017.

GOODCHILD, M. F. Editorial: Citizens as Voluntary Sensors: Spatial Data Infrastructure in the World of Web 2.0. International Journal of Spatial Data Infrastructures Research, v. 2, p. 24-32, 2007.

HAGBERG, A. A.; SCHULT, D. A.; SWART, P. J. Exploring network ntructure, nynamics, and nunction using NetworkX. 2008, Pasadena, CA USA: [s.n.], 2008. p. 11-15.

HAJRASOULIHA, A.; YIN, L. The impact of street network connectivity on pedestrian volume. Urban Studies, v. 52, n. 13, p. 2483-2497, out. 2015.

HAKLAY, M. How good is volunteered geographical information? A comparative study of OpenStreetMap and ordnance survey datasets. Environment and Planning B: Planning and Design, v. 37, n. 4, p. 682-703, 2010.

HARRIS, J.; HIRST, J. L.; MOSSINGHOFF, M. Combinatorics and Graph Theory. New York, NY: Springer New York, 2008. v. 82. (Undergraduate Texts in Mathematics).

HILLIER, B et al. Natural movement: or, configuration and attraction in urban pedestrian movement. Environment and Planning B: Planning and Design, v. 20, p. 29-66, 1993.

HILLIER, B.; HANSON, J. The social logic of space. New Yotk: Cambridge Unversity Press, 1984.

HIRATA, E. et al. Mapeamento dinâmico e colaborativo de alagamentos na cidade de São Paulo. Boletim de Ciências Geodésicas, v. 19, n. 4, p. 602-623, dez. 2013.

HOFER, C.; JÄGER, G.; FÜLLSACK, M. Large scale simulation of CO2 emissions caused by urban car traffic: An agent-based network approach. Journal of Cleaner Production, v. 183, n. February, p. 1-10, maio 2018.

HUNTER, J. D. Matplotlib: A 2D Graphics Environment. Computing in Science \& Engineering, v. 9, n. 3, p. 90-95, 2007.

IBGE. Área dos Municípios., 2017a. Disponível em: 
<ftp://geoftp.ibge.gov.br/.../AR_BR_RG_UF_MES_MIC_MUN_2017.xls>.

. Estimativa de população de 2017., 2017b. Disponível em:

$<\mathrm{ftp}: / / \mathrm{ftp}$. ibge.gov.br/Estimativas_de...2017/estimativa_dou_2017.pdf $>$.

. Produção Agrícola Municipal - Culturas temporárias e permanentes. . Rio

de Janeiro, 2016. Disponível em: <https://www.ibge.gov.br/.../agricultura.../9117-producaoagricola-municipal-culturas-temporarias-e-permanentes.html>.

. Uso da terra no Estado do Pará : relatório técnico, 2013. Disponível em: $<$ https://biblioteca.ibge.gov.br/visualizacao/livros/liv95892.pdf $>$.

LIMA, R. da S. et al. Mapeamento Colaborativo: uma alternativa para obtenção de mapas digitais para aplicações em transportes. ENGEVISTA, v. 12, n. 1, p. 10-21, 2010.

. Promoting More Efficient Use of Urban Areas in Developing Countries: An Alternative. Transportation Research Record: Journal of the Transportation Research Board, v. 1726, n. 1, p. 8-15, jan. 2000.

LIMA, R. da S.; SILVA, A. N. R. da; VAN DER WAERDEN, P. Espalhamento urbano: mito ou realidade no Brasil? O caso das cidades médias. Revista dos Transportes Públicos, v. 98, p. 31-46, 2003.

LIPSCHUTZ, S.; LIPSON, M. Teorias e problemas de matemática discreta. $2^{\mathrm{a}}$ ed. Porto Alegre: Bookman, 2004.

MANAUS. Plano de mobilidade urbana de Manaus 2015. . Prefeitura de Manaus:, 2015. Disponível em:

<www2.manaus.am.gov.br/docs/portal/secretarias/smtu/PlanMobManaus.pdf>.

MARCHETTI, S. et al. Small Area Model-Based Estimators Using Big Data Sources. Journal of Official Statistics. v. 31, n. 2, p. 263-281, 2015.

MARSHALL, S. et al. Street Network Studies: from Networks to Models and their Representations. Networks and Spatial Economics, nov. 2018.

MCKINNEY, W. Data Structures for Statistical Computing in Python. 2010. Proceedings of the 9th Python in Science Conference. Disponível em:

$<$ https://conference.scipy.org/proceedings/scipy2010/pdfs/mckinney.pdf $>$.

MEDEIROS, V. A. S. de. Urbis Brasiliae ou sobre cidades do Brasil: inserindo assentamentos urbanos do país em investigações configuracionais comparativas. 2006. 520 
f. Tese (Doutorado) - Faculdade de Arquitetura e Urbanismo, Univerisdade de Brasília, 2006.

NEIS, P.; ZIELSTRA, D. Recent Developments and Future Trends in Volunteered Geographic Information Research: The Case of OpenStreetMap. Future Internet, v. 6, n. 1, p. 76-106, jan. 2014.

NEWMAN, M. E. J. The Structure and Function of Complex Networks. SIAM Review, v. 45 , n. 2, p. 167-256, jan. 2003.

NOMINATIM. Nominatim. Disponível em: $<$ https://nominatim.openstreetmap.org/>.

OLIPHANT, T. E. Python for Scientific Computing. Computing in Science \& Engineering, v. 9, n. 3, p. 10-20, 2007.

OORT, P. van. Spatial Data quality: from description to application. Rotterdam: Optima, 2006. Disponível em:

$<$ https://www.researchgate.net/publication/40115183_Spatial_data_quality_from_description _to_application>.

OPENSTREETMAP WIKI. API OSM v0.6. Disponível em: $<$ https://wiki.openstreetmap.org/wiki/API_v0.6>, 2018a.

. Editor iD. Disponível em: <https://wiki.openstreetmap.org/wiki/ID>, 2018b

Guia do iniciante. Disponível em: $<$ https://wiki.openstreetmap.org/wiki/Ptbr:Beginners\%27_guide>, 2018c.

PENN, A. et al. Configurational modelling of urban movement networks. Environment and Planning B: Planning and Design, v. 25, p. 59-84, 1998.

PEREIRA, R. H. M. et al. O uso da Sintaxe Espacial na Análise do Desempenho do Transporte Urbano: Limites e Potencialidades. Ipea, n. 1415-4765, p. 56, 2011.

PORTA, S.; CRUCITTI, P.; LATORA, V. The network analysis of urban streets: A dual approach. Physica A: Statistical Mechanics and its Applications, v. 369, n. 2, p. 853-866, set. 2006a. Disponível em:

$<$ http://www.sciencedirect.com/science/article/pii/S0378437106001282>.

. The network analysis of urban streets: A primal approach. Environment and Planning B: Planning and Design, v. 33, n. 5, p. 705-725, $2006 \mathrm{~b}$.

SAMPAIO, J. C. V. Passeios de Euler E As Pontes De Königsberg. Disponível em: 
$<$ https://www.dm.ufscar.br/profs/sampaio/PasseiosdeEuler.pdf>, 2002.

SEVERANCE, C. Python para Informática - Explorando a Informação. [S.1: s.n.], 2009.

SHANNON, C. E. A Mathematical Theory of Communication. The Bell System Technical Journal, v. 27, n. April 1928, p. 379-423, 1948.

SHARIFI, A. Resilient urban forms: A review of literature on streets and street networks. Building and Environment, v. 147, n. July 2018, p. 171-187, jan. 2019.

SOARES, A. J. Análise de autocorrelação em redes aplicada ao caso de acidentes urbanos de trânsito. 138 f. Dissertação (Mestrado) - Escola de Engenharia de São Carlos, Universidade de São Paulo, 2007.

SOUSA, M. T. R. de; BRAGA, R. As influências do efeito de barreira na dinâmica das cidades: o caso da cidade de Rio ClaroSP. Geografia Ensino \& Pesquisa, p. 53-70, 2011.

SZWOCH, G. Combining Road Network Data from OpenStreetMap with an Authoritative Database. Journal of Transportation Engineering, Part A: Systems, v. 145, n. 2, fev. 2019.

TURNER, B. A. J. Introduction to Neogeography Introduction to Neogeography. [S.1: s.n.], 2006. Disponível em:

$<$ https://www.researchgate.net/publication/228386176_Introduction_to_Neogeography $>$.

WIKI, O. Fontes oficiais de dados livres para uso no OSM. Disponível em: $<$ https://wiki.openstreetmap.org/wiki/Pt:Brazilian_data_sources $>$. 
APÊNDICE A - BANCO DE DADOS DE MÉTRICAS TOPOLÓGICAS E TOPO-GEOMÉTRICAS 
Tabela 27 - Banco de dados de métricas topológicas e topo-geométricas

\begin{tabular}{|c|c|c|c|c|c|c|c|c|c|c|c|c|c|c|}
\hline Cidade/Estado & Área $\left[\mathrm{km}^{2}\right]$ & Nós & Arestas & População & $I_{0}$ & $\mathbf{I}_{\mathbf{C}}$ & $\mathbf{L}$ & $\mathbf{B i}$ & $\mathbf{K}$ & $\mathrm{H}_{\mathrm{O}}$ & $\mathbf{A}$ & $\mathrm{C}$ & $\mathbf{N} / \mathbf{k m}^{2}$ & $\mathbf{m} / \mathbf{k m}^{2}$ \\
\hline Abaetetuba/PA & 1610,404 & 1284 & 1903 & 153380 & 0,663 & 0,337 & 213,704 & 0,018 & 2,964 & 3,487 & 4,805 & 1,047 & 0,797 & 249,992 \\
\hline Açailândia/MA & 5806,439 & 3189 & 5106 & 111339 & 0,621 & 0,379 & 135,446 & 0,012 & 3,202 & 3,382 & 9,399 & 1,040 & 0,549 & 118,304 \\
\hline $\begin{array}{l}\text { Águas Lindas de } \\
\text { Goiás/GO }\end{array}$ & 188,385 & 4353 & 6595 & 195810 & 0,739 & 0,261 & 136,375 & 0,009 & 3,030 & 3,492 & 6,583 & 1,031 & 23,107 & 4806,993 \\
\hline Alagoinhas/BA & 707,558 & 2903 & 4188 & 155979 & 0,863 & 0,137 & 149,519 & 0,010 & 2,885 & 3,561 & 5,358 & 1,069 & 4,103 & 874,295 \\
\hline $\begin{array}{l}\text { Almirante } \\
\text { Tamandaré/PR }\end{array}$ & 194,744 & 2420 & 3233 & 115364 & 0,811 & 0,189 & 165,691 & 0,012 & 2,672 & 3,548 & 6,973 & 1,092 & 12,427 & 2727,100 \\
\hline Altamira/PA & 159533,328 & 3684 & 5770 & 111435 & 0,729 & 0,271 & 123,385 & 0,010 & 3,132 & 3,444 & 5,883 & 1,037 & 0,023 & 4,390 \\
\hline Alvorada/RS & 71,311 & 2726 & 4097 & 208177 & 0,742 & 0,258 & 124,438 & 0,012 & 3,006 & 3,459 & 4,278 & 1,025 & 38,227 & 7085,172 \\
\hline Americana/SP & 133,912 & 6548 & 10317 & 233868 & 0,677 & 0,323 & 104,685 & 0,007 & 3,151 & 3,524 & 6,804 & 1,027 & 48,898 & 8036,912 \\
\hline Ananindeua/PA & 190,451 & 7999 & 11349 & 516057 & 0,793 & 0,207 & 94,261 & 0,007 & 2,838 & 3,406 & 6,042 & 1,032 & 42,000 & 5650,260 \\
\hline Anápolis/GO & 933,156 & 11261 & 17603 & 375142 & 0,736 & 0,264 & 120,028 & 0,004 & 3,126 & 3,567 & 8,426 & 1,034 & 12,068 & 2278,669 \\
\hline Angra dos Reis/RJ & 825,082 & 4010 & 5014 & 194619 & 0,902 & 0,098 & 136,909 & 0,024 & 2,501 & 3,531 & 26,553 & 1,142 & 4,860 & 812,583 \\
\hline $\begin{array}{l}\text { Aparecida de } \\
\text { Goiânia/GO }\end{array}$ & 278,539 & 15062 & 24631 & 542090 & 0,661 & 0,339 & 109,570 & 0,005 & 3,271 & 3,545 & 9,293 & 1,018 & 54,075 & 9701,381 \\
\hline Apucarana/PR & 558,389 & 3892 & 6018 & 132691 & 0,667 & 0,333 & 175,684 & 0,008 & 3,092 & 3,513 & 6,813 & 1,066 & 6,970 & 1873,643 \\
\hline Aracaju/SE & 181,857 & 10706 & 16096 & 650106 & 0,805 & 0,195 & 94,278 & 0,006 & 3,007 & 3,431 & 9,816 & 1,035 & 58,870 & 8442,487 \\
\hline Araçatuba/SP & 1167,126 & 6355 & 10573 & 194874 & 0,581 & 0,419 & 124,721 & 0,006 & 3,328 & 3,414 & 6,694 & 1,025 & 5,445 & 1113,447 \\
\hline Araguaína/TO & 4000,416 & 6675 & 10857 & 175960 & 0,602 & 0,398 & 148,564 & 0,007 & 3,253 & 3,521 & 8,238 & 1,051 & 1,669 & 401,913 \\
\hline Araguari/MG & 2729,508 & 4031 & 6514 & 117445 & 0,626 & 0,374 & 165,432 & 0,010 & 3,232 & 3,403 & 7,621 & 1,071 & 1,477 & 388,319 \\
\hline Arapiraca/AL & 345,655 & 6779 & 10134 & 234185 & 0,785 & 0,215 & 128,074 & 0,006 & 2,990 & 3,525 & 7,157 & 1,043 & 19,612 & 3728,183 \\
\hline Arapongas/PR & 382,215 & 3682 & 5651 & 118477 & 0,697 & 0,303 & 142,825 & 0,009 & 3,070 & 3,442 & 5,772 & 1,040 & 9,633 & 2101,880 \\
\hline Araraquara/SP & 1003,625 & 8118 & 13064 & 230770 & 0,613 & 0,387 & 130,986 & 0,006 & 3,219 & 3,476 & 7,124 & 1,035 & 8,089 & 1659,283 \\
\hline Araras/SP & 644,831 & 4390 & 6737 & 131282 & 0,800 & 0,200 & 132,005 & 0,009 & 3,069 & 3,530 & 5,291 & 1,057 & 6,808 & 1367,523 \\
\hline Araruama/RJ & 638,480 & 5782 & 8180 & 126742 & 0,840 & 0,160 & 140,271 & 0,008 & 2,829 & 3,460 & 8,518 & 1,047 & 9,056 & 1779,704 \\
\hline Araucária/PR & 469,240 & 3291 & 4825 & 137452 & 0,712 & 0,288 & 216,644 & 0,011 & 2,932 & 3,495 & 7,624 & 1,083 & 7,013 & 2170,614 \\
\hline Araxá/MG & 1164,062 & 4348 & 6699 & 104283 & 0,756 & 0,244 & 143,661 & 0,009 & 3,081 & 3,542 & 5,887 & 1,087 & 3,735 & 802,744 \\
\hline
\end{tabular}




\begin{tabular}{|c|c|c|c|c|c|c|c|c|c|c|c|c|c|c|}
\hline Cidade/Estado & Área $\left[\mathrm{km}^{2}\right]$ & Nós & Arestas & População & $\mathbf{I}_{\mathbf{O}}$ & $\mathbf{I}_{\mathbf{C}}$ & $\mathbf{L}$ & $\mathbf{B i}$ & $\mathbf{K}$ & $\mathbf{H}_{\mathbf{O}}$ & $\mathbf{A}$ & $\mathrm{C}$ & $\mathbf{N} / \mathbf{k m}^{2}$ & $\mathbf{m} / \mathbf{k m}^{2}$ \\
\hline Ariquemes/RO & 4426,571 & 3001 & 4670 & 107345 & 0,716 & 0,284 & 183,603 & 0,011 & 3,112 & 2,639 & 4,388 & 1,035 & 0,678 & 178,525 \\
\hline Assis/SP & 460,609 & 3629 & 5973 & 102924 & 0,592 & 0,408 & 154,325 & 0,009 & 3,292 & 3,372 & 4,612 & 1,051 & 7,879 & 1981,365 \\
\hline Atibaia/SP & 478,521 & 5030 & 7079 & 139683 & 0,841 & 0,159 & 183,272 & 0,008 & 2,815 & 3,570 & 9,771 & 1,102 & 10,512 & 2667,531 \\
\hline Bacabal/MA & 1683,073 & 1970 & 2964 & 103359 & 0,705 & 0,295 & 178,278 & 0,014 & 3,009 & 3,424 & 5,355 & 1,060 & 1,170 & 311,346 \\
\hline Bagé/RS & 4093,582 & 2902 & 4610 & 122209 & 0,594 & 0,406 & 305,423 & 0,010 & 3,177 & 3,391 & 7,735 & 1,090 & 0,709 & 337,257 \\
\hline $\begin{array}{l}\text { Balneário } \\
\text { Camboriú/SC }\end{array}$ & 46,244 & 2119 & 3012 & 135268 & 0,794 & 0,206 & 116,635 & 0,020 & 2,843 & 3,268 & 4,608 & 1,040 & 45,822 & 7430,202 \\
\hline Barbacena/MG & 759,186 & 3132 & 4331 & 136689 & 0,871 & 0,129 & 184,476 & 0,012 & 2,766 & 3,579 & 9,944 & 1,133 & 4,125 & 1060,078 \\
\hline Barcarena/PA & 1310,588 & 1979 & 2991 & 121190 & 0,681 & 0,319 & 168,882 & 0,016 & 3,023 & 3,204 & 9,000 & 1,032 & 1,510 & 384,406 \\
\hline Barra Mansa/RJ & 547,133 & 3270 & 4148 & 179451 & 0,917 & 0,083 & 185,419 & 0,014 & 2,537 & 3,568 & 11,437 & 1,149 & 5,977 & 1396,704 \\
\hline Barreiras/BA & 7861,762 & 9719 & 14841 & 157638 & 0,766 & 0,234 & 493,909 & 0,007 & 3,054 & 3,503 & 67,878 & 1,089 & 1,236 & 919,551 \\
\hline Barretos/SP & 1566,161 & 4602 & 7564 & 120638 & 0,616 & 0,384 & 218,621 & 0,008 & 3,287 & 3,290 & 6,978 & 1,078 & 2,938 & 1006,184 \\
\hline Barueri/SP & 65,701 & 3378 & 4888 & 267534 & 0,871 & 0,129 & 116,576 & 0,012 & 2,894 & 3,573 & 6,662 & 1,087 & 51,415 & 8727,917 \\
\hline Bauru/SP & 667,684 & 10683 & 17598 & 371690 & 0,577 & 0,423 & 103,881 & 0,004 & 3,295 & 3,533 & 6,953 & 1,033 & 16,000 & 2777,455 \\
\hline Belém/PA & 1059,458 & 12726 & 18546 & 1452275 & 0,796 & 0,204 & 102,605 & 0,006 & 2,915 & 3,425 & 11,010 & 1,038 & 12,012 & 1814,378 \\
\hline Belford Roxo/RJ & 78,985 & 7255 & 10382 & 495783 & 0,835 & 0,165 & 98,253 & 0,007 & 2,862 & 3,561 & 5,514 & 1,043 & 91,853 & 12910,351 \\
\hline Belo Horizonte/MG & 331,401 & 29120 & 45437 & 2523794 & 0,715 & 0,285 & 104,668 & 0,003 & 3,121 & 3,572 & 12,290 & 1,036 & 87,869 & 14410,016 \\
\hline Bento Gonçalves/RS & 274,070 & 2769 & 3774 & 115069 & 0,804 & 0,196 & 197,066 & 0,012 & 2,726 & 3,056 & 6,125 & 1,176 & 10,103 & 2591,244 \\
\hline Betim/MG & 343,856 & 8871 & 13047 & 427146 & 0,789 & 0,211 & 132,730 & 0,006 & 2,941 & 3,574 & 10,826 & 1,069 & 25,799 & 5077,648 \\
\hline Birigui/SP & 530,031 & 4082 & 6779 & 120692 & 0,554 & 0,446 & 116,821 & 0,009 & 3,321 & 3,288 & 4,431 & 1,017 & 7,701 & 1486,920 \\
\hline Blumenau/SC & 518,497 & 8841 & 10241 & 348513 & 0,941 & 0,059 & 150,623 & 0,009 & 2,317 & 3,509 & 11,336 & 1,097 & 17,051 & 2884,854 \\
\hline Boa Vista/RR & 5687,037 & 9019 & 15256 & 332020 & 0,497 & 0,503 & 178,138 & 0,006 & 3,383 & 3,466 & 9,631 & 1,041 & 1,586 & 452,590 \\
\hline Botucatu/SP & 1482,642 & 5879 & 9181 & 142546 & 0,664 & 0,336 & 180,778 & 0,007 & 3,123 & 3,515 & 10,781 & 1,082 & 3,965 & 1076,502 \\
\hline Bragança Paulista/SP & 512,584 & 4743 & 6837 & 164163 & 0,815 & 0,185 & 168,410 & 0,008 & 2,883 & 3,556 & 8,122 & 1,084 & 9,253 & 2144,701 \\
\hline Bragança/PA & 2091,930 & 1591 & 2362 & 124184 & 0,724 & 0,276 & 217,428 & 0,019 & 2,969 & 3,211 & 7,553 & 1,080 & 0,761 & 234,015 \\
\hline Brusque/SC & 283,223 & 4868 & 5681 & 128818 & 0,933 & 0,067 & 128,735 & 0,012 & 2,334 & 3,427 & 7,945 & 1,086 & 17,188 & 2520,717 \\
\hline $\begin{array}{l}\text { Cabo de Santo } \\
\text { Agostinho/PE }\end{array}$ & 448,735 & 3897 & 5396 & 204653 & 0,861 & 0,139 & 110,937 & 0,010 & 2,769 & 3,549 & 9,798 & 1,072 & 8,684 & 1437,696 \\
\hline
\end{tabular}




\begin{tabular}{|c|c|c|c|c|c|c|c|c|c|c|c|c|c|c|}
\hline Cidade/Estado & Área $\left[\mathrm{km}^{2}\right]$ & Nós & Arestas & População & $\mathbf{I}_{\mathbf{o}}$ & $\mathbf{I}_{\mathbf{C}}$ & $\mathbf{L}$ & $\mathbf{B i}$ & $\mathbf{K}$ & $\mathbf{H}_{\mathbf{O}}$ & $\mathbf{A}$ & $\mathrm{C}$ & $\mathbf{N} / \mathbf{k m}^{2}$ & $\mathbf{m} / \mathbf{k m}^{2}$ \\
\hline Cabo Frio/RJ & 413,645 & 3881 & 5280 & 216030 & 0,833 & 0,167 & 116,537 & 0,013 & 2,721 & 3,160 & 7,912 & 1,035 & 9,382 & 1485,092 \\
\hline Cachoeirinha/RS & 44,018 & 2344 & 3594 & 127318 & 0,719 & 0,281 & 105,104 & 0,012 & 3,067 & 3,454 & 3,960 & 1,026 & 53,251 & 8669,797 \\
\hline $\begin{array}{l}\text { Cachoeiro de } \\
\text { Itapemirim/ES }\end{array}$ & 864,583 & 3599 & 4991 & 211649 & 0,881 & 0,119 & 195,886 & 0,010 & 2,774 & 3,573 & 9,870 & 1,139 & 4,163 & 1108,473 \\
\hline Camaçari/BA & 784,658 & 7755 & 10519 & 296893 & 0,878 & 0,122 & 140,391 & 0,007 & 2,713 & 3,551 & 19,760 & 1,078 & 9,883 & 1914,469 \\
\hline Camaragibe/PE & 51,257 & 3418 & 4677 & 156361 & 0,857 & 0,143 & 103,282 & 0,013 & 2,737 & 3,522 & 5,860 & 1,062 & 66,684 & 9353,611 \\
\hline Cambé/PR & 495,375 & 2980 & 4425 & 105347 & 0,733 & 0,267 & 148,622 & 0,012 & 2,970 & 3,485 & 5,387 & 1,051 & 6,016 & 1306,227 \\
\hline Cametá/PA & 3081,367 & 734 & 1119 & 134100 & 0,684 & 0,316 & 191,256 & 0,029 & 3,049 & 3,389 & 6,391 & 1,060 & 0,238 & 69,036 \\
\hline Campina Grande/PB & 593,026 & 8639 & 13159 & 410332 & 0,757 & 0,243 & 105,694 & 0,006 & 3,046 & 3,477 & 6,970 & 1,034 & 14,568 & 2330,986 \\
\hline Campinas/SP & 794,571 & 26937 & 40800 & 1182429 & 0,774 & 0,226 & 111,293 & 0,002 & 3,029 & 3,577 & 13,580 & 1,048 & 33,901 & 5785,715 \\
\hline Campo Grande/MS & 8092,951 & 25279 & 41825 & 874210 & 0,602 & 0,398 & 128,084 & 0,003 & 3,309 & 3,523 & 12,450 & 1,032 & 3,124 & 652,059 \\
\hline $\begin{array}{l}\text { Campos dos } \\
\text { Goytacazes/RJ }\end{array}$ & 4032 & 9948 & 14 & 490288 & 0,794 & 0,206 & 14 & 0,006 & 2,922 & 3,527 & 22,3 & 1,089 & 2,467 & 681,200 \\
\hline Canoas/RS & 131,096 & 5366 & 8143 & 343853 & 0,721 & 0,279 & 122,181 & 0,007 & 3,035 & 3,063 & 6,216 & 1,027 & 40,932 & 7657,176 \\
\hline Caraguatatuba/SP & 484,947 & 5173 & 7493 & 116786 & 0,754 & 0,246 & 111,178 & 0,013 & 2,897 & 3,511 & 9,580 & 1,070 & 10,667 & 1704,676 \\
\hline Carapicuíba/SP & 34,546 & 3544 & 4874 & 396587 & 0,901 & 0,099 & 100,580 & 0,011 & 2,751 & 3,557 & 3,877 & 1,071 & 102,588 & 14075,078 \\
\hline Cariacica/ES & 279,718 & 7600 & 11291 & 387368 & 0,806 & 0,194 & 113,503 & 0,007 & 2,971 & 3,573 & 7,444 & 1,069 & 27,170 & 4570,033 \\
\hline Caruaru/PE & 920,610 & 9308 & 14055 & 356128 & 0,759 & 0,241 & 103,374 & 0,005 & 3,020 & 3,387 & 8,567 & 1,045 & 10,111 & 1625,678 \\
\hline Cascavel/PR & 2100,831 & 8070 & 13024 & 319608 & 0,551 & 0,449 & 173,334 & 0,005 & 3,228 & 3,498 & 9,948 & 1,058 & 3,841 & 1049,521 \\
\hline Castanhal/PA & 1028,889 & 4772 & 7629 & 195253 & 0,623 & 0,377 & 128,514 & 0,008 & 3,197 & 2,557 & 6,259 & 1,031 & 4,638 & 953,970 \\
\hline Catalão/GO & 3821,463 & 5063 & 8344 & 102393 & 0,586 & 0,414 & 187,078 & 0,007 & 3,296 & 3,473 & 10,163 & 1,074 & 1,325 & 388,470 \\
\hline Catanduva/SP & 290,596 & 4277 & 7029 & 120691 & 0,616 & 0,384 & 109,684 & 0,008 & 3,287 & 3,541 & 4,358 & 1,030 & 14,718 & 2620,599 \\
\hline Caucaia/CE & 1228,506 & 7707 & 11366 & 362223 & 0,759 & 0,241 & 156,044 & 0,007 & 2,950 & 3,425 & 14,022 & 1,054 & 6,273 & 1450,319 \\
\hline Caxias do Sul/RS & 5196,769 & 11765 & 16473 & 162657 & 0,803 & 0,197 & 182,951 & 0,004 & 2,800 & 3,082 & 11,791 & 1,116 & 2,264 & 555,895 \\
\hline Caxias/MA & 5196,769 & 3353 & 5116 & 483377 & 0,742 & 0,258 & 204,843 & 0,011 & 3,052 & 3,542 & 8,482 & 1,075 & 0,645 & 195,229 \\
\hline Chapecó/SC & 626,060 & 6041 & 9401 & 213279 & 0,613 & 0,387 & 165,180 & 0,007 & 3,112 & 3,256 & 7,819 & 1,102 & 9,649 & 2371,718 \\
\hline Codó/MA & 4361,344 & 1745 & 2703 & 120810 & 0,704 & 0,296 & 280,048 & 0,018 & 3,098 & 3,454 & 9,901 & 1,090 & 0,400 & 169,889 \\
\hline Colatina/ES & 1416,804 & 3353 & 4746 & 124525 & 0,832 & 0,168 & 200,243 & 0,012 & 2,831 & 3,563 & 9,930 & 1,158 & 2,367 & 629,433 \\
\hline
\end{tabular}




\begin{tabular}{|c|c|c|c|c|c|c|c|c|c|c|c|c|c|c|}
\hline Cidade/Estado & Área $\left[\mathbf{k m}^{2}\right]$ & Nós & Arestas & População & $\mathbf{I}_{\mathbf{O}}$ & $\mathbf{I}_{\mathbf{C}}$ & $\mathbf{L}$ & $\mathbf{B i}$ & $\mathbf{K}$ & $\mathbf{H}_{\mathbf{O}}$ & $\mathbf{A}$ & $\mathbf{C}$ & $\mathbf{N} / \mathbf{k m}^{2}$ & $\mathbf{m} / \mathbf{k m}^{2}$ \\
\hline Colombo/PR & 197,793 & 4813 & 6745 & 237402 & 0,747 & 0,253 & 134,408 & 0,008 & 2,803 & 3,512 & 7,539 & 1,054 & 24,334 & 4576,821 \\
\hline $\begin{array}{l}\text { Conselheiro } \\
\text { Lafaiete/MG }\end{array}$ & 370,246 & 3713 & 5392 & 127369 & 0,784 & 0,216 & 137,314 & 0,009 & 2,904 & 3,562 & 5,213 & 1,081 & 10,028 & 1967,769 \\
\hline Contagem/MG & 195,045 & 9259 & 13902 & 658580 & 0,773 & 0,227 & 118,442 & 0,006 & 3,003 & 3,567 & 10,232 & 1,042 & 47,471 & 8456,331 \\
\hline $\begin{array}{l}\text { Coronel } \\
\text { Fabriciano/MG }\end{array}$ & 221,252 & 2026 & 2944 & 110326 & 0,767 & 0,233 & 136,676 & 0,019 & 2,906 & 3,551 & 5,854 & 1,117 & 9,157 & 1763,880 \\
\hline Corumbá/MS & 64721,719 & 1806 & 2780 & 109899 & 0,636 & 0,364 & 181,636 & 0,014 & 3,079 & 2,479 & 4,788 & 1,045 & 0,028 & 7,741 \\
\hline Cotia/SP & 323,994 & 4042 & 5192 & 237750 & 0,931 & 0,069 & 148,305 & 0,012 & 2,569 & 3,578 & 9,380 & 1,115 & 12,476 & 2321,685 \\
\hline Crato/CE & 1176,467 & 3210 & 4593 & 130604 & 0,753 & 0,247 & 143,246 & 0,011 & 2,862 & 3,504 & 7,635 & 1,056 & 2,729 & 551,051 \\
\hline Criciúma/SC & 235,701 & 7471 & 10597 & 211369 & 0,769 & 0,231 & 117,318 & 0,007 & 2,837 & 3,142 & 8,065 & 1,037 & 31,697 & 5247,073 \\
\hline Cubatão/SP & 142,879 & 1619 & 2335 & 128748 & 0,788 & 0,212 & 106,182 & 0,018 & 2,884 & 3,498 & 4,993 & 1,065 & 11,331 & 1901,104 \\
\hline Cuiabá/MT & 3293,537 & 16643 & 25306 & 590118 & 0,769 & 0,231 & 125,860 & 0,004 & 3,041 & 3,520 & 11,533 & 1,063 & 5,053 & 964,107 \\
\hline Curitiba/PR & 435,036 & 31353 & 46469 & 1908359 & 0,712 & 0,288 & 106,829 & 0,002 & 2,964 & 3,543 & 12,330 & 1,029 & 72,070 & 11481,637 \\
\hline Diadema/SP & 30,732 & 3493 & 5018 & 417869 & 0,861 & 0,139 & 94,323 & 0,010 & 2,873 & 3,566 & 4,154 & 1,063 & 113,660 & 15344,693 \\
\hline Divinópolis/MG & 708,115 & 7953 & 12641 & 234937 & 0,542 & 0,458 & 143,178 & 0,007 & 3,179 & 3,500 & 9,192 & 1,061 & 11,231 & 2523,882 \\
\hline Dourados/MS & 4086,237 & 8117 & 13543 & 218069 & 0,500 & 0,500 & 158,085 & 0,005 & 3,337 & 2,945 & 9,574 & 1,039 & 1,986 & 505,286 \\
\hline Duque de Caxias/RJ & 467,271 & 13101 & 18843 & 890997 & 0,781 & 0,219 & 118,785 & 0,004 & 2,877 & 3,559 & 13,096 & 1,043 & 28,037 & 4885,515 \\
\hline Embu das Artes/SP & 70,398 & 2444 & 3337 & 267054 & 0,928 & 0,072 & 137,736 & 0,014 & 2,731 & 3,574 & 6,123 & 1,105 & 34,717 & 6480,880 \\
\hline Erechim/RS & 430,668 & 3340 & 5005 & 103437 & 0,674 & 0,326 & 138,539 & 0,009 & 2,997 & 3,246 & 4,530 & 1,067 & 7,755 & 1519,139 \\
\hline Eunápolis/BA & 1425,968 & 3110 & 4893 & 115290 & 0,684 & 0,316 & 114,060 & 0,011 & 3,147 & 3,254 & 6,148 & 1,054 & 2,181 & 384,969 \\
\hline Feira de Santana/BA & 1304,425 & 12948 & 18697 & 627477 & 0,834 & 0,166 & 117,223 & 0,004 & 2,888 & 3,511 & 7,753 & 1,047 & 9,926 & 1691,221 \\
\hline $\begin{array}{l}\text { Ferraz de } \\
\text { Vasconcelos/SP }\end{array}$ & 29,564 & 1947 & 2659 & 188868 & 0,884 & 0,116 & 107,031 & 0,0 & 2,733 & 3,563 & 3,448 & 1,053 & 65,857 & 9584,711 \\
\hline Florianópolis/SC & 675,409 & 10045 & 12734 & 485838 & 0,878 & 0,122 & 133,610 & 0,009 & 2,535 & 3,528 & 20,294 & 1,047 & 14,872 & 2490,599 \\
\hline Formosa/GO & 5811,788 & 4480 & 7235 & 115789 & 0,658 & 0,342 & 190,538 & 0,009 & 3,230 & 3,497 & 10,858 & 1,098 & 0,771 & 225,990 \\
\hline Fortaleza/CE & 314,930 & 33900 & 52818 & 2627482 & 0,692 & 0,308 & 88,931 & 0,003 & 3,116 & 3,399 & 11,133 & 1,024 & 107,643 & 15067,403 \\
\hline Foz do Iguaçu/PR & 618,353 & 6928 & 10895 & 264044 & 0,644 & 0,356 & 129,205 & 0,006 & 3,145 & 3,176 & 7,537 & 1,033 & 11,204 & 2276,900 \\
\hline Franca/SP & 605,679 & 9411 & 15121 & 347237 & 0,653 & 0,347 & 110,382 & 0,005 & 3,213 & 3,553 & 6,725 & 1,028 & 15,538 & 2706,394 \\
\hline Francisco Morato/SP & 49,001 & 1867 & 2497 & 171602 & 0,943 & 0,057 & 146,248 & 0,016 & 2,675 & 3,576 & 4,485 & 1,118 & 38,101 & 7409,331 \\
\hline
\end{tabular}




\begin{tabular}{|c|c|c|c|c|c|c|c|c|c|c|c|c|c|c|}
\hline Cidade/Estado & Área $\left[\mathbf{k m}^{2}\right]$ & Nós & Arestas & População & $I_{0}$ & $\mathbf{I}_{\mathbf{C}}$ & $\mathbf{L}$ & $\mathbf{B i}$ & K & $\mathbf{H}_{\mathbf{O}}$ & $\mathbf{A}$ & $\mathrm{C}$ & $\mathbf{N} / \mathbf{k m}^{2}$ & $\mathbf{m} / \mathbf{k m}^{2}$ \\
\hline Franco da Rocha/SP & 132,775 & 2155 & 2862 & 149502 & 0,922 & 0,078 & 166,842 & 0,020 & 2,656 & 3,576 & 6,435 & 1,131 & 16,230 & 3508,631 \\
\hline Garanhuns/PE & 458,552 & 4111 & 6470 & 138642 & 0,692 & 0,308 & 124,044 & 0,009 & 3,148 & 3,526 & 5,918 & 1,052 & 8,965 & 1721,508 \\
\hline Goiânia/GO & 728,841 & 35070 & 56136 & 1466105 & 0,736 & 0,264 & 107,138 & 0,003 & 3,200 & 3,571 & 13,050 & 1,042 & 48,117 & 8159,130 \\
\hline $\begin{array}{l}\text { Governador } \\
\text { Valadares/MG }\end{array}$ & 2342,325 & 5861 & 9017 & 280901 & 0,745 & 0,255 & 142,659 & 0,008 & 3,077 & 3,546 & 11,648 & 1,099 & 2,502 & 532,685 \\
\hline Gravataí/RS & 463,499 & 5206 & 7444 & 275146 & 0,771 & 0,229 & 159,838 & 0,008 & 2,860 & 3,573 & 8,702 & 1,052 & 11,232 & 2531,602 \\
\hline Guarapari/ES & 591,815 & 4178 & 6012 & 123166 & 0,789 & 0,211 & 188,710 & 0,009 & 2,878 & 3,562 & 12,374 & 1,116 & 7,060 & 1876,253 \\
\hline Guarapuava/PR & 3178,649 & 5443 & 8643 & 180364 & 0,614 & 0,386 & 207,502 & 0,008 & 3,176 & 3,487 & 11,476 & 1,107 & 1,712 & 524,902 \\
\hline Guaratinguetá/SP & 752,636 & 3405 & 4889 & 120417 & 0,849 & 0,151 & 157,685 & 0,012 & 2,872 & 3,558 & 6,366 & 1,104 & 4,524 & 988,788 \\
\hline Guarujá/SP & 144,794 & 5256 & 8201 & 315563 & 0,695 & 0,305 & 90,282 & 0,013 & 3,121 & 3,401 & 7,924 & 1,048 & 36,300 & 5125,976 \\
\hline Guarulhos/SP & 318,675 & 14205 & 20622 & 1349113 & 0,839 & 0,161 & 109,859 & 0,004 & 2,903 & 3,563 & 10,633 & 1,050 & 44,575 & 7172,666 \\
\hline Hortolândia/SP & 62,416 & 4332 & 6534 & 222186 & 0,753 & 0,247 & 104,630 & 0,010 & 3,017 & 3,568 & 5,703 & 1,026 & 69,405 & 10813,048 \\
\hline Ibirité/MG & 72,573 & 2534 & 3556 & 177475 & 0,845 & 0,155 & 117,600 & 0,014 & 2,807 & 3,555 & 5,109 & 1,083 & 34,917 & 5737,737 \\
\hline Igarassu/PE & 305,560 & 2813 & 3883 & 115398 & 0,840 & 0,160 & 144,716 & 0,012 & 2,761 & 3,491 & 6,316 & 1,075 & 9,206 & 1839,381 \\
\hline Iguatu/CE & 1029,214 & 2535 & 3700 & 102614 & 0,750 & 0,250 & 164,461 & 0,013 & 2,919 & 3,292 & 7,883 & 1,074 & 2,463 & 577,895 \\
\hline Ilhéus/BA & 1584,693 & 2473 & 3415 & 176341 & 0,815 & 0,185 & 193,990 & 0,020 & 2,763 & 3,506 & 13,111 & 1,125 & 1,561 & 408,334 \\
\hline Imperatriz/MA & 1368,988 & 6446 & 9795 & 254569 & 0,685 & 0,315 & 113,544 & 0,007 & 3,039 & 3,434 & 7,337 & 1,036 & 4,709 & 805,158 \\
\hline Indaiatuba/SP & 311,545 & 5333 & 8138 & 239602 & 0,698 & 0,302 & 139,525 & 0,008 & 3,052 & 3,449 & 6,507 & 1,055 & 17,118 & 3550,395 \\
\hline Ipatinga/MG & 164,884 & 4176 & 6305 & 261203 & 0,800 & 0,200 & 117,288 & 0,010 & 3,020 & 3,554 & 5,810 & 1,068 & 25,327 & 4431,666 \\
\hline Itabira/MG & 1253,704 & 3001 & 4332 & 119285 & 0,832 & 0,168 & 226,909 & 0,011 & 2,887 & 3,577 & 12,209 & 1,182 & 2,394 & 736,128 \\
\hline Itaboraí/RJ & 430,590 & 6854 & 10089 & 232394 & 0,766 & 0,234 & 158,052 & 0,007 & 2,944 & 3,531 & 10,433 & 1,057 & 15,918 & 3781,879 \\
\hline Itabuna/BA & 401,028 & 3571 & 5351 & 221046 & 0,746 & 0,254 & 98,175 & 0,010 & 2,997 & 3,547 & 4,257 & 1,054 & 8,905 & 1311,542 \\
\hline Itaguaí/RJ & 273,368 & 2290 & 3418 & 122369 & 0,760 & 0,240 & 159,139 & 0,015 & 2,985 & 3,535 & 5,633 & 1,052 & 8,377 & 2003,108 \\
\hline Itajaí/SC & 288,286 & 4316 & 6090 & 212615 & 0,763 & 0,237 & 141,022 & 0,011 & 2,822 & 3,154 & 7,434 & 1,051 & 14,971 & 2920,453 \\
\hline $\begin{array}{l}\text { Itapecerica da } \\
\text { Serra/SP }\end{array}$ & 150,742 & 2353 & 3067 & 170927 & 0,924 & 0,076 & 169,338 & 0,015 & 2,606 & 3,575 & 8,719 & 1,113 & 15,609 & 3392,885 \\
\hline Itapetininga/SP & 1789,350 & 4504 & 6835 & 160070 & 0,740 & 0,260 & 175,399 & 0,008 & 3,035 & 3,518 & 12,414 & 1,080 & 2,517 & 661,902 \\
\hline Itapevi/SP & 82,658 & 2554 & 3517 & 229502 & 0,889 & 0,111 & 132,328 & 0,013 & 2,754 & 3,567 & 5,261 & 1,094 & 30,898 & 5594,808 \\
\hline
\end{tabular}




\begin{tabular}{|c|c|c|c|c|c|c|c|c|c|c|c|c|c|c|}
\hline Cidade/Estado & Área $\left[\mathrm{km}^{2}\right]$ & Nós & Arestas & População & $\mathbf{I}_{\mathbf{O}}$ & $\mathbf{I}_{\mathbf{C}}$ & $\mathbf{L}$ & $\mathbf{B i}$ & $\mathbf{K}$ & $\mathbf{H}_{\mathbf{O}}$ & $\mathbf{A}$ & $\mathrm{C}$ & $\mathbf{N} / \mathbf{k m}^{2}$ & $\mathbf{m} / \mathbf{k m}^{2}$ \\
\hline Itapipoca/CE & 1614,159 & 1883 & 2727 & 127465 & 0,771 & 0,229 & 254,150 & 0,014 & 2,896 & 3,314 & 15,301 & 1,082 & 1,167 & 421,268 \\
\hline Itaquaquecetuba/SP & 82,622 & 4965 & 6822 & 360657 & 0,878 & 0,122 & 116,159 & 0,010 & 2,748 & 3,542 & 6,816 & 1,060 & 60,093 & 9628,285 \\
\hline Itatiba/SP & 322,276 & 3408 & 4634 & 116503 & 0,883 & 0,117 & 145,553 & 0,012 & 2,719 & 3,574 & 7,721 & 1,078 & 10,575 & 2101,150 \\
\hline Ituiutaba/MG & 2598,046 & 3786 & 6165 & 104526 & 0,605 & 0,395 & 281,464 & 0,009 & 3,257 & 3,336 & 8,725 & 1,102 & 1,457 & 613,719 \\
\hline Itumbiara/GO & 2464,510 & 4065 & 6753 & 102513 & 0,611 & 0,389 & 106,988 & 0,010 & 3,323 & 3,343 & 4,668 & 1,027 & 1,649 & 299,618 \\
\hline Itu/SP & 640,719 & 4431 & 6433 & 170157 & 0,836 & 0,164 & 168,547 & 0,009 & 2,904 & 3,555 & 9,785 & 1,102 & 6,916 & 1687,261 \\
\hline $\begin{array}{l}\text { Jaboatão dos } \\
\text { Guararapes/PE }\end{array}$ & 258,694 & 8097 & 11193 & 695956 & 0,827 & 0,173 & 104,541 & 0,008 & 2,765 & 3,565 & 11,349 & 1,055 & 31,300 &, 378 \\
\hline Jacareí/SP & 464,272 & 5417 & 7237 & 229851 & 0,865 & 0,135 & 147,780 & 0,008 & 2,672 & 3,548 & 7,973 & 1,093 & 11,668 & 2329,697 \\
\hline Jandira/SP & 17,449 & 1351 & 1862 & 121492 & 0,880 & 0,120 & 108,268 & 0,022 & 2,756 & 3,569 & 3,296 & 1,076 & 77,426 & 11452,723 \\
\hline Japeri/RJ & 81,697 & 1924 & 2733 & 101237 & 0,785 & 0,215 & 140,426 & 0,023 & 2,841 & 3,498 & 7,153 & 1,056 & 23,550 & 4726,744 \\
\hline Jaraguá do Sul/SC & 529,447 & 5068 & 6128 & 170835 & 0,870 & 0,130 & 171,624 & 0,011 & 2,418 & 3,452 & 9,561 & 1,088 & 9,572 & 1912,324 \\
\hline Jaú/SP & 687,103 & 4372 & 6970 & 146338 & 0,729 & 0,271 & 117,615 & 0,009 & 3,188 & 3,485 & 5,846 & 1,035 & 6,363 & 1196,227 \\
\hline Jequié/BA & 2969,034 & 4443 & 6763 & 162209 & 0,764 & 0,236 & 134,617 & 0,008 & 3,044 & 3,479 & 6,731 & 1,066 & 1,496 & 304,473 \\
\hline Ji-Paraná/Parana & 6896,649 & 3223 & 5133 & 132667 & 0,600 & 0,400 & 202,162 & 0,009 & 3,185 & 2,963 & 8,148 & 1,069 & 0,467 & 147,269 \\
\hline João Pessoa/PB & 211,475 & 13312 & 20857 & 811598 & 0,761 & 0,239 & 98,810 & 0,005 & 3,134 & 3,480 & 8,635 & 1,030 & 62,948 & 9838,782 \\
\hline Joinville/SC & 1126,106 & 12876 & 17412 & 577077 & 0,788 & 0,212 & 133,306 & 0,005 & 2,705 & 3,432 & 10,585 & 1,042 & 11,434 & 2051,682 \\
\hline Juazeiro do Norte/CE & 248,832 & 7139 & 11415 & 270383 & 0,616 & 0,384 & 108,402 & 0,006 & 3,198 & 2,952 & 6,485 & 1,023 & 28,690 & 4968,840 \\
\hline Juazeiro/BA & 6721,198 & 5674 & 8618 & 221773 & 0,781 & 0,219 & 170,865 & 0,007 & 3,038 & 3,477 & 14,355 & 1,058 & 0,844 & 213,476 \\
\hline Juiz de Fora/MG & 1435,749 & 8432 & 11396 & 563769 & 0,880 & 0,120 & 181,113 & 0,007 & 2,703 & 3,574 & 14,488 & 1,152 & 5,873 & 1399,442 \\
\hline Jundiaí/SP & 431,207 & 10197 & 14176 & 409497 & 0,857 & 0,143 & 131,763 & 0,005 & 2,780 & 3,572 & 9,913 & 1,082 & 23,648 & 4206,898 \\
\hline Lagarto/SE & 968,921 & 2905 & 4289 & 104099 & 0,840 & 0,160 & 292,388 & 0,010 & 2,953 & 3,516 & 12,662 & 1,071 & 2,998 & 1270,843 \\
\hline Lages/SC & 2631,504 & 5336 & 7897 & 158508 & 0,708 & 0,292 & 180,015 & 0,008 & 2,960 & 3,522 & 7,512 & 1,098 & 2,028 & 518,026 \\
\hline Lauro de Freitas/BA & 57,664 & 2940 & 3977 & 197636 & 0,891 & 0,109 & 114,688 & 0,012 & 2,705 & 3,538 & 5,210 & 1,086 & 50,985 & 7946,245 \\
\hline Lavras/MG & 564,744 & 3543 & 5175 & 102124 & 0,774 & 0,226 & 130,937 & 0,011 & 2,921 & 3,568 & 6,186 & 1,099 & 6,274 & 1218,978 \\
\hline Leme/SP & 402,871 & 2724 & 4418 & 101184 & 0,629 & 0,371 & 125,635 & 0,011 & 3,244 & 3,549 & 4,359 & 1,029 & 6,761 & 1356,296 \\
\hline Limeira/SP & 580,711 & 8018 & 12242 & 300911 & 0,746 & 0,254 & 126,063 & 0,007 & 3,054 & 3,549 & 7,226 & 1,057 & 13,807 & 2605,566 \\
\hline Linhares/ES & 3496,559 & 4140 & 6383 & 169048 & 0,639 & 0,361 & 255,949 & 0,010 & 3,084 & 3,421 & 20,461 & 1,086 & 1,184 & 438,387 \\
\hline
\end{tabular}




\begin{tabular}{|c|c|c|c|c|c|c|c|c|c|c|c|c|c|c|}
\hline Cidade/Estado & Área $\left[\mathrm{km}^{2}\right]$ & Nós & Arestas & População & $\mathbf{I}_{\mathbf{O}}$ & $\mathbf{I}_{\mathbf{C}}$ & $\mathbf{L}$ & $\mathbf{B i}$ & $\mathbf{K}$ & $\mathbf{H}_{\mathrm{O}}$ & $\mathbf{A}$ & $\mathrm{C}$ & $\mathbf{N} / \mathbf{k m}^{2}$ & $\mathbf{m} / \mathbf{k m}^{2}$ \\
\hline Londrina/PR & 1652,569 & 13319 & 20728 & 558439 & 0,758 & 0,242 & 153,367 & 0,004 & 3,113 & 3,463 & 11,770 & 1,069 & 8,060 & 1835,905 \\
\hline Luziânia/GO & 3961,100 & 8072 & 13106 & 199615 & 0,624 & 0,376 & 196,783 & 0,006 & 3,247 & 3,457 & 13,428 & 1,072 & 2,038 & 640,775 \\
\hline Macaé/RJ & 1215,291 & 5848 & 8030 & 244139 & 0,863 & 0,137 & 161,307 & 0,009 & 2,746 & 3,458 & 14,049 & 1,126 & 4,812 & 1036,429 \\
\hline Macapá/AP & 6503,458 & 6251 & 9471 & 474706 & 0,644 & 0,356 & 141,373 & 0,011 & 3,030 & 3,391 & 11,342 & 1,045 & 0,961 & 204,147 \\
\hline Maceió/AL & 509,552 & 16173 & 22579 & 1029129 & 0,843 & 0,157 & 96,710 & 0,004 & 2,792 & 3,447 & 10,623 & 1,064 & 31,740 & 4292,173 \\
\hline Magé/RJ & 393,914 & 4995 & 6844 & 237420 & 0,848 & 0,152 & 150,771 & 0,010 & 2,740 & 3,561 & 14,115 & 1,069 & 12,680 & 2648,956 \\
\hline Manaus/AM & 11401,092 & 27582 & 39601 & 2130264 & 0,804 & 0,196 & 116,785 & 0,003 & 2,872 & 3,445 & 12,960 & 1,071 & 2,419 & 408,121 \\
\hline Marabá/PA & 15128,058 & 5778 & 8813 & 271594 & 0,675 & 0,325 & 126,894 & 0,009 & 3,051 & 3,440 & 12,269 & 1,066 & 0,382 & 75,201 \\
\hline Maracanaú/CE & 106,648 & 4550 & 7021 & 224804 & 0,725 & 0,275 & 107,385 & 0,010 & 3,086 & 3,356 & 6,236 & 1,025 & 42,664 & 7010,231 \\
\hline Maranguape/CE & 590,873 & 1858 & 2642 & 126486 & 0,825 & 0,175 & 202,050 & 0,024 & 2,844 & 3,451 & 15,461 & 1,098 & 3,144 & 890,191 \\
\hline Maricá/RJ & 361,995 & 6852 & 9955 & 153008 & 0,792 & 0,208 & 146,613 & 0,010 & 2,906 & 3,495 & 14,869 & 1,068 & 18,928 & 4003,559 \\
\hline Marília/SP & 1170,515 & 7744 & 12076 & 235234 & 0,703 & 0,297 & 144,558 & 0,006 & 3,119 & 3,558 & 8,926 & 1,070 & 6,616 & 1448,084 \\
\hline Maringá/PR & 487,052 & 9930 & 16249 & 406693 & 0,589 & 0,411 & 128,723 & 0,005 & 3,273 & 3,501 & 7,987 & 1,020 & 20,388 & 4254,637 \\
\hline Marituba/PA & 103,343 & 1657 & 2342 & 127858 & 0,839 & 0,161 & 133,616 & 0,016 & 2,827 & 3,138 & 3,862 & 1,036 & 16,034 & 3051,831 \\
\hline Mauá/SP & 61,909 & 3728 & 5337 & 462005 & 0,866 & 0,134 & 115,842 & 0,010 & 2,863 & 3,568 & 4,630 & 1,067 & 60,217 & 9822,222 \\
\hline Mesquita/RJ & 41,490 & 1778 & 2650 & 171280 & 0,750 & 0,250 & 97,533 & 0,019 & 2,981 & 3,218 & 3,387 & 1,035 & 42,854 & 6217,573 \\
\hline Mogi das Cruzes/SP & 712,541 & 8105 & 11810 & 433901 & 0,784 & 0,216 & 156,003 & 0,007 & 2,914 & 3,568 & 11,734 & 1,082 & 11,375 & 2523,857 \\
\hline Mogi Guaçu/SP & 812,753 & 4404 & 6827 & 149396 & 0,770 & 0,230 & 125,789 & 0,010 & 3,100 & 3,541 & 6,459 & 1,038 & 5,419 & 1081,817 \\
\hline Montes Claros/MG & 3568,941 & 10375 & 16317 & 402027 & 0,659 & 0,341 & 141,929 & 0,005 & 3,145 & 3,562 & 11,965 & 1,058 & 2,907 & 637,281 \\
\hline Mossoró/RN & 2099,333 & 8888 & 13974 & 295619 & 0,695 & 0,305 & 132,039 & 0,006 & 3,144 & 3,048 & 9,862 & 1,026 & 4,234 & 850,346 \\
\hline Muriaé/MG & 841,693 & 2334 & 3172 & 108537 & 0,904 & 0,096 & 183,234 & 0,014 & 2,718 & 3,562 & 8,433 & 1,131 & 2,773 & 673,596 \\
\hline Natal/RN & 167,264 & 15478 & 23606 & 885180 & 0,796 & 0,204 & 86,191 & 0,005 & 3,050 & 3,394 & 10,779 & 1,030 & 92,536 & 12299,527 \\
\hline Nilópolis/RJ & 19,393 & 1362 & 1858 & 158329 & 0,770 & 0,230 & 95,035 & 0,018 & 2,728 & 2,357 & 2,547 & 1,013 & 70,232 & 9110,226 \\
\hline Niterói/RJ & 134,074 & 5613 & 7708 & 499028 & 0,834 & 0,166 & 128,132 & 0,011 & 2,746 & 3,562 & 9,354 & 1,102 & 41,865 & 7269,713 \\
\hline $\begin{array}{l}\text { Nossa Senhora do } \\
\text { Socorro/SE }\end{array}$ & 155,018 & 3398 & 4990 & 181928 & 0,893 & 0,107 & 112,160 & 0,013 & 2,937 & 3,542 & 9,511 & 1,060 & 21,920 & 3713,829 \\
\hline Nova Friburgo/RJ & 935,429 & 5134 & 6028 & 185381 & 0,950 & 0,050 & 253,372 & 0,012 & 2,349 & 3,574 & 21,128 & 1,248 & 5,488 & 1606,525 \\
\hline Nova Iguaçu/RJ & 520,807 & 14782 & 20938 & 798647 & 0,828 & 0,172 & 109,420 & 0,006 & 2,833 & 3,565 & 12,136 & 1,038 & 28,383 & 4424,071 \\
\hline
\end{tabular}




\begin{tabular}{|c|c|c|c|c|c|c|c|c|c|c|c|c|c|c|}
\hline Cidade/Estado & Área $\left[\mathbf{k m}^{2}\right]$ & Nós & Arestas & População & $\mathbf{I}_{\mathbf{O}}$ & $\mathbf{I}_{\mathbf{C}}$ & $\mathbf{L}$ & $\mathbf{B i}$ & $\mathbf{K}$ & $\mathbf{H}_{\mathbf{O}}$ & $\mathbf{A}$ & $\mathbf{C}$ & $\mathbf{N} / \mathbf{k m}^{2}$ & $\mathbf{m} / \mathbf{k m}^{2}$ \\
\hline Novo Gama/GO & 194,992 & 2286 & 3476 & 110096 & 0,746 & 0,254 & 140,589 & 0,017 & 3,041 & 3,485 & 6,626 & 1,039 & 11,724 & 2486,273 \\
\hline Novo Hamburgo/RS & 223,821 & 5076 & 7684 & 249508 & 0,730 & 0,270 & 125,375 & 0,008 & 3,028 & 3,294 & 6,076 & 1,046 & 22,679 & 4286,169 \\
\hline Olinda/PE & 41,681 & 4854 & 6967 & 390771 & 0,827 & 0,173 & 89,046 & 0,009 & 2,871 & 3,456 & 5,108 & 1,033 & 116,456 & 14969,771 \\
\hline Osasco/SP & 64,954 & 6559 & 9671 & 697886 & 0,856 & 0,144 & 98,688 & 0,008 & 2,949 & 3,557 & 5,692 & 1,059 & 100,979 & 14716,292 \\
\hline Paço do Lumiar/MA & 125,259 & 3243 & 4885 & 122420 & 0,780 & 0,220 & 118,841 & 0,011 & 3,013 & 3,008 & 5,290 & 1,020 & 25,890 & 4611,759 \\
\hline Palhoça/SC & 395,133 & 6752 & 8574 & 164926 & 0,852 & 0,148 & 116,207 & 0,008 & 2,540 & 3,345 & 13,610 & 1,059 & 17,088 & 2575,417 \\
\hline Palmas/TO & 2218,942 & 11504 & 17171 & 286787 & 0,785 & 0,215 & 154,018 & 0,005 & 2,985 & 3,197 & 14,052 & 1,082 & 5,184 & 1167,761 \\
\hline Paragominas/PA & 19342,254 & 2426 & 3800 & 110026 & 0,726 & 0,274 & 289,972 & 0,012 & 3,133 & 3,016 & 24,285 & 1,087 & 0,125 & 54,579 \\
\hline Paranaguá/PR & 826,674 & 2820 & 4155 & 152975 & 0,709 & 0,291 & 128,460 & 0,011 & 2,947 & 3,212 & 5,581 & 1,048 & 3,411 & 664,640 \\
\hline Parauapebas/PA & 6886,208 & 7102 & 11374 & 202356 & 0,650 & 0,350 & 139,289 & 0,008 & 3,204 & 3,499 & 10,454 & 1,076 & 1,031 & 224,438 \\
\hline Parintins/AM & 5956,373 & 1101 & 1723 & 113832 & 0,644 & 0,356 & 116,698 & 0,020 & 3,130 & 2,906 & 2,795 & 1,032 & 0,185 & 33,492 \\
\hline Parnaíba/PI & 434,229 & 5074 & 8144 & 150547 & 0,623 & 0,377 & 115,189 & 0,008 & 3,210 & 3,155 & 6,115 & 1,035 & 11,685 & 2133,132 \\
\hline Parnamirim/RN & 123,471 & 5502 & 8474 & 254709 & 0,762 & 0,238 & 96,544 & 0,010 & 3,080 & 3,430 & 7,747 & 1,028 & 44,561 & 6744,399 \\
\hline Passo Fundo/RS & 783,421 & 4632 & 7172 & 198799 & 0,657 & 0,343 & 187,575 & 0,007 & 3,097 & 3,576 & 6,964 & 1,075 & 5,913 & 1654,327 \\
\hline Passos/MG & 1338,070 & 3302 & 5316 & 114458 & 0,652 & 0,348 & 156,721 & 0,010 & 3,220 & 3,517 & 4,381 & 1,064 & 2,468 & 597,231 \\
\hline Patos de Minas/MG & 3190,187 & 5407 & 8527 & 150893 & 0,699 & 0,301 & 138,590 & 0,008 & 3,154 & 3,498 & 8,369 & 1,059 & 1,695 & 361,412 \\
\hline Patos/PB & 3190,187 & 4103 & 6687 & 107790 & 0,573 & 0,427 & 108,900 & 0,010 & 3,260 & 3,378 & 4,952 & 1,038 & 1,286 & 222,653 \\
\hline Paulínia/SP & 138,777 & 3210 & 4877 & 102499 & 0,780 & 0,220 & 119,207 & 0,013 & 3,039 & 3,542 & 5,784 & 1,051 & 23,131 & 4263,251 \\
\hline Paulista/PE & 97,312 & 5932 & 8461 & 328353 & 0,806 & 0,194 & 91,502 & 0,010 & 2,853 & 3,540 & 6,944 & 1,033 & 60,959 & 7977,806 \\
\hline Paulo Afonso/BA & 1545,192 & 2916 & 4398 & 120706 & 0,841 & 0,159 & 152,706 & 0,013 & 3,016 & 3,530 & 9,622 & 1,055 & 1,887 & 419,687 \\
\hline Pelotas/RS & 1610,084 & 6839 & 10272 & 344385 & 0,705 & 0,295 & 227,405 & 0,007 & 3,004 & 3,499 & 13,021 & 1,078 & 4,248 & 1378,749 \\
\hline Petrolina/PE & 4561,874 & 9556 & 14675 & 343219 & 0,769 & 0,231 & 150,115 & 0,005 & 3,071 & 3,548 & 15,153 & 1,066 & 2,095 & 469,407 \\
\hline Petrópolis/RJ & 791,144 & 5467 & 6315 & 298235 & 0,961 & 0,039 & 232,707 & 0,011 & 2,310 & 3,573 & 15,932 & 1,270 & 6,910 & 1848,009 \\
\hline Pindamonhangaba/SP & 729,998 & 4184 & 6100 & 164000 & 0,790 & 0,210 & 144,263 & 0,010 & 2,916 & 3,504 & 8,822 & 1,062 & 5,732 & 1198,282 \\
\hline Pinhais/PR & 60,869 & 2462 & 3810 & 129445 & 0,611 & 0,389 & 114,145 & 0,013 & 3,095 & 3,207 & 4,111 & 1,019 & 40,448 & 7110,395 \\
\hline Piracicaba/SP & 1378,069 & 11580 & 17065 & 397322 & 0,769 & 0,231 & 133,935 & 0,005 & 2,947 & 3,542 & 10,075 & 1,067 & 8,403 & 1630,031 \\
\hline Piraquara/PR & 227,042 & 2018 & 2938 & 107751 & 0,711 & 0,289 & 172,529 & 0,016 & 2,912 & 3,463 & 7,409 & 1,067 & 8,888 & 2273,677 \\
\hline Poá/SP & 17,264 & 1544 & 2234 & 115488 & 0,826 & 0,174 & 100,600 & 0,019 & 2,894 & 3,531 & 3,076 & 1,031 & 89,435 & 12867,680 \\
\hline
\end{tabular}




\begin{tabular}{|c|c|c|c|c|c|c|c|c|c|c|c|c|c|c|}
\hline Cidade/Estado & Área $\left[\mathbf{k m}^{2}\right]$ & Nós & Arestas & População & $\mathbf{I}_{\mathbf{O}}$ & $\mathbf{I}_{\mathbf{C}}$ & $\mathbf{L}$ & $\mathbf{B i}$ & $\mathbf{K}$ & $\mathbf{H}_{\mathbf{O}}$ & $\mathbf{A}$ & $\mathbf{C}$ & $\mathbf{N} / \mathbf{k m}^{2}$ & $\mathbf{m} / \mathbf{k m}^{2}$ \\
\hline Poços de Caldas/MG & 546,670 & 3932 & 5862 & 166085 & 0,781 & 0,219 & 141,785 & 0,010 & 2,982 & 3,564 & 7,371 & 1,096 & 7,193 & 1502,160 \\
\hline Ponta Grossa/PR & 2054,732 & 9607 & 15137 & 344332 & 0,610 & 0,390 & 162,342 & 0,005 & 3,151 & 3,552 & 9,968 & 1,078 & 4,676 & 1192,061 \\
\hline Porto Alegre/RS & 496,682 & 17287 & 25521 & 1484941 & 0,760 & 0,240 & 118,821 & 0,004 & 2,953 & 3,509 & 12,868 & 1,042 & 34,805 & 6051,000 \\
\hline Porto Seguro/BA & 2287,085 & 3761 & 5427 & 149324 & 0,805 & 0,195 & 179,352 & 0,014 & 2,886 & 3,507 & 41,415 & 1,111 & 1,644 & 420,743 \\
\hline Porto Velho/RO & 34090,962 & 10938 & 16479 & 519436 & 0,709 & 0,291 & 239,869 & 0,006 & 3,013 & 3,219 & 37,366 & 1,076 & 0,321 & 112,443 \\
\hline Pouso Alegre/MG & 542,797 & 5226 & 7674 & 147137 & 0,757 & 0,243 & 152,100 & 0,007 & 2,937 & 3,543 & 7,533 & 1,086 & 9,628 & 2132,043 \\
\hline Praia Grande/SP & 149,253 & 5304 & 8592 & 310024 & 0,629 & 0,371 & 102,419 & 0,008 & 3,240 & 3,144 & 7,966 & 1,017 & 35,537 & 5906,388 \\
\hline $\begin{array}{l}\text { Presidente } \\
\text { Prudente/SP }\end{array}$ & 560,637 & 8706 & 13902 & 225271 & 0,682 & 0,318 & 109,680 & 0,006 & 3,194 & 3,508 & 7,594 & 1,044 & 15,529 & 2675,767 \\
\hline Queimados/RJ & 75,701 & 2586 & 3688 & 145386 & 0,808 & 0,192 & 117,366 & 0,015 & 2,852 & 3,551 & 4,375 & 1,039 & 34,161 & 5766,295 \\
\hline Recife/PE & 218,435 & 16480 & 24200 & 1633697 & 0,807 & 0,193 & 90,920 & 0,004 & 2,937 & 3,543 & 9,007 & 1,040 & 75,446 & 10273,107 \\
\hline Resende/RJ & 1099,336 & 3121 & 4469 & 126923 & 0,848 & 0,152 & 205,115 & 0,016 & 2,864 & 3,505 & 11,640 & 1,157 & 2,839 & 792,429 \\
\hline $\begin{array}{l}\text { Ribeirão das } \\
\text { Neves/MG }\end{array}$ & 155,454 & 5208 & 7636 & 328871 & 0,809 & 0,191 & 122,708 & 0,010 & 2,932 & 3,572 & 11,672 & 1,053 & 33,502 & 6106,701 \\
\hline Ribeirão Pires/SP & 99,075 & 2234 & 2965 & 121848 & 0,893 & 0,107 & 148,447 & 0,016 & 2,654 & 3,563 & 6,099 & 1,109 & 22,549 & 4272,912 \\
\hline Ribeirão Preto/SP & 650,916 & 15849 & 24813 & 682302 & 0,686 & 0,314 & 111,888 & 0,003 & 3,131 & 3,486 & 8,976 & 1,029 & 24,349 & 4257,816 \\
\hline Rio Branco/AC & 8834,942 & 9251 & 13122 & 383443 & 0,809 & 0,191 & 155,803 & 0,006 & 2,837 & 3,550 & 9,397 & 1,073 & 1,047 & 229,789 \\
\hline Rio Claro/SP & 498,422 & 5276 & 8493 & 202952 & 0,643 & 0,357 & 111,165 & 0,008 & 3,220 & 3,489 & 5,610 & 1,036 & 10,585 & 1901,893 \\
\hline Rio das Ostras/RJ & 228,114 & 4464 & 6475 & 141117 & 0,781 & 0,219 & 126,435 & 0,011 & 2,901 & 3,439 & 7,822 & 1,059 & 19,569 & 3564,874 \\
\hline Rio de Janeiro/RJ & 1200,177 & 62302 & 87650 & 6520266 & 0,848 & 0,152 & 105,992 & 0,002 & 2,814 & 3,561 & 25,440 & 1,058 & 51,911 & 7917,311 \\
\hline Rio Grande/RS & 2709,522 & 4667 & 7578 & 209378 & 0,600 & 0,400 & 202,977 & 0,011 & 3,247 & 3,330 & 15,024 & 1,041 & 1,722 & 551,955 \\
\hline Rio Verde/GO & 8386,827 & 6286 & 10428 & 217048 & 0,564 & 0,436 & 245,930 & 0,006 & 3,321 & 3,497 & 14,836 & 1,094 & 0,750 & 289,087 \\
\hline Rondonópolis/MT & 4686,622 & 8335 & 13830 & 222316 & 0,594 & 0,406 & 136,471 & 0,006 & 3,319 & 3,383 & 7,573 & 1,037 & 1,778 & 412,465 \\
\hline Sabará/MG & 302,419 & 1990 & 2772 & 135968 & 0,836 & 0,164 & 156,504 & 0,017 & 2,786 & 3,567 & 7,426 & 1,115 & 6,580 & 1423,623 \\
\hline Salto/SP & 133,057 & 3490 & 5172 & 116191 & 0,771 & 0,229 & 127,377 & 0,010 & 2,964 & 3,525 & 5,566 & 1,071 & 26,229 & 4916,005 \\
\hline Salvador/BA & 692,818 & 22135 & 29471 & 2953986 & 0,904 & 0,096 & 101,216 & 0,003 & 2,663 & 3,581 & 12,780 & 1,092 & 31,949 & 4407,488 \\
\hline $\begin{array}{l}\text { Santa Bárbara } \\
\text { d'Oeste/SP }\end{array}$ & 271,030 & 4310 & 6767 & 191889 & 0,683 & 0,317 & 119,260 & 0,009 & 3,141 & 3,521 & 5,741 & 1,038 & 15,902 & 2984,564 \\
\hline
\end{tabular}




\begin{tabular}{|c|c|c|c|c|c|c|c|c|c|c|c|c|c|c|}
\hline Cidade/Estado & Área $\left[\mathbf{k m}^{2}\right]$ & Nós & Arestas & População & $\mathbf{I}_{\mathbf{O}}$ & $\mathbf{I}_{\mathbf{C}}$ & $\mathbf{L}$ & $\mathbf{B i}$ & $\mathbf{K}$ & $\mathbf{H}_{\mathbf{O}}$ & $\mathbf{A}$ & $\mathrm{C}$ & $\mathbf{N} / \mathbf{k m}^{2}$ & $\mathbf{m} / \mathbf{k m}^{2}$ \\
\hline $\begin{array}{l}\text { Santa Cruz do } \\
\text { Capibaribe/PE }\end{array}$ & 335,309 & 2625 & 4066 & 105761 & 0,684 & 0,316 & 104,901 & 0,013 & 3,098 & 2,967 & 4,895 & 1,036 & 7,829 & 1265,701 \\
\hline Santa Cruz do Sul/RS & 733,409 & 3379 & 4833 & 127429 & 0,754 & 0,246 & 219,257 & 0,010 & 2,861 & 3,145 & 8,457 & 1,104 & 4,607 & 1397,054 \\
\hline Santa Luzia/MG & 235,076 & 586 & 849 & 218897 & 0,744 & 0,256 & 179,719 & 0,031 & 2,898 & 3,498 & 2,691 & 1,122 & 2,493 & 645,196 \\
\hline Santa Maria/RS & 1781,757 & 6463 & 9467 & 278445 & 0,738 & 0,262 & 197,163 & 0,007 & 2,930 & 3,499 & 9,980 & 1,071 & 3,627 & 995,654 \\
\hline Santa Rita/PB & 730,205 & 3245 & 4984 & 136851 & 0,766 & 0,234 & 140,983 & 0,012 & 3,072 & 3,526 & 8,646 & 1,045 & 4,444 & 1002,988 \\
\hline $\begin{array}{l}\text { Santana de } \\
\text { Parnaíba/SP }\end{array}$ & 179,949 & 3520 & 4840 & 115471 & 0,911 & 0,089 & 139,716 & 0,015 & 2,750 & 3,570 & 10,344 & 1,124 & 19,561 & 3523,848 \\
\hline Santana/AP & 179,949 & 1271 & 1905 & 131887 & 0,656 & 0,344 & 138,013 & 0,019 & 2,998 & 2,644 & 3,472 & 1,032 & 7,063 & 1435,913 \\
\hline Santarém/PA & 17898,389 & 5564 & 8895 & 296302 & 0,629 & 0,371 & 160,643 & 0,009 & 3,197 & 3,300 & 11,249 & 1,061 & 0,311 & 78,336 \\
\hline Santo André/SP & 175,782 & 7941 & 12103 & 715231 & 0,768 & 0,232 & 97,306 & 0,006 & 3,048 & 3,570 & 6,178 & 1,044 & 45,175 & 6675,162 \\
\hline $\begin{array}{l}\text { Santo Antônio de } \\
\text { Jesus/BA }\end{array}$ & 261,740 & 1859 & 2534 & 103342 & 0,877 & 0,123 & 165,904 & 0,014 & 2,726 & 3,544 & 4,183 & 1,102 & 7,102 & 1570,979 \\
\hline Santos/SP & 281,033 & 3800 & 5974 & 434742 & 0,701 & 0,299 & 92,296 & 0,011 & 3,144 & 3,302 & 5,449 & 1,039 & 13,522 & 1996,253 \\
\hline $\begin{array}{l}\text { São Bernardo do } \\
\text { Campo/SP }\end{array}$ & 409,532 & 10102 & 14299 & 827437 & 0,842 & 0,158 & 111,924 & 0,005 & 2,831 & 3,570 & 9,619 & 1,076 & 24,667 & 3968,291 \\
\hline $\begin{array}{l}\text { São Caetano do } \\
\text { Sul/SP }\end{array}$ & 15,331 & 1870 & 2966 & 159608 & 0,716 & 0,284 & 85,970 & 0,014 & 3,172 & 3,428 & 2,522 & 1,016 & 121,975 & 16782,587 \\
\hline São Carlos/SP & 1136,907 & 7191 & 11267 & 246088 & 0,707 & 0,293 & 138,454 & 0,006 & 3,134 & 3,541 & 8,200 & 1,046 & 6,325 & 1323,742 \\
\hline $\begin{array}{l}\text { São Félix do } \\
\text { Xingu/PA }\end{array}$ & 84212,847 & 1113 & 1771 & 124806 & 0,524 & 0,476 & 245,230 & 0,025 & 3,182 & 3,046 & 21,469 & 1,120 & 0,013 & 5,066 \\
\hline $\begin{array}{l}\text { São Gonçalo do } \\
\text { Amarante/RN }\end{array}$ & 249,124 & 3790 & 5477 & 101492 & 0,856 & 0,144 & 141,033 & 0,013 & 2,890 & 3,489 & 7,897 & 1,042 & 15,263 & 3107,188 \\
\hline São Gonçalo/RJ & 248,319 & 11524 & 16330 & 1049826 & 0,823 & 0,177 & 125,916 & 0,005 & 2,834 & 3,532 & 8,732 & 1,054 & 46,258 & 8315,593 \\
\hline $\begin{array}{l}\text { São João de } \\
\text { Meriti/RJ }\end{array}$ & 35,216 & 3876 & 5834 & 460461 & 0,753 & 0,247 & 103,478 & 0,009 & 3,010 & 3,435 & 4,276 & 1,029 & 110,064 & 17189,161 \\
\hline $\begin{array}{l}\text { São José de } \\
\text { Ribamar/MA }\end{array}$ & 150,453 & 3252 & 4747 & 239718 & 0,762 & 0,238 & 126,057 & 0,018 & 2,919 & 3,424 & 9,426 & 1,026 & 21,615 & 3948,132 \\
\hline $\begin{array}{l}\text { São José do Rio } \\
\text { Preto/SP }\end{array}$ & 385,777 & 15031 & 24011 & 176418 & 0,667 & 0,333 & 108,026 & 0,004 & 3,195 & 3,489 & 8,425 & 1,033 & 38,963 & 6632,093 \\
\hline
\end{tabular}




\begin{tabular}{|c|c|c|c|c|c|c|c|c|c|c|c|c|c|c|}
\hline Cidade/Estado & Área [km²] & Nós & Arestas & População & $I_{0}$ & $\mathbf{I}_{\mathbf{C}}$ & $\mathbf{L}$ & $\mathbf{B i}$ & $\mathbf{K}$ & $\mathrm{H}_{\mathrm{O}}$ & $\mathbf{A}$ & $\mathrm{C}$ & $\mathbf{N} / \mathbf{k m}^{2}$ & $\mathbf{m} / \mathbf{k m}^{2}$ \\
\hline $\begin{array}{l}\text { São José dos } \\
\text { Campos/SP }\end{array}$ & 431,944 & 14093 & 20435 & 450657 & 0,833 & 0,167 & 114,171 & 0,005 & 2,900 & 3,566 & 11,675 & 1,064 & 32,627 & 5374,233 \\
\hline $\begin{array}{l}\text { São José dos } \\
\text { Pinhais/PR }\end{array}$ & 1099,409 & 6273 & 9036 & 703219 & 0,714 & 0,286 & 188,415 & 0,006 & 2,881 & 3,481 & 11,595 & 1,074 & 5,706 & 1547,548 \\
\hline São José/SC & 150,453 & 5162 & 6928 & 307530 & 0,829 & 0,171 & 108,805 & 0,008 & 2,684 & 3,355 & 6,421 & 1,057 & 34,310 & 5082,302 \\
\hline São Leopoldo/RS & 102,738 & 5266 & 8158 & 230914 & 0,719 & 0,281 & 100,053 & 0,009 & 3,098 & 3,445 & 5,921 & 1,025 & 51,257 & 7976,600 \\
\hline $\begin{array}{l}\text { São Lourenço da } \\
\text { Mata/PE }\end{array}$ & 262,106 & 2283 & 3191 & 112099 & 0,877 & 0,123 & 127,517 & 0,015 & 2,795 & 3,545 & 5,676 & 1,083 & 8,710 & 1575,291 \\
\hline São Luís/MA & 834,827 & 19255 & 28355 & 1091868 & 0,805 & 0,195 & 98,505 & 0,004 & 2,945 & 3,503 & 11,406 & 1,045 & 23,065 & 3418,426 \\
\hline São Mateus/ES & 2345,730 & 4279 & 6425 & 128449 & 0,671 & 0,329 & 237,006 & 0,011 & 3,003 & 3,249 & 20,015 & 1,094 & 1,824 & 621,881 \\
\hline São Paulo/SP & 1521,110 & 110850 & 163488 & 12106920 & 0,817 & 0,183 & 101,752 & 0,001 & 5,172 & 3,579 & 23,405 & 1,053 & 72,874 & 10931,447 \\
\hline São Vicente/SP & 148,100 & 3572 & 5758 & 360380 & 0,606 & 0,394 & 95,520 & 0,014 & 3,224 & 3,511 & 7,102 & 1,020 & 24,119 & 3722,115 \\
\hline Sapucaia do Sul/RS & 58,309 & 2653 & 3906 & 139476 & 0,765 & 0,235 & 104,368 & 0,013 & 2,945 & 3,555 & 3,571 & 1,030 & 45,499 & 6965,674 \\
\hline Senador Canedo/GO & 248,291 & 3892 & 6162 & 105459 & 0,736 & 0,264 & 133,302 & 0,010 & 3,166 & 3,519 & 7,061 & 1,059 & 15,675 & 3322,808 \\
\hline Serra/ES & 547,637 & 10840 & 16254 & 502618 & 0,773 & 0,227 & 113,331 & 0,006 & 2,999 & 3,561 & 12,396 & 1,072 & 19,794 & 3359,875 \\
\hline Sertãozinho/SP & 403,089 & 3693 & 5971 & 122643 & 0,639 & 0,361 & 137,611 & 0,009 & 3,234 & 3,312 & 5,301 & 1,036 & 9,162 & 1948,733 \\
\hline Sete Lagoas/MG & 536,644 & 6233 & 9763 & 236228 & 0,719 & 0,281 & 142,711 & 0,007 & 3,133 & 3,561 & 7,946 & 1,069 & 11,615 & 2604,271 \\
\hline Simões Filho/BA & 201,577 & 1743 & 2366 & 136050 & 0,899 & 0,101 & 153,966 & 0,018 & 2,715 & 3,564 & 5,803 & 1,100 & 8,647 & 1864,417 \\
\hline Sinop/MT & 3942,229 & 5916 & 9491 & 135874 & 0,626 & 0,374 & 179,656 & 0,007 & 3,209 & 3,144 & 7,939 & 1,038 & 1,501 & 409,202 \\
\hline Sobral/CE & 2122,897 & 4072 & 6346 & 205529 & 0,692 & 0,308 & 129,196 & 0,010 & 3,119 & 3,540 & 9,322 & 1,049 & 1,918 & 372,939 \\
\hline Sorocaba/SP & 450,382 & 14807 & 21587 & 659871 & 0,780 & 0,220 & 112,816 & 0,004 & 2,916 & 3,573 & 9,488 & 1,050 & 32,877 & 5440,984 \\
\hline Sumaré/SP & 153,465 & 5770 & 8592 & 273007 & 0,772 & 0,228 & 109,077 & 0,009 & 2,978 & 3,511 & 8,695 & 1,037 & 37,598 & 6192,820 \\
\hline Suzano/SP & 206,236 & 4755 & 6974 & 290769 & 0,784 & 0,216 & 136,437 & 0,011 & 2,933 & 3,494 & 9,717 & 1,061 & 23,056 & 4491,852 \\
\hline Taboão da Serra/SP & 20,388 & 2404 & 3472 & 279634 & 0,868 & 0,132 & 97,800 & 0,013 & 2,889 & 3,572 & 3,720 & 1,075 & 117,912 & 16256,912 \\
\hline Tatuí/SP & 523,749 & 3182 & 4869 & 118939 & 0,748 & 0,252 & 165,967 & 0,010 & 3,060 & 3,535 & 6,088 & 1,068 & 6,075 & 1561,306 \\
\hline Taubaté/SP & 625,003 & 7312 & 10723 & 307953 & 0,806 & 0,194 & 124,426 & 0,006 & 2,933 & 3,544 & 6,648 & 1,056 & 11,699 & 2121,645 \\
\hline $\begin{array}{l}\text { Teixeira de } \\
\text { Freitas/BA }\end{array}$ & 1165,622 & 4479 & 7278 & 161690 & 0,619 & 0,381 & 97,339 & 0,009 & 3,250 & 3,407 & 6,126 & 1,031 & 3,843 & 605,403 \\
\hline Teófilo Otoni/MG & 3242,270 & 2790 & 3867 & 141934 & 0,869 & 0,131 & 261,338 & 0,012 & 2,772 & 3,527 & 11,956 & 1,188 & 0,861 & 302,309 \\
\hline
\end{tabular}




\begin{tabular}{|c|c|c|c|c|c|c|c|c|c|c|c|c|c|c|}
\hline Cidade/Estado & Área $\left[\mathbf{k m}^{2}\right]$ & Nós & Arestas & População & Io & $\mathbf{I}_{\mathbf{C}}$ & $\mathbf{L}$ & $\mathbf{B i}$ & $\mathbf{K}$ & $\mathbf{H}_{\mathbf{O}}$ & $\mathbf{A}$ & $\mathbf{C}$ & $\mathbf{N} / \mathbf{k m}^{2}$ & $\mathbf{m} / \mathbf{k m}^{2}$ \\
\hline Teresina/PI & 1391,981 & 20816 & 33541 & 850198 & 0,650 & 0,350 & 116,525 & 0,003 & 3,223 & 3,409 & 12,317 & 1,029 & 14,954 & 2799,567 \\
\hline Teresópolis/RJ & 773,338 & 4336 & 5079 & 176060 & 0,940 & 0,060 & 265,041 & 0,012 & 2,343 & 3,573 & 18,039 & 1,261 & 5,607 & 1702,799 \\
\hline Timon/MA & 1764,612 & 3675 & 5963 & 167619 & 0,595 & 0,405 & 139,795 & 0,008 & 3,245 & 3,098 & 5,879 & 1,038 & 2,083 & 466,311 \\
\hline Toledo/PR & 1196,999 & 7198 & 10829 & 135538 & 0,684 & 0,316 & 251,469 & 0,006 & 3,009 & 3,135 & 13,186 & 1,080 & 6,013 & 2098,776 \\
\hline Três Lagoas/MS & 10206,949 & 5018 & 8453 & 117477 & 0,518 & 0,482 & 255,886 & 0,007 & 3,369 & 2,446 & 12,608 & 1,060 & 0,492 & 202,646 \\
\hline Trindade/GO & 710,328 & 4658 & 7416 & 121266 & 0,714 & 0,286 & 122,300 & 0,010 & 3,184 & 3,542 & 8,286 & 1,028 & 6,558 & 1267,950 \\
\hline Tubarão/SC & 301,755 & 3437 & 4738 & 104457 & 0,772 & 0,228 & 150,578 & 0,011 & 2,757 & 3,239 & 5,950 & 1,062 & 11,390 & 2358,196 \\
\hline Tucuruí/PA & 2086,189 & 2098 & 3082 & 110516 & 0,719 & 0,281 & 117,226 & 0,015 & 2,938 & 3,508 & 4,892 & 1,040 & 1,006 & 172,156 \\
\hline Ubá/MG & 407,452 & 2893 & 3790 & 113300 & 0,884 & 0,116 & 177,649 & 0,012 & 2,620 & 3,570 & 7,039 & 1,127 & 7,100 & 1611,413 \\
\hline Uberaba/MG & 4523,957 & 11056 & 17521 & 328272 & 0,702 & 0,298 & 191,040 & 0,005 & 3,170 & 3,515 & 12,094 & 1,076 & 2,444 & 724,066 \\
\hline Uberlândia/MG & 4115,206 & 17168 & 27747 & 676613 & 0,659 & 0,341 & 152,372 & 0,003 & 3,232 & 3,529 & 10,771 & 1,052 & 4,172 & 991,837 \\
\hline Umuarama/PR & 1234,537 & 7971 & 11685 & 109955 & 0,726 & 0,274 & 231,670 & 0,008 & 2,932 & 3,545 & 14,156 & 1,095 & 6,457 & 2056,825 \\
\hline Uruguaiana/RS & 5703,586 & 2142 & 3262 & 129784 & 0,655 & 0,345 & 421,562 & 0,013 & 3,046 & 3,193 & 14,422 & 1,100 & 0,376 & 228,508 \\
\hline Valinhos/SP & 148,538 & 3545 & 5107 & 124024 & 0,829 & 0,171 & 133,740 & 0,011 & 2,881 & 3,572 & 5,836 & 1,073 & 23,866 & 4504,564 \\
\hline $\begin{array}{l}\text { Valparaíso de } \\
\text { Goiás/GO }\end{array}$ & 61,450 & 3560 & 4883 & 159500 & 0,835 & 0,165 & 119,423 & 0,012 & 2,743 & 3,283 & 5,398 & 1,056 & 57,933 & 9404,924 \\
\hline Varginha/MG & 395,396 & 4287 & 6591 & 134364 & 0,749 & 0,251 & 147,311 & 0,008 & 3,075 & 3,563 & 5,587 & 1,114 & 10,842 & 2409,640 \\
\hline Várzea Grande/MT & 1048,210 & 9033 & 14253 & 274013 & 0,656 & 0,344 & 116,035 & 0,006 & 3,156 & 3,500 & 7,791 & 1,041 & 8,618 & 1592,295 \\
\hline Várzea Paulista/SP & 35,120 & 1543 & 2154 & 118917 & 0,896 & 0,104 & 129,416 & 0,020 & 2,792 & 3,568 & 3,934 & 1,071 & 43,935 & 7783,470 \\
\hline Vespasiano/MG & 71,080 & 2039 & 2952 & 122365 & 0,806 & 0,194 & 139,304 & 0,019 & 2,896 & 3,542 & 6,775 & 1,080 & 28,686 & 5894,597 \\
\hline Viamão/RS & 1497,094 & 4597 & 6421 & 253717 & 0,837 & 0,163 & 238,466 & 0,010 & 2,794 & 3,567 & 14,621 & 1,086 & 3,071 & 994,690 \\
\hline Vila Velha/ES & 209,965 & 7888 & 12229 & 486388 & 0,675 & 0,325 & 99,871 & 0,007 & 3,101 & 3,493 & 9,608 & 1,039 & 37,568 & 5848,751 \\
\hline $\begin{array}{l}\text { Vitória da } \\
\text { Conquista/BA }\end{array}$ & 3705,838 & 10324 & 15900 & 348718 & 0,776 & 0,224 & 201,729 & 0,004 & 3,080 & 3,463 & 14,990 & 1,065 & 2,786 & 824,353 \\
\hline $\begin{array}{l}\text { Vitória de Santo } \\
\text { Antão/PE }\end{array}$ & 335,941 & 3505 & 5084 & 137578 & 0,793 & 0,207 & 117,022 & 0,009 & 2,901 & 3,525 & 4,026 & 1,090 & 10,433 & 1786,033 \\
\hline Vitória/ES & 96,536 & 5562 & 8047 & 363140 & 0,815 & 0,185 & 76,183 & 0,010 & 2,894 & 3,532 & 6,130 & 1,059 & 57,616 & 6439,957 \\
\hline Volta Redonda/RJ & 182,105 & 4648 & 6595 & 265201 & 0,859 & 0,141 & 115,891 & 0,010 & 2,838 & 3,562 & 6,958 & 1,099 & 25,524 & 4126,960 \\
\hline Votorantim/SP & 183,517 & 2609 & 3691 & 119898 & 0,839 & 0,161 & 119,999 & 0,015 & 2,829 & 3,512 & 4,900 & 1,074 & 14,217 & 2366,047 \\
\hline
\end{tabular}


